\title{
Gait and balance characteristics in patients with diabetes type 2 : evaluation and treatment efficacy
}

Citation for published version (APA):

Allet, L. (2009). Gait and balance characteristics in patients with diabetes type 2 : evaluation and treatment efficacy. [Doctoral Thesis, Maastricht University]. Datawyse / Universitaire Pers Maastricht. https://doi.org/10.26481/dis.20091216la

Document status and date:

Published: 01/01/2009

DOI:

10.26481/dis.20091216la

Document Version:

Publisher's PDF, also known as Version of record

\section{Please check the document version of this publication:}

- A submitted manuscript is the version of the article upon submission and before peer-review. There can be important differences between the submitted version and the official published version of record.

People interested in the research are advised to contact the author for the final version of the publication, or visit the DOI to the publisher's website.

- The final author version and the galley proof are versions of the publication after peer review.

- The final published version features the final layout of the paper including the volume, issue and page numbers.

Link to publication

\footnotetext{
General rights rights.

- You may freely distribute the URL identifying the publication in the public portal. please follow below link for the End User Agreement:

www.umlib.nl/taverne-license

Take down policy

If you believe that this document breaches copyright please contact us at:

repository@maastrichtuniversity.nl

providing details and we will investigate your claim.
}

Copyright and moral rights for the publications made accessible in the public portal are retained by the authors and/or other copyright owners and it is a condition of accessing publications that users recognise and abide by the legal requirements associated with these

- Users may download and print one copy of any publication from the public portal for the purpose of private study or research.

- You may not further distribute the material or use it for any profit-making activity or commercial gain

If the publication is distributed under the terms of Article $25 \mathrm{fa}$ of the Dutch Copyright Act, indicated by the "Taverne" license above, 


\section{Gait and balance}

\section{characteristics in patients with diabetes type 2}

Evaluation and treatment efficacy 
A financial contribution towards the studies presented in Chapter 3 to 7 and for the finalisation of this thesis was received from the Swiss National Foundation (SNF) and the Swiss Physiotherapy Association.

A financial contribution towards the printing costs was received from the Dutch Diabetes Research Foundation (Diabetes Fonds), the Clinical Services Directorate and the Service of Therapeutic Education for Chronic Diseases of the University Hospitals of Geneva.

The studies presented in this dissertation were conducted in the University Hospital of Geneva, Switzerland. The development and dissemination of this dissertation were performed under the auspices of the School for Public Health and Primary Care (CAPHRI), at Maastricht University Medical Centre, the Netherlands. CAPHRI is part of the Netherlands School of Primary Care Research (CaRe), which has been acknowledged since 1995 by the Royal Netherlands Academy of Arts and Sciences (KNWAW).

Lay-out: Lara Allet with the support of Datawyse| Universitaire Pers Maastricht Cover: $\quad$ Lara Allet in collaboration with Datawyse| Universitaire Pers Maastricht Printed by: Datawyse| Universitaire Pers Maastricht

Copyright $^{\odot}$ Lara Allet, 2009. All rights reserved. No part of this thesis may be reproduced or transmitted in any form or by any means, electronic or mechanical, including photocopying, recording or any information storage or retrieval system without permission in writing from the author, or, when appropriate from the publisher of the publications. 


\title{
Gait and balance characteristics in patients with diabetes type 2 Evaluation and treatment efficacy
}

\author{
DISSERTATION \\ to obtain the degree of Doctor at the Maastricht University, \\ on the authority of the Rector Magnificus, \\ Prof. dr. G.P.M.F. Mols, \\ in accordance with the decision of the Board of Deans, \\ to be defended in public on \\ Wednesday, $16^{\text {th }}$ of December 2009 at 16 o'clock \\ by
}

Lara Allet

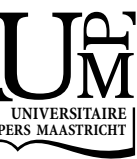




\section{Supervisor}

Prof. dr. R.A. de Bie

\section{Co-Supervisors}

Dr. E.D. de Bruin (ETH, Zürich)

Dr. S. Armand (UH, Geneva)

\section{Assessment Committee}

Prof. dr. G.H.I.M. Walenkamp (chairman)

Prof. dr. M.W.G. Nijhuis - Van der Sanden (UMC, St Radboud Nijmegen)

Prof. dr. M.H. Prins

Prof. dr. H.H.C.M. Savelberg

Prof. dr. C.P. van Schayck 


\section{Contents}

$\begin{array}{lr}\text { List of abbreviations } & 6\end{array}$

Chapter 1 General introduction 9

Chapter 2 Gait characteristics of diabetic patients with and without 29 neuropathy: a systematic review

Chapter $3 \quad$ Reliability of diabetic patients' gait parameters in a challenging 55 environment

Chapter $4 \quad$ Gait alterations of diabetic patients while walking on different 69 surfaces

Chapter $5 \quad$ Investigation of standing balance in diabetic patients with and 81 without peripheral neuropathy using accelerometers

Chapter 6 Clinical factors associated with gait alterations in diabetic patients 95

$\begin{array}{lll}\text { Chapter } 7 & \text { Diabetic patients' gait and balance can be improved with a specific } & 109\end{array}$ training program. A randomised controlled trial

$\begin{array}{lll}\text { Chapter } 8 & \text { General discussion } & 125\end{array}$

$\begin{array}{lll}\text { Summaries English summary } & 144\end{array}$

$\begin{array}{ll}\text { Netherlandse samenvatting } & 147\end{array}$

Résumé en français $\quad 151$

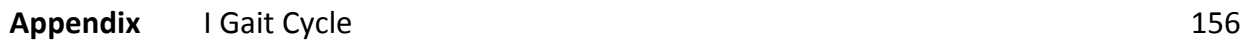

II Definition of spatiotemporal gait parameters 158

III The ambulatory gait measurement system 159

IV Treatment 161

$\begin{array}{ll}\text { Acknowledgements } & 165\end{array}$

$\begin{array}{ll}\text { About the author } & 169\end{array}$ 


\section{ABBREVIATIONS}

\begin{tabular}{|c|c|}
\hline A & Age \\
\hline ACC & Accelerations \\
\hline ADA & American Diabetes Association \\
\hline ANOVA & Analysis of variance \\
\hline AP & Anterior posterior \\
\hline BA & Baseline \\
\hline BMI & Body Mass Index \\
\hline CAD & Cadence \\
\hline CNS & Central nervous system \\
\hline CG & Control group \\
\hline COM & Centre of mass \\
\hline COP & Centre of pressure \\
\hline COPnet & COP computed with two force-plates \\
\hline CV & Coefficient of variation \\
\hline CVGCT & Coefficient of variation of gait cycle time \\
\hline $\mathrm{D}$ & Diabetes without neuropathy \\
\hline DEG & Degree \\
\hline DFR & Dorsiflexion range of motion \\
\hline DG & Diabetic group \\
\hline DIFF & Difference \\
\hline DM & Diabetic patients without peripheral neuropathy \\
\hline DPN & Diabetic patients with peripheral neuropathy \\
\hline DPU & Diabetic patients with a previous ulcer \\
\hline E.G. & Exempli gratia (For example) \\
\hline EMG & Electromyogram \\
\hline ENMG & Electro-neuro-myogramm \\
\hline EO & Eyes open \\
\hline EC & Eyes closed \\
\hline ES & Effect sizes \\
\hline FES-I & Falls Efficacy Scale- International version \\
\hline FLD & Feedback loop delay \\
\hline FP & Force platform / Force plate \\
\hline FU & Follow-up \\
\hline G & Grass \\
\hline GC & Gait cycle \\
\hline GCT & Gait cycle time \\
\hline GE & Gender \\
\hline GRFs & Ground reaction forces \\
\hline $\mathrm{H}$ & Healthy \\
\hline
\end{tabular}




$\begin{array}{ll}\text { HC } & \text { Heel contact } \\ \text { HE } & \text { Height } \\ \text { ICC } & \text { Intraclass correlation coefficient } \\ \text { I.E. } & \text { Id est (namely) } \\ \text { IG } & \text { Intervention group } \\ \text { L } & \text { Left } \\ \text { ML } & \text { Medial lateral } \\ \text { NCT } & \text { National clinical trial } \\ \text { NE } & \text { Not evaluated } \\ \text { NRV } & \text { Non-reported values } \\ \text { PFTP } & \text { Plantar flexor peak torque } \\ \text { PI } & \text { Post-intervention } \\ \text { PN } & \text { Peripheral neuropathy } \\ \text { POMA } & \text { Performance-Oriented Mobility Assessment } \\ \text { POMA-B } & \text { Performance-Oriented Mobility Assessment-Balance } \\ \text { PRoFaNE } & \text { Prevention of Falls Network Europe } \\ \text { PSSD } & \text { Pressure specified sensory device } \\ \text { PVD } & \text { Peripheral vascular disease } \\ \text { R } & \text { Right } \\ \text { RMS } & \text { Root mean square } \\ \text { RSG } & \text { Rosiglitazone } \\ \text { S } & \text { Cobblestones } \\ \text { SD } & \text { Standard deviation } \\ \text { SDC } & \text { Smallest detectable change } \\ \text { SEM } & \text { Standard error of measurement } \\ \text { SI } & \text { Sway index } \\ \text { T } & \text { Tarred surface/tarred terrain/tarred pathway } \\ \text { TO } & \text { Toe-off } \\ \text { U } & \text { Unselected } \\ \text { V } & \text { Vertical } \\ \text { VIF } & \text { Variance inflation factor } \\ \text { VPT } & \text { Vibration perception threshold } \\ \text { W } & \text { Weight } \\ \text { WHO } & \text { World Health Organisation } \\ & \end{array}$

Comment: When a unit of measurement is associated with another, the following internationally recognised format is applied: i.e. for "metres per second" read: " $\mathrm{ms}^{-1 " \text { "; }}$ "kilograms per metre": "kgm ${ }^{-1 "}$. 

Chapter 1

General introduction 


\section{BACKGROUND}

My interest in the gait patterns, balance and fall prevention springs from my background in Physiotherapy and introduced me to the world of gait analysis and human movement sciences. This, combined with a realisation of the high prevalence of diabetes [1] and of its costly consequences for health care management, made it worthwhile to investigate further the impact of the disease on patients' gait and physical function.

The American Diabetes Association (ADA) estimates that diabetes affects more than 20 million Americans and costs employers more than $\$ 132$ billion annually in direct and indirect costs [2]. Approximately $58 \%$ of patients with type 2 diabetes have one or more complications from the disease resulting in an increased demand for medical services [2]. The most symptomatic complication of this disease is peripheral neuropathy (PN) which affects approximately $50 \%$ of all patients diagnosed with diabetes, older than 60 years of age [3].

Gait characteristics differ in individuals with diabetes compared with those without diabetes [4]. Furthermore, diabetes mellitus is recognised as an independent risk factor for falls among elderly persons [5]. In a prospective study of 139 elderly patients in a long-term care facility, Maurer et al. [5] examined the association between falls and multiple domains, which included clinical diagnoses, medication, orthostatic blood pressure change, gait, balance, mental status, well being, activities of daily living, affect/behaviour, range of motion and communication. The results identified diabetes, gait and balance as significant and independent predictors for a heightened risk of falling. Wallace et al. [6] reported an overall incidence of falls of 1.25 falls per person-year in cohorts of diabetic individuals. Forty-one percent reported 2 or more falls, which could be associated with higher fracture risk.

Two main care paradigms are suggested for diabetic patients. The first paradigm is lifestyle management (including behavioural advice on diet and physical activity) $[7,8]$ and the second is medication (oral hypoglycaemias and insulin), proposed when lifestyle changes fail to be effective [9]. In order to avoid the complications of diabetes, patients are recommended to be physically active for at least $30 \mathrm{~min}$ a day, 6 days a week [10]. However, this advice leads to a dilemma: how can individuals at increased risk of falling carry out a regular physical activity? Patients with inadequate gait stability or who experience a fall related injury, may consequently not be able to meet these recommendations, thereby finding themselves in a vicious circle of reduced physical activity levels, leading to an increased risk of diabetic complications and decreased musculoskeletal function. This decline in musculoskeletal function may have a further negative impact on physical activity, thus perpetuating the cycle. Within this context, one may further wonder whether fear of falling could be an additional factor influencing this whole model (Figure 1.1).

Another complex issue, which is described in the literature, is the importance of patients' compliance with the regimen and adherence to self-management behaviours to achieve long-term diabetes control. However, diabetic patients are known to show only moderate motivation as well as sparse compliance and treatment achievement [11, 12], which can 
have a further negative influence on patient's physical activity level and consequently on their gait.

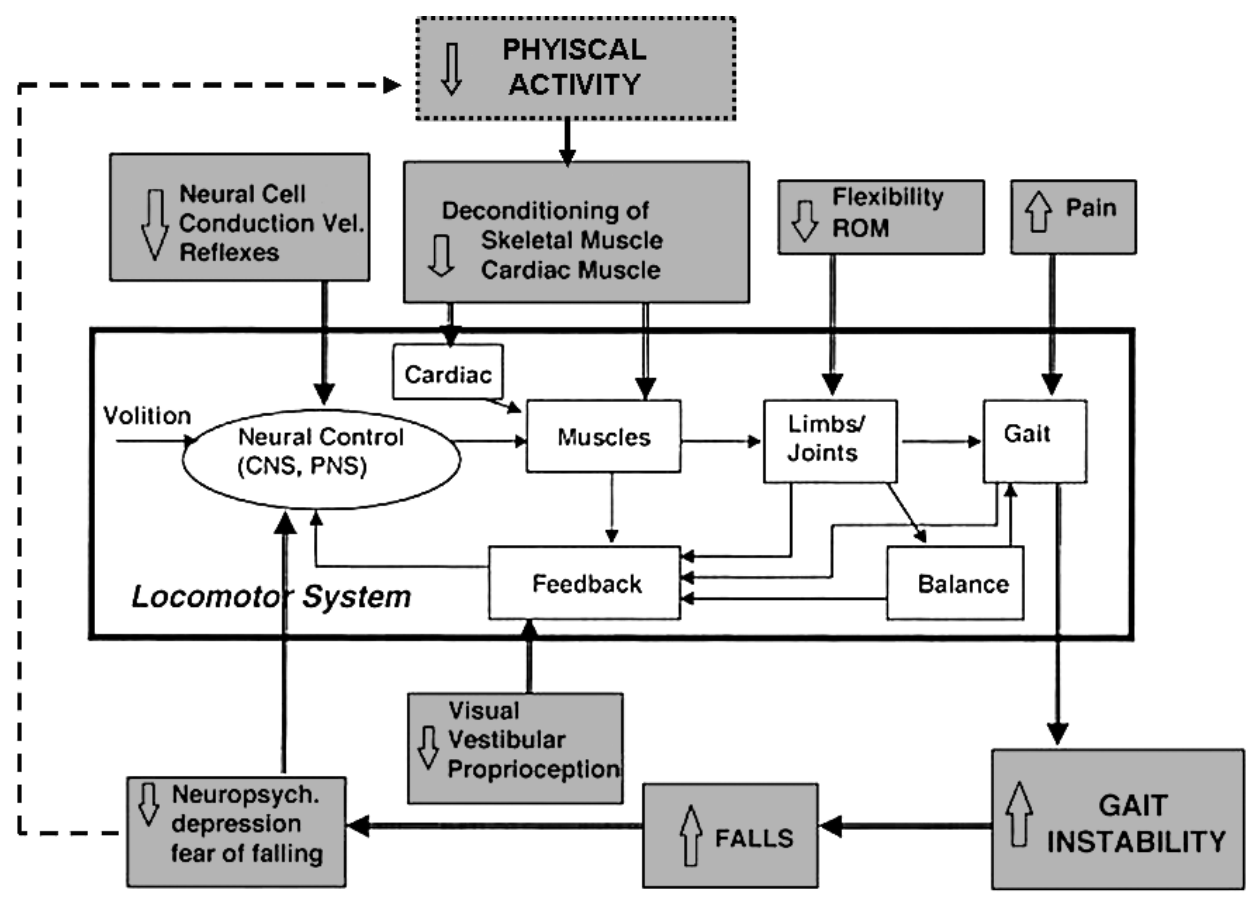

Figure 1.1. Vicious circle between risk of falling and regular physical activity. This block diagram was adapted from the diagram published by Hausdorff et al. [13]. It shows some of the physiological and neuropsychological factors that may be associated with gait instability. It further illustrates the locomotor system's and certain age-associated changes (shaded boxes) in physiological capacity that may mediate gait instability. An unstable gait with its consequences of falls and fear of falling may further negatively influence physical activity levels, a fact, which itself leads to a de-conditioning of skeletal and cardiac muscle and thus perpetuates this cycle.

With this in mind, our research group was interested in what is already known about gait characteristics of diabetic patients, the causes of gait alterations and possible treatment strategies.

Evidence that diabetic neuropathy is strongly associated with gait alterations, postural instability and with an increased risk of falls has been identified [5, 6, 14-16]. However, the variety of studies, providing a wealth of experimental data, made it difficult to gain a thorough insight into possible causes of gait alterations and fall risk in diabetic patients or to get a clear view of which gait parameters could be clinically relevant to fall risk prevention [15]. Furthermore, discussion about the causes and clinical factors related to gait abnormalities $[4,15]$ hampered the definition of what kind of population should be targeted for prevention or intervention. Most surprisingly, only very few studies investigating how to improve the gait of patients with type 2 diabetes were identified, a fact which provided the incentive to investigate whether the gait and balance of a diabetic 
patient, as well as other clinical factors related to gait (e.g. muscle strength, joint mobility), may be improved with a physiotherapy treatment.

To achieve the aforementioned goals, several steps were necessary. Firstly, an adequate method and tool to measure gait abnormalities in patients with type 2 diabetes had to be identified. Secondly, knowledge gaps in the current literature had to be addressed in order to gain an in-depth understanding of the gait characteristics of diabetic patients, with and without neuropathy. As several functions, such as plantar cutaneous sensation and proprioception, which are compromised in the presence of diabetic neuropathy $[17,18]$ affect both gait and balance, and as balance impairments are likely to contribute to diabetic patients' gait alterations, we were further interested in the postural control of diabetic patients with and without neuropathy. Finally, clinical parameters associated with gait abnormalities of patients with type 2 diabetes had to be identified in order to adequately develop and test a treatment approach.

Before specifying the objectives and outline of this thesis, information about Diabetes Mellitus will be provided and the fundamental characteristics of gait analysis along with some reference values for normal gait will be presented. At the end of this introduction the general practical and methodological choices made in order to address the study's aims will be explained.

\section{DIABETES}

Diabetes is a condition primarily defined by the level of hyperglycaemia giving rise to risk of microvascular damage (retinopathy, nephropathy and neuropathy). It is associated with reduced life expectancy and significant morbidity due to specific diabetes related microvascular complications, increased risk of macrovascular complications (ischemic heart disease, stroke and peripheral vascular disease) and diminished quality of life [19].

Although all forms of diabetes are characterised by hyperglycaemia, the pathogenic mechanisms by which hyperglycaemia arises differ widely [20]. Some forms of Diabetes Mellitus are characterised by absolute insulin deficiency or a genetic defect leading to defective insulin secretion, whereas other forms share insulin resistance as their underlying aetiology $[20,21]$. The pancreatic $\beta$-cell and its secretory product insulin are central in the pathophysiology of diabetes. Type 1 or insulin-dependent diabetes mellitus results from an absolute deficiency of insulin due to auto-immunological destruction of the insulinproducing pancreatic $\beta$-cell. Type 2 diabetes, which is the focus of this thesis, is a heterogeneous group of disorders usually characterised by variable degrees of insulin resistance, $\beta$-cell dysfunction with impaired insulin secretion [22] and increased glucose production $[20,21]$. At each end of this spectrum are single-gene disorders that affect the ability of the pancreatic $\beta$-cell to secrete insulin or the ability of muscle, fat and liver cells to respond to insulin's actions. Muscle and fat cells are 'resistant' to the actions of insulin and compensatory mechanisms that are activated in the $\beta$-cell to secrete more insulin are insufficient to maintain blood glucose levels within a normal physiological range [20, 22]. This chronic hyperglycaemia of diabetes is associated with long-term damage, dysfunction and failure of various organs, especially the eyes, kidneys, nerves, heart and blood vessels 
[20-22]. Although the major genes that predispose to this disorder have yet to be identified, it is clear that the disease is polygenic and multifactorial [21]. Various genetic loci contribute to susceptibility [21, 23]. Additionally environmental factors (such as nutrition and physical activity) further modulate phenotypic expression of the disease [21].

\section{Diagnosis}

Consensus panels of experts from the National Diabetes Data Group and the World Health Organisation (WHO) have issued criteria for diagnosis of Diabetes Mellitus. These criteria are a fasting plasma glucose $\geq 7.0 \mathrm{mmoll}^{-1}\left(126 \mathrm{mgdl}^{-1}\right)$ or 2 hour plasma glucose $\geq 11.1$ $\mathrm{mmol}^{-1}\left(200 \mathrm{mgdl}^{-1}\right)$ [19].

\section{Prevalence of diabetes}

The WHO has described type 2 diabetes as an international epidemic. Recent estimates indicated 171 million people in the world with diabetes in the year 2000. The number is projected to increase to 366 million by the year 2030 [1]. In Europe there are 2 data sources on the prevalence of diabetes. The WHO European Health for All database compiles data from national diabetes registers, where available, or from routine reporting systems [24]. These data show that the prevalence of diagnosed diabetes is increasing in nearly all countries of Europe with the highest prevalence in 2004 in Malta (7.6\%) and the Czech Republic (7.0\%) [24]. The WHO data however, greatly underestimates the true prevalence of diabetes in the population as around $50 \%$ of diabetes is undiagnosed [25-27]. The Atlas of the International Diabetes Federation [27] collates population-based prevalence studies across Europe and reports data on diagnosed and non-diagnosed diabetes combined. This study estimates an overall European prevalence of $7.8 \%$ with over 48 million adults aged 20 to 79 years in Europe living with diabetes in 2003.

\section{Risk factors}

Non-modifiable risk factors for type 2 diabetes include age (diabetes incidence and prevalence increases with age), race or ethnicity [28, 29] (e.g. African Americans are more likely to develop diabetes), family history [30] (genetic predisposition), history of gestational diabetes [21] and low birth weight [21]. Modifiable or lifestyle risk factors include, among others [28, 29, 35], increased Body Mass Index (BMI) [29, 31], physical inactivity [29, 32], overly rich nutrition [29], hypertension [21], smoking [21, 33] and excessive alcohol consumption [21, 34].

\section{Complications}

The risk of chronic complications increases as a function of the duration of hyperglycaemia [21]. Since type 2 diabetes may have an asymptomatic period many individuals have complications at the time of diagnosis [21,35]. The chronic complications of diabetes can be subdivided into vascular and nonvascular complications [21]. The vascular complications 
are further subdivided into microvascular (retinopathy, neuropathy, nephropathy) and macrovascular complications (coronary artery disease, peripheral vascular disease, cerebrovascular disease) [36]. Nonvascular complications include problems such as gastroparesis [37], sexual dysfunction [38] and skin changes [39]. In addition to these chronic complications Diabetes Mellitus is a major cause of non-traumatic lower extremity amputation [21, 40] due to foot ulcers and infections (Figure 1.2).

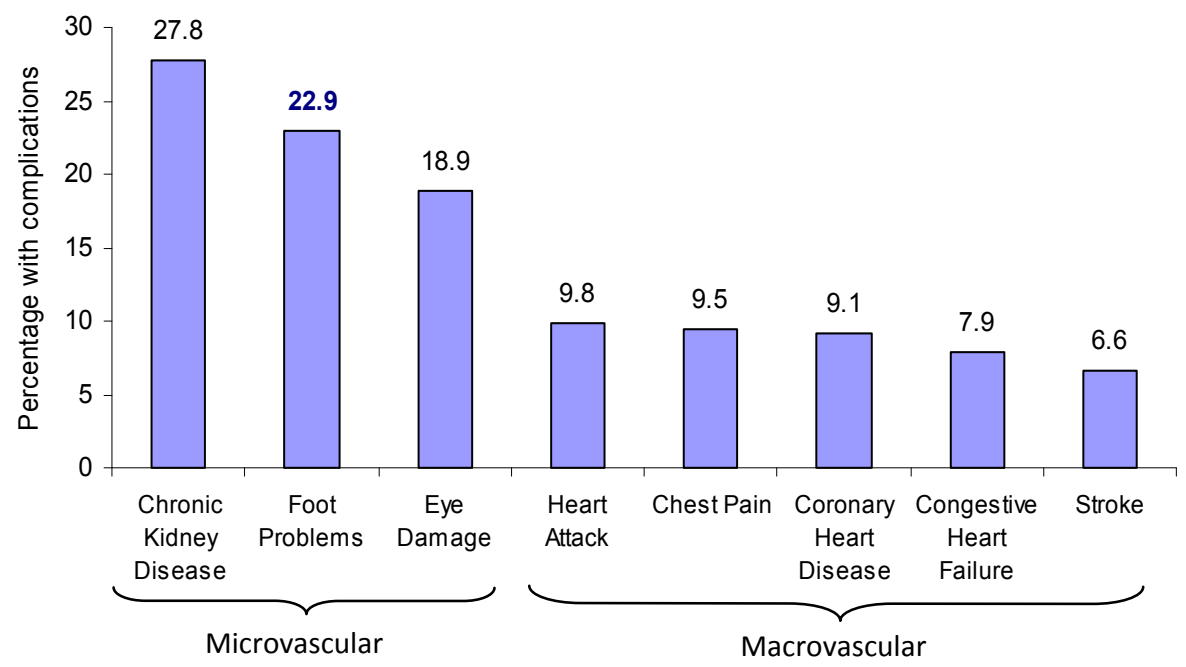

Figure 1.2. Prevalence of most common diabetes-related complications among people with diabetes. National Health and Nutrition survey 1999-2004 [46].

Foot ulcers and infections are known to be major sources of morbidity in individuals with diabetes [41, 42]. The reasons for this lower extremity complication are complex and involve the interaction of several pathogenic factors: neuropathy, abnormal foot biomechanics, peripheral vascular disease and poor wound healing $[21,43]$. Peripheral sensory neuropathy interferes with normal protective mechanisms and allows the patient to sustain major or repetitive minor trauma to the foot, often without knowledge of the injury [21]. Disordered proprioception causes abnormal weight bearing [21, 44]. Motor and sensory neuropathy in the foot leads to abnormal foot muscle mechanism and to structural changes $[21,44,45]$.

After having described the basis of the disease Diabetes, the following paragraph will address the fundamentals of gait analysis, in view of facilitating the appraisal of the studies included in this thesis.

\section{GAIT}

Walking is the body's natural means of moving from one location to another. Functional versatility allows the lower limbs to readily accommodate stairs, doorways, changing 
surfaces and obstacles in the path of progression. Efficiency in these endeavours depends on free joint mobility and muscle activity that is selective in timing and intensity [47]. Walking is also known as a pattern of motion under control, a repetitious sequence of limb motion while simultaneously maintaining stance stability and forward motion. Interestingly, every individual has a unique gait pattern [47]. By evaluating the gait pattern of an individual, a therapist can determine specific weaknesses and adjust rehabilitation programs to address these issues [48]. The term "gait cycle" is used to depict the complex activity of walking, or our gait pattern. It describes the motions from initial placement of the supporting heel on the ground to when the same heel contacts the ground for a second time. Each gait cycle (also known as stride) is divided into 2 periods, stance (entire period during which the foot is on the ground) and swing (foot is in the air for limb advancement). Stance is subdivided into 3 intervals according to the sequence of floor contact (initial double stance, single limb support and terminal double support). The gross normal distribution of the floor contact is $60 \%$ for stance $(10 \%$ for each double stance and $40 \%$ for single limb support) and $40 \%$ for swing (Figure 1.3). The gait cycle provides a framework for gait analysis. The gait characteristics (spatiotemporal gait parameters, kinematic, kinetic and muscular activity values) can be extracted from each gait cycle and used to interpret the walking pattern of an individual or of a group of patients [50].

This thesis will focus on spatiotemporal gait parameters (gait speed, cadence, stride length and gait cycle time, single support time, double support time and the stride to stride variability) because of their clinical relevance for patients' quality of life and daily activities $[51,52]$ and because of their association with heightened fall risk [53-55]. Before continuing with some reference values, interested readers can refer to Appendix I for a precise description and illustration of the divisions of gait cycles, and to Appendix II for a definition of spatiotemporal gait parameters.

Gait speed is one of the most widely reported spatiotemporal gait parameters. Gait speed depends on several factors such as height, lower limb length and age [56]. It can be further influenced by the conditions under which it is measured [57]. Gait speed is greater in a large and spacious place than in a narrow short corridor [58]. For these reasons it is most appropriate to compare the measured parameters of a target group with values from an age and height-matched healthy control group using the same measurement method. As shown in Table 1.1, different authors propose a considerable range of values for the speed categories slow, comfortable and rapid gait. The range of slow gait speed has been described as between $0.5 \mathrm{~ms}^{-1}$ and $1 \mathrm{~ms}^{-1}$ (1.8 to $3.8 \mathrm{kmh}^{-1}$ ), comfortable walking speed from $1.3 \mathrm{~ms}^{-1}$ to $1.6 \mathrm{~ms}^{-1}$ ( 4.7 to $5.8 \mathrm{kmh}^{-1}$ ) and a range of $1.9 \mathrm{~ms}^{-1}$ to $2.45 \mathrm{~ms}^{-1}$ (6.8 to 8.8 $\mathrm{kmh}^{-1}$ ) is considered a rapid walking speed. Summarising these findings, Viel [56] suggests values for adult gait speed that may be a useful reference point for data interpretation (Table 1.2). 


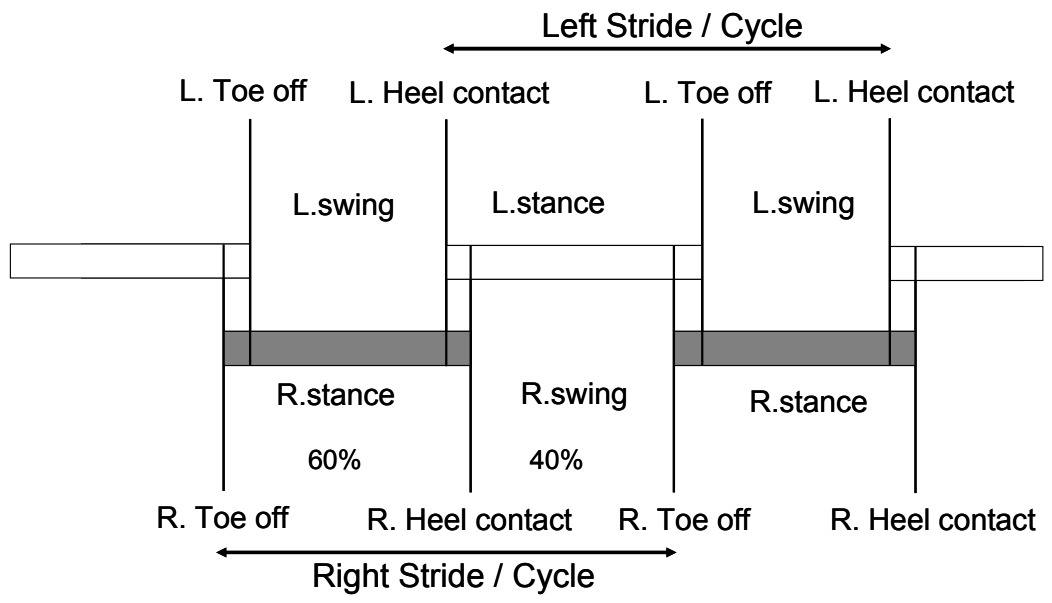

Figure 1.3. Schematic diagram of the temporal sequence of the gait cycle showing complete right (shaded bars) and left strides (white bars). $\mathrm{HC}=$ heel/initial contact; $\mathrm{L}=$ left; $\mathrm{R}=$ right.

The areas of overlap between HC and TO represent periods of double limb support, which coincidences with the period of pre-swing on the trailing limb and loading response on the leading limb. The figure above was inserted with reference to the original diagram published by Barr and Backus [49].

Table 1.1. Tables with reference values of gait speed in $\mathrm{ms}^{-1}[56]$

\begin{tabular}{llll}
\hline Author & Slow & Comfortable & Fast \\
\hline Lamoreux [59] & 0.97 & 1.45 & 1.72 \\
Winter [60] & 1.04 & 1.26 & 1.54 \\
Herman [61] & 0.92 & 1.28 & 1.98 \\
Larsson [62] & 1.24 & 1.54 & 2.40 \\
Riley [63] & - & 1.25 to 1.56 & - \\
Growney [64] & - & 1.19 & - \\
Stolze [65] & - & 1.51 to 1.54 & - \\
\hline
\end{tabular}

Table 1.2. Estimated gait speed for adults [56]

\begin{tabular}{llcl}
\hline Speed & $\mathbf{m s}^{-1}$ & $\mathbf{m m i n}^{-1}$ & $\mathbf{k m h}^{-1}$ \\
\hline Very slow & 0.4 & 24 & 1.44 \\
Slow & 0.5 & 30 & 1.80 \\
& 0.7 & 42 & 2.52 \\
Moderate & 1.0 & 60 & 3.60 \\
Ascertained & 1.3 & 79 & 4.68 \\
& 1.6 & 96 & 5.76 \\
Fast & 1.9 & 114 & 6.84 \\
\hline
\end{tabular}




\section{Associations of gait parameters with an increased fall risk}

Several changes in gait characteristics such as slower self-selected gait speed [66-69], shorter stride length [66-69], increased double support time $[68,69]$ and increased gait variability $[66,69,70]$ have been related to an increased risk of falls. These parameters have been frequently studied in elderly persons. The next table (Table 1.3) provides a comparison of different studies evaluating spatiotemporal gait parameters of older adults considered as active, independent, frail or as fearful fallers [53, 69, 71, 72].

Table 1.3. Spatiotemporal parameters of older adults considered as active, independent, frail or as fearful fallers

\begin{tabular}{lclll}
\hline Population & $\begin{array}{l}\text { Active life style, } \\
\text { No gait-related } \\
\text { pathologies }\end{array}$ & $\begin{array}{l}\text { Independent, } \\
\text { Randomly selected } \\
\text { from community }\end{array}$ & $\begin{array}{l}\text { Transitioning to } \\
\text { frailty }\end{array}$ & $\begin{array}{l}\text { Fearful } \\
\text { fallers }\end{array}$ \\
\hline Winter [72] & Lord [71] & Kressig [53] & Maki [69] \\
\hline Age (years) & 15 & 80 & 50 & 26 \\
Gait speed ( $\left.\mathrm{ms}^{-1}\right)$ & $68.90(4.0)$ & $71.10(5.2)$ & $79.60(5.8)$ & $82.00(6.0)$ \\
Stride length (m) & $1.29(-)$ & $1.11(0.19)$ & $0.97(0.23)$ & $0.66(0.19)$ \\
Cadence (stepsmin $\left.{ }^{-1}\right)$ & $1.38(0.12)$ & $1.15(0.13)$ & $1.11(0.18)$ & $0.83(0.16)$ \\
Stance (\%) & $111.80(8.7)$ & $115.40(11.2)$ & $105.70(12.7)$ & - \\
Double Support (\%) & $65.50(1.7)$ & $64.20(1.8)$ & $66.00(3.1)$ & - \\
\hline
\end{tabular}

In a recent article [73], it was shown that slower gait speed was associated with higher risk of falls. Moreover, a higher variability for swing time and stride length variability were identified as fall risk predictors. This confirms quantitative gait markers as independent predictors of falls in older adults.

Among these gait markers, gait variability is increasingly used as a fall risk predictor [54, 55, 74]. For example an evaluation in a one year prospective study of gait variability and fall risk in community-living older adults [70] showed that measures of gait variability were predictive of future falls. Survival analysis indicated that subjects with increased gait variability were likely to fall sooner than those subjects who had less variability in gait during their clinical assessment (the 2 groups did not differ significantly with respect to age, gender, height, weight, BMI, health status, mental health, level of education, physical activity levels or ability to perform daily activities).

Like most physiological parameters, measures of gait are not constant but rather fluctuate with time and change from one stride to the next, even when environmental and external conditions are fixed [54]. In healthy adults, these stride-to-stride fluctuations are relatively small and the coefficient of variation (CV) of many gait parameters (e.g. gait speed, gait cycle time) is of the order of just a few percent. When the systems regulating gait are disturbed (e.g., as a result of certain diseases), movement control may be impaired leading to increased stride-to-stride fluctuations [54] (Figure 1.4).

However, only few articles describe a cut-off point above which patients were declared at high fall risk. In spite of this, a binary threshold was determined post hoc using a sensitivity analysis (CV gait cycle time $>4 \%$ ) in a study conducted by Kressig et al. [74]. This cut off point supports the results of another clinical study in which a CV of $2.1 \%$ was reported for elderly non-fallers compared to a CV of $4.1 \%$ for elderly fallers during a 6 min walking test [55]. 

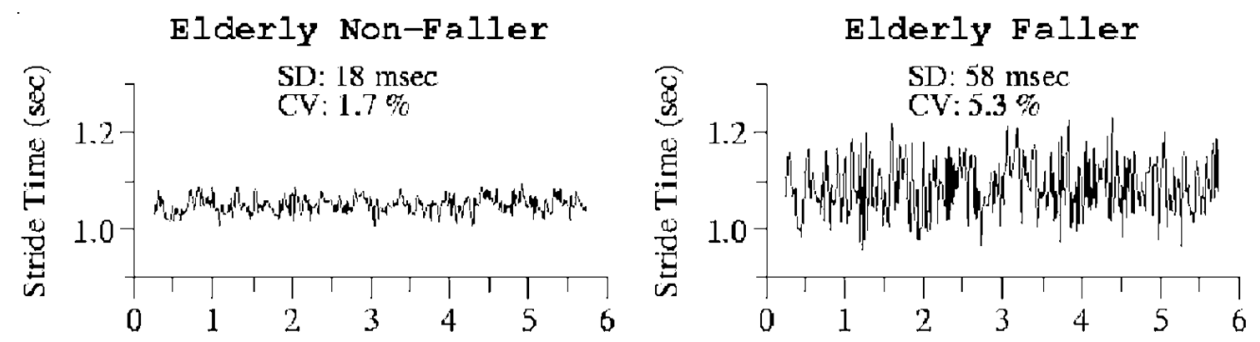

Figure 1.4. Example of the stride-to-stride fluctuations in the gait cycle time as measured in older adults by Hausdorff [54]. An older adult non-faller and an idiopathic faller; SD = standard deviation; CV = coefficient of variation.

Before providing the outline of this thesis some general practical and methodological choices are now described.

\section{GENERAL PRACTICAL AND METHODOLOGICAL CHOICES}

\section{Population}

In this research only patients with diagnosed type 2 diabetes were studied. The previously described diagnostic criterion from the WHO (fasting plasma glucose $\geq 7.0 \mathrm{mmoll}^{-1}$ ) was applied by the medical staff working in the recruitment units. All patients were recruited either from the Service of Therapeutic Education for Chronic Diseases or from the Service of Endocrinology at the University Hospital in Geneva.

\section{Choice of environment and equipment for gait analysis}

Gait is normally analysed in specialised laboratories which are equipped with specific measurement tools. The choice of equipment depends mainly on the target parameters which are to be measured. Spatiotemporal gait parameters can be measured with pressure mats [75, 76], optoelectronic systems [77], accelerometers [78, 79] and/or gyroscopes [80, 81] or footswitches [79]. To measure kinematics, goniometers [82], an optoelectronic system [83] or accelerometers and gyroscopes [84] are needed. Kinetic parameters are measured with either load cells [85] or force platforms [83]. However, the traditionally performed indoor gait analysis does not reflect real life conditions. The predefined, clean and flat specific pathways enable standardisation and control of the environment and permit precise recordings, but are not representative of a patient's typical daily environment. Activities of daily life require us to move in challenging environments and to walk on varied surfaces. Irregular terrain has been shown to influence gait parameters such as speed, especially in a population at risk of falls [57]. Its influence on gait parameters and the fact that falls most commonly occur in a complex environment [86] emphasise the need for clinicians to dispose of objective gait data recorded in a real life context. For the 
aforementioned reasons and based on the results of our systematic review, all gait analyses in this project were performed outdoors, in a challenging environment.

Gait can be studied in different environments with recently developed body-fixed sensors. In comparison with other motion measurement devices, body-fixed sensors have the advantage of being lightweight and portable, which enables subjects to move relatively freely [87]. They permit data collection in a challenging environment, they are easy to use and capture data from many gait cycles. At the moment a large choice of sensors exists. Body-fixed sensors have not only been used to monitor gait [88-90] but also to examine sitto-stand transfers [91], postural sway and fall risk [92] as well as physical activity levels [93]. Although an overview of all these different systems is beyond the scope of this thesis, it is important to remember that the choice of body-fixed sensors and their location must be consistent with the objective of the assessment [94]. If the main interest is to detect spatiotemporal gait parameters, it has been shown that one accelerometer on the trunk [90] or one gyroscope at each shin [80] is sufficient [90]. For clinical decision making however, the evaluation of spatiotemporal gait parameters is often insufficient. In this case, further information is provided by kinematic data measured by accelerometers and gyroscopes on hips, knees and ankles. Thus, a system computed with sensors (combination of accelerometers and gyroscopes) on the trunk and limbs may enable better interpretation of gait parameters. Having consulted the literature we decided that the Physilog system (BioAGM, CH) [80] best met our requirements for the study. This system is presented in detail in Appendix III. The gyroscopes on both thighs and shins were used for the analysis of spatiotemporal gait parameters. The data provided from the trunk sensor as well as the data from the shin were used to assess patients' postural stability, which may influence patients' gait and fall risk.

\section{Standing balance and measurements}

As several structures which are compromised in the presence of diabetic neuropathy, such as plantar cutaneous and proprioception sensation $[17,18]$, affect both gait and balance, and as balance impairments are likely to contribute to diabetic patients' gait alterations, postural control could not be ignored. Thus, a balance study to investigate and quantify more precisely the balance alterations in diabetic patients has been conducted. Nevertheless, as most falls occur during physical activities rather than in a static position [86] we opted to focus on gait parameters as main indicators in this thesis. The analysis of the relationship between quantified gait and balance parameters will be addressed in further studies and thus not included in this thesis. Regarding to standing balance, it is relevant that most studies evaluated postural stability with force plates, using measurements of the centre of pressure (COP) displacement [95]. Ankle and hip postural strategies using inverse dynamic calculations, sway area, as well as the scalar distance between the COP and the centre of mass (COM) are also reported [16]. In recent years, however, the use of miniature sensors such as accelerometers has become increasingly well accepted [96]. Although accelerometry data cannot be directly compared to COP parameters, it can discriminate between different conditions challenging the balance system [97]. Using an accelerometer fixed near the COM, trunk accelerometry data shows 
good discriminative validity during standing [97]. In addition, the root mean square (RMS) value of the accelerometric signal was previously used [97] as the main parameter to discriminate young from elderly subjects during different standing conditions (i.e. quiet standing with eyes open, quiet standing with eyes closed and quiet standing on a compliant mat).

Based on this knowledge, the range and RMS of trunk and shin acceleration during quiet standing was compared between healthy persons and diabetic patients with neuropathy and with diabetic patients without neuropathy. All data were recorded during the POMA-B test, a performance-oriented assessment of balance [98] and measured with the Physilog system.

\section{Development of treatment}

Since elderly people often show symptoms similar to those in diabetic patients (deconditioning, muscle weakness, decreased joint mobility and decreased foot sensation), we surmise that programs developed for the elderly could also be effective to improve gait patterns and balance in diabetics and consequently decrease their fall risk. Thus, we reviewed the different fall prevention protocols available for the elderly in order to develop a specific treatment approach to improve diabetic patients' gait characteristics and balance. The most effective exercises described in the literature to reduce the fall risk in a geriatric population are balance exercises, Tai Chi and strengthening [99]. Davies et al. [100] further showed that an agility training component is an equally promising type of exercise. Furthermore, Barnett et al. [101] found that participation in a weekly group exercise program with ancillary home exercises can improve balance and reduce the rate of falling in at-risk community dwelling older people.

Faber et al. [102] provide a clear description of 2 exercise programs, both derived from programs with evidence for effectiveness in preventing falls in the elderly. Key components in both programs were balance and functional strength. Treatments were carried out in groups to increase motivation for participation. The exercises were tailored to the functional needs of the participants, maintaining a moderate intensity that focused on long-term sustainability and enjoyment. The first program, referred to as functional walking, was derived from the tailored exercise program developed by Robertson et al. [103] in New Zealand. Functional walking consisted of 10 clearly described exercises forming the core program, which focused on balance, mobility and transfer training. The exercises consisted of standing up from a chair, reaching and stepping forward and sideways, heel and toe stands, walking and turning, stepping on and over an obstacle, staircase walking, tandem foot standing and single-limb standing. The second program, referred to as "in Balance", was derived from principles of Tai Chi. Functional walking and "in Balance" exercise programs were effective for reducing fall risk and improving the balance and physical performance scores in the subgroup of pre-frail elderly. Positive effects became apparent after 11 weeks of exercise and the authors concluded that supervised in-patient exercise rehabilitation is a safe and effective intervention. Finally, Rubenstein et al. [104] investigated effects of a group exercise program on strength, mobility and falls among fall-prone elderly men. They conducted a 12 week group exercise 
program. Exercise sessions (90 min, 3 times per week) focused on increasing strength and endurance and improving mobility and balance. Results showed an improvement in strength, physical activity, general health, muscle endurance and gait.

On the basis of the aforementioned literature about fall prevention in the elderly and of our knowledge about gait characteristics and postural stability in diabetic patients we developed a specific treatment approach. The training program we designed took place twice a week for 60 min over 12 weeks. Each session was directed by a physiotherapist and an assistant. Four different physiotherapists and 4 assistants were trained to direct the sessions in order to guarantee continuity. A session consisted of a warm up (5 min) followed by a circuit training $(40 \mathrm{~min}$ ) including gait and balance exercises. The circuit training was composed of a set of 10 tasks. Static and dynamic balance tasks were altered with functional strength exercises. Each task was performed twice during $1 \mathrm{~min}$ and the complexity of each task could be increased progressively. Each session was completed with interactive games to train agility $(10 \mathrm{~min})$ and a short feedback with suggestions for individual home exercises $(5 \mathrm{~min}$ ). The treatment exercises are summarised in the corresponding study and a detailed description is provided in Appendix IV.

Now that the general practical and methodological choices of this thesis have been made explicit, its detailed aims and outline are presented.

\section{AIM OF THIS THESIS}

This thesis encompasses 3 objectives. Firstly, we wanted to identify gait characteristics of patients with type 2 diabetes. The second objective was to identify clinical factors associated with gait difficulties of patients with type 2 diabetes. These 2 aims were prerequisites for our third and final purpose, which was to develop and test the efficacy of a physiotherapy program that aimed to improve the gait, balance and related clinical factors of patients with diabetes.

In order to achieve these aims several steps were necessary. The following section presents these steps and describes which chapter addresses the different aims.

\section{OUTLINE OF THE THESIS}

The project started with a systematic literature review about gait characteristics of diabetic patients (Chapter 2: Gait characteristics of diabetic patients: a systematic review), which partially addressed the first aim. With respect to this systematic review's conclusions and considering the advantages of ambulatory gait measurements, we proposed to further study the gait characteristics of diabetic patients, with and without neuropathy, outdoors under real life conditions. This would allow us to gain an in-depth knowledge of gait difficulties in patients with type 2 diabetes. In view of this objective, an ambulatory gait measurement system was needed. The Physilog is a valid ambulatory gait measurement 
system [80], which fulfils all necessary criteria for carrying out our study. However, its reliability was never measured among diabetic patients walking outside on challenging surfaces. Thus, a reliability study was conducted prior to studying the gait of diabetic patients under real life conditions (Chapter 3: Reliability of diabetic patients' gait parameters in a challenging environment). In the next step, we completed our first objective and studied the gait characteristics of diabetic patients, with and without neuropathy, outdoors. (Chapter 4: Gait alterations of diabetic patients while walking on different surfaces). Conscious that falling is a complex phenomenon and that poor balance is one of the major risk factors for falls [105], we were interested to investigate the balance performance of patients with diabetes. Thus, balance performance of diabetic patients with and without neuropathy was compared to that of healthy control group using the Performance-Oriented Mobility Assessment scale for balance (POMA-B) [98], which is a widely used tool for assessing mobility and fall risk in older people. Simultaneously postural stability was evaluated by means of trunk and shin sensors including accelerometers and gyroscopes. (Chapter 5: Investigation of standing balance in diabetic patients with and without peripheral neuropathy using accelerometers). However, as most falls occur during physical activities rather than in a static position [86], we opted to follow-up on gait parameters as indicators of dynamic balance abilities instead of postural stability parameters derived from static testing conditions. The next chapter identified clinical parameters associated with gait alterations of patients with diabetes and thus addressed our second objective (Chapter 6: Clinical factors associated with gait alterations in diabetic patients). Finally, based on this information a physiotherapeutic approach was developed, which was subsequently tested by means of a randomised controlled trial (Chapter 7: Diabetic patients' gait and balance can be improved with a specific training program. A randomised controlled trial). The paper about this randomised controlled trial (submitted for publication) presents the most clinically relevant parameters: influence of the treatment on gait speed and coefficient of variation while walking on a tarred surface together with the results concerning balance, strength, mobility and fear of falls. However, several other gait parameters (speed and coefficient of variation on cobblestones, cadence, stride length, stance phase and swing phase while walking on a tarred surface and on cobblestones) were explored and will also be submitted for publication. For the sake of completeness these results will be summarised at the end of the said publication, which figures in Chapter 7. Chapters 2 to 7 have been originally written as separate articles for publication in international peer-reviewed scientific journals, which is why some overlap between chapters could not be avoided. The last chapter (Chapter 8: General discussion) provides an overall discussion and conclusion about this PhD thesis project (Figure 1.5). 


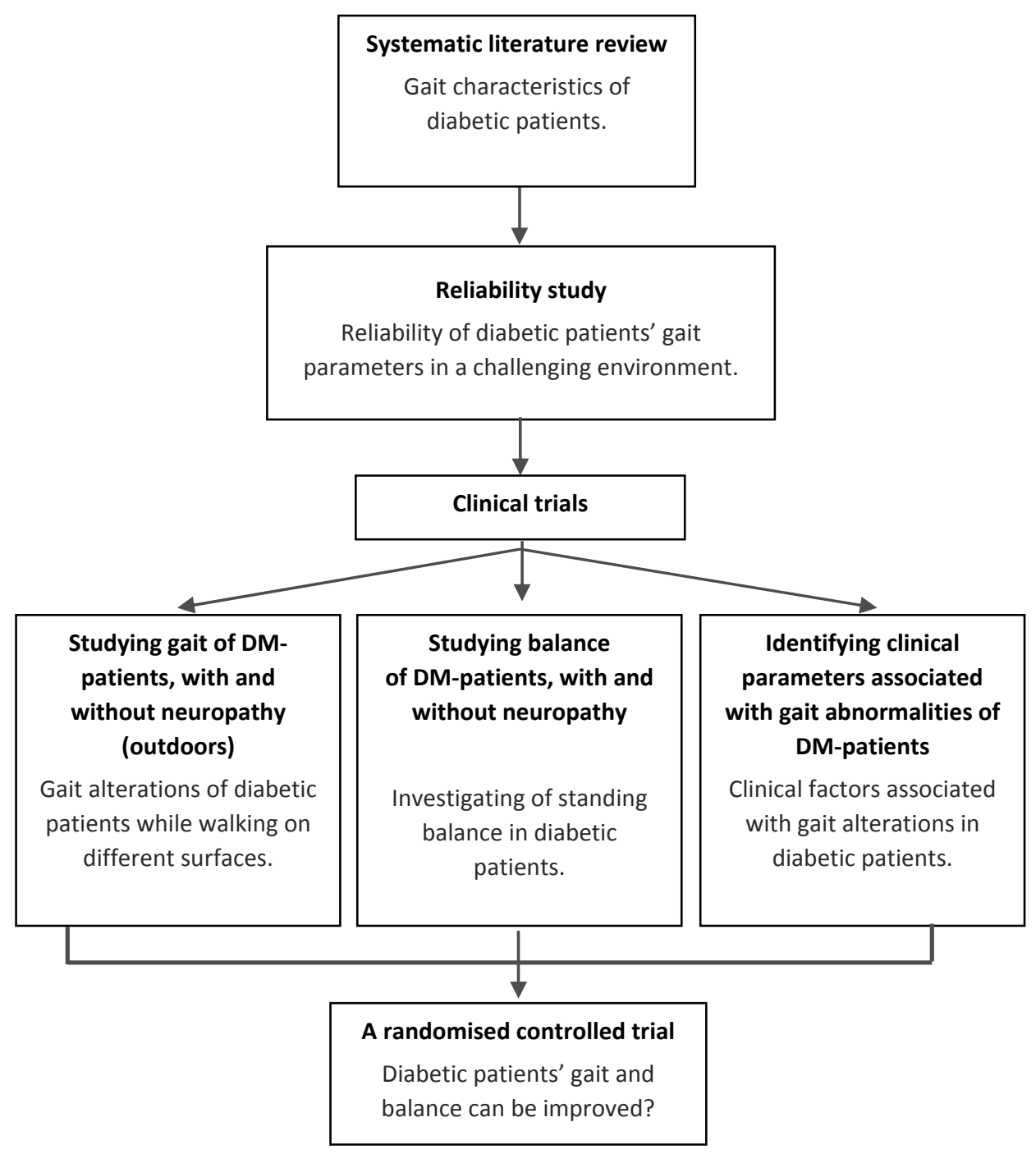

Figure 1.5. Flow chart of the outline of the thesis. 


\section{REFERENCES}

1. Wild S, Roglic G, Green A, Sicree R, King H: Global prevalence of diabetes: estimates for the year 2000 and projections for 2030. Diabetes Care 27:1047-1053, 2004.

2. Cohn R: Economic realities associated with diabetes care: opportunities to expand delivery of physical therapist services to a vulnerable population. Phys Ther 88:1417-1424, 2008.

3. van Schie $\mathrm{CH}$ : Neuropathy: mobility and quality of life. Diabetes Metab Res Rev 24 Suppl 1:45-51, 2008.

4. Brach JS, Talkowski JB, Strotmeyer ES, Newman AB: Diabetes mellitus and gait dysfunction: possible explanatory factors. Phys Ther 88:1365-1374, 2008.

5. Maurer MS, Burcham J, Cheng H: Diabetes mellitus is associated with an increased risk of falls in elderly residents of a long-term care facility. J Gerontol A Biol Sci Med Sci 60:1157-1162, 2005.

6. Wallace C, Reiber GE, LeMaster J, Smith DG, Sullivan K, Hayes S, Vath C: Incidence of falls, risk factors for falls, and fall-related fractures in individuals with diabetes and a prior foot ulcer. Diabetes Care 25:1983-1986, 2002.

7. American Diabetes Association. All about diabetes. 2007 [cited 2009 5th of April]; Available from:http://diabetes.niddk.nih.gov/dm/pubs/physical_ez /\#lifestyle.

8. Kriska AM, La Porte RE, Patrick SL, Kuller LH, Orchard TJ: The association of physical activity and diabetic complications in individuals with insulin-dependent diabetes mellitus: the Epidemiology of Diabetes Complications Study - VII. J Clin Epidemiol 44:1207-1214, 1991.

9. Global Guideline for Type 2 Diabetes: recommendations for standard, comprehensive, and minimal care. Diabet Med 23:579-593, 2006.

10. World Health Organization (WHO). World Health Report 2002: Reducing risks, promoting healthy lifestyle. 2002 [cited 2009 5th of April]; Available from: http://www.who.int/whr/2002/en.

11. Khattab M, Khader YS, Al-Khawaldeh A, Ajlouni K: Factors associated with poor glycemic control among patients with Type 2 diabetes. J Diabetes Complications, 2009.

12. Plotnikoff RC, Taylor LM, Wilson PM, Courneya KS, Sigal RJ, Birkett N, Raine K, Svenson LW: Factors associated with physical activity in Canadian adults with diabetes. Med Sci Sports Exerc 38:1526-1534, 2006.

13. Hausdorff JM, Nelson ME, Kaliton D, Layne JE, Bernstein MJ, Nuernberger A, Singh MA: Etiology and modification of gait instability in older adults: a randomized controlled trial of exercise. J Appl Physiol 90:21172129, 2001.

14. Morley JE: Falls - where do we stand? Mo Med 104:63-67, 2007.

15. Allet L, Armand S, Golay A, Monnin D, de Bie RA, de Bruin ED: Gait characteristics of diabetic patients: a systematic review. Diabetes Metab Res Rev 24:173-191, 2008.

16. Bonnet C, Carello C, Turvey MT: Diabetes and postural stability: review and hypotheses. J Mot Behav 41:172190, 2009.

17. Simoneau GG, Ulbrecht JS, Derr JA, Becker MB, Cavanagh PR: Postural instability in patients with diabetic sensory neuropathy. Diabetes Care 17:1411-1421, 1994.

18. van Deursen RW, Simoneau GG: Foot and ankle sensory neuropathy, proprioception, and postural stability. J Orthop Sports Phys Ther 29:718-726, 1999.

19. World Health Organization (WHO). Definition and diagnosis of diabetes mellitus and intermediate hyperglycemia:report of a WHO/IDF consultation. [Report] 20062009 [cited 2009 5th of April]; Available from: http://www.who.int/diabetes/publications/Definition\%20and\%20diagnosis\%20of\% 20diabetes_new.pdf.

20. Report of the expert committee on the diagnosis and classification of diabetes mellitus. Diabetes Care 26 Suppl 1:5-20, 2003.

21. Powers AC (2001): Diabetes Mellitus. In Braunwald E, Fauci AS, Kasper DL, Hauser SL, Longo DL, Jameson JL (Eds.). Harrison's Principles of Internal Medicine. $15^{\text {th }}$ ed. New York: McGraw-Hill; p. 2109-2137.

22. Bell GI, Polonsky KS: Diabetes mellitus and genetically programmed defects in beta-cell function. Nature 414:788-791, 2001.

23. Prokopenko I, McCarthy MI, Lindgren CM: Type 2 diabetes: new genes, new understanding. Trends Genet 24:613-621, 2008.

24. European health for all database. European Health for All database (HFA-DB). Updated January 2009 [cited 5th of April 2009]; Available from: http://www.euro.who.int/HFADB.

25. British Heart Foundation. Heartstats. 19th of May 2009 [cited 2009 5th of June]; Available from: http://www.heartstats.org/datapage. asp?id=4529. 
26. Lipscombe LL, Hux JE: Trends in diabetes prevalence, incidence, and mortality in Ontario, Canada 1995-2005: a population-based study. Lancet 369:750-756, 2007.

27. The International Diabetes Federation (IDF). Diabetes Atlas. [cited 2009 5th of April]; Available from: http://www.eatlas.idf.org/index80fd.html.

28. Egede LE, Dagogo-Jack S: Epidemiology of type 2 diabetes: focus on ethnic minorities. Med Clin North Am 89:949-975, 2005.

29. Zimmet P, Alberti KG, Shaw J: Global and societal implications of the diabetes epidemic. Nature 414:782-787, 2001.

30. Schulz LO, Bennett PH, Ravussin E, Kidd JR, Kidd KK, Esparza J, Valencia ME: Effects of traditional and western environments on prevalence of type 2 diabetes in Pima Indians in Mexico and the U.S. Diabetes Care 29:18661871, 2006.

31. Hu FB, Manson JE, Stampfer MJ, Colditz G, Liu S, Solomon CG, Willett WC: Diet, lifestyle, and the risk of type 2 diabetes mellitus in women. N Engl J Med 345:790-797, 2001.

32. Jeon CY, Lokken RP, Hu FB, van Dam RM: Physical activity of moderate intensity and risk of type 2 diabetes: a systematic review. Diabetes Care 30:744-752, 2007.

33. Wannamethee SG, Shaper AG, Perry IJ: Smoking as a modifiable risk factor for type 2 diabetes in middle-aged men. Diabetes Care 24:1590-1595, 2001.

34. Athyros VG, Liberopoulos EN, Mikhailidis DP, Papageorgiou AA, Ganotakis ES, Tziomalos K, Kakafika Al, Karagiannis A, Lambropoulos S, Elisaf M: Association of drinking pattern and alcohol beverage type with the prevalence of metabolic syndrome, diabetes, coronary heart disease, stroke, and peripheral arterial disease in a Mediterranean cohort. Angiology 58:689-697, 2007.

35. Deshpande AD, Harris-Hayes M, Schootman M: Epidemiology of diabetes and diabetes-related complications. Phys Ther 88:1254-1264, 2008.

36. Meeuwisse-Pasterkamp SH, van der Klauw MM, Wolffenbuttel BH: Type 2 diabetes mellitus: prevention of macrovascular complications. Expert Rev Cardiovasc Ther 6:323-341, 2008.

37. Moldovan C, Dumitrascu DL, Demian L, Brisc C, Vatca L, Magheru S: Gastroparesis in diabetes mellitus: an ultrasonographic study. Rom J Gastroenterol 14:19-22, 2005.

38. Kendirci M, Trost L, Sikka SC, Hellstrom WJ: Diabetes mellitus is associated with severe Peyronie's disease. BJU Int 99:383-386, 2007.

39. Bristow I: Non-ulcerative skin pathologies of the diabetic foot. Diabetes Metab Res Rev 24 Suppl 1:84-89, 2008.

40. Brem H, Sheehan P, Boulton AJ: Protocol for treatment of diabetic foot ulcers. Am J Surg 187 Suppl 1:1-10, 2004.

41. Fosse S, Hartemann-Heurtier A, Jacqueminet S, Ha Van G, Grimaldi A, Fagot-Campagna A: Incidence and characteristics of lower limb amputations in people with diabetes. Diabet Med 26:391-396, 2009.

42. Brem H, Sheehan P, Rosenberg HJ, Schneider JS, Boulton AJ: Evidence-based protocol for diabetic foot ulcers. Plast Reconstr Surg 117 Suppl 7:193-209; Discussion 210-211, 2006.

43. Crawford F, Inkster M, Kleijnen J, Fahey T: Predicting foot ulcers in patients with diabetes: a systematic review and meta-analysis. QJM 100:65-86, 2007.

44. Shaw JE, van Schie $\mathrm{CH}$, Carrington AL, Abbott CA, Boulton AJ: An analysis of dynamic forces transmitted through the foot in diabetic neuropathy. Diabetes Care 21:1955-1959, 1998.

45. Akturk M, Ozdemir A, Maral I, Yetkin I, Arslan M: Evaluation of Achilles tendon thickening in type 2 diabetes mellitus. Exp Clin Endocrinol Diabetes 115:92-96, 2007.

46. American Association of Clinical Endocrinologists. State of diabetes complications in America. 2007 [cited 2009 5th June]; Available from: http://www.aace.com/newsroom/press/2007/image/Diabetes ComplicationsReport_FINAL.pdf.

47. Perry J. (1992): Gait Analysis: Normal and Pathological Function. Thorofare (NJ): Slack; p. 1-19.

48. Coutts FJ (2005): Gait assessment in the clinical situation. In Atkinson K, Coutts FJ, Hassenkamp AM (Eds.). Physiotherapy in Orthopaedics: A Problem-Solving Approach. $2^{\text {nd }}$ ed. Edinburgh: Elsevier; p. 289-309.

49. Barr AE, Backus SI (2001): Biomechanics of Gait. In Nordin M, Frankel VH (Eds.). Basic Biomechanics of the Musculoskeletal System. $3^{\text {rd }}$ ed. Philadephia: Lippincott Williams \& Wilkins; p. 438-459.

50. Baker R: Gait analysis methods in rehabilitation. J Neuroeng Rehabil 3:4, 2006.

51. Schmid A, Duncan PW, Studenski S, Lai SM, Richards L, Perera S, Wu SS: Improvements in speed-based gait classifications are meaningful. Stroke 38:2096-2100, 2007.

52. Lopopolo RB, Greco M, Sullivan D, Craik RL, Mangione KK: Effect of therapeutic exercise on gait speed in community-dwelling elderly people: a meta-analysis. Phys Ther 86:520-540, 2006. 
53. Kressig RW, Gregor RJ, Oliver A, Waddell D, Smith W, O'Grady M, Curns AT, Kutner M, Wolf SL: Temporal and spatial features of gait in older adults transitioning to frailty. Gait Posture 20:30-35, 2004.

54. Hausdorff JM: Gait variability: methods, modeling and meaning. J Neuroeng Rehabil 2:19, 2005.

55. Hausdorff JM, Edelberg HK, Mitchell SL, Goldberger AL, Wei JY: Increased gait unsteadiness in communitydwelling elderly fallers. Arch Phys Med Rehabil 78:278-283, 1997.

56. Viel E (2000): Repères normatifs pour l'observation de la marche. In : Viel E, et al. La marche humaine, la course et le saut: Biomécanique, explorations, normes et dysfonctionnement. Paris: Elsevier Masson; p. 91-111.

57. Richardson JK, Thies SB, DeMott TK, Ashton-Miller JA: Gait analysis in a challenging environment differentiates between fallers and nonfallers among older patients with peripheral neuropathy. Arch Phys Med Rehabil 86:1539-1544, 2005.

58. Kirtley C (2006): Clinical Gait Analysis: Theory and Practice, Edinburgh: Elsevier Churchill Livingstone; p. 23.

59. Lamoreux LW: Kinematic measurements in the study of human walking. Bull Prosthet Res 10:3-84, 1971.

60. Winter DA, Quanbury AO, Hobson DA, Sidwall HG, Reimer G, Trenholm BG, Steinke T, Shlosser H: Kinematics of normal locomotion - a statistical study based on T.V. data. J Biomech 7:479-486, 1974.

61. Herman R, Wirta R, Brampton S, Finley R (1976): Human solutions for locomotion. In: Herman RM, Grillner S, Stein PSG, Stuart DG (Eds.), Neural Control of Locomotion, New York: Plenum Press; p. 13-49.

62. Larsson LE, Odenrick P, Sandlund B, Weitz P, Oberg PA: The phases of the stride and their interaction in human gait. Scand J Rehabil Med 12:107-112, 1980.

63. Riley M, Goodman M, V.U. F: Gait Analysis: A comparison between observational analysis and temporal distance measurements. Physiother 52:27-30, 1996.

64. Growney E, Meglan D, Johnson M, Cahalan T, An KN: Repeated measures of adult normal walking using a video tracking system. Gait Posture 6:147-162, 1997.

65. Stolze H, Kuhtz-Buschbeck JP, Mondwurf C, Johnk K, Friege L: Retest reliability of spatiotemporal gait parameters in children and adults. Gait Posture 7:125-130, 1998.

66. Guimaraes RM, Isaacs B: Characteristics of the gait in old people who fall. Int Rehabil Med 2:177-180, 1980.

67. Luukinen H, Koski K, Laippala P, Kivela SL: Risk factors for recurrent falls in the elderly in long-term institutional care. Public Health 109:57-65, 1995.

68. Wolfson L, Whipple R, Amerman P, Tobin JN: Gait assessment in the elderly: a gait abnormality rating scale and its relation to falls. J Gerontol 45:12-19, 1990.

69. Maki BE: Gait changes in older adults: predictors of falls or indicators of fear. J Am Geriatr Soc 45:313-320, 1997.

70. Hausdorff JM, Rios DA, Edelberg HK: Gait variability and fall risk in community-living older adults: a 1-year prospective study. Arch Phys Med Rehabil 82:1050-1056, 2001.

71. Lord SR, Lloyd DG, Nirui M, Raymond J, Williams P, Stewart RA: The effect of exercise on gait patterns in older women: a randomized controlled trial. J Gerontol A Biol Sci Med Sci 51:64-70, 1996.

72. Winter DA, Patla AE, Frank JS, Walt SE: Biomechanical walking pattern changes in the fit and healthy elderly. Phys Ther 70:340-347, 1990.

73. Verghese J, Holtzer R, Lipton RB, Wang C: Quantitative gait markers and incident fall risk in older adults. J Gerontol A Biol Sci Med Sci, 2009.

74. Kressig RW, Herrmann FR, Grandjean R, Michel JP, Beauchet O: Gait variability while dual-tasking: fall predictor in older inpatients? Aging Clin Exp Res 20:123-130, 2008.

75. Webster KE, Wittwer JE, Feller JA: Validity of the GAITRite walkway system for the measurement of averaged and individual step parameters of gait. Gait Posture 22:317-321, 2005.

76. McDonough AL, Batavia M, Chen FC, Kwon S, Ziai J: The validity and reliability of the GAITRite system's measurements: A preliminary evaluation. Arch Phys Med Rehabil 82:419-425, 2001.

77. Schwartz $\mathrm{MH}$, Rozumalski A, Trost JP: The effect of walking speed on the gait of typically developing children. J Biomech 41:1639-1650, 2008.

78. Hartmann A, Luzi S, Murer K, de Bie RA, de Bruin ED: Concurrent validity of a trunk tri-axial accelerometer system for gait analysis in older adults. Gait Posture 29:444-448, 2009.

79. Saremi K, Marehbian J, Yan X, Regnaux JP, Elashoff R, Bussel B, Dobkin BH: Reliability and validity of bilateral thigh and foot accelerometry measures of walking in healthy and hemiparetic subjects. Neurorehabil Neural Repair 20:297-305, 2006.

80. Aminian K, Najafi B, Bula C, Leyvraz PF, Robert P: Spatio-temporal parameters of gait measured by an ambulatory system using miniature gyroscopes. J Biomech 35:689-699, 2002. 
81. Houdijk H, Appelman FM, Van Velzen JM, Van der Woude LH, Van Bennekom CA: Validity of DynaPort GaitMonitor for assessment of spatiotemporal parameters in amputee gait. J Rehabil Res Dev 45:1335-1342, 2008.

82. Jansen $\mathrm{E}$, Orbaek $\mathrm{H}$ : Reproducibility of gait measurement using the Lamoreux goniometer. Prosthet Orthot Int 4:159-161, 1980.

83. Gerber H, Zihlmann M, Foresti M, Stüssi E: Method to simultaneously measure 3D kinematic and kinetic data during normal level walking using Kistler force plates, Vicon System and videofluoroscopy, in Ninth Symposium On 3D Analysis Of Human Movement. 2006: Valenciennes.

84. Favre J, Jolles BM, Aissaoui R, Aminian K: Ambulatory measurement of 3D knee joint angle. J Biomech 41:10291035, 2008.

85. Slavens BA, Sturm PF, Wang M, Harris GF: A dynamic model of the upper extremities for quantitative assessment of Lofstrand crutch-assisted gait. Conf Proc IEEE Eng Med Biol Soc 1:1525-1528, 2006.

86. Freiberger E, Menz HB: [Characteristics of falls in physically active community-dwelling older people: findings from the "Standfest im Alter" study] in German. Z Gerontol Geriatr 39:261-267, 2006.

87. Culhane KM, O'Connor M, Lyons D, Lyons GM: Accelerometers in rehabilitation medicine for older adults. Age Ageing 34:556-560, 2005.

88. Aminian K, Najafi B, Bula C, Leyvraz PF, Robert P: Spatio-temporal parameters of gait measured by an ambulatory system using miniature gyroscopes. Clin Biomech 35:689-699, 2002.

89. Salarian A, Russmann H, Vingerhoets FJ, Dehollain C, Blanc Y, Burkhard PR, Aminian K: Gait assessment in Parkinson's disease: toward an ambulatory system for long-term monitoring. IEEE Trans Biomed Eng 51:14341443, 2004.

90. Zijlstra W, Hof AL: Assessment of spatio-temporal gait parameters from trunk accelerations during human walking. Gait Posture 18:1-10, 2003.

91. Boonstra MC, van der Slikke RM, Keijsers NL, van Lummel RC, de Waal Malefijt MC, Verdonschot N: The accuracy of measuring the kinematics of rising from a chair with accelerometers and gyroscopes. J Biomech 39:354-358, 2006.

92. Helbostad JL, Leirfall S, Moe-Nilssen R, Sletvold O: Physical fatigue affects gait characteristics in older persons. J Gerontol A Biol Sci Med Sci 62:1010-1015, 2007.

93. McClain JJ, Sisson SB, Tudor-Locke C: Actigraph accelerometer interinstrument reliability during free-living in adults. Med Sci Sports Exerc 39:1509-1514, 2007.

94. de Bruin ED, Hartmann A, Uebelhart D, Murer K, Zijlstra W: Wearable systems for monitoring mobility-related activities in older people: a systematic review. Clin Rehabil 22:878-895, 2008.

95. Winter DA: Human balance and posture control during standing and walking. Gait Posture 3:193-214, 1995.

96. Mathie MJ, Coster AC, Lovell NH, Celler BG: Accelerometry: providing an integrated, practical method for longterm, ambulatory monitoring of human movement. Physiol Meas 25:1-20, 2004.

97. Moe-Nilssen R, Helbostad JL: Trunk accelerometry as a measure of balance control during quiet standing. Gait Posture 16:60-68, 2002.

98. Tinetti ME: Performance-oriented assessment of mobility problems in elderly patients. J Am Geriatr Soc 34:119-126, 1986.

99. Gardner MM, Robertson MC, Campbell AJ: Exercise in preventing falls and fall related injuries in older people: a review of randomised controlled trials. Br J Sports Med 34:7-17, 2000.

100. Davis JC, Donaldson MG, Ashe MC, Khan KM: The role of balance and agility training in fall reduction. A comprehensive review. Eura Medicophys 40:211-221, 2004.

101. Barnett A, Smith B, Lord SR, Williams M, Baumand A: Community-based group exercise improves balance and reduces falls in at-risk older people: a randomised controlled trial. Age Ageing 32:407-414, 2003.

102. Faber MJ, Bosscher RJ, Chin APMJ, van Wieringen PC: Effects of exercise programs on falls and mobility in frail and pre-frail older adults: A multicenter randomized controlled trial. Arch Phys Med Rehabil 87:885-896, 2006.

103. Robertson MC, Campbell AJ, Gardner MM, Devlin N: Preventing injuries in older people by preventing falls: a meta-analysis of individual-level data. J Am Geriatr Soc 50:905-911, 2002.

104. Rubenstein LZ, Josephson KR, Trueblood PR, Loy S, Harker JO, Pietruszka FM, Robbins AS: Effects of a group exercise program on strength, mobility, and falls among fall-prone elderly men. J Gerontol A Biol Sci Med Sci 55:317-321, 2000.

105. Piirtola M, Era P: Force platform measurements as predictors of falls among older people - a review. Gerontology 52:1-16, 2006. 



\section{Chapter 2}

\section{Gait characteristics of diabetic patients with and without neuropathy:}

a systematic review

Article published in Diabetes Metab Res Rev 24(3):173-191, 2008

${ }^{1}$ Department of Neurosciences, Geneva University Hospital and University of Geneva, Geneva, Switzerland.

2 Department of Epidemiology, Maastricht University and Caphri Research School, Maastricht, The Netherlands.

${ }^{3}$ Willy Taillard Laboratory of Kinesiology, Geneva University Hospital and University of Geneva, Geneva, Switzerland.

${ }^{4}$ Service of Therapeutic Education for Chronic Diseases, WHO Collaborating Centre, Geneva University Hospital and University of Geneva, Geneva, Switzerland.

${ }^{5}$ Institute of Human Movement Sciences and Sport, ETHZ, Zürich, Switzerland.

${ }^{6}$ Department of Rheumatology and Institute of Physical Medicine, University Hospital Zürich, Zürich, Switzerland. 


\section{SUMMARY}

\section{Background}

Patients with diabetes are at higher risk of experiencing fall-related injuries when walking than healthy controls. The underlying mechanism responsible for this is not yet clear. Thus, we intend to summarise diabetic patients' gait characteristics and emphasise those which could be the possible underlying mechanisms for increased fall risk.

\section{Aims}

This systematic review aims, in particular, to: a) evaluate the quality of existing studies which investigate the gait characteristics of diabetic patients, b) highlight areas of agreement and contradiction in study results, c) discuss and emphasise parameters associated with fall risk and d) propose new orientations and further areas for research needed for fall risk prevention in diabetic patients.

\section{Methods}

We conducted an electronic search of Pedro, PubMed, Ovid and Cochrane. Two authors independently assessed all abstracts. Quality of the selected articles was scored and the study results summarised and discussed.

\section{Results}

We considered 236 abstracts of which 28 entered our full text review. Agreement on data quality between 2 reviewers was high (kappa: 0.90). Authors investigating gait parameters in a diabetic population evaluated in particular parameters either associated with fall risk (speed, step length or step-time variability) or with ulcers (pressure). There is agreement that diabetic patients walk slower, with greater step variability, and present higher plantar pressures than healthy controls.

\section{Discussion and conclusion}

Diabetic patients present gait abnormalities, some of which can lead to heightened fall risk. To understand its underlying mechanisms, and to promote efficient prevention, further studies should analyse gait under real life conditions. 


\section{INTRODUCTION}

The World Health Organisation has described type 2 diabetes as an international epidemic. Current estimates suggest that the number of persons with diabetes will reach 250 million by 2010 and 300 million by 2025 [1]. Fifty percent of patients who have suffered from diabetes for more than 20 years develop peripheral neuropathy (PN), which affects nerve function from the periphery to more proximal regions $[2,3]$.

Diabetes is associated with an increase in injurious falls [4-7]. Fall frequency in diabetic patients has been highlighted and as a consequence increased attention to fall prevention by diabetes care providers is recommended [8]. Wallace et al. [6] reported an overall incidence of falls of 1.25 falls per person-year in cohorts of diabetic individuals. Forty-one percent reported 2 or more falls, which could be associated with a higher fracture risk. The authors further showed that diabetes, gait and balance were significantly and independently associated with heightened risk of falling. A closer examination of the literature dealing with gait characteristics in diabetic patients revealed that gait abnormalities are common in the aforementioned population [2, 9-20]. Studies have shown a decrease in quality of spatiotemporal gait parameters such as speed, stride length, gait cycle time, or single support time in diabetic patients with or without PN, when compared to healthy controls. In similar groups, authors found increased gait variability [2], higher reaction times [21], less ankle mobility, ankle moment and ankle power [16] or changes in ground reaction forces (GRFs) during walking [17]. Parameters, such as gait variability (stride-to-stride temporal variations) [22, 23] or reduced speed [24-26] demonstrated clear association with falling, albeit in an elderly population. The impact of abnormal gait parameters on diabetic patients' falling is thus well demonstrated. Studying diabetic individuals' gait parameters could therefore be useful to predict falling and could also facilitate the understanding of the causes and underlying mechanisms of heightened fall risk in the said population. However, questions remain about the main causes of gait abnormalities in diabetic patients. Various authors [7, 12, 13, 19, 27] found an association between neuropathy and gait abnormalities and/or falls. Ducic et al. [28] examined the intuitive relationship between increasing loss of foot sensibility and increasing loss of balance in diabetic patients. They stated that PN rather than ocular changes are responsible for gait problems. These authors concluded that neuropathy, leading to loss of sensation and to the neuromuscular control system's inability to respond to a challenging environment, could be the mechanism responsible for gait abnormalities and increased risk of falls. Cavanagh et al. [7] also demonstrated that PN has an effect on gait and posture. The latter authors described 15 times more falling in the diabetic neuropathy group than in the diabetic control group. However, Petrofsky et al. [15] found gait impairments in diabetic patients with no sensory loss and concluded that whatever the mechanism, patients with diabetes present deficits in gait long before objective loss of sensation in the feet. This apparent contradiction between authors underscores the fact that the causes for gait abnormalities and falls are yet under debate.

There is sufficient evidence that diabetic patients show gait abnormalities and that some of these parameters lead to heightened risk of falling. However, the variety of studies, providing a wealth of experimental data, makes it difficult to get a clear view of what gait 
parameters could be clinically relevant to fall risk prevention. Furthermore, discussion about the influence of neuropathy on gait abnormalities hampers the definition of what population should be targeted for prevention.

We thus intend to summarise gait characteristics in diabetic patients and then emphasise those which could be possible underlying mechanisms for increased risk of falls. This systematic review aims in particular to: a) evaluate the quality of existing studies investigating diabetic patients' gait characteristics, b) highlight areas of agreement and contradiction in study result, c) discuss and emphasise parameters associated with fall risk and d) propose new orientations and further domains for research needed for fall risk prevention in diabetic patients.

\section{METHODS}

\section{Search methods for identification of studies}

In May 2006 a professional librarian performed an electronic search of the Pedro, PubMed (Medline since 1950), Ovid (Biosis, Cinahl) and Cochrane (Central, Dare/CRD, HTA) databases covering the years 1950 to May 2006. The search strategy included the following keywords: (gait OR gait disorder OR walking OR kinematic OR gait analysis system OR gait analysis device) AND (polyneuropathy OR diabetic neuropathy OR diabetes mellitus) NOT amputation. Language was restricted to English, German or French.

\section{First selection based on abstracts}

Two independent reviewers (L.A., S.A.) assessed the title and abstract of each identified study. Abstracts were included in the full text review when they satisfied criteria mentioned below about types of studies, patient characteristics and outcome measures.

\section{Types of studies}

Only clinical trials evaluating gait characteristics of patients with diabetes were included. We excluded single case studies and pilot studies.

\section{Types of participants}

Persons with diabetes (type 1 or 2, with or without PN) without amputation or dependence on assistive devices. Studies focusing on foot deformities were excluded.

\section{Types of outcome measures}

Gait-related characteristics for diabetic patients (e.g. spatiotemporal results, kinematics, kinetics and/or electromyography (EMG)) had to be reported.

In case of disagreement between the 2 reviewers, a third person (E.D.deB.) decided whether the article should be included in the systematic review. 


\section{Method for quality assessment in selected full text articles}

Quality assessment of the included articles was based on the checklist of Downs et al. [29], which was developed for the assessment of the methodological quality of both randomised and non-randomised studies. The reviewed articles did not focus on treatment approaches but rather on the evaluation of gait characteristics of patients with diabetes compared with a healthy group. We therefore had to adapt the checklist used, discarding items 14 and 15 about blinding, item 17 about follow-up, items 21 and 22 about recruitment of intervention and control groups and items 23 and 24 about randomisation. All other items remained in the quality checklist. Considering the item adverse events we also evaluated events as a consequence of a measurement system. Four independent reviewers (D.M., E.D.deB., L.A. and S.A.) piloted the adapted quality checklist on 3 articles to ensure the content and to certify reliable data extraction. Results were compared and differences were resolved by discussion. After the pilot session we standardised item description to ensure good interrater reliability. The final quality checklist consisted of 20 items with a theoretical maximum score of 25 points. The checklist scored on 5 different domains: quality of reporting (10 items, maximum 11 points), external validity ( 3 items, maximum 3 points), internal validity bias (4 items, maximum 4 points), internal validity ( 2 items, maximum 2 points) and power (1 item with maximum 5 points). The checklist was converted to an electronic extraction sheet and used to collect data and to control for quality of the included studies. We chose double extraction by 2 independent reviewers (L.A., S.A.). Where necessary we checked the precision of data in previous papers by the same author.

\section{Analysis}

Kappa statistics and bootstrapped confidence intervals were performed to ensure agreement in the quality assessment [30].

To describe the quality of the article the total points for each article and the mean value of each domain assessed, along with the standard deviation, were calculated. All articles fulfilling inclusion criteria after the abstracts had been read were considered in the results. A meta-analysis was not possible because results and data were presented in an incompatible form. A descriptive summary of the results was therefore carried out.

\section{RESULTS}

First selection based on abstracts: the literature search identified 236 abstracts for consideration. None of the articles had to be excluded on the basis of language. After application of the inclusion criteria 28 articles entered our full text review (Figure 2.1). 


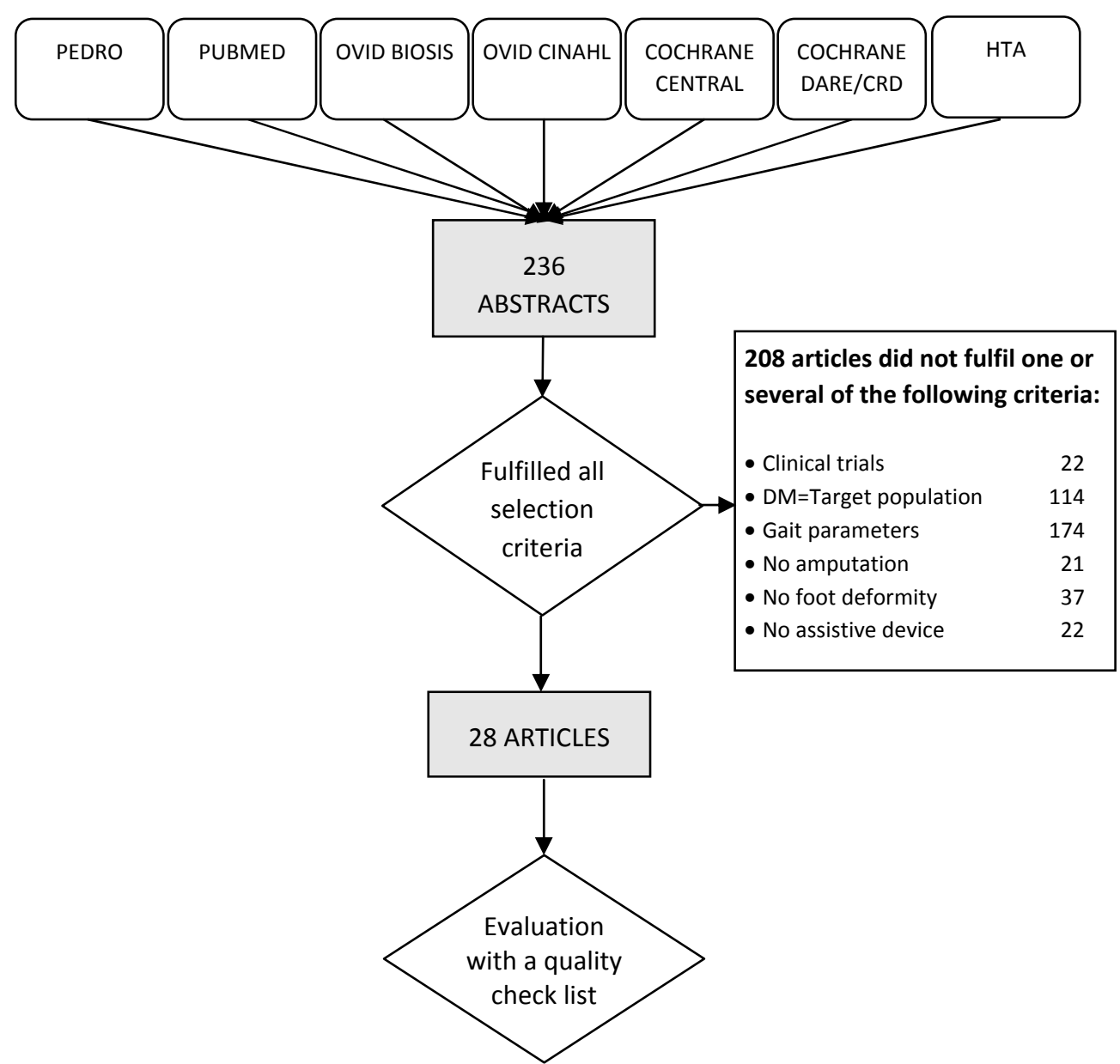

Figure 2.1. Procedure for the study selection with utilised database for the literature search and with defined selection criteria.

\section{Data quality}

The agreement on data quality between the 2 reviewers was high. The estimated Kappa value was 0.90 (0.02). The $95 \%$ confidence interval ranged from 0.86 to 0.93 . The quality scores of studies ranged from 13 to 21 points out of a maximum of 25 points. The mean quality was 16.74 (1.81). The mean score was 7.85 (1.35) out of 11 for reporting, 1.39 (0.49) out of 3 for external validity, $3.46(0.69)$ out of 4 for internal validity bias, $1.57(0.57)$ out of 2 for internal validity and 2.40 (1.50) out of 5 for power. For several items we had to report "unable to evaluate" due to lack of relevant information. For example, few authors discussed adverse events due to equipment, testing conditions or procedures. It is possible that authors did not feel it necessary to report the absence of adverse events. Another aspect that was not well reported was the number of patients approached for participation compared to the number of patients who actually agreed to participate. This raises 
questions about whether those who took part in the studies were truly representative of the population of diabetic patients. In addition, the staff and place of examination were often difficult to evaluate. We considered them to be standardised and adapted if measurements were performed in a gait laboratory (explicitly mentioned in the article) or if they described which person carried out the tests and under which conditions. We scored one point if it was always the same person or if the interrater reliability was reported and satisfactory (Table 2.1).

Table 2.1. Results of study scored by the reviewers L.A. and S.A. (score for each study based on the quality checklist published by Downs et al. [29])

\begin{tabular}{|c|c|c|c|c|c|c|c|c|c|c|c|c|}
\hline \multirow[t]{2}{*}{ Author [Ref] } & \multicolumn{2}{|c|}{$\begin{array}{l}\text { Reporting } \\
(\max 11)\end{array}$} & \multicolumn{2}{|c|}{$\begin{array}{l}\text { External } \\
\text { validtiy } \\
(\max 3)\end{array}$} & \multicolumn{2}{|c|}{$\begin{array}{c}\text { Internal } \\
\text { validity bias } \\
\text { (max 4) }\end{array}$} & \multicolumn{2}{|c|}{$\begin{array}{l}\text { Internal } \\
\text { validity } \\
\text { (max 2) }\end{array}$} & \multicolumn{2}{|c|}{$\begin{array}{l}\text { Power }^{\mathrm{a}} \\
(\max 5)\end{array}$} & \multicolumn{2}{|c|}{$\begin{array}{c}\text { Total } \\
\text { score } \\
(\max 25)\end{array}$} \\
\hline & L.A. & S.A. & L.A. & S.A. & L.A. & S.A. & L.A. & S.A. & L.A. & S.A. & L.A. & S.A. \\
\hline Abboud [31] & 6 & 5 & 2 & 2 & 4 & 4 & 1 & 1 & 3 & 3 & 16 & 15 \\
\hline D'Ambrogi [32] & 7 & 6 & 1 & 1 & 3 & 3 & 1 & 1 & 3 & 3 & 15 & 14 \\
\hline Courtemanche [21] & 9 & 9 & 2 & 2 & 3 & 3 & 2 & 2 & 0 & 0 & 16 & 16 \\
\hline Dingwell [18] & 8 & 8 & 1 & 1 & 4 & 4 & 2 & 2 & 2 & 2 & 17 & 17 \\
\hline Dingwell [2] & 9 & 9 & 1 & 1 & 4 & 4 & 2 & 2 & 1 & 1 & 17 & 17 \\
\hline Dingwell [19] & 9 & 9 & 1 & 1 & 4 & 4 & 2 & 2 & 1 & 1 & 17 & 17 \\
\hline Giacomozzi [33] & 7 & 6 & 1 & 1 & 4 & 4 & 1 & 1 & 3 & 3 & 16 & 15 \\
\hline Hiltunen [34] & 4 & 4 & 2 & 2 & 4 & 4 & 0 & 0 & 5 & 5 & 15 & 15 \\
\hline Hsi [35] & 10 & 10 & 1 & 1 & 3 & 3 & 2 & 2 & 4 & 4 & 20 & 20 \\
\hline Hsi [36] & 9 & 8 & 1 & 1 & 3 & 3 & 2 & 2 & 3 & 3 & 18 & 17 \\
\hline Menz [20] & 9 & 9 & 1 & 2 & 4 & 4 & 1 & 1 & 4 & 4 & 19 & 20 \\
\hline Katoulis[17] & 7 & 7 & 2 & 2 & 4 & 4 & 2 & 2 & 3 & 3 & 18 & 18 \\
\hline Kwon [37] & 9 & 9 & 2 & 2 & 3 & 3 & 2 & 2 & 0 & 0 & 16 & 16 \\
\hline Meier [38] & 9 & 9 & 2 & 2 & 3 & 4 & 1 & 1 & 2 & 2 & 17 & 18 \\
\hline Mueller [16] & 9 & 9 & 1 & 2 & 4 & 4 & 1 & 1 & 0 & 0 & 15 & 16 \\
\hline Mueller [39] & 8 & 8 & 1 & 1 & 4 & 3 & 2 & 2 & 0 & 0 & 15 & 14 \\
\hline Pataky [40] & 7 & 7 & 1 & 1 & 3 & 3 & 2 & 2 & 2 & 2 & 15 & 15 \\
\hline Patil [41] & 8 & 8 & 1 & 1 & 3 & 3 & 2 & 2 & 4 & 4 & 18 & 18 \\
\hline Perry [42] & 9 & 8 & 2 & 2 & 3 & 3 & 2 & 2 & 3 & 3 & 19 & 18 \\
\hline Petrofsky [15] & 6 & 6 & 1 & 1 & 3 & 3 & 2 & 2 & 2 & 2 & 14 & 14 \\
\hline Petrofsky [14] & 9 & 9 & 1 & 1 & 4 & 4 & 2 & 2 & 3 & 3 & 19 & 19 \\
\hline Petrofsky [43] & 8 & 7 & 1 & 1 & 3 & 3 & 1 & 2 & 3 & 3 & 16 & 16 \\
\hline Richardson [11] & 8 & 9 & 2 & 1 & 4 & 3 & 2 & 2 & 5 & 5 & 21 & 20 \\
\hline Richardson [9] & 8 & 9 & 1 & 1 & 4 & 4 & 2 & 2 & 1 & 1 & 16 & 17 \\
\hline Sacco [44] & 5 & 6 & 2 & 2 & 4 & 4 & 1 & 2 & 2 & 2 & 14 & 16 \\
\hline Sacco [45] & 7 & 7 & 2 & 1 & 4 & 3 & 1 & 2 & 1 & 1 & 15 & 14 \\
\hline Uccioli [46] & 8 & 8 & 1 & 1 & 3 & 3 & 2 & 2 & 3 & 3 & 17 & 17 \\
\hline Walker [47] & 8 & 7 & 2 & 2 & 1 & 1 & 1 & 2 & 3 & 3 & 15 & 15 \\
\hline
\end{tabular}

${ }^{a}$ Sample size have been calculated to detect a difference of $10 \%$. 


\section{Measurement conditions}

The 28 articles were written by 20 different authors. All authors conducted at least one of their studies on a straight walkway. Two articles evaluated gait while walking on a treadmill $[18,44]$. One article examined not only forward gait but also turning to one side or the other and the reaction time when stopping suddenly [43]. Two authors were interested in challenging environments $[9,11,20]$. Patients recruited for the study of Richardson et al. $[9,11]$ had to walk on a poorly lit walkway with different obstacles and the subjects in Menz et al.'s [20] study were asked to walk on a $20 \times 1.5 \mathrm{~m}$ walkway constructed to provide a partially yielding, irregular walking surface. Five further studies evaluated the influence of assistive devices or the use of medication in improving the gait parameters of diabetic people. Perry et al. [42] were interested to evaluate gait pressures in those wearing running shoes and Hsi et al. [35, 36] the influence of wearing rocker soles. Richardson et al. [11] analysed gait parameters using different assistive devices (a cane, a vertical surface or an orthosis). Petrofsky et al. [14] were the only authors who tested the influence of medication on gait parameters [14].

\section{Population}

Seventeen articles described a diabetic group versus a healthy control group. Three studies did not compare patients to a control group [9, 35, 36], but the same group of patients under different conditions. Three studies $[18,42,45]$ differentiated between diabetes with and without neuropathy and 5 further articles [17, 32, 33, 41, 46] distinguished a diabetic group with previous ulcers. The severity of the diabetes (with or without neuropathy or previous ulcer) was part of all of the studies' selection criteria. These criteria together with other selection criteria are summarised in Table 2.2 .

Seven $[20,21,31,34,41,45,47]$ out of the 25 studies comparing 2 or more groups did not report anything about matching factors used to guarantee similarity between groups. Five $[21,31,34,41,47]$ of these 7 articles did not discuss demographic data. However, their results suggest similarities between groups except in the study of Abboud et al. [31]. Sacco et al. [44] reported a significant difference in age and Menz et al. [20] in weight. All other studies comparing groups used at least the factor "Age" to match groups. Nine studies [2, 17-19, 32, 38, 40, 42, 44] used "Gender" and "Age" together with either "BMI" or "Weight and Height".

In all but 4 studies [31, 34, 41, 45] the authors clearly described exclusion criteria so as to avoid possible confounders for gait abnormalities. One study considered a diabetic population with a mean age of less than 30 years [34], 17 studies evaluated a population with a mean age between 40 and 60 and 9 studies with a mean age between 60 and 70 years. Only one study had a population with a mean age higher than 70 years [20]. Two studies did not report the mean age of their population $[41,47]$ and 4 studies that of their control group [20,40,46,47]. Four studies showed a significant difference in age between the patient and control groups [14, 31, 44, 45]. Weight ranged from 51.3 to $106.6 \mathrm{~kg}$ for the controls and from 62.5 to $105.4 \mathrm{~kg}$ for the diabetic group (Table 2.2). 


\begin{tabular}{|c|c|c|c|c|c|}
\hline & & 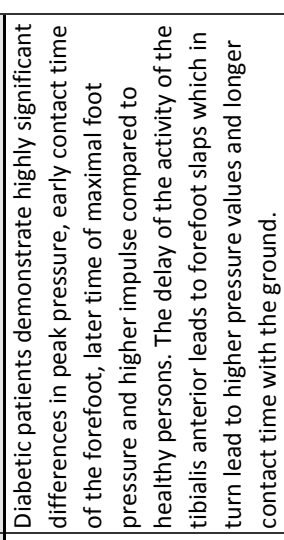 & 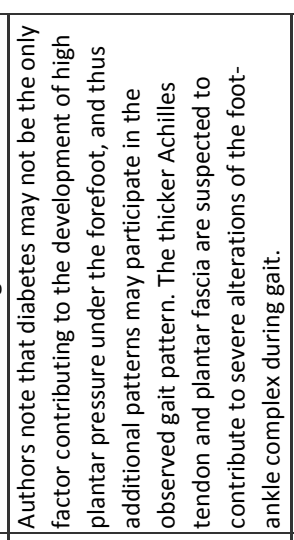 & 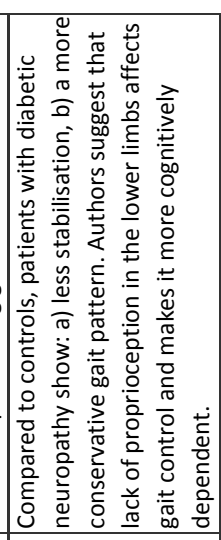 & 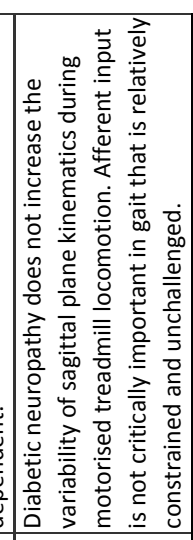 \\
\hline 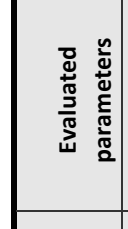 & & 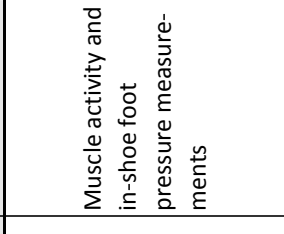 & 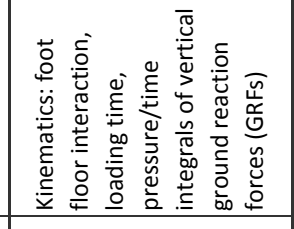 & 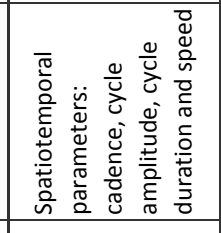 & 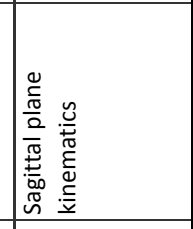 \\
\hline 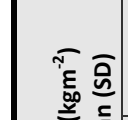 & 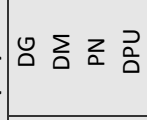 & $\frac{\vec{x}}{z}$ & $\cdot \frac{\overline{9}}{\stackrel{D}{~}}$ & $\frac{\vec{x}}{z}$ & $\frac{\vec{z}}{2}$ \\
\hline 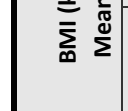 & 8 & $\frac{\vec{x}}{2}$ & $\frac{\bar{q}}{\sqrt{d}}$ & $\frac{\vec{x}}{2}$ & $\underset{\substack{\infty \\
i \\
i}}{i}$ \\
\hline & 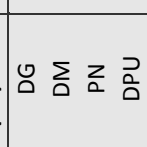 & 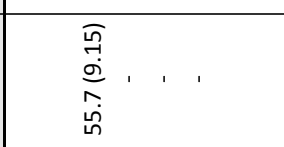 & 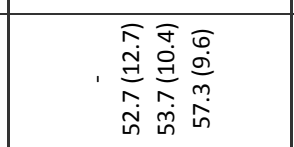 & 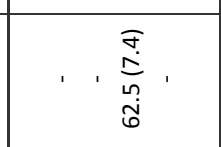 & 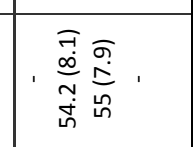 \\
\hline 童这 & ¿ & 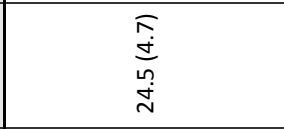 & 西 & 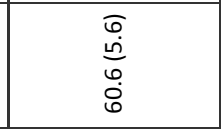 & 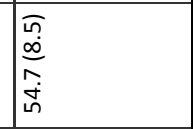 \\
\hline & 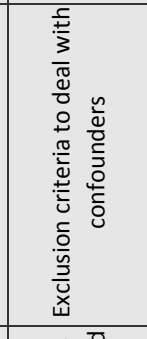 & 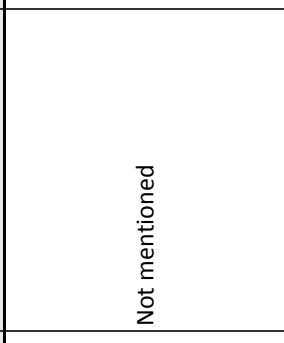 & 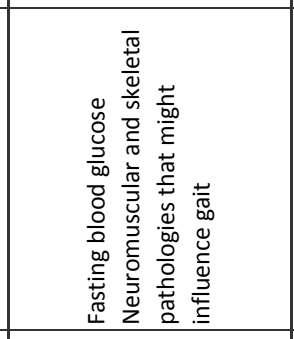 & 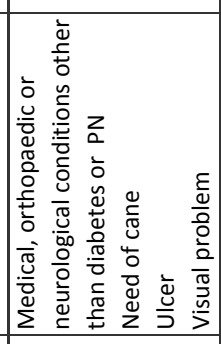 & 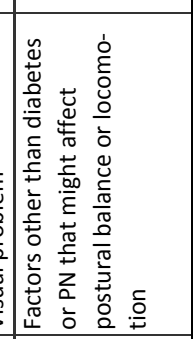 \\
\hline & 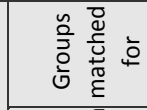 & כ & 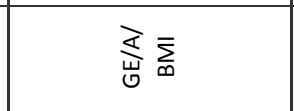 & o & 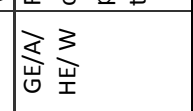 \\
\hline 45 & 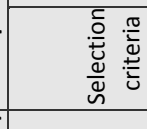 & כ & כ & כ & $\varangle$ \\
\hline 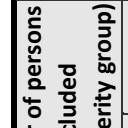 & 으ㅁㅡㅡㅇ & 2 & . $9 \approx$ & $\approx$ & . $\Rightarrow$ A. \\
\hline 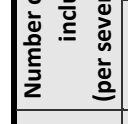 & 8 & ส & $\vec{\lambda}$ & r & $A$ \\
\hline 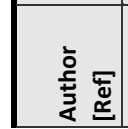 & & 吾 & 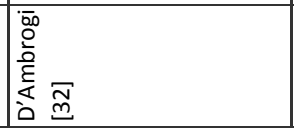 & 送 & 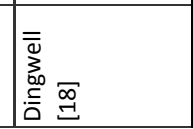 \\
\hline
\end{tabular}




\begin{tabular}{|c|c|c|c|c|}
\hline $\begin{array}{l}\frac{n}{0} \\
\frac{0}{n} \\
\bar{u} \\
\bar{c}\end{array}$ & & 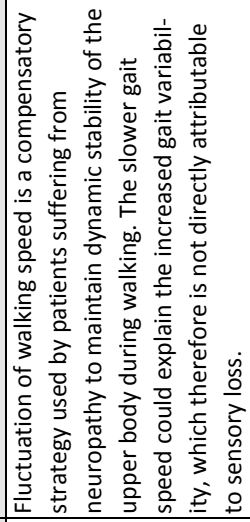 & 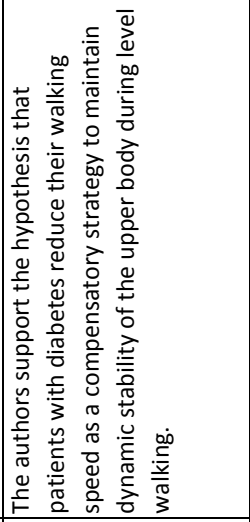 & 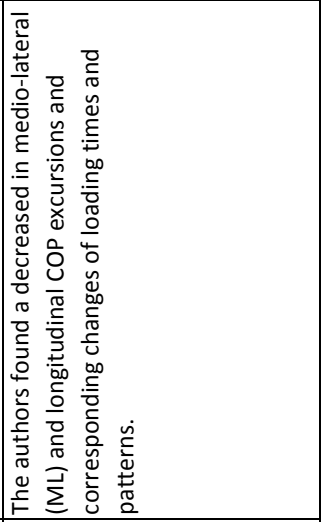 \\
\hline 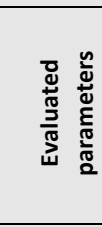 & & 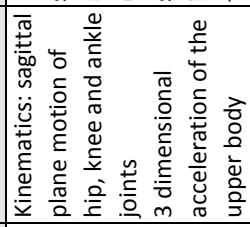 & 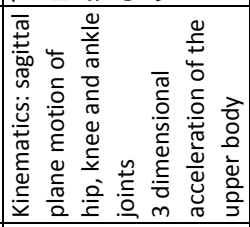 & 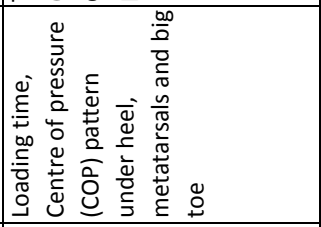 \\
\hline \multirow{2}{*}{ 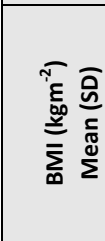 } & 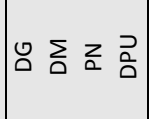 & 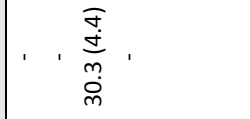 & 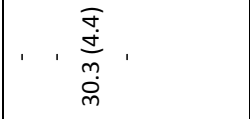 & , $\frac{\bar{g}}{\text { స }}$ \\
\hline & ப & $\begin{array}{l}\widehat{\widetilde{N}} \\
\stackrel{d}{d} \\
\dot{N} \\
\end{array}$ & 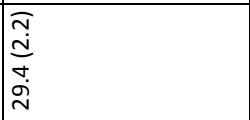 & \\
\hline \multirow{2}{*}{ 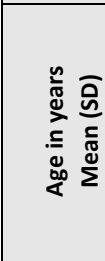 } & 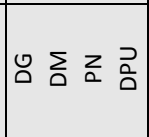 & 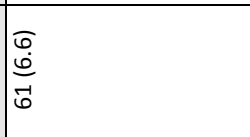 & $\begin{array}{l}\overline{0} \\
\dot{\omega} \\
\overrightarrow{6}\end{array}$ & 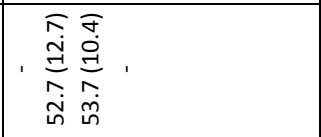 \\
\hline & ப & 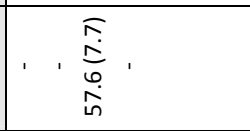 & 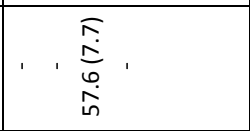 & \\
\hline 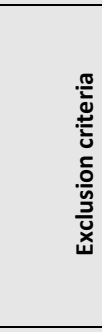 & 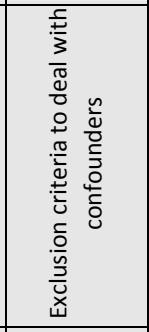 & 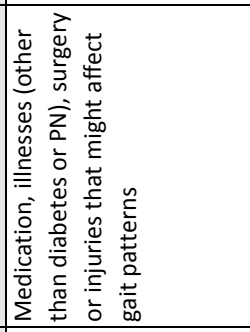 & 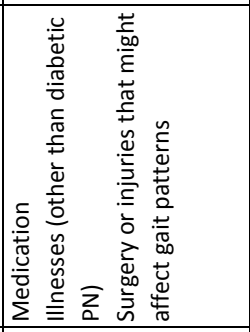 & 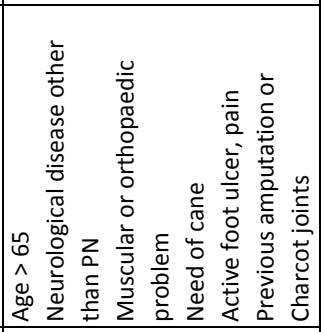 \\
\hline \multirow{2}{*}{ 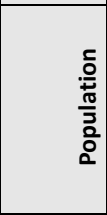 } & 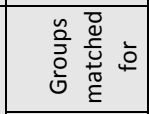 & 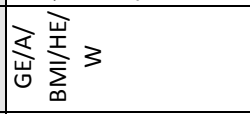 & 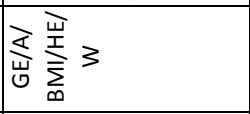 & $\ll$ \\
\hline & 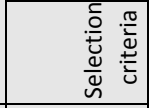 & $\supset$ & $\supset$ & $\varangle$ \\
\hline \multirow{2}{*}{ 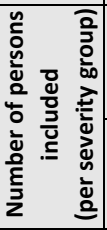 } & 음 $\sum_{0}$ ㅇํㅁ & , ' & , ' & . \\
\hline & ড্ & $\approx$ & ‡ & $\vec{N}$ \\
\hline 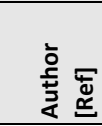 & & 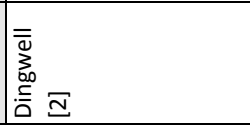 & 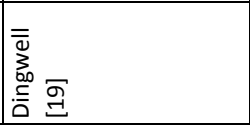 & 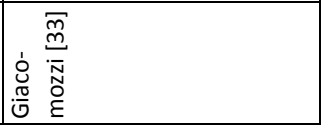 \\
\hline
\end{tabular}




\begin{tabular}{|c|c|c|c|}
\hline 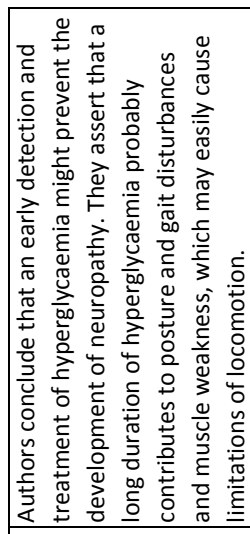 & 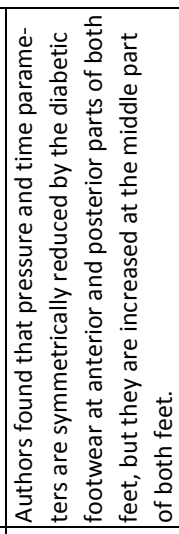 & 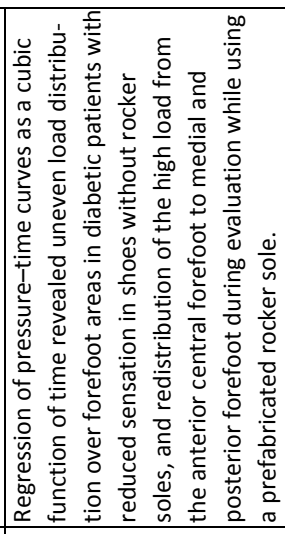 & 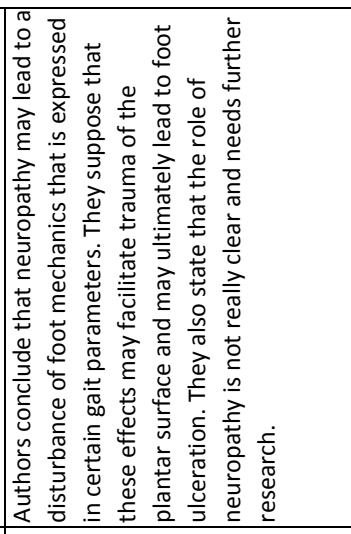 \\
\hline 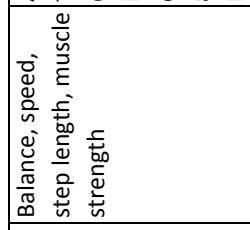 & 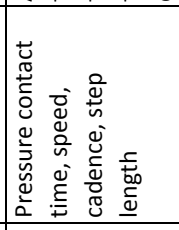 & 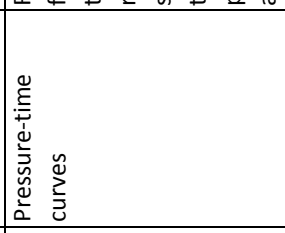 & 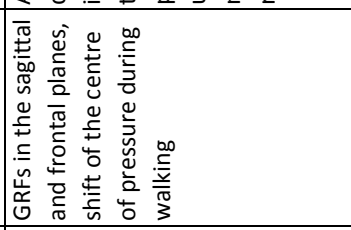 \\
\hline வें &,$\quad \frac{\substack{\tilde{n} \\
m}}{\stackrel{n}{n}}$ & ax & 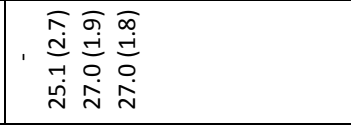 \\
\hline$\frac{8}{\grave{N}}$ & ü & 岁 & $\begin{array}{l}\text { 员 } \\
\text { ஸे }\end{array}$ \\
\hline & 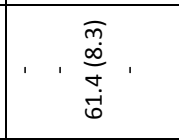 & .,$\frac{\bar{\sigma}}{\hat{\sigma}}$. & 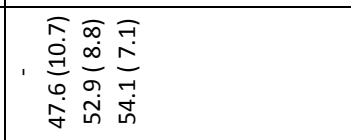 \\
\hline & 岁 & 亗 & $\begin{array}{l}0 \\
0 \\
\infty \\
6 \\
0 \\
0\end{array}$ \\
\hline 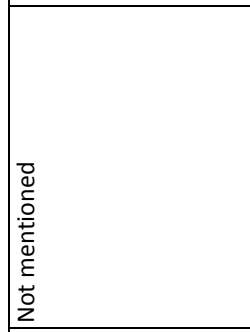 & 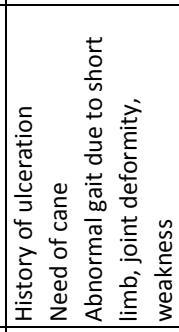 & 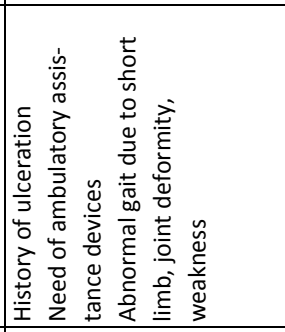 & 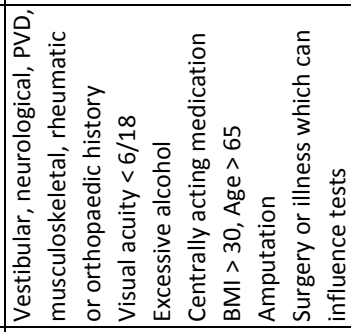 \\
\hline$\supset$ & 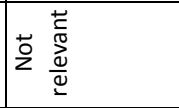 & 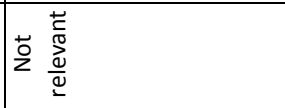 & 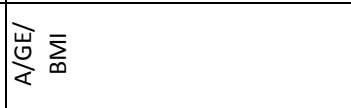 \\
\hline$\supset$ & $\supset$ & $\supset$ & $\sum_{\substack{\infty \\
\ll}}^{\bar{\Sigma}}$ \\
\hline ळ & ' , $\triangleleft$ & , ' 욱 ' & - 유 \\
\hline g & 0 & 0 & ํ. \\
\hline 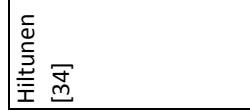 & 可 & $\overline{\underline{x}} \stackrel{\mathscr{m}}{\mathscr{m}}$ & 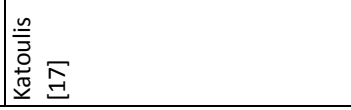 \\
\hline
\end{tabular}




\begin{tabular}{|c|c|c|c|c|}
\hline 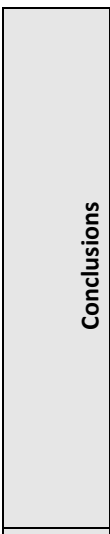 & & 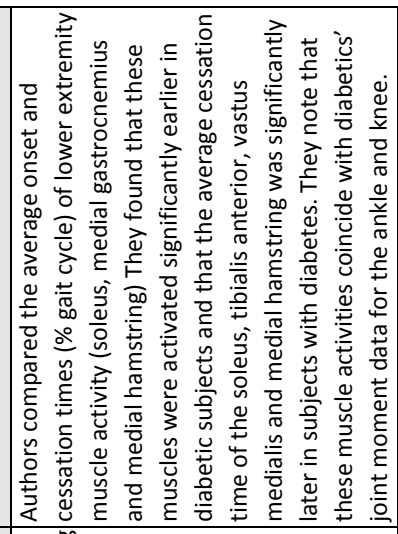 & 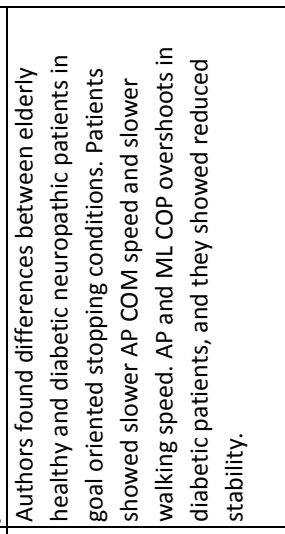 & 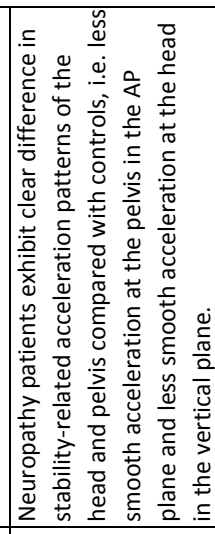 \\
\hline 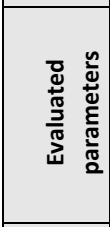 & & 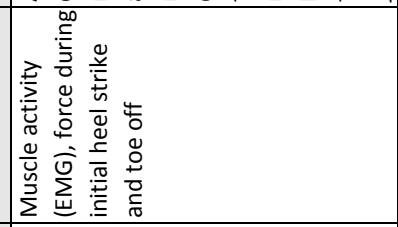 & 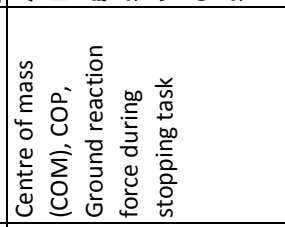 & 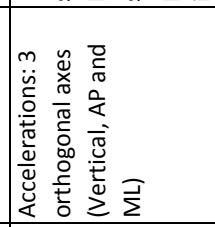 \\
\hline \multirow{2}{*}{ 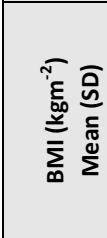 } & 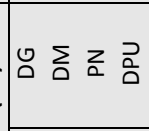 & $, \quad, \underset{m}{\stackrel{j}{m}}$ & 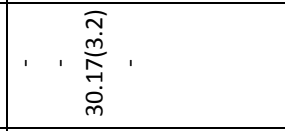 & $, \quad, \underset{\substack{d \\
\sim}}{\stackrel{d}{d}}$ \\
\hline & U & $\mid \begin{array}{l}-1 \\
\dot{f} \\
\text { mे }\end{array}$ & $\begin{array}{l}\widehat{n} \\
\ddot{m} \\
\omega \\
0 \\
\dot{m}\end{array}$ & 总 \\
\hline \multirow{2}{*}{ 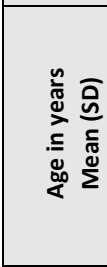 } & (동 & 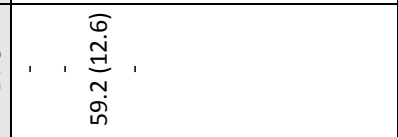 &,$\cdot \frac{\bar{\Xi}}{\tilde{b}}$, &,$\quad \frac{\substack{\infty \\
\infty}}{\stackrel{n}{n}}$ \\
\hline & บ & 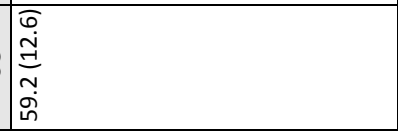 & $\frac{\bar{a}}{\hat{d}}$ & , $\quad \frac{\sigma}{a}$ \\
\hline 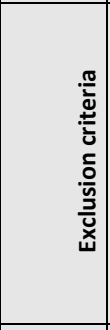 & 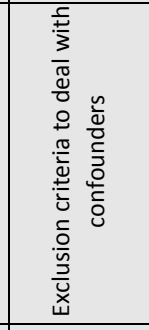 & 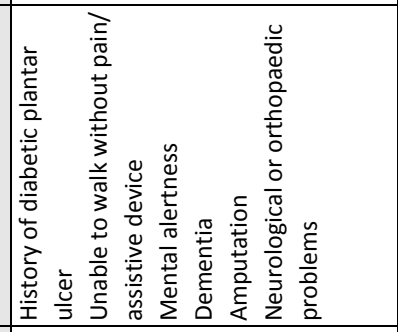 & 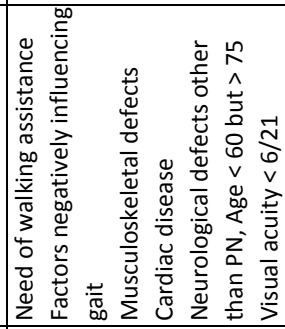 & 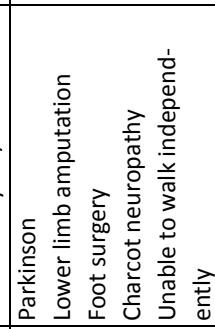 \\
\hline \multirow{2}{*}{$\begin{array}{l}\frac{0}{0} \\
\frac{0}{3} \\
\frac{0}{0} \\
\frac{0}{0}\end{array}$} & 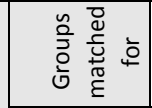 & $\stackrel{u}{0}$ & 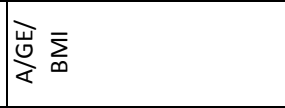 & $\supset$ \\
\hline & 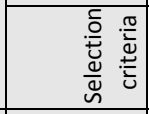 & $\supset$ & $\ll$ & $\supset$ \\
\hline \multirow{2}{*}{ 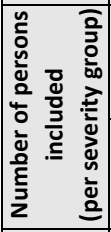 } & 임 $\sum_{0}$ z & $1 \cdot a$ & . , , 年 & , , 户 \\
\hline & ن & 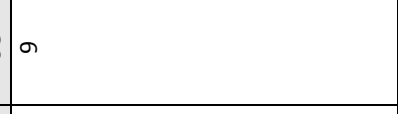 & $\stackrel{n}{\sim}$ & পి \\
\hline 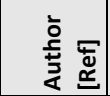 & & 音 & 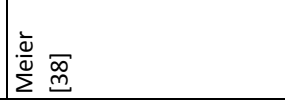 & 弪 \\
\hline
\end{tabular}




\begin{tabular}{|c|c|c|c|c|}
\hline 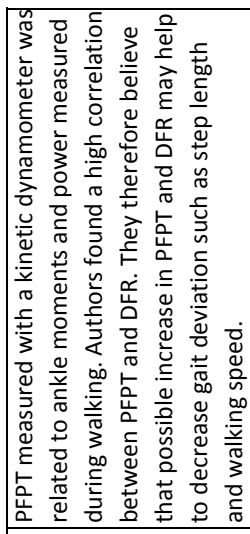 & 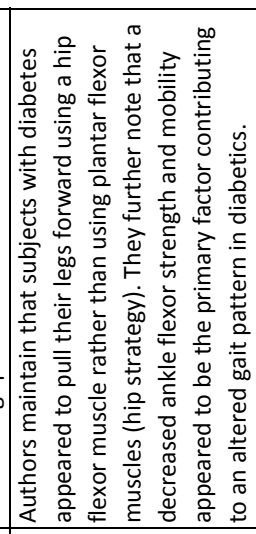 & 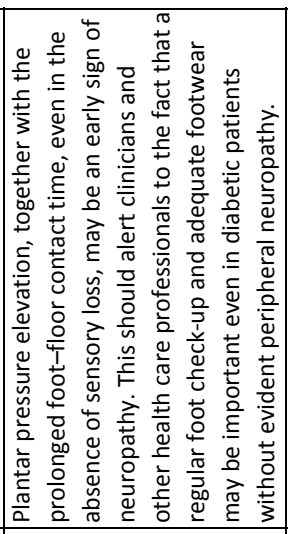 & 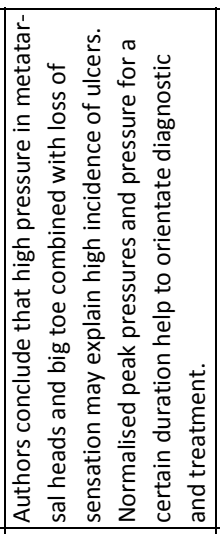 & 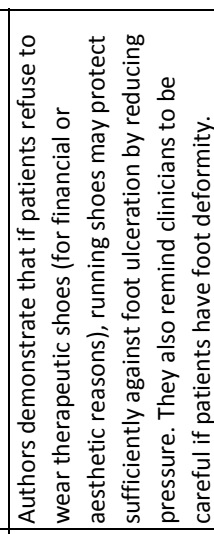 \\
\hline 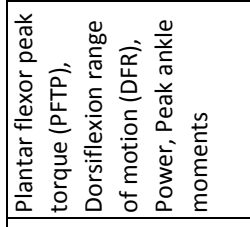 & 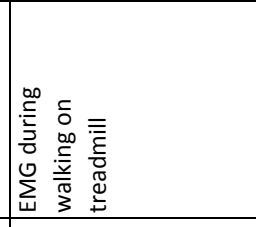 & 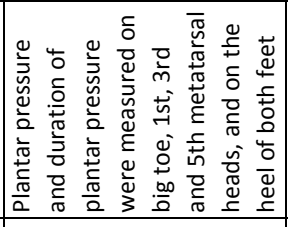 & 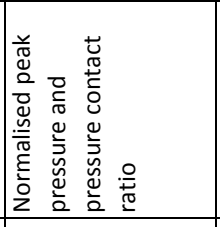 & 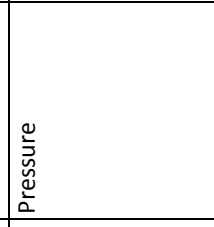 \\
\hline $\overrightarrow{\frac{x}{2}}$ & $\frac{\vec{c}}{z}$ & 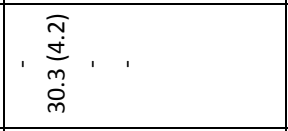 & 衣 & , $\stackrel{n}{\sim} \stackrel{\infty}{\stackrel{\infty}{\sim}}$ \\
\hline$\frac{\vec{x}}{z}$ & $\overrightarrow{\frac{c}{z}}$ & $\begin{array}{l}\sigma a \\
\ddot{n} \\
\dot{\sigma} \\
\text { Nं }\end{array}$ & $\frac{a x}{z}$ & 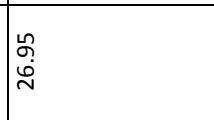 \\
\hline 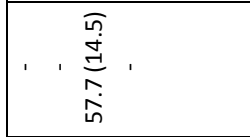 & 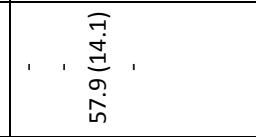 & , $\begin{array}{l}\bar{\sigma} \\
\frac{n}{n} \\
\tilde{y}\end{array}$ & 文 & 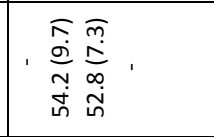 \\
\hline 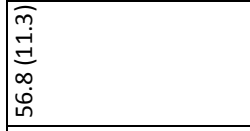 & $\begin{array}{l}\bar{m} \\
\stackrel{i}{i} \\
\infty \\
0 \\
b \\
i\end{array}$ & $\vec{x}$ & $\frac{a x}{z}$ & $\begin{array}{l}\sigma \\
\sigma \\
0 \\
6 \\
\dot{n} \\
\tilde{n}\end{array}$ \\
\hline 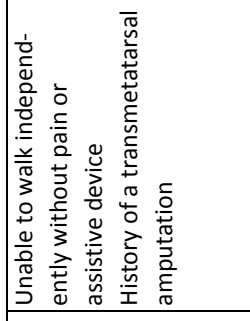 & 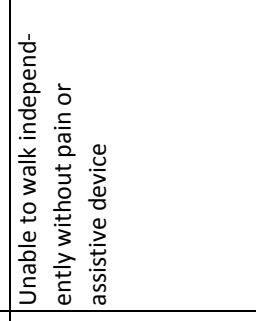 & 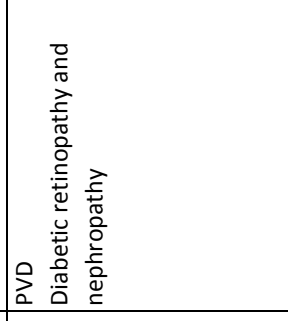 & 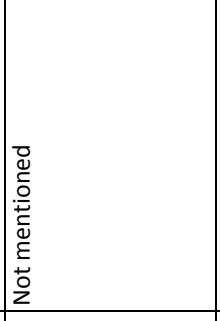 & 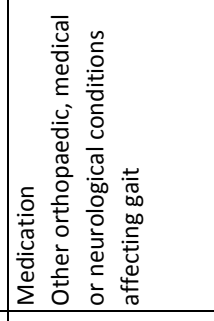 \\
\hline$\ll$ & $\ll$ & 岕 & $\supset$ & 岀 \\
\hline د & כ & כ & حا & כ \\
\hline , . 오 & $1, \sigma$. & $\stackrel{n}{\curvearrowleft}$. & $\dot{A} \wedge \sigma$ & . $\stackrel{m}{\rightarrow} \underset{\sim}{-}$ \\
\hline 으 & 으 & 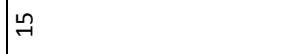 & กิ & 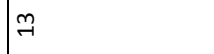 \\
\hline 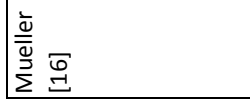 & 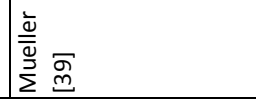 & 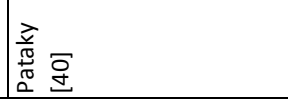 & 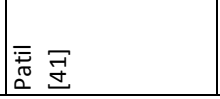 & 竎 \\
\hline
\end{tabular}




\begin{tabular}{|c|c|c|c|c|}
\hline 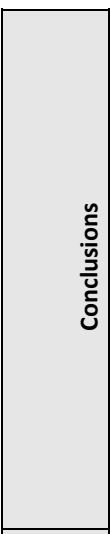 & & 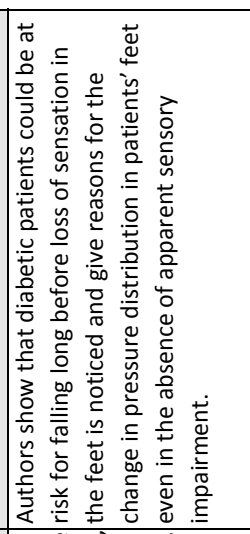 & 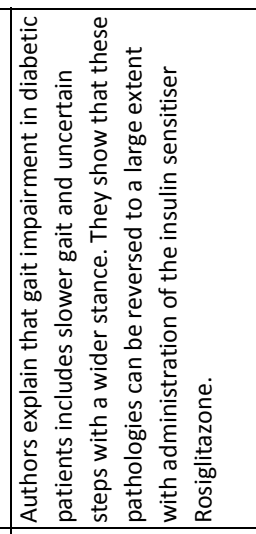 & 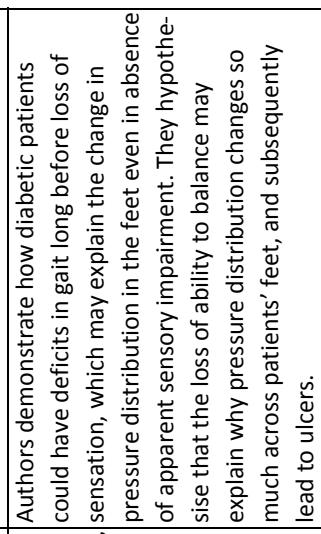 \\
\hline 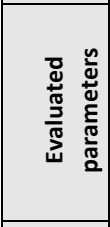 & & 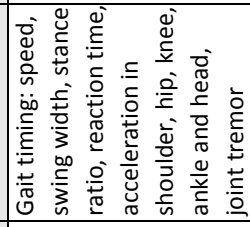 & 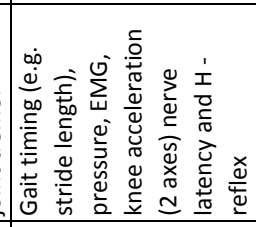 & 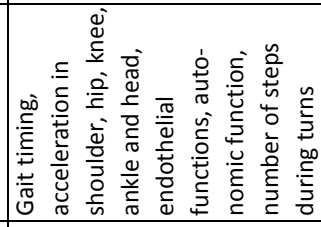 \\
\hline \multirow{2}{*}{ 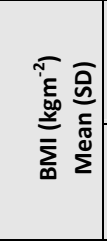 } & 임 & $\underset{\sim}{\stackrel{N}{N}}, \quad$, & 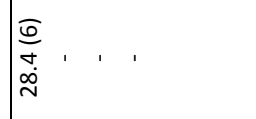 & $\mid \begin{array}{l}\infty \\
\infty \\
\stackrel{n}{n}\end{array}$ \\
\hline & ن & 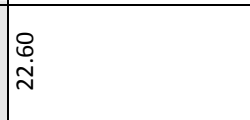 & $\begin{array}{l}\tilde{n} \\
\stackrel{n}{n} \\
m \\
\\
\end{array}$ & 文 \\
\hline \multirow{2}{*}{ 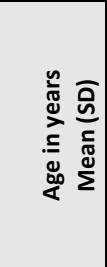 } & 임 $\sum_{0} z \frac{0}{0}$ & $\begin{array}{l}\bar{F} \\
\frac{i \dot{n}}{n} \\
\hat{n}\end{array}$ & $\begin{array}{l}\sigma \\
0 \\
\infty \\
0 \\
\\
\dot{0} \\
\end{array}$ & 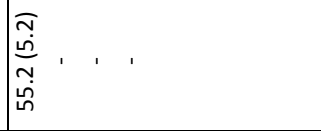 \\
\hline & U & $\begin{array}{l}\bar{m} \\
\dot{0} \\
0 \\
0 \\
n\end{array}$ & 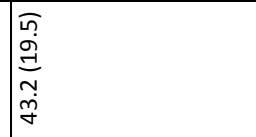 & 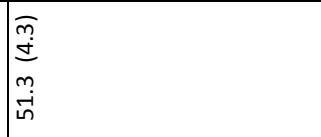 \\
\hline 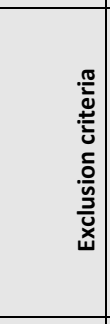 & 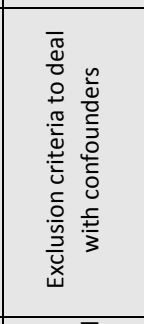 & 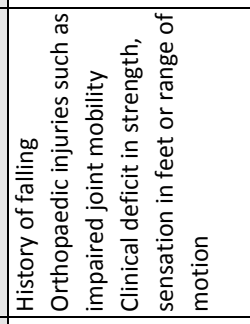 & 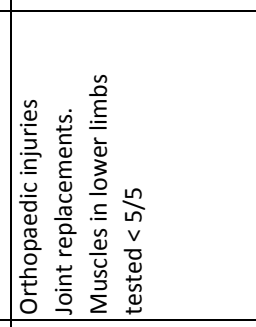 & 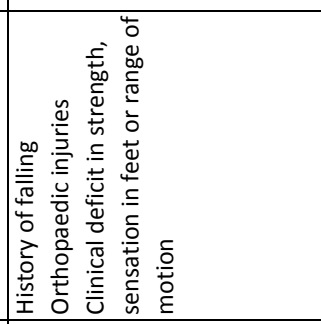 \\
\hline \multirow{2}{*}{$\begin{array}{l}\frac{c}{0} \\
\frac{0}{t} \\
\bar{z} \\
\overline{0} \\
0\end{array}$} & 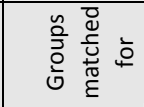 & $\ll$ & $\mid \ll$ & $\mid \ll$ \\
\hline & 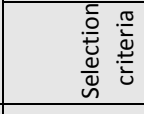 & $\supset$ & כ & $\supset$ \\
\hline \multirow{2}{*}{ 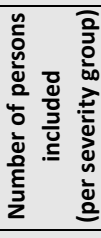 } & 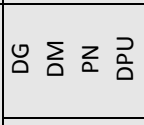 & ' ' & $\stackrel{\Perp}{N}$ & 우 \\
\hline & ن & $\stackrel{\sim}{\sim}$ & m & 윽 \\
\hline 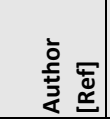 & & 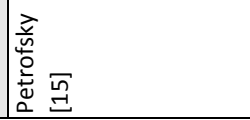 & 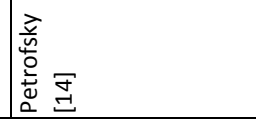 & 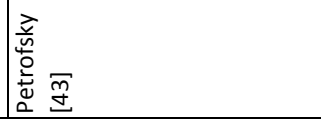 \\
\hline
\end{tabular}




\begin{tabular}{|c|c|c|c|}
\hline 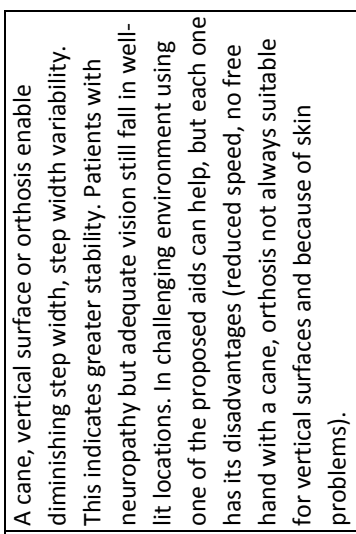 & 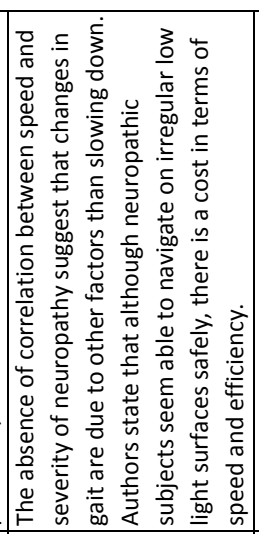 & 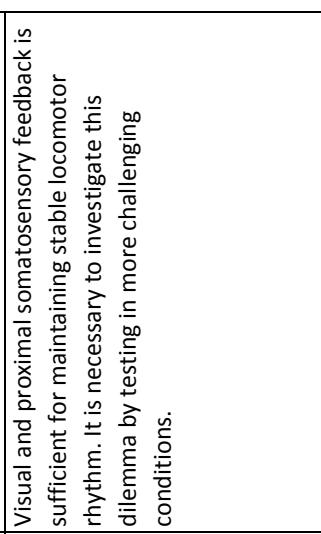 & 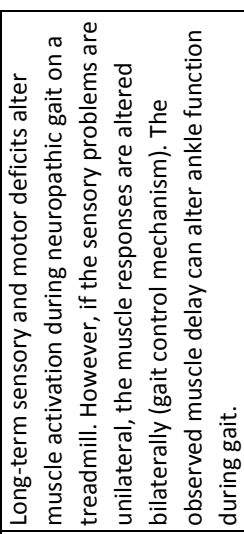 \\
\hline 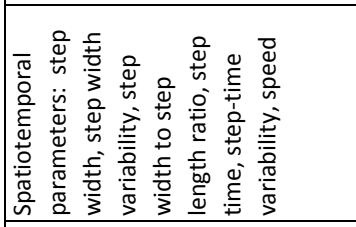 & 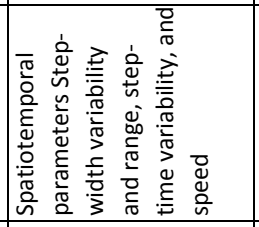 & 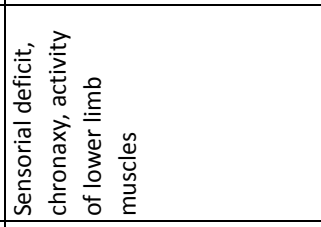 & 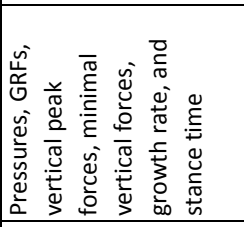 \\
\hline 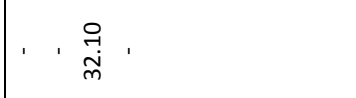 & 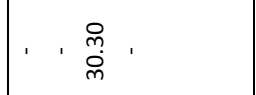 & 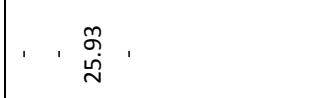 & 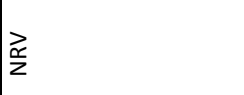 \\
\hline 岁 & $\begin{array}{l}\stackrel{p}{m} \\
m \\
\dot{m}\end{array}$ & $\begin{array}{l}\stackrel{2}{\infty} \\
\sim \\
\sim\end{array}$ & $\frac{\vec{x}}{2}$ \\
\hline 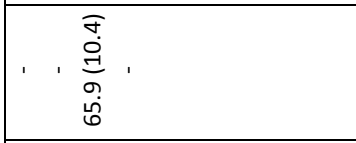 & 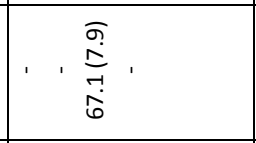 & 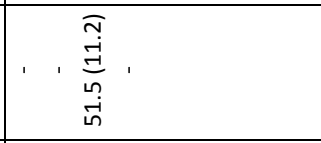 & 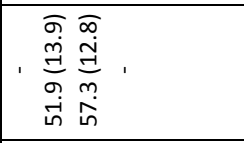 \\
\hline 岂 & 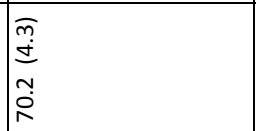 & 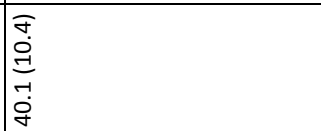 & $\begin{array}{l}\pi \\
\infty \\
\infty \\
\infty \\
\dot{\infty} \\
\infty\end{array}$ \\
\hline 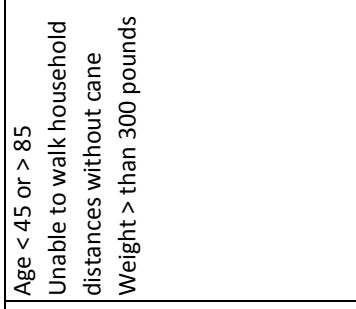 & 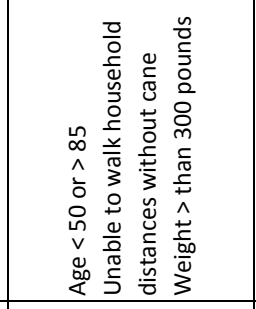 & 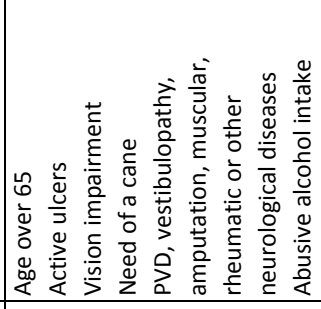 & 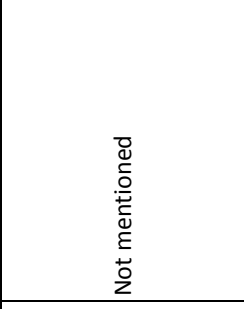 \\
\hline 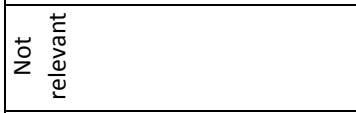 & $\varangle$ & 岀 $\sum_{\infty}$ & د \\
\hline$\sum_{4}^{3}$ & $\begin{array}{l}3 \\
8\end{array}$ & $\varangle$ & $\supset$ \\
\hline , , ₹ ' & ' , $\approx$, & . , & , $\approx \approx$ \\
\hline 0 & $\approx$ & ำ & $\approx$ \\
\hline 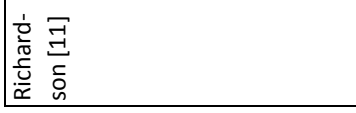 & 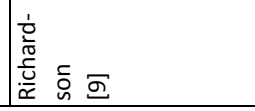 & $\begin{array}{l}\stackrel{8}{u} \\
\tilde{u} \\
\\
\end{array}$ & 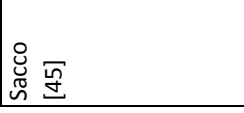 \\
\hline
\end{tabular}




\begin{tabular}{|c|c|c|c|}
\hline 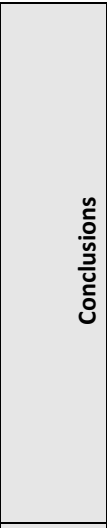 & & 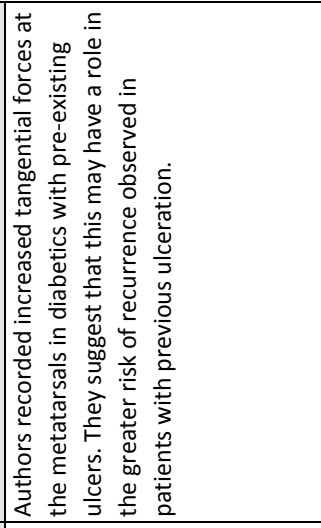 & 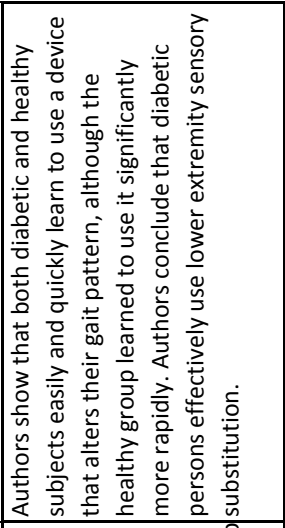 \\
\hline 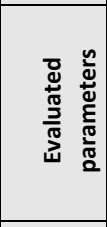 & & 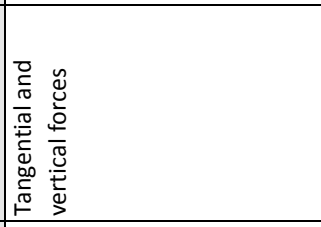 & 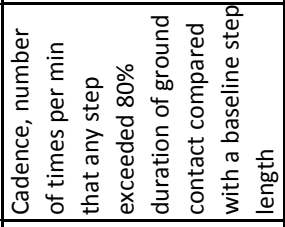 \\
\hline \multirow{2}{*}{ 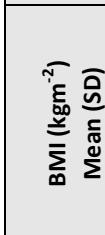 } & 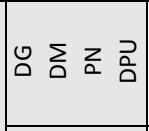 & 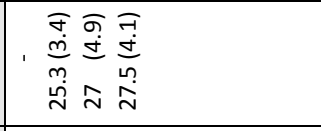 & , . \\
\hline & ૫) & $\begin{array}{l}\bar{a} \\
\stackrel{m}{n} \\
\stackrel{n}{n}\end{array}$ & 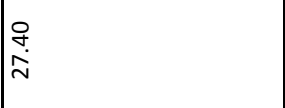 \\
\hline \multirow{2}{*}{ 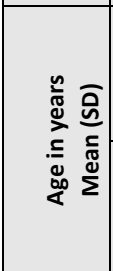 } & 님 $\sum$ z & 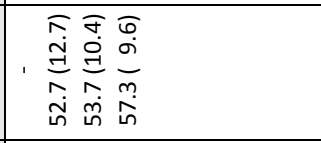 & 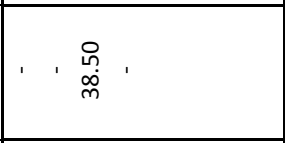 \\
\hline & ن & 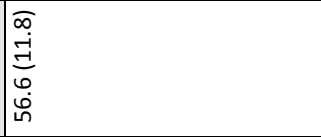 & 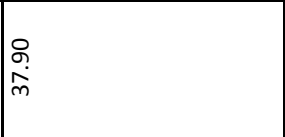 \\
\hline 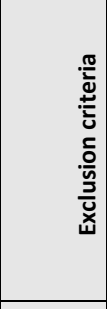 & 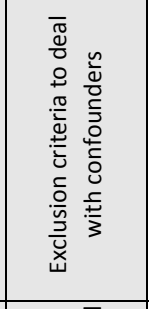 & 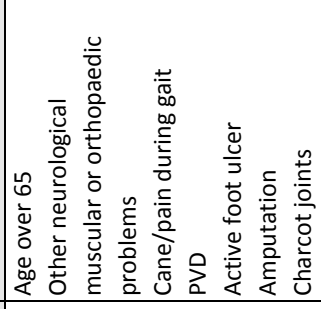 & 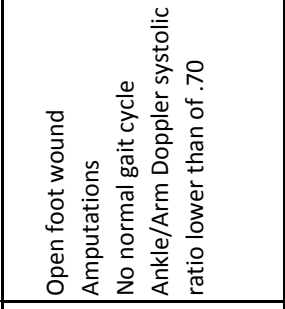 \\
\hline 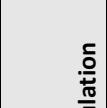 & 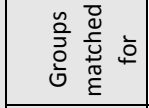 & $\varangle$ & $\supset$ \\
\hline 흥 & 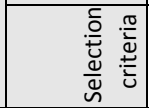 & $\varangle$ & $\supset$ \\
\hline 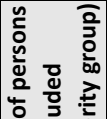 & 임 z & ' $\curvearrowright \stackrel{\overbrace{}}{\sim}$ & , , 户 \\
\hline 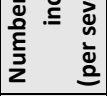 & ن & $\ddot{\sim}$ & ก \\
\hline 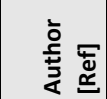 & & $\mid \overline{\bar{o}}$ & 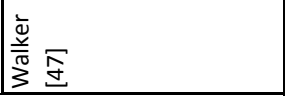 \\
\hline
\end{tabular}




\section{Gait characteristics}

It is worth looking closer at the different gait parameters described in the included studies to understand the walking pattern of diabetic patients.

\section{Spatiotemporal parameters}

Gait speed of controls and diabetic patients was described in 10 studies. The speed in diabetic patients ranged from 0.7 to $1.24 \mathrm{~ms}^{-1}$ and was significantly lower than that of controls, which ranged from 0.9 to $1.47 \mathrm{~ms}^{-1}$. Petrofsky et al. [43] described a significantly higher speed in controls compared to groups with either type 1 or 2 diabetes. Additionally they assessed slower reaction times in patients with diabetes and a much slower gait while turning than among control subjects. They demonstrated that subjects with type 2 diabetes used an average of 2 steps to turn, whereas control subjects on average used one step. The subjects with type 2 diabetes took $1.66 \mathrm{~s}$ to execute this free pivot, whereas the control subjects took on average $0.78 \mathrm{~s}$.

Step length was described in 6 studies [2, 16, 18-20, 39]. Values ranged from 1.38 to $1.54 \mathrm{~m}$ for controls and from 1.08 to $1.38 \mathrm{~m}$ in diabetic patients. Four authors [9, 16, 18, 21, 39] described gait cycle time. Gait cycle time ranged from 1.00 to $1.22 \mathrm{~s}$ for controls and from 1.15 to $1.26 \mathrm{~s}$ in diabetic patients $[2,9,11,13,16,18,19,21,39]$. Only 2 authors [9, 20] described step time variation which ranged from 0.04 to $0.07 \mathrm{~s}$ in diabetic patients (Table 2.3).

Richardson et al. [9] showed that environmental factors have a significant effect on all spatiotemporal gait parameters in diabetic subjects. In a challenging environment in which either walking surface conditions or lighting intensity were manipulated, a decrease in step length and speed and an increase in step width, step width variability, step width to step length ratio and step time variability were observed. In general, controls showed similar effects, although less markedly. Furthermore, the controls did not decrease their step length or increase step width in the challenging environment, unlike patients with diabetes. Another finding was that under standard conditions (ideal walking surface and optimal lighting) only one parameter (mean step width) correlated with neuropathy severity, whereas 4 parameters (step width, step width variability, step width range, step time variability) correlated with neuropathy severity when gait was analysed under the challenging conditions. Comparable results were found by Menz et al. [20]. They reported that the walking speed of patients with PN was $19 \%$ slower while walking on a level surface and $25 \%$ slower on an irregular surface than among healthy controls. Patients with diabetic neuropathy reduced their step length significantly when walking on the irregular surface $(17.8 \%$ vs. $12.9 \% p=0.02)$ and showed a greater variability in step time $(p=0.003)$. 


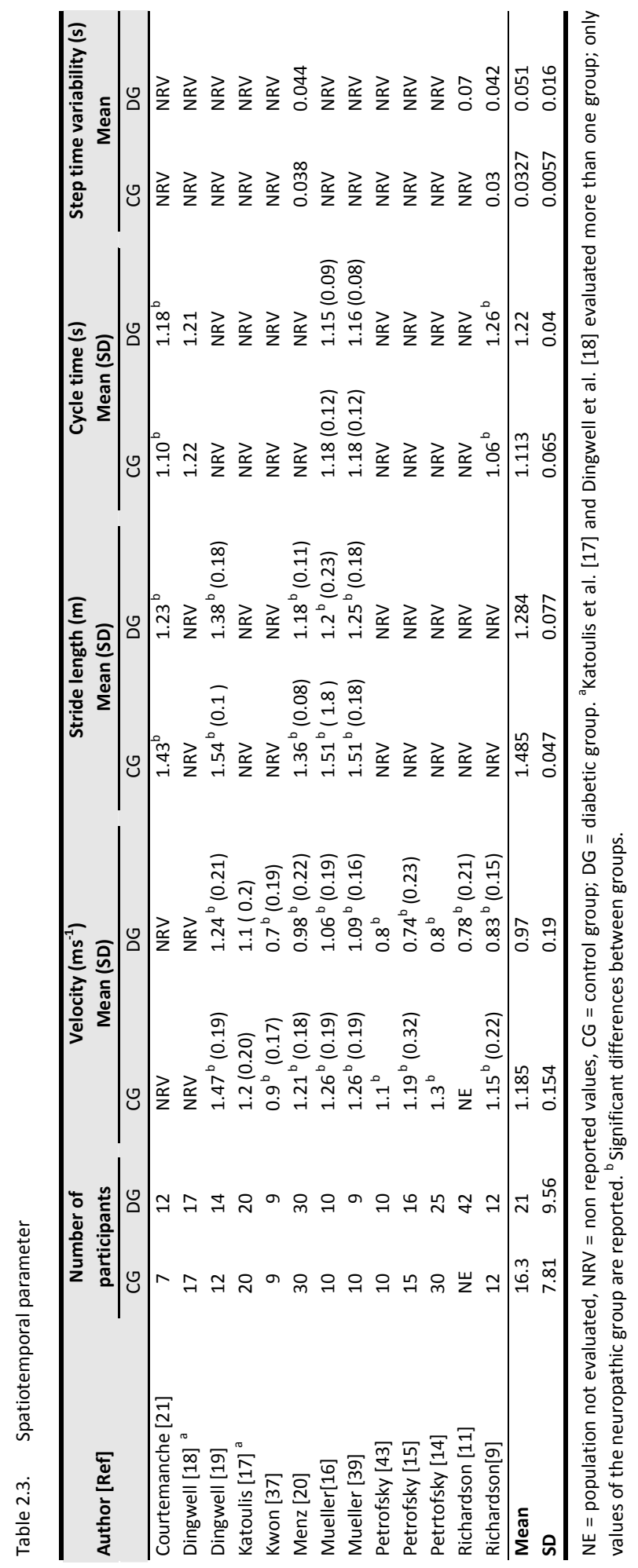




\section{Kinematics}

Three authors [2, 14, 15, 20, 43] investigated acceleration. Petrofsky et al. [14, 15, 43] compared healthy controls to diabetic patients without sensory loss in the feet or muscle weakness in the legs. The accelerometers measured side-to-side and forward-backward directions. The coefficient of variation was higher at the head than the shoulders and higher for the hip than the shoulders for both controls and diabetics. However, the coefficient of variation for movement was much larger in diabetic patients. Based on these findings they concluded that patients with diabetes would apparently be at risk of falling long before loss of sensation or muscle weakness is noticed. Menz et al. [20] found smaller magnitude accelerations in patients with diabetes compared to controls and recorded more erratic acceleration signals in diabetic patients, particularly at the head. Dingwell et al. [2] using a tri-axial accelerometer on the upper body to measure the standard deviation could find no difference between diabetes patients with neuropathy and healthy controls.

\section{Kinetics}

Four authors [17, 38, 45, 46] described GRFs. All authors found similar results for healthy controls and for diabetic patients with and without neuropathy in comparing peak vertical GRFs. Sacco et al. [45] were the only group who differentiated 2 peaks, the first at heel strike and another at the moment of propulsion. For the first peak they agreed with Katoulis et al. [17] and Uccioli et al. [46] who did not find a difference in the mean GRFs between controls and patients with or without neuropathy. Concerning the second peak, however, they found a significant difference between vertical forces of controls and the values of the diabetic group. In addition to patients with and without neuropathy, Katoulis et al. [17] evaluated a group with previous ulcers. They described a decrease in the maximum value of the vertical component of the GRF for these patients compared to healthy controls and diabetic patients without neuropathy $(p<0.03)$.

Meier et al. [38] were interested in anterior posterior (AP) and medial lateral (ML) forces during stopping tasks. They found a slower AP velocity of the centre of mass (COM) and larger $\mathrm{AP}$ and $\mathrm{ML}$ centre of pressure (COP) overshoots than in controls. Furthermore, they described decreased shock absorption at heel strike and increased impulsion at the forefoot. Uccioli et al. [46] described significantly reduced peak forces recorded mainly during heel strike and push off for patients with diabetes compared to a healthy group. Also Katoulis et al. [17] described larger AP forces for controls than for diabetics with neuropathy or previous ulcer than for controls or diabetics without neuropathy. Their results, however, were only significant when comparing patients with previous ulcers versus diabetics without neuropathy. Three authors [17, 37, 39] described joint moments during walking. Two of them said authors, Kwon et al. [37] and Mueller et al. [39] had similar findings and reported a significant difference, with lower plantar flexor peak moment, for patients with diabetes.

\section{Muscle activity}

Four authors used electromyography (EMG) $[14,31,37,44]$ to record muscle activity. Two authors $[37,44]$ described the results of activity onset or cessation in either percentage of the gait cycle [37] or in percentage of the stance phase [44]. Abboud et al. [31] described the results as time difference between heel strike and maximum muscle contraction. Sacco 
et al. [44] evaluated muscle activity to investigate the dynamic mechanisms developed to compensate for sensory and motor deficits. They collected electromyographic data of the vastus lateralis, the tibialis anterior and the lateral gastrocnemius muscles simultaneously with GRFs when subjects walked on a treadmill, reporting a significant delay in the right vastus lateralis and in both tibialis anteriors muscles compared to controls. These results were replicated by Abboud et al. [31] who recorded muscle activity and measured shoe pressures over 6 steps. Aiming to find a correlation between in-shoe plantar foot pressure and the coordinated activity of 5 lower limb muscles (tibialis anterior, gastrocnemius, soleus and peroneus brevis and longus) for patients with diabetes, they found that all muscles showed a delay in contraction compared to controls and a faster forefoot contact with the ground. The significant delay recorded for the tibialis anterior muscle means that its normal modulating role in lowering the foot to the ground after heel strike through eccentric contraction is disturbed. In contrast, Kwon et al. [37] described a significantly earlier activation for the soleus, medial gastrocnemius and medial hamstring muscles in patients with diabetes and PN. Cessation time for the soleus, tibialis anterior, vastus medialis and the medial hamstring muscles occurred later in subjects with PN. These results contradict those of Abboud et al. [31]. Petrofsky et al. [14] recorded the muscle activity of the gastrocnemii and tibialis anterior during initiation of gait, steady state walking and turns of 0.33 and 0.66 radius. They showed that controls used on average approximately $30 \%$ of the maximum muscle activity of the tibialis anterior and gastrocnemius to initiate gait. Persons suffering from diabetes used nearly twice the muscular activity compared to controls to initiate and maintain gait at a lower walking speed as well as to turn.

\section{Pressures}

Nine authors investigated pressure measurements that might have relevance for the prevention of ulcers [31-33, 35, 36, 40-42, 45, 47]. Four authors used in-shoe transducers [31, 35, 36, 42, 47], 3 authors used a force platform [32, 33, 45] and Patil et al. [41] used an optical pedograph. Higher pressure values were found in diabetic patients with neuropathy compared to diabetic patients without neuropathy $[42,45]$. Sacco et al. $[44,45]$ found that patients with ulcers had higher values than normal but lower values than diabetic patients. Diabetic patients with neuropathy had the highest peak pressures, followed by diabetic patients without neuropathy whose pressures were higher than controls. In contrast to these findings, however, Pataky et al. [40] found increased plantar pressure and pressure duration under the big toe and fifth metatarsal head in patients with no clinical evidence of neuropathy and described an anterior displacement of weight bearing even in this early stage of diabetes.

\section{Intervention studies}

Six studies investigated interventions to improve diabetic patients' gait. Perry et al. [42] investigated the use of running shoes to reduce plantar pressures; Hsi et al. [35] compared plantar pressures in patients wearing their own shoes compared to wearing diabetic footwear. In another study [36], they investigated the influence of rocker soles on plantar pressure. Perry et al. [42] showed that modestly priced athletic shoes can reduce plantar pressures in diabetic patients. They state that a number of factors must be considered 
before the routine use of running shoes can be recommended, the main one being foot deformities. Hsi et al. [35] described a positive effect on pressure measurements in patients wearing rocker soles or diabetic shoes. A method of reducing ground contact time was assessed by Walker et al. [47] who found that diabetic patients could modify their gait pattern to reduce ground contact, using an auditory sensory feedback system.

Ways to improve the spatiotemporal parameters of gait were evaluated by Petrofsky et al. [15] and Richardson et al. [11]. Petrofsky et al. [15] investigated the effect of medication (Rosiglitazone) on different gait parameters. They reported positive results after administration of Rosiglitazone in a decreased step width $(p<0.01)$, a reduction in reaction time $(p<0.01)$ and less acceleration at the joints. Richardson et al. [11] found that the use of a cane, ankle orthoses or touching a wall all improved step width range, step time variability and speed while walking under challenging conditions.

\section{DISCUSSION}

The quality of articles investigating gait characteristics in diabetic patients, when scored with an adapted and reliable checklist [29], was moderate to high. Although some gait characteristics of patients with diabetes were well described, we noted that results varied in different studies and that authors sometimes disagreed on general tendencies. Spatiotemporal data and pressure values seem to be well established parameters whereas opinions on accelerations, EMG and kinetic parameters, such as GRFs are not yet clear.

Some gait parameters, namely variation of step time and/or step width [22, 23], or reaction time $[22,23,48]$, are known to be associated with an increased risk of falls. As in a geriatric population $[22,23,25]$, these parameters are also associated with fall risk in diabetic patients, as shown by Menz et al. [20].

Other factors, such as acceleration measurements [25] or specific alterations in sagittal plane joint kinetics [48] are not yet used as characteristic indicators for fall risk. However, both Menz et al. [25] and Kerrigan et al. [48] show that the latter two may be potential, identifiable markers with which to detect individuals who may be at risk for falls. In our overview of gait characteristics, we seek to highlight those factors which, in particular, may explain increased risk of falling in diabetics.

\section{Gait characteristics}

\section{Spatiotemporal data}

The most frequently cited spatiotemporal parameter for fall risk prediction is the variation of step parameters $[22,23,48]$, such as step time variability. However, one should be aware that this factor is speed dependent $[49,50]$. Reduced speed itself has been described several times as a predictor [24-26].

Menz et al. [20] and Richardson et al. [9-11] studied step time variability in a diabetic population. They could not find significant differences between groups regarding measurements done on a level surface. However, they found significant differences when subjects walked on an irregular surface, which could be related to an increased demand on 
balance control. Richardson et al. [11] further described a significant cost in terms of speed and efficiency when patients with PN walk on irregular surfaces under low light conditions. As irregular surfaces and unfamiliar circumstances reflect patients' environments, these study results have a high clinical relevance. Clinical experiences indicate that diabetic subjects have higher walking related fall accidents that happen during performance of daily activities. Similar findings were described by Freiberger et al. [51] investigating falls among elderly people. From this, it can be inferred that gait analysis in diabetic patients should be performed in environments that mimic real life conditions when we want to be able to pinpoint problems related to walking in this population. We should take gait analysis for this population out of laboratory settings and into environments in which people move during their daily routine.

The examination of speed, which is also known to be associated with fall risk, emphasises again the importance of gait analysis under real life conditions. Authors generally agree that diabetics walk more slowly than healthy controls. This loss of speed becomes even more marked when patients walk in challenging environments. However, there are major differences in the measured walking velocities which remain difficult to explain. Age is said to decrease walking speed in persons older than 70 [52] but this cannot explain the considerable speed range between different studies. Regarding the protocols that were used, all authors asked patients to walk with a self-selected, comfortable speed, except Petrofsky et al. $[14,15]$. This group did not report on this item. Thus, even this parameter can not explain the speed differences observed. Two possible parameters which may explain the speed difference between the various studies could be the group composition $[9,17,37]$ or in one study [37] the high body weight of the included population.

\section{Kinematics}

Menz et al. [25] found that acceleration patterns at the head and pelvis were associated with an increased fall risk in elderly. In our review, only 3 authors reported acceleration data in 5 studies [2, 14, 15, 20, 43]. Although they reported contradictory findings concerning comparisons of acceleration magnitude between controls and diabetic patients, 2 authors [14, 15, 20, 43] recorded more erratic accelerations in diabetic patients compared to healthy controls and higher acceleration variation whilst walking under demanding circumstances. These results again reveal the importance of measuring gait characteristics in challenging conditions. These authors further showed that acceleration data could be of interest in fall risk evaluation in diabetic patients.

\section{Kinetics}

Kerrigan et al. [48] demonstrated that sagittal plane joint moments could be useful parameters to understand the gait mechanics of the elderly suffering from falls. The presence of alterations in sagittal plane joint kinetics in fallers implies specific intrinsic pattern differences and may help for the evaluation of fall risk in elderly.

In our review 3 authors [17, 37, 39] observed joint moment during diabetics' walking, but only Kwon et al. [37] reported knee extension moments. They found lower knee extension moments in subjects with diabetic neuropathy compared to control subjects. Mueller et al. [39] and Kwon et al. [37] observed a decreased plantar flexor moment during walking in patients with diabetes, which could be related to decreased strength in calf muscles [20, 
$33,37,39]$. Questions remain about the utility of these parameters for fall risk evaluation in diabetic patients. In addition, causes and consequences are not yet clear; is it decreased muscle strength or sensitivity that alters the gait pattern, or does the altered pattern contribute to a loss of strength?

Several authors described other kinetic values, such asGRFs, [17, 38, 45, 46] which are not yet known to be associated with fall risk. Comparisons between their results are difficult because of diverse evaluated variables and the use of different material. The reported results do not permit us to take a firm stand. It seems, however, that vertical forces are quite similar in patients with diabetes and in healthy controls. Sacco et al. [45] and Uccioli et al. [46] even agreed on measured absolute values, whereas Katoulis et al. [17] reported slightly higher forces for all assessed groups. The significant difference between diabetic and controls showed by Sacco et al. [45] during the second peak needs more investigation to determine whether the second peak is a discriminating factor, whereas the mean peak force is not. Although those vertical forces do not really differ between healthy persons and patients with diabetes, the AP forces revealed differences indicating a so-called flat-footed gait.

\section{Muscle activity}

EMG is not yet used in the evaluation of fall risk. Nevertheless, it appears to be an interesting parameter. Whereas Abboud et al. [31] associated muscle dysfunction of the lower extremity with the development of abnormal plantar pressure distribution, Petrofsky et al. [14] and Kwon et al. [37] hypothesised that muscle co-contraction might reflect increased use of agonist-antagonist muscle pairs, which denotes search for stability and balance during gait. However, authors found different results concerning the timing and amplitude of muscle activity in diabetic patients. Several factors could have influenced these discrepancies [31, 37, 44]. First, it is apparent that data over studies have not been normalised in the same way concerning amplitude and timing. Several studies, using different methods for amplitude normalisation [53-55] showed the influence of normalisation methods on the interpretation of EMG signals. Another difficulty is the determination of onset and or cessation of muscle activity. Further the difference in weight of the control group could be another parameter influencing the results. It is therefore important to remember that Kwon et al. [37], who contradicted the study results of Abboud et al. [31] and Sacco et al. [44], had the population with the highest body weight. Another important demographic factor is age, which is known to influence walking speed and further could have an effect on muscle activity.

\section{Pressures}

Plantar pressure is a well-described parameter in the diabetic population. However, it is usually studied in relation with "ulcers". It could be used to investigate a preventive approach that would regulate pressure distribution and thus avoid ulcers. Various types of shoes and auditory sensory feedback were tested [35, 36, 42, 47]. However, the most effective strategy to reduce plantar pressure remains to be determined. 


\section{Intervention studies}

Only a few interventions such as auditory feedback, different shoes or soles as well as medication were tested. All showed positive effects on gait parameters. However, we could not find any studies concerning preventive approaches for falls among diabetic patients.

\section{CONCLUSIONS}

This systematic review evaluated 28 studies with moderate to high quality, investigating gait characteristics of 772 diabetic patients. The large number of articles published about diabetic gait reflects the importance of research in this domain. The increasing prevalence of diabetes and the well-known risk of falling require understanding of the possible gait pattern changes where diabetic patients are confronted with.

Authors investigating gait parameters in a diabetic population evaluated in particular parameters either clearly associated with fall risk (speed, step length or step time variability) or with ulcers (pressure). There is agreement that diabetic patients walk slower and with greater step variability, although one should be aware that speed is a confounding factor for step variability. Patients also present more plantar pressure and higher peak pressures under the metatarsal heads than healthy controls.

Our review also demonstrates that less well studied parameters, such as accelerations and changes in muscle activity could be of interest in fall risk evaluation in diabetic patients.

However, questions remain about the exact causes of gait alterations and about how to prevent falling in diabetic individuals.

Which of the measured parameters are especially involved and which could contribute to developing protective strategies? To understand the underlying mechanism that causes a subject to fall and to promote efficient prevention, further studies are needed. Future research should analyse gait under real life conditions in more challenging environments (e.g. walking on different road surfaces, on grass, on ramps and stairs), since falls occur mostly during a patient's daily routine. Treatment strategies that influence gait should be established and reassessed on the basis of fall predictive gait parameters, taking into account possible confounding factors. 


\section{REFERENCES}

1. Osei K: Global epidemic of type 2 diabetes: implications for developing countries. Ethn Dis 13:102-106, 2003.

2. Dingwell JB, Cavanagh PR: Increased variability of continuous overground walking in neuropathic patients is only indirectly related to sensory loss. Gait Posture 14:1-10, 2001.

3. Pirart J: Diabetes mellitus and its degenerative complications: a prospective study of 4,400 patients observed between 1947 and 1973. Diabetes Metab 3:97-107, 1977.

4. Morley JE: Falls - where do we stand? Mo Med 104:63-67, 2007.

5. Miller DK, Lui LY, Perry HM 3rd, Kaiser FE, Morley JE: Reported and measured physical functioning in older inner-city diabetic African Americans. J Gerontol A Biol Sci Med Sci 54:230-236, 1999.

6. Wallace C, Reiber GE, LeMaster J, Smith DG, Sullivan K, Hayes S, Vath C: Incidence of falls, risk factors for falls, and fall-related fractures in individuals with diabetes and a prior foot ulcer. Diabetes Care 25:1983-1986, 2002.

7. Cavanagh PR, Derr JA, Ulbrecht JS, Maser RE, Orchard TJ: Problems with gait and posture in neuropathic patients with insulin-dependent diabetes mellitus. Diabet Med 9:469-474, 1992.

8. Maurer MS, Burcham J, Cheng H: Diabetes mellitus is associated with an increased risk of falls in elderly residents of a long-term care facility. J Gerontol A Biol Sci Med Sci 60:1157-1162, 2005.

9. Richardson JK, Thies SB, DeMott TK, Ashton-Miller JA: A comparison of gait characteristics between older women with and without peripheral neuropathy in standard and challenging environments. J Am Geriatr Soc 52:1532-1537, 2004

10. Richardson JK, Thies SB, DeMott TK, Ashton-Miller JA: Gait analysis in a challenging environment differentiates between fallers and nonfallers among older patients with peripheral neuropathy. Arch Phys Med Rehabil 86:1539-1544, 2005.

11. Richardson JK, Thies SB, DeMott TK, Ashton Miller JA: Interventions improve gait regularity in patients with peripheral neuropathy while walking on an irregular surface under low light. J Am Geriatr Soc 52:510-515, 2004.

12. Richardson JK, Ching C, Hurvitz EA: The relationship between electromyographically documented peripheral neuropathy and falls. J Am Geriatr Soc 40:1008-1012, 1992.

13. Richardson JK: Factors associated with falls in older patients with diffuse polyneuropathy. J Am Geriatr Soc 50:1767-1773, 2002

14. Petrofsky J, Lee S, Cuneo ML: Gait characteristics in patients with type 2 diabetes; improvement after administration of rosiglitazone. Med Sci Monit 11:43-51, 2005.

15. Petrofsky J, Lee S, Bweir S: Gait characteristics in people with type 2 diabetes mellitus. Eur J Appl Physiol 93:640-647, 2005.

16. Mueller MJ, Minor SD, Sahrmann SA, Schaaf JA, Strube MJ: Differences in the gait characteristics of patients with diabetes and peripheral neuropathy compared with age-matched controls. Phys Ther 74:299-308, 1994.

17. Katoulis EC, Ebdon-Parry M, Lanshammar H, Vileikyte L, Kulkarni J, Boulton AJ: Gait abnormalities in diabetic neuropathy. Diabetes Care 20:1904-1907, 1997.

18. Dingwell JB, Ulbrecht JS, Boch J, Becker MB, O'Gorman JT, Cavanagh PR: Neuropathic gait shows only trends towards increased variability of sagittal plane kinematics during treadmill locomotion. Gait Posture 10:21-29, 1999.

19. Dingwell JB, Cusumano JP, Sternad D, Cavanagh PR: Slower speeds in patients with diabetic neuropathy lead to improved local dynamic stability of continuous overground walking. J Biomech 33:1269-1277, 2000.

20. Menz HB, Lord SR, St George R, Fitzpatrick RC: Walking stability and sensorimotor function in older people with diabetic peripheral neuropathy. Arch Phys Med Rehabil 85:245-252, 2004.

21. Courtemanche R, Teasdale N, Boucher P, Fleury M, Lajoie Y, Bard C: Gait problems in diabetic neuropathic patients. Arch Phys Med Rehabil 77:849-855, 1996.

22. Hausdorff JM, Edelberg HK, Mitchell SL, Goldberger AL, Wei JY: Increased gait unsteadiness in communitydwelling elderly fallers. Arch Phys Med Rehabil 78:278-283, 1997.

23. Hausdorff JM, Rios DA, Edelberg HK: Gait variability and fall risk in community-living older adults: a 1-year prospective study. Arch Phys Med Rehabil 82:1050-1056, 2001.

24. Fried AV, Cwikel J, Ring H, Galinsky D: ELGAM--extra-laboratory gait assessment method: identification of risk factors for falls among the elderly at home. Int Disabil Stud 12:161-164, 1990.

25. Menz HB, Lord SR, Fitzpatrick RC: Acceleration patterns of the head and pelvis when walking are associated with risk of falling in community-dwelling older people. J Gerontol A Biol Sci Med Sci 58:446-452, 2003.

26. Krauss MJ, Evanoff B, Hitcho E, Ngugi KE, Dunagan WC, Fischer I, Birge S, Johnson S, Costantinou E, Fraser VJ: A case-control study of patient, medication, and care-related risk factors for inpatient falls. J Gen Intern Med 20:116-122, 2005. 
27. Stolze H, Klebe S, Zechlin C, Baecker C, Friege L, Deuschl G: Falls in frequent neurological diseases--prevalence, risk factors and aetiology. J Neurol 251:79-84, 2004.

28. Ducic I, Short KW, Dellon AL: Relationship between loss of pedal sensibility, balance, and falls in patients with peripheral neuropathy. Ann Plast Surg 52:535-540, 2004.

29. Downs SH, Black N: The feasibility of creating a checklist for the assessment of the methodological quality both of randomised and non-randomised studies of health care interventions. J Epidemiol Community Health 52:377-384, 1998.

30. Cohen A: Comparison of correlated correlations. Stat Med 8:1485-1495, 1989.

31. Abboud RJ, Rowley DI, Newton RW: Lower limb muscle dysfunction may contribute to foot ulceration in diabetic patients. Clin Biomech 15:37-45, 2000.

32. D'Ambrogi E, Giacomozzi C, Macellari V, Uccioli L: Abnormal foot function in diabetic patients: the altered onset of Windlass mechanism. Diabet Med 22:1713-1719, 2005.

33. Giacomozzi C, Caselli A, Macellari V, Giurato L, Lardieri L, Uccioli L: Walking strategy in diabetic patients with peripheral neuropathy. Diabetes Care 25:1451-1457, 2002.

34. Hiltunen LA: Does glucose tolerance affect elderly persons' balance, gait or muscle strength? Cent Eur J Public Health 9:22-25, 2001.

35. Hsi WL, Chai HM, Lai JS: Comparison of pressure and time parameters in evaluating diabetic footwear. Am J Phys Med Rehabil 81:822-829, 2002.

36. Hsi WL, Chai HM, Lai JS: Evaluation of rocker sole by pressure-time curves in insensate forefoot during gait. Am J Phys Med Rehabil 83:500-506, 2004.

37. Kwon OY, Minor SD, Maluf KS, Mueller MJ: Comparison of muscle activity during walking in subjects with and without diabetic neuropathy. Gait Posture 18:105-113, 2003.

38. Meier MR, Desrosiers J, Bourassa P, Blaszczyk J: Effect of type II diabetic peripheral neuropathy on gait termination in the elderly. Diabetologia 44:585-592, 2001.

39. Mueller MJ, Minor SD, Schaaf JA, Strube MJ, Sahrmann SA: Relationship of plantar-flexor peak torque and dorsiflexion range of motion to kinetic variables during walking. Phys Ther 75:684-693, 1995.

40. Pataky Z, Assal JP, Conne P, Vuagnat H, Golay A: Plantar pressure distribution in Type 2 diabetic patients without peripheral neuropathy and peripheral vascular disease. Diabet Med 22:762-767, 2005.

41. Patil KM, Bhat MV, Bhatia MM, Narayanamurthy VB, Parivalavan R: New on-line methods for analysis of walking foot pressures in diabetic neuropathy. Front Med Biol Eng 9:49-62, 1999.

42. Perry JE, Ulbrecht JS, Derr JA, Cavanagh PR: The use of running shoes to reduce plantar pressures in patients who have diabetes. J Bone Joint Surg Am 77:1819-1828, 1995.

43. Petrofsky J, Lee S, Macnider M, Navarro E: Autonomic, endothelial function and the analysis of gait in patients with type 1 and type 2 diabetes. Acta Diabetol 42:7-15, 2005.

44. Sacco IC, Amadio AC: Influence of the diabetic neuropathy on the behavior of electromyographic and sensorial responses in treadmill gait. Clin Biomech 18:426-434, 2003.

45. Sacco IC, Amadio AC: A study of biomechanical parameters in gait analysis and sensitive cronaxie of diabetic neuropathic patients. Clin Biomech 15:196-202, 2000.

46. Uccioli L, Caselli A, Giacomozzi C, Macellari V, Giurato L, Lardieri L, Menzinger G: Pattern of abnormal tangential forces in the diabetic neuropathic foot. Clin Biomech 16:446-454, 2001.

47. Walker SC, Helm PA, Lavery LA: Gait pattern alteration by functional sensory substitution in healthy subjects and in diabetic subjects with peripheral neuropathy. Arch Phys Med Rehabil 78:853-856, 1997.

48. Kerrigan DC, Lee LW, Nieto TJ, Markman JD, Collins JJ, Riley PO: Kinetic alterations independent of walking speed in elderly fallers. Arch Phys Med Rehabil 81:730-735, 2000.

49. Brach JS, Studenski S, Perera S, VanSwearingen JM, Newman AB: Stance time and step width variability have unique contributing impairments in older persons. Gait Posture 27:431-439, 2008.

50. Jordan K, Challis JH, Newell KM: Walking speed influences on gait cycle variability. Gait Posture 26:128-134, 2007.

51. Freiberger E, Menz HB: [Characteristics of falls in physically active community-dwelling older people: findings from the "Standfest im Alter" study] in German. Z Gerontol Geriatr 39:261-267, 2006.

52. Hollman JH, Kovash FM, Kubik JJ, Linbo RA: Age-related differences in spatiotemporal markers of gait stability during dual task walking. Gait Posture 26:113-119, 2007.

53. Mirka GA: The quantification of EMG normalization error. Ergonomics 34:343-352, 1991.

54. Yang JF, Winter DA: Electromyographic amplitude normalization methods: improving their sensitivity as diagnostic tools in gait analysis. Arch Phys Med Rehabil 65:517-521, 1984.

55. Burden AM, Trew M, Baltzopoulos V: Normalisation of gait EMGs: a re-examination. J Electromyogr Kinesiol 13:519-532, 2003. 


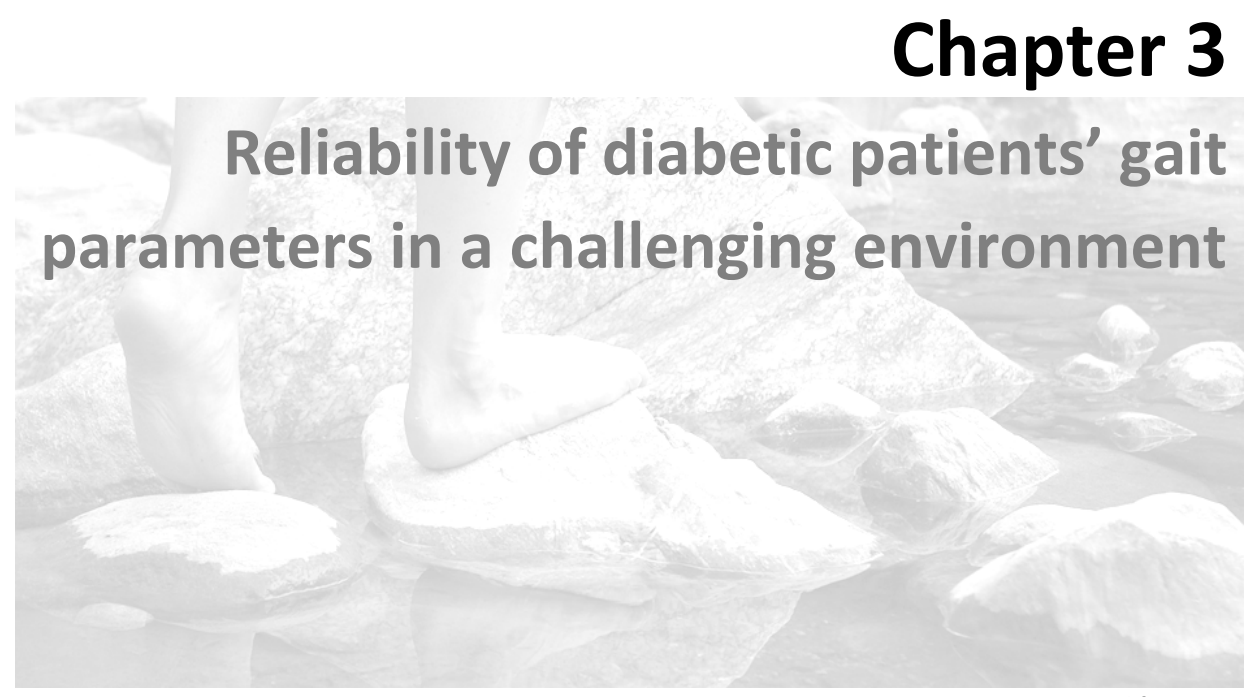

Allet L. ${ }^{1,2}$

Armand $\mathrm{S}^{3}$

de Bie R.A. ${ }^{2}$

Golay A. ${ }^{4}$

Monnin D. ${ }^{1}$

Aminian $\mathrm{K}^{5}$

de Bruin E.D.,

Article published in Gait Posture 28(4):680-686, 2008

${ }^{1}$ Department of Neuroscience, Geneva University Hospital and University of Geneva, Geneva, Switzerland.

2 Department of Epidemiology, Maastricht University and Caphri Research School, Maastricht, The Netherlands.

${ }^{3}$ Willy Taillard Laboratory of Kinesiology, Geneva University Hospital and University of Geneva, Geneva, Switzerland.

${ }^{4}$ Service of Therapeutic Education for Chronic Diseases, WHO Collaborating Centre, Geneva University Hospital and University of Geneva, Geneva, Switzerland.

${ }^{5}$ Laboratory of Movement Analysis and Measurement, EPFL, Lausanne, Switzerland.

${ }^{6}$ Institute of Human Movement Sciences and Sport, ETHZ, Zürich, Switzerland.

${ }^{7}$ Department of Rheumatology and Institute of Physical Medicine, University Hospital Zürich, Zürich, Switzerland. 


\section{SUMMARY}

\section{Background}

Activities of daily life require us to move about in challenging environments and to walk on varied surfaces. Irregular terrain has been shown to influence gait parameters, especially in a population at risk for falling. A precise portable measurement system would permit objective gait analysis under such conditions.

\section{Aims}

The aims of this study are to a) investigate the reliability of gait parameters measured with the Physilog in diabetic patients walking on different surfaces (tarred pathway, grass and cobblestones); b) identify the measurement error (precision); c) identify the minimal clinically detectable change.

\section{Methods}

Sixteen patients with type 2 diabetes were measured twice within 8 days. After a clinical examination, patients walked, equipped with a Physilog, on the 3 aforementioned surfaces.

\section{Results}

Intraclass correlation coefficients for each surface were excellent for within-visit analyses (> 0.938). Inter-visit intraclass correlation coefficients were excellent $(>0.753)$ except for the knee range parameter $(>0.503$ ). The coefficient of variation was lower than $5 \%$ for most of the parameters. Bland and Altman Plots, the standard error of the mean difference and the value of the smallest detectable change showed precise values, distributed around zero for all surfaces.

\section{Discussion and conclusion}

Gait parameters during complex locomotor activities (e.g. walking on uneven terrains, stairclimbing, slopes) have not yet been extensively investigated. Good reliability, small measurement error, and values of minimal clinically detectable change recommend the utilisation of Physilog ${ }^{\circledR}$ for the evaluation of diabetic patients' gait in conditions close to real life situations. 


\section{INTRODUCTION}

Human movement analysis is usually performed in specialised kinesiology laboratories. Cameras, force platforms, magnetic and ultrasound systems are commonly used technologies for gait analysis [1, 2]. However, time expenditure and financial constraints limit their use in clinical practice [3]. Moreover, gait analyses are traditionally performed indoors, on a predefined, clean and flat specific pathway. Such conditions enable precise recording but are not representative of the real life context. Activities of daily life require us to move about in challenging environments and to walk on varied surfaces. Irregular terrain has been shown to influence gait parameters such as speed, especially in a population at risk for falling [4]. Its influence on gait parameters and the fact that falls mainly occur in a complex environment [5] emphasise clinicians' need for objective gait data recorded in a real life context [6].

The recent use of body-fixed sensors suggests that they could serve as a tool for analysing patients' gait in their own environment [2, 7]. Body-fixed sensors (for example Physilog [2], DynaPort $^{\circ}[8,9]$, Xsens ${ }^{\oplus}[10]$ ) have already been shown to be valuable for the analysis of human movement $[1,11,12]$. In comparison with other motion measurement devices, body-fixed sensors have the advantage of being lightweight and portable, which enables subjects to move relatively freely. They permit data collection in a challenging environment; they are easy to use, cost-effective and can capture data from many gait cycles. Thus, they seem ideal for analysing gait parameters in specific populations, such as diabetic patients.

Diabetic individuals have been shown to suffer from increased risk of injurious falls [13]. Moreover, diabetes can seriously damage many of the body's systems, especially nerves and blood vessels. However, the cause for diabetics' increased fall risk is still under debate [14]. An objective evaluation in real life conditions might help to understand the causes of their gait problems and ultimately facilitate the choice or the development of appropriate physical treatment. For these reasons sensors' potential should be investigated so as to ensure the precision and the reliability of data recorded during gait analysis on changing types of surfaces.

With this in mind, we conducted this study to a) investigate the reliability of gait parameters measured with Physilog in diabetic patients walking on different surfaces (tarred pathway, grass and cobblestones), b) identify the measurement error (precision) and c) identify the minimal clinically detectable change.

\section{METHODS}

The study was approved by the ethics committee in Geneva. All participants received written and oral information and were requested to sign an informed consent statement. 


\section{Subjects}

A convenience sample of 16 patients (mean age: $55 \pm 8$ years; Body Mass Index: $30.28 \pm 5$ ) with type 2 diabetes (with and without neuropathy) was recruited from the patients consulting the Service of Therapeutic Education for Chronic Diseases or the Service of Endocrinology at the University Hospital in Geneva. Patients were included if they were medically diagnosed with type 2 diabetes (blood sugar $>7.0 \mathrm{mmoll}^{-1}$ in fasting state). Patients were excluded if they had concomitant foot ulcer, orthopaedic or surgical problems influencing gait parameters, a non-diabetic neuropathy (due to Charcot-MarieTooth disease, alcohol or thyroid dysfunction), neurological pathology influencing gait parameters or incapacity to walk without a walking aid.

\section{Apparatus}

Gait analysis was performed using 4 miniature gyroscopes (ADXRS 250, Analog device) attached to each shin and thigh. Each sensor measured the velocity of the angular rotation per segment around the coronal axis (flexion-extension). Signals were digitised (16 bit) at a sampling rate of $200 \mathrm{~Hz}$ by a light portable data logger (Physilog , BioAGM, CH) and stored for off-line analysis on a memory card (Figure 3.1a and 3.1b). Temporal parameters (including speed, cadence, gait cycle time, stance phase and double support relative to the gait cycle) and spatial parameters (including stride length, sagittal shin, thigh and knee range, and the maximal sagittal shin angle velocity during swing phase $\left.\left(\operatorname{degs}^{-1}\right)\right)$ were computed [15].

\section{Procedure}

After signing informed consent patients received 2 appointments within 8 days. As diabetes type 2 is defined as a chronic disease with complications that increase progressively over time, we assumed that diabetic patients with stable blood sugar values would not change their physical status and gait within one week.

At each appointment a clinical examination was performed. We checked that patients did not have foot ulcers and we controlled blood sugar values. The type of shoes patients wore during the first appointment was noted and patients were requested to use identical shoes during the second session.

Patients were then equipped with the Physilog system and requested to walk with a preferred walking speed (e.g. posting a letter) outside in the backyard of the hospital. The walkway consisted of two $50 \mathrm{~m}$ long tarred pathways, two $50 \mathrm{~m}$ grass pathways and two 20 $\mathrm{m}$ cobblestone pathways. Three different combinations of the order of surfaces were possible. The order of the surfaces was randomly assigned but remained the same for both appointments. Between each surface the patients paused for 8 to $10 \mathrm{~s}$. This interval was necessary for the Physiolog ${ }^{\circledR}$ system to identify the change from one surface to another (grass, tarred pathway or cobblestones). The identical procedure was repeated after 8 days. 
(a)

Thigh
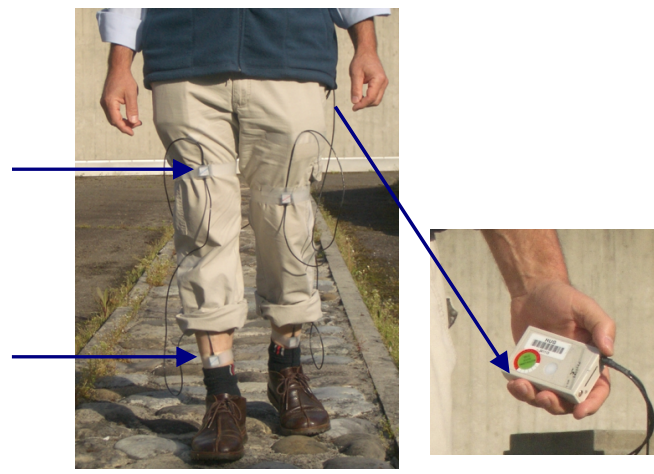

Signals were digitised at a sampling

Shin rate of $200 \mathrm{~Hz}$ by the portable data logger (Physilog, BioAGM, CH) and stored for off-line analysis on a memory card.

(b)

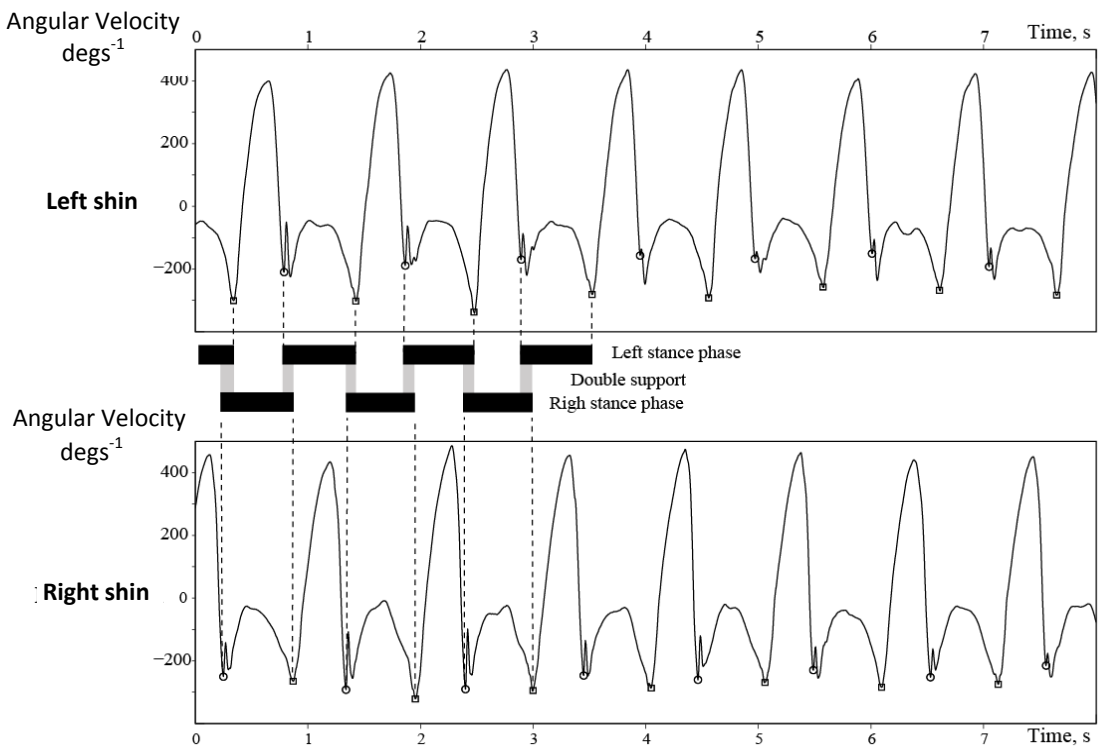

Figure 3.1. (a) Equipment with the Physiolog ${ }^{\circledR}$ system. Gait analysis was performed using 4 miniature gyroscopes (ADXRS 250, Analog device) attached to each shin and thigh. Each sensor measured the velocity of the angular rotation per segment around the coronal axis (flexion-extension). (b) Raw data recorded with the Physilog ${ }^{\circledR}$ and its interpretation. Angular velocity recorded from shin segments during successive gait cycles. The detection of heel-strikes (o) and toe-offs ( $\square$ ) enables the estimation of stance phase (black zone) and double support periods (grey zone).

\section{Statistical analysis}

Descriptive statistics were used to define the study population and to calculate gait characteristics. We used the intra-class correlation coefficient $\left(\mathrm{ICC}_{1.1}\right)$ to calculate withinvisit reliability (during visit 1 ) by having patients walk along the same surface twice [16]. We further evaluated inter-visit reliability between visit 1 and visit 2 . The descriptive statistics and the ICC were computed with SPSS (SPSS for Windows rel. 15. Chicago: SPSS Inc.). To interpret ICC values we used benchmarks suggested by Shrout and Fleiss [16] (> 0.75 excellent reliability, 0.4-0.75 fair to good reliability and $<0.4$ poor reliability). 
To evaluate precision the $95 \%$ limits of agreement statistics (Bland and Altman) was used. It expresses the degree of error proportional to the mean and was calculated as $\bar{d} \pm 2$ SDdiff. $[17,18]$, where $\bar{d}$ is the mean of the difference and SDdiff the standard deviation of the difference. We further calculated the relative precision by the coefficient of variation (CV) as a ratio of the standard deviation to the mean.

The measurement error (standard error of the mean difference (SEM)) [19] was reported and the smallest detectable change for each parameter was calculated as described by de Vet et al. [20]. SEM was derived by $\sigma \sqrt{(1-I C C)}$ in which $\sigma$ represents the total variance. The smallest detectable change (SDC) was calculated with the formula $1.96 \times \operatorname{SEM} \times \sqrt{2}$. Limits of agreement, SEM and SDC were calculated with Excel.

To identify differences between surfaces we used an analysis of variance (ANOVA). All data were explored for normality and we checked with a skewness kurtosis test whether the distribution was Gaussian or not. Data were considered normally distributed if they were not significantly different $(p>0.05)$ from a normal distribution. Where necessary we applied an automatic algorithm which detects the best way of normalisation for each variable [21] to normalise data.

\section{RESULTS}

\section{Gait Parameters}

The mean values and standard deviations of the gait parameters of 16 evaluated patients are reported in Table 3.1. Since the intra-visit reliability was based on the first visit, the results of laps 1 and 2 on each surface as well as the mean of both laps of this visit are summarised. For the second visit only the mean values of both laps are reported.

The ICC for each surface within visit 1 was excellent (> 0.938). The inter-visit ICCs were excellent for all variables except for the sagittal knee range, for which it was good. The values ranged from 0.503 for sagittal knee range to 0.946 for the gait cycle time on a tarred pathway, from 0.639 for sagittal knee range to 0.958 for cadence and the gait cycle time on grass and from 0.728 for sagittal knee range to 0.955 for the maximal sagittal shin angle velocity in swing phase on cobblestones. All ICC values and their lower and upper boundaries are reported together with the CV (\%), the mean difference between two recordings and the $95 \%$ limits of agreement in Table 3.2.

The CV was lower than $5 \%$ for most of the parameters. Comparing the results within one visit the best CV was calculated for the stance phase on a tarred pathway $(0.5 \%)$ and the worst was identified for the double support on cobblestones (4.8\%). Comparing the intervisit values, the $\mathrm{CV}$ ranged from $1.26 \%$ for stance phase while walking on cobblestones to $11.28 \%$ for double support while walking on a tarred pathway. Only 2 other parameters exceed a CV of $5 \%$ for the inter-visit comparison, namely speed and double support. The SEM and the SDC are illustrated along with the Bland Altman Plot in Figure 3.2. 
Table 3.1. Mean and SD of gait parameters on different surfaces (tarred pathway, grass and cobblestones) evaluated during visit 1 and visit 2

\begin{tabular}{|c|c|c|c|c|c|}
\hline \multirow[t]{3}{*}{ Parameter } & \multirow[t]{3}{*}{ Surface } & \multicolumn{3}{|l|}{ Visit 1} & \multirow{2}{*}{$\begin{array}{l}\text { Visit } 2 \\
\text { Mean (SD) }\end{array}$} \\
\hline & & Mean (SD) & Mean (SD) & Mean (SD) & \\
\hline & & First lap & Second lap & Both laps & Both laps \\
\hline \multirow{3}{*}{$\begin{array}{l}\text { Cadence } \\
\left(\text { cyclemin }^{-1} \text { ) }\right.\end{array}$} & Tarred pathway & $55.63(4.43)$ & $56.42(4.54)$ & $56.03(4.45)$ & $56.34(5.12)$ \\
\hline & Grass & $54.32(4.91)$ & $54.86(4.33)$ & $54.59(4.58)$ & $54.90(4.90)$ \\
\hline & Cobblestones & $52.03(4.77)$ & $52.55(5.18)$ & $52.29(4.93)$ & $52.98(5.43)$ \\
\hline \multirow{3}{*}{$\begin{array}{l}\text { Speed } \\
\left(\mathrm{ms}^{-1}\right)\end{array}$} & Tarred pathway & $1.23(0.20)$ & $1.27(0.20)$ & $1.25(0.20)$ & $1.27(0.21)$ \\
\hline & Grass & $1.20(0.22)$ & $1.22(0.20)$ & $1.21(0.21)$ & $1.24(0.21)$ \\
\hline & Cobblestones & $1.11(0.23)$ & $1.13(0.24)$ & $1.12(0.23)$ & $1.17(0.25)$ \\
\hline \multirow{3}{*}{$\begin{array}{l}\text { Gait cycle time } \\
\text { (s) }\end{array}$} & Tarred pathway & $1.09(0.08)$ & $1.07(0.09)$ & $1.08(0.08)$ & $1.07(0.09)$ \\
\hline & Grass & $1.11(0.10)$ & $1.1(0.09)$ & $1.11(0.09)$ & $1.10(0.10)$ \\
\hline & Cobblestones & $1.16(0.11)$ & $1.15(0.12)$ & $1.16(0.12)$ & $1.15(0.12)$ \\
\hline \multirow{3}{*}{$\begin{array}{l}\text { Stance phase } \\
(\%)\end{array}$} & Tarred pathway & $59.90(2.19)$ & $59.71(2.18)$ & $59.80(2.17)$ & $59.81(2.16)$ \\
\hline & Grass & $59.62(2.18)$ & $59.62(2.07)$ & $59.62(2.11)$ & $59.67(1.88)$ \\
\hline & Cobblestones & $60.07(1.81)$ & $59.99(2.13)$ & $60.03(1.95)$ & $59.79(2.06)$ \\
\hline \multirow{3}{*}{$\begin{array}{l}\text { Double support } \\
\text { (\%) }\end{array}$} & Tarred pathway & $19.80(4.37)$ & $19.41(4.36)$ & $19.61(4.34)$ & $19.62(4.32)$ \\
\hline & Grass & $19.23(4.35)$ & $19.23(4.13)$ & $19.23(4.21)$ & $19.34(3.76)$ \\
\hline & Cobblestones & $20.14(3.61)$ & $19.97(4.26)$ & $20.05(3.89)$ & $19.58(4.11)$ \\
\hline \multirow{3}{*}{$\begin{array}{l}\text { Stride } \\
(\mathrm{m})\end{array}$} & Tarred pathway & $1.33(0.18)$ & $1.35(0.19)$ & $1.34(0.19)$ & $1.34(0.18)$ \\
\hline & Grass & $1.33(0.19)$ & $1.34(0.19)$ & $1.33(0.19)$ & $1.35(0.18)$ \\
\hline & Cobblestones & $1.28(0.21)$ & $1.29(0.22)$ & $1.29(0.22)$ & $1.32(0.21)$ \\
\hline \multirow{3}{*}{$\begin{array}{l}\text { Shin range } \\
\text { (deg) }\end{array}$} & Tarred pathway & $77.00(5.78)$ & $77.99(6.11)$ & $77.50(5.93)$ & $76.46(5.71)$ \\
\hline & Grass & $77.25(6.41)$ & $77.78(6.31)$ & $77.51(6.34)$ & 77.20 (5.69) \\
\hline & Cobblestones & $74.50(8.18)$ & $74.83(8.00)$ & $74.67(8.04)$ & 74.78 (7.33) \\
\hline \multirow{3}{*}{$\begin{array}{l}\text { Thigh range } \\
\text { (deg) }\end{array}$} & Tarred pathway & $40.48(6.64)$ & $41.41(6.72)$ & $40.95(6.66)$ & $41.26(6.47)$ \\
\hline & Grass & $41.85(6.80)$ & $42.28(6.69)$ & $42.06(6.72)$ & $43.35(6.06)$ \\
\hline & Cobblestones & $40.97(7.34)$ & $41.32(7.36)$ & $41.14(7.33)$ & $42.72(7.40)$ \\
\hline \multirow{3}{*}{$\begin{array}{l}\text { Knee range } \\
\text { (deg) }\end{array}$} & Tarred pathway & $61.60(3.78)$ & $62.03(4.25)$ & $61.82(4.00)$ & $60.24(4.26)$ \\
\hline & Grass & $62.04(3.49)$ & $62.30(3.79)$ & $62.17(3.59)$ & $61.37(4.18)$ \\
\hline & Cobblestones & $60.66(5.06)$ & $60.90(4.63)$ & $60.78(4.79)$ & $59.97(5.54)$ \\
\hline \multirow{3}{*}{$\begin{array}{l}\text { Max shin angle } \\
\text { velocity }\left(\text { degs }^{-1} \text { ) }\right.\end{array}$} & Tarred pathway & $371.39(33.43)$ & $379.16(37.55)$ & $375.27(35.37)$ & $371.17(36.78)$ \\
\hline & Grass & $366.90(41.58)$ & 372.08 (39.97) & $369.49(40.52)$ & $369.11(38.41)$ \\
\hline & Cobblestones & $339.64(50.28)$ & 344.39 (51.15) & $342.01(50.47)$ & $344.58(50.66)$ \\
\hline
\end{tabular}




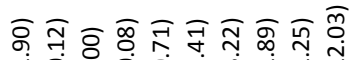
ก.i.

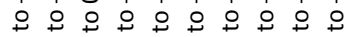
m ㄴํ ๆ

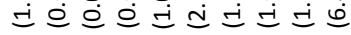

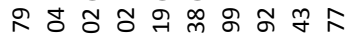
○े

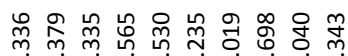

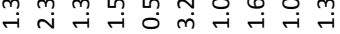

হু হু হু হু ুু ুু 0000000000 $+\div \circ \circ \circ \circ \div 0 \%$

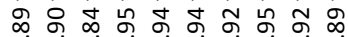
응ㅇㅇㅇㅇㅇㅇㅇㅇ

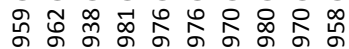

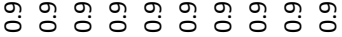

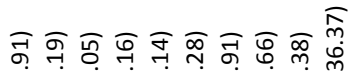
mo ó

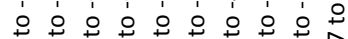

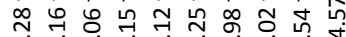

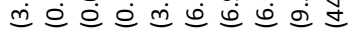
กิ 

윰 咅 N

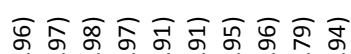
0 ०० 0 0 0 ० 0 0

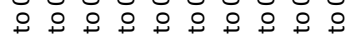
กิ

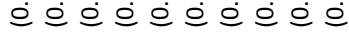
స్ જิ

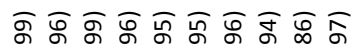

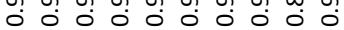

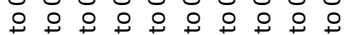
๙

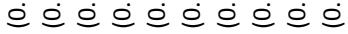

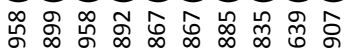
○.:

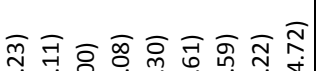

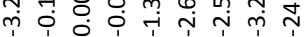

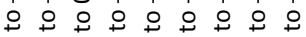

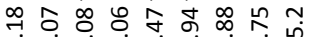

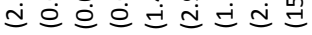
ก๊ำ

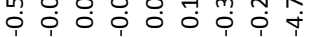

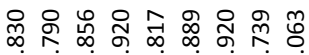

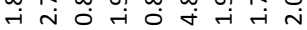

হু হু চ্চ চ চ চ হু

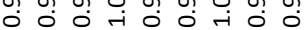
웅ㅇㅇㅇㅇ ळ సँ ळ 응ㅇㅇํㅇํㅇ

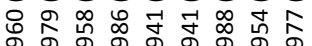

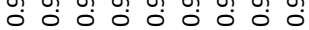

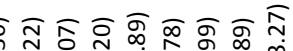

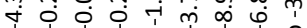

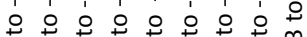
の

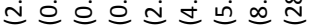
बำ o o o o o o

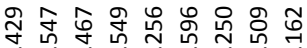

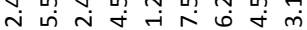

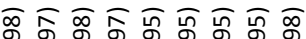

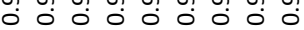
웅ㅇㅇㅇㅇㅇ ๓

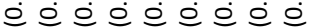

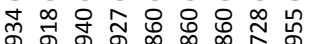

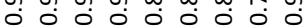




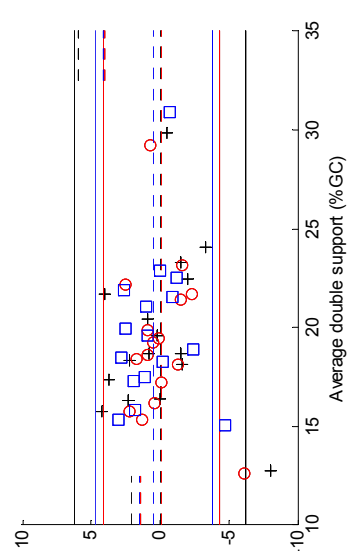

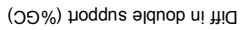

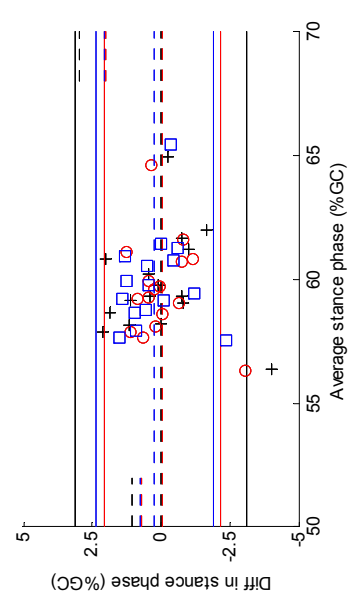

(ว૭\%) әseud әэuełs u! H!

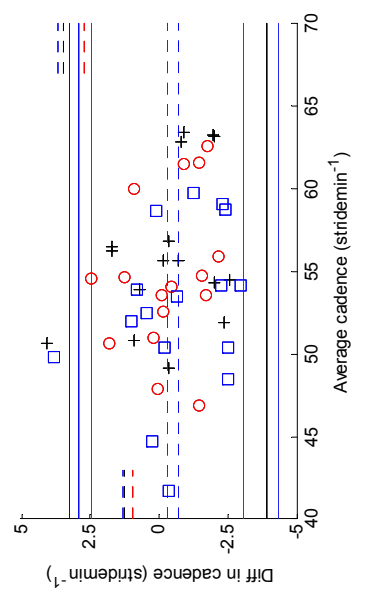

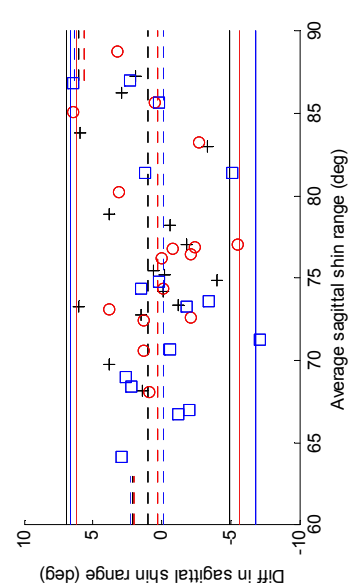

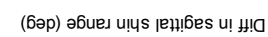

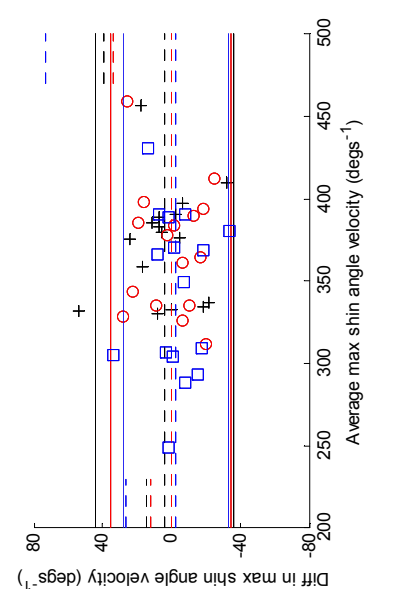

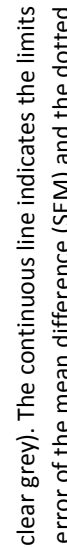

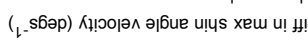
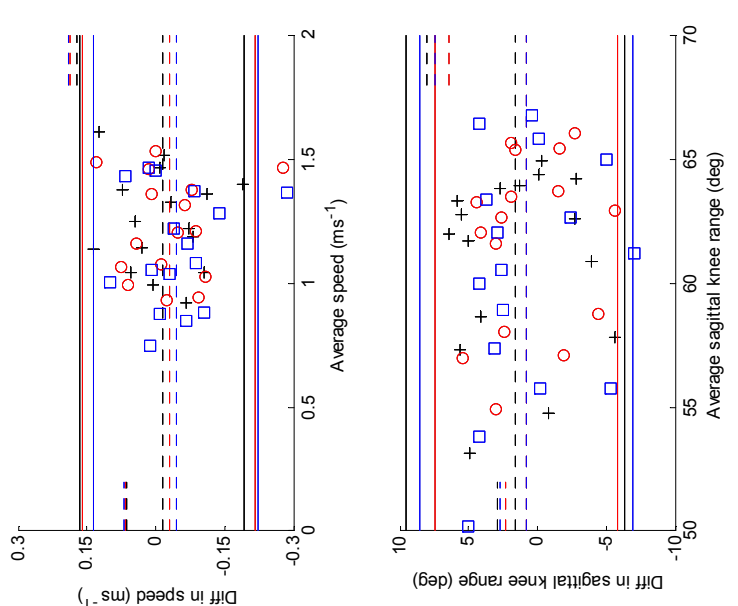

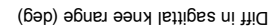

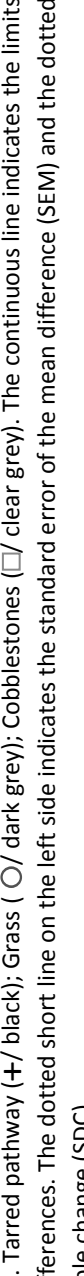

它弯

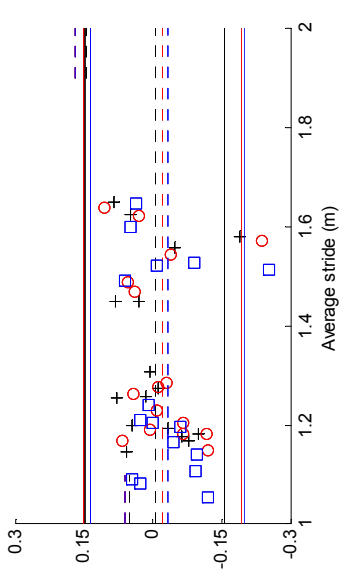

(u) әр!̣ıs u!

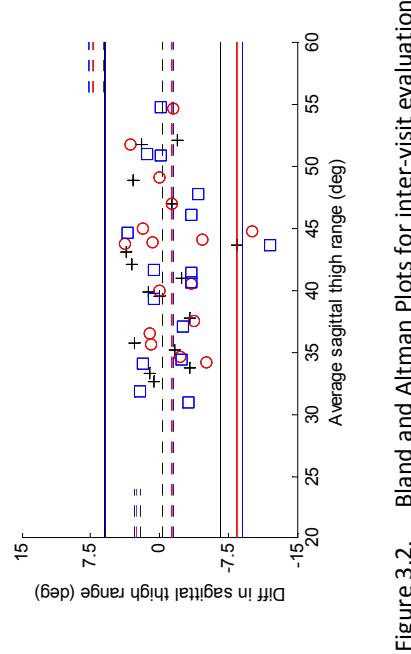


The SEM revealed similar values for all surfaces within one visit. Comparing visit 1 with visit 2 , most of the parameters (cadence, stride length, speed, sagittal shin range, sagittal thigh range and maximal sagittal shin angle velocity in swing phase) showed a higher SEM and SDC while walking on cobblestones than while walking on grass or on a tarred pathway. However, stance phase, double support and sagittal knee range presented the highest SEM and SDC values while walking on a tarred pathway.

\section{Difference on surfaces}

Our findings show that patients tend to walk slower on cobblestones than on grass and slower on grass than on a tarred pathway. In line with these results, cadence decreases, gait cycle time increases and the degree of the shin and knee mobility decreases. Furthermore, we observed a decrease in the maximal sagittal shin angle velocity during the swing phase. The ANOVA showed that surfaces had an effect on these gait parameters. Compared to a tarred pathway, walking on cobblestones was significantly different $(p<$ 0.05 ) regarding cadence, speed, gait cycle time and maximal sagittal shin angle velocity in swing phase. The maximal sagittal shin angle velocity in swing phase was also significantly different when comparing grass and cobblestones.

\section{DISCUSSION}

This study aimed to investigate the reliability of gait parameters measured with body-fixed sensors in diabetic patients and to evaluate this tool's clinical potential for gait analysis on varied surfaces (tarred pathway, grass and cobblestones).

Overall Bland and Altman Plots showed similar results for all surfaces with values well distributed around zero. The ICC, SEM and SDC evaluated in this paper showed that the Physilog ${ }^{\circ}$ enables precise recordings and detection of small changes in gait parameters. It could therefore be considered an appropriate tool for gait analysis in diabetic patients under real life conditions.

All ICC values are higher than 0.8 except for the sagittal knee range. As the knee range calculation is based on the hip and shin values the low sagittal knee range ICC could be explained by interactions between these measurements.

However, the SEM and SDC (inter-visit) for stance phase and double support showed higher values when recorded on a tarred pathway than on grass or cobblestones. Since we expected opposite results we checked our dataset for possible explanations. We found that the outlier, which was well identified on the Bland and Altman Plots, presented a short stance phase and a short double stance although with a speed corresponding to those of the other diabetic patients. This phenomenon could be due to a problem of gait cycle detection for this specific patient and might explain the higher observed values on the tarred pathway.

Comparison with other study results: as far as we know this article is the first to evaluate reliability of gait parameters on different types of surfaces. For this reason we can only compare our results with studies performed on a level surface. Nevertheless, our ICCs and 
CVs of spatiotemporal parameters showed similar values to those of other gait measurement systems [22, 23].

We found comparable between-visit ICCs for speed, cadence and step length (ICCs between 0.89 and 0.93 ) to those calculated with the GaitRite walkway [23] (within visit ICCS between 0.82 and 0.92 ). Our intra-visit CVs for these parameters (between $1.78 \%$ and $5.55 \%)$ were slightly higher but still comparable to those recorded with the GaitRite (between $1.4 \%$ and $3.5 \%$ ).

However, our intra-visit CVs were lower (between 1.34\% and 2.79\%). We further compared our ICC and CVs of spatiotemporal parameters (speed, cadence and stride length) with those recorded with an IDEEA (body-fixed sensor composed of 5 accelerometers) and those recorded with a Kistler force platform (FP) [22]. The latter found similar ICCS (between 0.988 and 0.994 on force platforms and between 0.965 and 0.987 with the IDEEA) to ours. Their CVs, recorded with a FP (between $1.6 \%$ and $2.6 \%$ ), were similar to our intra-visit results. However, CVs recorded with the IDEEA ${ }^{\circledast}$ (between $2.7 \%$ and $5.7 \%$ ) were significantly higher, in particular for stride length. In short, our ICCS and CVs show as good results as those of other measurement instruments, which recorded gait parameters on a level surface. All in all we may say that the reliability of the Physilog reached similar results for gait analysis of diabetic patients on different surfaces to those obtained with other measurement instruments recording gait parameters of healthy persons while walking on a level surface. As irregular surfaces were shown to influence gait parameters such as speed, especially in a population at risk for falling [24], our results are of high clinical relevance. We may now start to investigate the possible causes for diabetics' increased fall risk. Future studies should compare diabetics' gait parameters with those of a healthy control group while walking on different surfaces.

Another interesting clinical parameter to be evaluated is gait variability. Hausdorff et al. [25] showed that using gait variability measures could potentially enhance the prospective evaluation of fall risk. It is therefore necessary to extend gait analysis to gait variability features. Nevertheless, one should be careful with the interpretation of the said variability measures. As it was shown that this parameter is speed dependent [26], when studying gait variability, speed needs to be taken into account.

The choice of body-fixed sensors and their location should be in line with the objective of the assessment. If the main interest is to detect spatiotemporal gait parameters, it has been shown that one accelerometer on the trunk is sufficient [27]. For clinical decision making however, the evaluation of spatiotemporal gait parameters are often not conclusive enough. In the clinic, assessment of other parameters such as joint kinematics would be useful and could be provided, as shown in our study, by accelerometers and gyroscopes on trunk, thighs and shins. However, in order to adequately evaluate varied surfaces' influence on these patients' gait, it was still necessary to supervise and standardise the acquisition of data. For this reason we restricted the extent of our study to a standardised pathway, even if real life conditions require an individualised assessment in the patient's environment. Such an evaluation obviously incorporates situations such as stair climbing, walking up/down a slope, crossing a street and multiple-task situations. Devices enabling 3-D reconstruction have already been developed and evaluated during the execution of 3 different locomotion tasks [28], but many complex locomotor activities have not yet been 
fully investigated. Therefore gait evaluation and its interpretation under real life conditions can still be improved.

\section{CONCLUSION}

Body-fixed sensors provide reliable assessment of gait parameters outdoors on different surfaces. The small measurement error and the values of the minimal clinically detectable change recommend their utilisation for the evaluation of gait parameters in diabetic patients. The influence of different surfaces on gait parameters reveals further interesting findings and shows the importance of analysing gait in a challenging environment. Further studies are needed to investigate the surface and group effect on gait parameters in a challenging environment. 


\section{REFERENCES}

1. Dejnabadi $\mathrm{H}$, Jolles BM, Aminian K: A new approach to accurate measurement of uniaxial joint angles based on a combination of accelerometers and gyroscopes. IEEE Trans Biomed Eng 52:1478-1484, 2005.

2. Aminian K, Trevisan C, Najafi B, Dejnabadi H, Frigo C, Pavan E, Telonio A, Cerati F, Marinoni EC, Robert P, Leyvraz PF: Evaluation of an ambulatory system for gait analysis in hip osteoarthritis and after total hip replacement. Gait Posture 20:102-107, 2004.

3. Simon SR: Quantification of human motion: gait analysis-benefits and limitations to its application to clinical problems. J Biomech 37:1869-1880, 2004.

4. Richardson JK, Thies SB, DeMott TK, Ashton-Miller JA: Gait analysis in a challenging environment differentiates between fallers and nonfallers among older patients with peripheral neuropathy. Arch Phys Med Rehabil 86:1539-1544, 2005.

5. Freiberger E, Menz HB: [Characteristics of falls in physically active community-dwelling older people: findings from the "Standfest im Alter" study] in German. Z Gerontol Geriatr 39:261-267, 2006.

6. Tong K, Granat MH: A practical gait analysis system using gyroscopes. Med Eng Phys 21:87-94, 1999.

7. Zijlstra W, Aminian K: Mobility assessment in older people: new possibilities and challenges Eur J Aging 4:1-12, 2007.

8. Zijlstra A, Goosen JH, Verheyen CC, Zijlstra W: A body-fixed-sensor based analysis of compensatory trunk movements during unconstrained walking. Gait Posture 27:164-167, 2008.

9. van den Akker-Scheek I, Stevens M, Bulstra SK, Groothoff JW, van Horn JR, Zijlstra W: Recovery of gait after short-stay total hip arthroplasty. Arch Phys Med Rehabil 88:361-367, 2007.

10. Moore ST, MacDougall HG, Gracies JM, Cohen HS, Ondo WG: Long-term monitoring of gait in Parkinson's disease. Gait Posture 26:200-207, 2007.

11. Aminian K, Robert P, Buchser EE, Rutschmann B, Hayoz D, Depairon M: Physical activity monitoring based on accelerometry: validation and comparison with video observation. Med Biol Eng Comput 37:304-308, 1999.

12. Salarian A, Russmann H, Vingerhoets FJ, Dehollain C, Blanc Y, Burkhard PR, Aminian K: Gait assessment in Parkinson's disease: toward an ambulatory system for long-term monitoring. IEEE Trans Biomed Eng 51:14341443, 2004.

13. Miller DK, Lui LY, Perry HM 3rd, Kaiser FE, Morley JE: Reported and measured physical functioning in older inner-city diabetic African Americans. J Gerontol A Biol Sci Med Sci 54:230-236, 1999.

14. Allet L, Armand S, Golay A, Monnin D, de Bie RA, de Bruin ED: Gait characteristics of diabetic patients: a systematic review. Diabetes Metab Res Rev 24:173-191, 2008.

15. Aminian K, Najafi B, Bula C, Leyvraz PF, Robert P: Spatio-temporal parameters of gait measured by an ambulatory system using miniature gyroscopes. J Biomech 35:689-699, 2002.

16. Shrout PE and Fleiss JL. Intraclass correlations: uses in assessing rater reliability. Psychol Bull 86: 420-428, 1979

17. Rankin G, Stokes M: Reliability of assessment tools in rehabilitation: an illustration of appropriate statistical analyses. Clin Rehabil 12:187-199, 1998.

18. Bland JM, Altman DG: Statistical methods for assessing agreement between two methods of clinical measurement. Lancet 1:307-310, 1986.

19. Bland JM, Altman DG: Measurement error. Bmj 312:1654, 1996.

20. de Vet HC, Terwee CB, Knol DL, Bouter LM: When to use agreement versus reliability measures. J Clin Epidemiol 59:1033-1039, 2006.

21. Buchner DM, Findley TW: Research in physical medicine and rehabilitation. Preliminary data analysis. Am J Phys Med Rehabil 69:154-169, 1990.

22. Maffiuletti NA, Gorelick M, Kramers-de Quervain I, Bizzini M, Munzinger JP, Tomasetti S, Stacoff A: Concurrent validity and intrasession reliability of the IDEEA accelerometry system for the quantification of spatiotemporal gait parameters. Gait Posture 27:160-163, 2008.

23. Menz HB, Latt MD, Tiedemann A, Mun San Kwan M, Lord SR: Reliability of the GAITRite walkway system for the quantification of temporo-spatial parameters of gait in young and older people. Gait Posture 20:20-25, 2004.

24. Richardson JK, Thies SB, DeMott TK, Ashton Miller JA: Interventions improve gait regularity in patients with peripheral neuropathy while walking on an irregular surface under low light. J Am Geriatr Soc 52:510-515, 2004.

25. Hausdorff JM, Rios DA, Edelberg HK: Gait variability and fall risk in community-living older adults: a 1-year prospective study. Arch Phys Med Rehabil 82:1050-1056, 2001. 
26. Jordan K, Challis JH, Newell KM: Walking speed influences on gait cycle variability. Gait Posture 26:128-134, 2007.

27. Zijlstra W, Hof AL: Assessment of spatio-temporal gait parameters from trunk accelerations during human walking. Gait Posture 18:1-10, 2003.

28. Giansanti D, Maccioni G, Macellari V: The development and test of a device for the reconstruction of 3-D position and orientation by means of a kinematic sensor assembly with rate gyroscopes and accelerometers. IEEE Trans Biomed Eng 52:1271-1277, 2005. 


\title{
Chapter 4
}

\section{Gait alterations of diabetic patients while walking on different surfaces}

\author{
Allet L. ${ }^{1,2}$ \\ Armand $\mathrm{S}^{3}$ \\ de Bie R.A. ${ }^{2}$ \\ Pataky Z. ${ }^{4}$ \\ Aminian $\mathrm{K}^{5}$ \\ Herrmann F.R. ${ }^{6}$ \\ de Bruin E.D. ${ }^{7}$
}

${ }^{1}$ Department of Neuroscience, Geneva University Hospital and University of Geneva, Geneva, Switzerland.

2 Department of Epidemiology, Maastricht University and Caphri Research School, Maastricht, The Netherlands.

${ }^{3}$ Willy Taillard Laboratory of Kinesiology, Geneva University Hospital and University of Geneva, Geneva, Switzerland.

${ }^{4}$ Service of Therapeutic Education for Chronic Diseases, WHO Collaborating Centre, Geneva University Hospital and University of Geneva, Geneva, Switzerland.

${ }^{5}$ Laboratory of Movement Analysis and Measurement, EPFL, Lausanne, Switzerland.

${ }^{6}$ Department of Rehabilitation and Geriatrics, Geneva University Hospitals and University of Geneva, Thônex-Geneva, Switzerland.

${ }^{7}$ Institute of Human Movement Sciences and Sport, ETHZ, Zürich, Switzerland. 


\section{SUMMARY}

\section{Background}

Patients with diabetes have been shown to suffer from increased fall risk. However, authors disagree as to whether only diabetic patients with neuropathy, or also those without neuropathy, present gait alterations. Existing studies evaluate gait indoors, i.e. in specialised gait laboratories.

\section{Aims}

This study aims to evaluate gait parameters in diabetic patients under various real life conditions and compares them to those recorded for healthy controls.

\section{Methods}

We conducted a clinical observation study. Forty-five subjects' gait was assessed on 3 different surfaces (tarred pathway, grass and cobblestones) with a Physilog system (BioAGM, CH), consisting of accelerometers and gyroscopes. Temporal and spatial gait parameters as well as stride-to-stride variability of 30 patients with type 2 diabetes, 15 with and 15 without neuropathy were compared to 15 healthy controls. The 3 groups were comparable for age, height and body weight $(p>0.05)$.

\section{Results}

Diabetic patients' gait parameters differed significantly from those of healthy controls. Post hoc analysis revealed a significant difference between healthy individuals and patients with neuropathy and between healthy individuals and patients without neuropathy. No significant difference was observed between patients with or without neuropathy. The highest surface effect was found in patients with diabetic neuropathy, followed by patients without neuropathy and healthy controls.

\section{Discussion and conclusion}

Walking under real life conditions revealed gait difficulties in patients with type 2 diabetes before neuropathy was clinically detectable. Clinicians should be aware that diabetic individuals' gait capacity decreases and fall risk increases at an early stage of the disease. 


\section{INTRODUCTION}

Diabetic patients have been shown to suffer from increased risk of injuries from falls [1]. Since peripheral neuropathy (PN) affects both sensory and motor functions [2], the consecutive neuromuscular damage may result in altered lower extremity biomechanics. This could lead to gait abnormalities with the aforementioned increased fall risk. However, to date, the cause of increased fall risk in diabetic patients is still a subject of debate [3]. A systematic review [3] revealed that significant questions remain about the main causes of gait abnormalities in diabetic patients. Various authors [4-7] have found an association between neuropathy and gait abnormalities and/or falls. Cavanagh et al. [4] for example demonstrated that PN affects gait and posture. They described 15 times more falls in the diabetic neuropathy group than in the diabetic control group. Ducic et al. [5] further examined the intuitive relationship between increasing loss of foot sensibility (defined as 2 and 1-point discrimination loss) and increasing loss of balance in diabetic patients. They stated that PN, rather than ocular changes, is responsible for gait problems and concluded that neuropathy could well represent the mechanism for gait abnormalities and increased risk of falls. Katoulis et al. [7], evaluating patients with and without diabetic PN found no gait alterations in diabetic patients without neuropathy but did in subjects with peripheral neuropathy. However, Petrofsky et al. [8] found gait impairments in diabetic patients with no sensory loss. These authors emphasised that whatever the mechanism, diabetic patients develop gait alterations well before objective loss of sensation in the feet. This apparent contradiction between authors underscores the need for further research in order to understand diabetic patients' gait abnormalities and their increased risk of falls. In most existing studies authors assessed gait indoors, i.e. in specialised gait laboratories or on a flat indoor surface. Few authors have attempted to evaluate gait under various conditions such as irregular surfaces [9], a poorly lit pathway or an obstacle course [10]. Gait analysis performed indoors, on a predefined, clean and essentially flat, specific pathway is not representative of a real life situation. Activities of daily life require moving in challenging environments and walking on varied surfaces. Freiberger et al. [11], evaluating fall risk in the elderly, showed that falls often occur in a complex context. Falls are related to both intrinsic and extrinsic factors, such as physiological changes or environmental hazards [12]. We therefore consider that gait analysis should be performed in a real life environment to correctly understand what makes individuals fall $[13,14]$.

Nowadays, gait parameters can be reliably measured in real life situations with body-fixed measurement devices [15]. We were therefore able to assess diabetic patients' gait parameters on 3 different surfaces, namely a tarred pathway $(T)$, grass $(G)$ and cobblestones (S). We then compared them to those recorded for healthy controls. Our overall hypothesis was that diabetic neuropathy influences the neuromuscular control system's ability to respond to a challenging environment and therefore that: a) gait parameters deteriorate with the progression of diabetes (diabetic patients with neuropathy $>$ diabetic patients without neuropathy $>$ healthy controls), b) diabetic patients show more gait abnormalities on irregular surfaces than on a flat pathway (cobblestones $>$ grass $>$ tarred pathway) and c) that the influence of surfaces on gait parameters increases with the severity of the neuropathy. 


\section{METHODS}

The study was approved by the local ethics committee in Geneva. All participants received written and oral information and were requested to sign an informed consent statement.

\section{Subjects}

Forty-five subjects were included in the study. A convenience sample of 30 type 2 diabetes patients, 15 with (mean age: $61.3 \pm 6.5$ year; height: $1.67 \pm 0.1 \mathrm{~m}$, weight: $86.94 \pm 9.1 \mathrm{~kg}$ ) and 15 without neuropathy (mean age: $55.83 \pm 8.2$ year; height: $1.72 \pm 0.1 \mathrm{~m}$, weight: 90.3 $\pm 22.2 \mathrm{~kg}$ ) was recruited from the patients consulting the Service of Therapeutic Education for Chronic Diseases or the Service of Endocrinology at the University Hospital in Geneva. A healthy control group of 15 individuals (matched for age, height and body weight) were recruited and compared to this diabetic population (Table 4.1).

PN was evaluated by the vibration perception threshold (VPT) using a $128 \mathrm{~Hz}$ Rydel-Seiffer tuning fork at the big toe and medial malleolus of both feet [16]. The patient was requested to indicate when he could no longer feel the vibration. At this point the investigator rated the vibration on a 9-point scale (0 to 8 ). The patient was considered to have peripheral neuropathy (PN group) if the VPT was equal to, or lower than 4/8. He was assigned to the non-neuropathic group (DM group) if the VPT was superior to 4 , as 4 is the lower confidence limit for normal foot sensibility $[16,17]$. Retinopathy was evaluated by a trained ophthalmologist and by a routine fundal examination (fundoscopy).

Patients were excluded if they had concomitant foot ulcer, orthopaedic or surgical problems influencing gait parameters, Charcot foot, non-diabetes related neuropathy and/or a neurological pathology influencing gait parameters or incapacity to walk without a walking aid.

\section{Material}

Patients' gait was recorded with a Physilog system (BioAGM, CH), consisting of accelerometers and gyroscopes. The analysis of gait parameters was performed using 4 miniature gyroscopes (ADXRS 250, Analog device) attached to each shin and thigh. Each sensor measured the velocity of the angular rotation per segment around the coronal axis (flexion-extension). Signals were digitised (16 bit) at a sampling rate of $200 \mathrm{~Hz}$ by a portable data logger and stored for analysis on a memory card. Temporal parameters (including cadence, gait cycle time, stance phase and double support relative to the gait cycle) and spatial parameters (including gait speed, stride length, sagittal shin, thigh and knee range) were computed [18]. We further evaluated the stride-to-stride variability (coefficient of variation (CV) of stride length and gait cycle time).

\section{Procedure}

After signing the informed consent form, patients underwent a clinical examination, during which a trained physiotherapist checked that patients did not have foot ulcers, controlled 
blood sugar values and VPT. Each participant was then equipped with the Physilog system and was asked to walk with a preferred walking speed outdoors, in the backyard of the hospital. The walkway consisted of two $50 \mathrm{~m}$ long relatively smooth tarred pathways, two $50 \mathrm{~m}$ grass (lawn) and two $20 \mathrm{~m}$ cobblestone pathways (flat stones, 20 to $30 \mathrm{~cm}$ in diameter).

For clinical interpretation one should be aware that the tarred pathway in this study is not analogous to the level walkways used in previous indoor studies, but it can be compared to level, outdoor surfaces. Outdoor studies report higher speeds and stride length than indoor studies [19].

The reliability of diabetic patients' gait parameters on these surfaces has already been tested in a previous study [15]. Three different combinations of the order of surfaces were possible and were randomly assigned to each patient. Between each surface the patients paused for 8 to $10 \mathrm{~s}$. This time period was necessary to identify the change from one surface to another (grass, tarred pathway or cobblestones) for the Physilog system.

\section{Statistical analysis}

Statistical analyses were performed by using SPSS (SPSS for Windows rel. 15. Chicago: SPSS Inc.). The binary variable "retinopathy" was analysed using the Mann-Whitney test. The effect of diabetes and that of surfaces, as well as their interaction, were calculated with an analysis of variance (ANOVA) for repeated measures and a Bonferroni post hoc analysis. Results are expressed as means \pm standard deviations (SD). A $p$ value $\leq 0.05$ was considered as statistically significant. All data were explored for normality and we checked with a skewness kurtosis test whether the distribution was Gaussian or not. For the non-normally distributed variables, namely the CV for stride length and the CV for gait cycle time, it was necessary to perform an inverse square root transformation. The variable "gait cycle time" was normalised using an inverse square transformation.

\section{RESULTS}

\section{Group comparison}

The 3 groups were comparable for age, height and body weight $(p>0.05)$ (Table 4.1). Diabetic patients' gait parameters differed significantly $(p<0.05)$ from those of healthy controls. Post hoc analysis revealed a significant difference between healthy persons and patients without neuropathy for speed $(p=0.002)$, cadence $(p=0.003)$ and gait cycle time $(p=0.002)$. Diabetic patients with neuropathy showed significant differences in all evaluated gait parameters except for the shin angle and knee angle when compared with healthy persons. Regarding the stride-to-stride variability, we recorded a significantly higher coefficient of variation of the gait cycle time in the PN group than in the healthy control group ( $p=0.014$ ). No difference between groups was found for the CV of stride length. Between the 2 diabetic populations, i.e. with and without neuropathy, no significant difference in their gait parameter was detected (Table 4.2). 
Table 4.1. Description of the population

\begin{tabular}{|c|c|c|c|c|c|c|}
\hline \multirow[t]{2}{*}{$\begin{array}{l}\text { Participants' } \\
\text { characteristics }\end{array}$} & \multirow{2}{*}{$\begin{array}{r}\begin{array}{r}\text { Healthy } \\
\text { Persons } \\
(n=15)\end{array} \\
\text { Mean (SD) }\end{array}$} & \multirow{2}{*}{$\begin{array}{c}\begin{array}{c}\text { Without } \\
\text { Neuropathy } \\
(\mathbf{n}=15)\end{array} \\
\text { Mean (SD) }\end{array}$} & \multirow{2}{*}{$\begin{array}{c}\text { With } \\
\begin{array}{c}\text { Neuropathy } \\
(n=15)\end{array} \\
\text { Mean (SD) }\end{array}$} & \multicolumn{3}{|c|}{$\mathbf{P}$} \\
\hline & & & & $\begin{array}{l}\text { H vs } \\
\text { DM }\end{array}$ & $\begin{array}{l}\text { H vs } \\
\text { PN }\end{array}$ & $\begin{array}{l}\text { DM vs } \\
\text { PN }\end{array}$ \\
\hline Age (years) & $57.42(4.31)$ & $55.83(8.20)$ & $61.29(6.5)$ & 1 & 0.336 & 0.082 \\
\hline Height (m) & $1.73(0.10)$ & $1.72(0.12)$ & $1.67(0.0)$ & 1 & 0.500 & 0.640 \\
\hline Weight (kg) & $79.93(11.53)$ & $90.30(22.15)$ & $86.94(9.1)$ & 0.214 & 0.655 & 1.000 \\
\hline Vibration perception threshold & $6.80(0.86)$ & $5.65(1.14)$ & $2.63(1.5)$ & 0.042 & $<0.001$ & $<0.001$ \\
\hline Diabetes duration (year) ${ }^{a}$ & & $9.87(7.78)$ & $8.83(4.6)$ & & & 0.688 \\
\hline $\begin{array}{l}\text { Number of cases with diabetic } \\
\text { non-proliferative retinopathy }\end{array}$ & & 3 & 5 & & & \\
\hline
\end{tabular}

${ }^{a}$ We registered 3 missing values for these variables.

${ }^{\mathrm{b}}$ All of the 8 patients presented the background (non-proliferative) and unilateral retinopathy.

\section{Surface comparison}

Diabetic patients with, and those without, neuropathy adjusted to the variety of different surfaces using identical strategies. These strategies were similar to those used by healthy controls. In general the surface altered significantly all gait parameters (Figure 4.1). To change from a level surface (tarred pathway) to an irregular surface (cobblestones), patients with diabetes and healthy persons decreased their gait speed by reducing their cadence and increasing their gait cycle time. While changing from grass to cobblestones, again both patients and healthy subjects further decreased their speed and cadence and continued to increase their gait cycle time. Regarding stride length, all 3 groups shortened only slightly their stride length while changing from a tarred pathway to grass. When changing from grass to cobblestones, however, we observed a shortened stride length. This adaptation was more important in patients with neuropathy than in the other 2 populations. Figure 4.1 further illustrates how all 3 groups increased their thigh and knee range while changing from a tarred surface to grass and decreased it while changing from grass to cobblestones.

In contrast stance and double support time decreased while changing from the tarred surface to grass but increased again while changing from grass to cobblestones for all observed groups. Interestingly the gap between healthy controls and patients with neuropathy increased for the variables shin, knee and thigh range as well as for stance and double support time on the stony surface. Although similar strategies were used while changing from one to another surface, their effect was less marked in healthy controls than in diabetic patients. The highest surface effect was found in diabetic patients with neuropathy followed by diabetic patients without neuropathy and healthy controls. For example the alteration in the CV of the gait cycle time when changing from a tarred pathway to a cobblestone surface was significantly greater in the PN group $(p<0.05)$ than in the healthy control group. 
Table 4.2. Gait characteristics of the 3 different populations

\begin{tabular}{|c|c|c|c|c|c|c|c|c|c|}
\hline \multirow[t]{2}{*}{ Variable } & \multicolumn{3}{|c|}{ Mean (SD) } & \multicolumn{3}{|c|}{$P$ for group effect } & \multicolumn{3}{|c|}{$P$ for surface effect } \\
\hline & $\begin{array}{l}\text { Tarred } \\
\text { surface }\end{array}$ & Grass & $\begin{array}{l}\text { Cobble- } \\
\text { stones }\end{array}$ & $\begin{array}{l}\mathrm{H} \text { vs } \\
\mathrm{DM}\end{array}$ & $\begin{array}{l}\text { H vs } \\
\text { PN }\end{array}$ & $\begin{array}{l}\text { DM vs } \\
\text { PN }\end{array}$ & T vs $G$ & T vs $S$ & G vs S \\
\hline \multicolumn{10}{|l|}{ Speed $\left(\mathrm{ms}^{-1}\right)$} \\
\hline Healthy & $1.53(0.12)$ & $1.49(0.12)$ & $1.42(0.19)$ & & & & & & \\
\hline Without PN & $1.30(0.17)$ & $1.27(0.17)$ & $1.19(0.2)$ & 0.002 & $<0.001$ & 0.333 & $<0.001$ & $<0.001$ & $<0.001$ \\
\hline With PN & $1.22(0.15)$ & $1.19(0.17)$ & $1.06(0.21)$ & & & & & & \\
\hline \multicolumn{10}{|c|}{ Cadence (stridemin ${ }^{-1}$ ) } \\
\hline Healthy & $62.1(4.2)$ & $60.6(4.3)$ & $59.2(4.9)$ & & & & & & \\
\hline Without PN & $55.9(3.4)$ & $54.7(3.1)$ & $53.2(3.2)$ & 0.003 & 0.002 & 1 & $<0.001$ & $<0.001$ & $<0.001$ \\
\hline With PN & $55.9(6.2)$ & $54.6(6.5)$ & $52.0(6.5)$ & & & & & & \\
\hline \multicolumn{10}{|c|}{ Stance (\% of GCT) } \\
\hline Healthy & $58(1)$ & $58(1)$ & $58(1)$ & & & & & & \\
\hline Without PN & $60(1)$ & $59(1)$ & $60(1)$ & 0.073 & $<0.001$ & 0.112 & 0.043 & 0.136 & 0.012 \\
\hline With PN & $61(2)$ & $61(2)$ & $62(3)$ & & & & & & \\
\hline \multicolumn{10}{|c|}{ Double support (\% of GCT)* } \\
\hline Healthy & $17(2)$ & $16(2)$ & $17(2)$ & & & & & & \\
\hline Without PN & $19(2)$ & $19(2)$ & $20(2)$ & 0.073 & $<0.001$ & 0.112 & 0.043 & 0.136 & 0.012 \\
\hline With PN & $21(4)$ & $21(4)$ & $23(7)$ & & & & & & \\
\hline \multicolumn{10}{|c|}{ Gait cycle time (s) } \\
\hline Healthy & $0.97(0.06)$ & $0.99(0.07)$ & $1.02(0.08)$ & & & & & & \\
\hline Without PN & $1.08(0.06)$ & $1.1(0.06)$ & $1.13(0.07)$ & 0.002 & 0.001 & 1 & 1 & $<0.001$ & $<0.001$ \\
\hline With PN & $1.09(0.13)$ & $1.12(0.15)$ & $1.18(0.18)$ & & & & & & \\
\hline \multicolumn{10}{|l|}{ Stride $(\mathrm{m})$} \\
\hline Healthy & $1.49(0.14)$ & $1.49(0.15)$ & $1.44(0.18)$ & & & & & & \\
\hline Without PN & $1.40(0.18)$ & $1.40(0.18)$ & $1.34(0.22)$ & 0.413 & 0.009 & 0.325 & 1 & $<0.001$ & $<0.001$ \\
\hline With PN & $1.31(0.14)$ & $1.31(0.15)$ & $1.21(0.18)$ & & & & & & \\
\hline \multicolumn{10}{|c|}{ Shin range (deg) } \\
\hline Healthy & $81(5)$ & $81(6)$ & $79(7)$ & & & & & & \\
\hline Without PN & $80(6)$ & $80(6)$ & $77(8)$ & 1 & 0.062 & 0.262 & 0.489 & $<0.001$ & $<0.001$ \\
\hline With PN & $77(5)$ & $77(6)$ & $72(7)$ & & & & & & \\
\hline \multicolumn{10}{|c|}{ Knee range (deg) } \\
\hline Healthy & $62(5)$ & $64(4)$ & $63(5)$ & & & & & & \\
\hline Without PN & $63(3)$ & $64(3)$ & $62(5)$ & 1 & 1 & 1 & $<0.001$ & 1 & 0.001 \\
\hline With PN & $63(4)$ & $64(5)$ & $61(5)$ & & & & & & \\
\hline \multicolumn{10}{|c|}{ Thigh range (deg) } \\
\hline Healthy & $48(6)$ & $50(6)$ & $48(7)$ & & & & & & \\
\hline Without PN & $43(6)$ & $45(6)$ & $43(6)$ & 0.067 & 0.018 & 1 & $<0.001$ & 1 & $<0.001$ \\
\hline With PN & $42(5)$ & $44(5)$ & $42(5)$ & & & & & & \\
\hline \multicolumn{10}{|c|}{ CV Stride length (\%) } \\
\hline Healthy & $1.6(0.5)$ & $1.9(0.8)$ & $3.0(1.4)$ & & & & & & \\
\hline Without PN & $2.2(0.8)$ & $2.2(0.8)$ & $3.9(2.2)$ & 0.176 & 0.250 & 1 & 0.670 & $<0.001$ & $<0.001$ \\
\hline With PN & $2.0(0.6)$ & $2.1(0.8)$ & $4.5(2.8)$ & & & & & & \\
\hline \multicolumn{10}{|l|}{ CVGCT (\%) } \\
\hline Healthy & $1.8(0.5)$ & $2.1(0.6)$ & $2.9(0.9)$ & & & & & & \\
\hline Without PN & $2.3(0.9)$ & $2.2(0.72)$ & $3.8(1.3)$ & 0.554 & 0.014 & 0.327 & 0.952 & $<0.001$ & $<0.001$ \\
\hline With PN & $2.6(0.9)$ & $2.7(1.1)$ & $5.9(4.2)$ & & & & & & \\
\hline
\end{tabular}

$\mathrm{H}=$ healthy; $\mathrm{DM}=$ diabetes without neuropathy; $\mathrm{PN}=$ peripheral neuropathy; $\mathrm{T}=$ tarred surface; $\mathrm{G}=$ grass;

$\mathrm{S}=$ cobblestones; $\mathrm{GCT}$ = gait cycle time; $\mathrm{CV}=$ coefficient of variation.

* Double support and stance are reported in percentage of the gait cycle. 

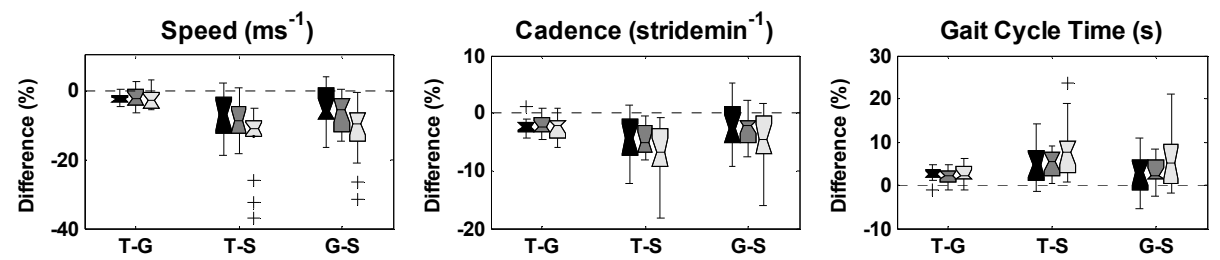

Double Support $(\% \mathrm{GC})$
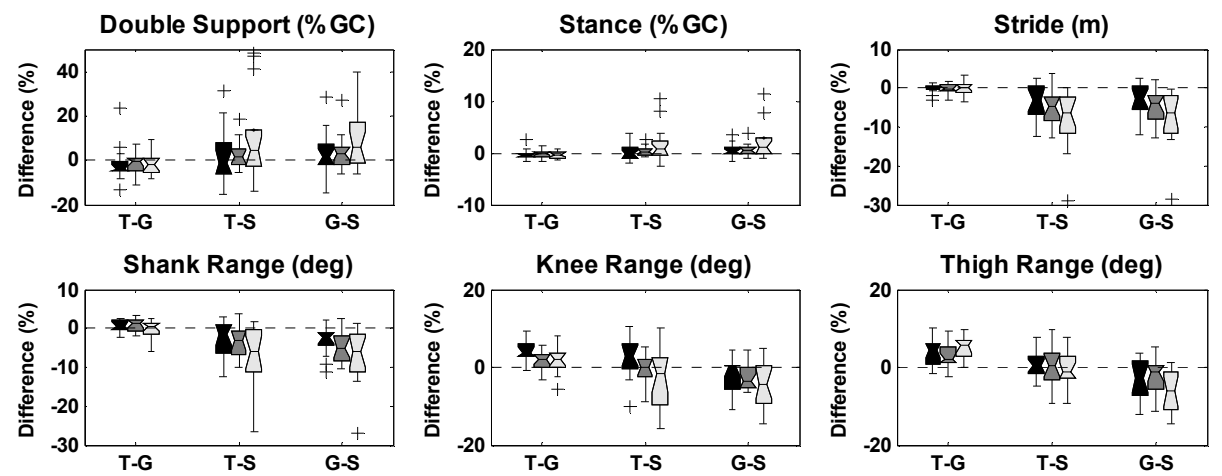

Figure 4.1. Boxplot representation of the recorded differences in gait parameters when changing from one to another surface ( $\mathrm{T}=$ tarred surface; $\mathrm{G}=$ grass; $\mathrm{S}=$ cobblestones, e.g. $\mathrm{T}$ - $\mathrm{G}=$ difference between tarred surface and Grass) for the 3 groups: healthy (black), diabetic patients without PN (dark grey) and diabetic patients with PN (clear grey). All differences are expressed in $\%$ of the reference surface value (a negative value indicates a decrease for the variable compared to the reference surface; a positive value an increase).

\section{Interaction Group - Surface}

The interaction term was statistically significant $(p=0.0028)$ for only one parameter (CV stride length). Its values on the tarred surface (with $\mathrm{PN}=2$, without $\mathrm{PN}=2.12$ ) and grass (with $\mathrm{PN}=2.1$ without $\mathrm{PN}=2.2$ ) were similar in patients with and without PN. However, patients with $\mathrm{PN}$ showed a higher CV on cobblestones (mean CV $=4.5$ ) than patients without PN (mean CV = 3.9).

\section{DISCUSSION}

The purpose of this study was to analyse gait parameters in diabetic patients and to investigate the surface effect on their walking pattern compared to healthy controls. We hypothesised that neuropathy would influence the neuromuscular control system's ability to respond to a challenging environment. We therefore considered that gait parameters would deteriorate concomitantly with the severity of the patients' diabetes and that the influence of surfaces on gait parameters would increase proportionally. Our results confirmed these hypotheses, which are in line with Ducic et al.'s [5], who described an association between loss of foot sensibility and balance in patients with peripheral neuropathy. However, our study showed that some of the diabetic patients' gait 
parameters are already significantly altered before neuropathy is clinically detected. The strategies used to change from a flat, tarred walkway to a more complex surface (grass or cobblestones) were the same, although less marked, in patients with type 2 diabetes without sensory loss. Patients' adaptation was furthermore comparable to that used by healthy controls. The decrease in speed and cadence seems to be the first adaptation (tarred surface to grass), followed by shortening of stride length (grass to cobblestones). Our findings that some gait parameters are already altered in patients without sensory loss are in line with the conclusions of Petrofsky et al. [8], who were among the first authors to identify gait alterations in a diabetic population. Similarly to their recordings performed during a gait analysis on a linear path and, making turns, we observed a significantly slower walking speed in diabetic patients without neuropathy compared to healthy controls under real life conditions. Petrofsky et al. [8] evaluated only 2 groups, healthy persons and diabetic patients without sensory loss, so we were unable to compare our findings for patients with neuropathy with theirs. To demonstrate the relationship between disease severity and gait alterations it is necessary to carry out a 3-group-comparison, as was done in this study or in that of Katoulis et al. [7]. In contrast to our and Petrofsky's et al. [8] results, Katoulis et al. [7] found no gait alterations in diabetic patients without sensory loss. Several points could explain these findings. Firstly, a flat $10 \mathrm{~m}$ surface inside a laboratory, used by Katoulis et al. [7], may not be challenging enough to reveal gait difficulties in nonneuropathic patients. Our observations demonstrate that gait alterations are more sensitively detected on irregular, rather than on flat surfaces, which is in line with the observations of Richardson et al. [20] and Menz et al. [9]. Nevertheless, Petrofsky et al. [8] still found gait alterations in patients without sensory loss although evaluating them on a linear, flat path. Secondly, in Katoulis' et al. [7] study, there was a significant difference in disease duration between patients with and without neuropathy. Their study population was also only matched for Body Mass Index, but not for height. Patients' height or the short disease duration of the non-neuropathic group could have positively influenced gait speed in these patients. Another article [21], not actually evaluating spatiotemporal gait parameters but the distribution of plantar pressure during walking on a level gradient, revealed other significant alterations in type 2 diabetic patients without either peripheral neuropathy or peripheral vascular disease. The non-neuropathic population showed a significant increase in peak plantar pressure at the level of the big toe and 5th metatarsal head as well as significantly prolonged duration of plantar pressure compared to healthy controls. The authors concluded that these plantar pressure alterations could be premature signs of peripheral neuropathy.

Our results show that a challenging environment could reveal gait alterations better than a level surface. We also demonstrated that gait is already altered in diabetic patients without sensory loss. The decreased gait speed in diabetic patients compared to healthy controls is not only statistically significant but also of great clinical relevance. A decrease of $0.36 \mathrm{~ms}^{-1}$ represents a reduction of $25 \%$ compared to normal walking speed $\left(1.53 \mathrm{~ms}^{-1}\right)$. It is very likely that such a reduction in gait speed could influence individuals' activities of daily living [22]. In addition to the decreased walking speed and the alteration of other gait abnormalities, both patients with and without neuropathy showed a tendency to increase stride-to-stride variability. This parameter is reported to be related to a heightened fall risk 
[23]. For this reason, if gait analysis is included in the assessment of diabetic patients and if increased stride-to-stride variability is detected, clinicians should take it as a warning sign. The application of prevention strategies is thus shown to be imperative. Although we identified gait abnormalities in both patient groups (with and without neuropathy) the deterioration of gait parameters increases with disease severity (neuropathy). Patients with neuropathy have the most trouble adapting their gait to irregular surfaces when compared to those without neuropathy, or healthy controls. The possible causes of these gait alterations could include small fibre damage, which is undetected on clinical examination [24], impaired sight or simple retinopathy [25], leading to difficulty seeing details [26], vestibular disorders, or a combination of several of these factors. Longer disease duration may aggravate metabolic disorders, thus increasing fibre damage.

Our subjects' sight was regularly checked. We also compared the disease duration and the number of patients presenting retinopathy, but there was no significant difference between the group of patients with neuropathy and those without (Table 4.1 about population description). None of the patients reported vestibular problems. Further investigations should now evaluate the association between sensory loss, increased gait alterations and the risk of falls. With this intention in mind, Ducic et al. [5] evaluated the relationship between loss of foot sensitivity and balance in patients with PN with a pressure-specified sensory device (PSSD). They found a correlation coefficient between sway (degree to which the person moves while attempting to stand still) and foot sensitivity of 0.36. However, the VPT [16] we used to attribute patients to either the neuropathic or non-neuropathic group did not permit us to study such a relationship. For this reason a more sensitive sensory examination for example the PSSD or electroneuromyography [24] would have been necessary. Furthermore, other possible factors for heightened fall risk, such as muscle weakness or a decrease in joint mobility should be considered.

\section{CONCLUSIONS}

Walking in real life conditions revealed gait difficulties in patients with type 2 diabetes before neuropathy was clinically detectable. The strategies used by patients while changing from a flat, tarred walkway to a more challenging surface (grass or cobblestones) were similar between patients with and without sensory loss. Clinicians should therefore be aware that diabetic individuals' gait capacity decreases and fall risk increases in an early stage of the disease. 


\section{REFERENCES}

1. Miller DK, Lui LY, Perry HM 3rd, Kaiser FE, Morley JE: Reported and measured physical functioning in older inner-city diabetic African Americans. J Gerontol A Biol Sci Med Sci 54:230-236, 1999.

2. Kwon OY, Minor SD, Maluf KS, Mueller MJ: Comparison of muscle activity during walking in subjects with and without diabetic neuropathy. Gait Posture 18:105-113, 2003.

3. Allet L, Armand S, Golay A, Monnin D, de Bie RA, de Bruin ED: Gait characteristics of diabetic patients: a systematic review. Diabetes Metab Res Rev 24:173-191, 2008.

4. Cavanagh PR, Derr JA, Ulbrecht JS, Maser RE, Orchard TJ: Problems with gait and posture in neuropathic patients with insulin-dependent diabetes mellitus. Diabet Med 9:469-474, 1992.

5. Ducic I, Short KW, Dellon AL: Relationship between loss of pedal sensibility, balance, and falls in patients with peripheral neuropathy. Ann Plast Surg 52:535-540, 2004.

6. Richardson JK: Factors associated with falls in older patients with diffuse polyneuropathy. J Am Geriatr Soc 50:1767-1773, 2002.

7. Katoulis EC, Ebdon-Parry M, Lanshammar H, Vileikyte L, Kulkarni J, Boulton AJ: Gait abnormalities in diabetic neuropathy. Diabetes Care 20:1904-1907, 1997.

8. Petrofsky J, Lee S, Bweir S: Gait characteristics in people with type 2 diabetes mellitus. Eur J Appl Physiol 93:640-647, 2005.

9. Menz HB, Lord SR, St George R, Fitzpatrick RC: Walking stability and sensorimotor function in older people with diabetic peripheral neuropathy. Arch Phys Med Rehabil 85:245-252, 2004.

10. Richardson JK, Thies SB, DeMott TK, Ashton Miller JA: Interventions improve gait regularity in patients with peripheral neuropathy while walking on an irregular surface under low light. J Am Geriatr Soc 52:510-515, 2004.

11. Freiberger E, Menz HB: [Characteristics of falls in physically active community-dwelling older people: findings from the "Standfest im Alter" study] in German. Z Gerontol Geriatr 39:261-267, 2006.

12. Morley JE: Falls - where do we stand? Mo Med 104:63-67, 2007.

13. Hausdorff JM, Rios DA, Edelberg HK: Gait variability and fall risk in community-living older adults: a 1-year prospective study. Arch Phys Med Rehabil 82:1050-1056, 2001.

14. Kerrigan DC, Lee LW, Nieto TJ, Markman JD, Collins JJ, Riley PO: Kinetic alterations independent of walking speed in elderly fallers. Arch Phys Med Rehabil 81:730-735, 2000.

15. Allet L, Armand S, de Bie RA, Golay A, Monnin D, Aminian K, de Bruin ED: Reliability of diabetic patients' gait parameters in a challenging environment. Gait Posture 28:680-686, 2008.

16. Kastenbauer T, Sauseng S, Brath H, Abrahamian H, Irsigler K: The value of the Rydel-Seiffer tuning fork as a predictor of diabetic polyneuropathy compared with a neurothesiometer. Diabet Med 21:563-567, 2004.

17. Liniger C, Albeanu A, Bloise D, Assal JP: The tuning fork revisited. Diabet Med 7:859-864, 1990.

18. Aminian K, Najafi B, Bula C, Leyvraz PF, Robert P: Spatio-temporal parameters of gait measured by an ambulatory system using miniature gyroscopes. J Biomech 35:689-699, 2002.

19. Kirtley C (2006): Clinical Gait Analysis: Theory and Practice, Edinburgh: Elsevier Churchill Livingstone; p. 23.

20. Richardson JK, Thies SB, DeMott TK, Ashton-Miller JA: Gait analysis in a challenging environment differentiates between fallers and nonfallers among older patients with peripheral neuropathy. Arch Phys Med Rehabil 86:1539-1544, 2005.

21. Pataky Z, Assal JP, Conne P, Vuagnat H, Golay A: Plantar pressure distribution in Type 2 diabetic patients without peripheral neuropathy and peripheral vascular disease. Diabet Med 22:762-767, 2005.

22. Judge JO, Schechtman K, Cress E: The relationship between physical performance measures and independence in instrumental activities of daily living. The FICSIT Group. Frailty and Injury: Cooperative Studies of Intervention Trials. J Am Geriatr Soc 44:1332-1341, 1996.

23. Hausdorff JM, Peng CK, Goldberger AL, Stoll AL: Gait unsteadiness and fall risk in two affective disorders: a preliminary study. BMC Psychiatry 4:39, 2004.

24. Ovayolu N, Akarsu E, Madenci E, Torun S, Ucan O, Yilmaz M: Clinical characteristics of patients with diabetic polyneuropathy: the role of clinical and electromyographic evaluation and the effect of the various types on the quality of life. Int J Clin Pract 62:1019-1025, 2008.

25. Kennedy PM, Cressman EK, Carlsen AN, Chua R: Assessing vestibular contributions during changes in gait trajectory. Neuroreport 16:1097-1100, 2005.

26. Perry SD, Santos LC, Patla AE: Contribution of vision and cutaneous sensation to the control of centre of mass (COM) during gait termination. Brain Res 913:27-34, 2001. 



\section{Chapter 5}

\section{Investigation of standing balance in diabetic patients with and without peripheral neuropathy using}

accelerometers

Turcot K. ${ }^{1}$

Allet L. ${ }^{2,3}$

Golay A. ${ }^{4}$

Hoffmeyer P. ${ }^{5}$

Armand $\mathrm{S}^{1}$

Article published in Clinical Biomechanics 24(9):716-21, 2009

${ }^{1}$ Willy Taillard Laboratory of Kinesiology, Geneva University Hospital and Geneva University, Geneva, Switzerland.

2 Department of Neuroscience, Geneva University Hospital and University of Geneva, Geneva, Switzerland.

3 Department of Epidemiology, Maastricht University and Caphri Research School, Maastricht, The Netherlands.

${ }^{4}$ Service of Therapeutic Education for Chronic Diseases, WHO Collaborating Centre, Geneva University Hospitals and Geneva University, Geneva, Switzerland.

${ }^{5}$ Department of Orthopaedic Surgery, Geneva University Hospital and Geneva University, Geneva, Switzerland. 


\section{SUMMARY}

\section{Background}

Peripheral neuropathy is acknowledged to be the most symptomatic complication of diabetes. Moreover, it is also linked to postural instability. No study has yet evaluated the balance instability of diabetic patients using accelerometers. In addition, no balance study has explored the combination of accelerometers fixed at lumbar and ankle levels, which could bring additional insights into distal balance instability in diabetic patients.

\section{Aims}

The aim of the present study was to investigate the standing balance of type 2 diabetic patients with and without peripheral neuropathy using accelerometers.

\section{Methods}

Quiet standing balance was investigated using an accelerometric-based method in 24 diabetic patients ( 12 with and 12 without peripheral neuropathy) compared with 12 control subjects. Accelerations were measured at lumbar and ankle levels using 3 accelerometers. Two standing conditions of $30 \mathrm{~s}$ were evaluated (i.e. eyes open, eyes closed). The range and root mean square values were calculated on the anterior posterior component of lumbar and ankle accelerations and for the medial lateral component of lumbar accelerations. Differences between parameters were compared between groups using analysis of variance and post hoc comparisons.

\section{Results}

Diabetic patients with peripheral neuropathy show higher range and root mean square values compared with those of control subjects and diabetic individuals without peripheral neuropathy. Significant differences between groups have been detected for anterior posterior range of lumbar acceleration, which was significantly higher for diabetic patients with peripheral neuropathy, compared with those of other groups. Significantly higher values for diabetic patients with peripheral neuropathy were also detected for anterior posterior range and root mean square of ankle accelerations compared with control subjects. Visual deprivation shows an increase in accelerometric parameters for each group.

\section{Discussion and conclusion}

This study is the first to investigate diabetic individuals' balance instability using accelerometers. Results confirm that diabetic patients with peripheral neuropathy have greater postural instability with higher acceleration values than those of a control group and diabetic patients without peripheral neuropathy. 


\section{INTRODUCTION}

In $2002,2.8 \%$ of the population was reported to suffer from diabetes. This proportion is estimated to increase to $4.4 \%$ in 2030 [1]. The main factors associated with the burden of this disease are obesity, increase in inactivity as well as the ageing of the population [1]. Amongst all patients diagnosed with diabetes and older than 60 years of age, approximately $50 \%$ is affected by peripheral neuropathy (PN), known to be the most symptomatic complication of this disease [2]. In the presence of diabetic PN plantar cutaneous and proprioception sensations are compromised [3], which together can result in postural instability and an increased risk of falling [4].

Postural control is a complex motor skill that involves mechanical and physiological aspects, linked together to maintain balance and prevent falls [5]. Recently, a framework has illustrated the numerous resources involved in the maintainance of postural stability and orientation [6]. Biomechanical constraints, movement and sensory strategies, orientation in space, control of dynamics, and cognitive processing were described as the main components. When one of these elements is impaired, postural stability is compromised. In diabetic PN, the possible loss of muscle spindle function, the decrease in plantar cutaneous sensation as well as the decline in the perception of movement may alter the sensory strategies required to maintain postural stability [3].

Although postural control during upright standing has been extensively studied in literature, the nature of its control mechanisms is still controversial [7]. The global approach of postural control supposes that in a quiet standing position, the entire body acts as an inverted pendulum around the centre of rotation of the ankles [8], which supposes a passive process. The other approach considers the nature of quiet stance as multi-segmental, which implies a constant and active reaction of the central nervous system (CNS) [7, 9]. The latter suggests that multiple strategies (i.e. various body configurations), which depend on multiple body segments, are used to maintain proper balance [9].

Postural stability is mostly investigated with force plates (FPs), using the measurement of the centre of pressure (COP) displacement [8]. The major measures extracted from the COP during standing are the COPnet and the total excursion of the COP in medial lateral (ML) and anterior posterior (AP) directions. Ankle and hip postural strategies using inverse dynamic calculations, sway area, as well as the scalar distance between the COP and the centre of mass (COM) are also reported (see review written by Bonnet et al. [10]).

In diabetic patients with $\mathrm{PN}$, the presence of postural instability has been well documented in biomechanical studies [11-18]. All the cited studies reported higher instability during standing in diabetic patients with PN compared with diabetic patients without PN and healthy control subjects. Larger COPnet [14], higher sway area [15, 17, 18], larger COP-COM distances in ML and AP directions [12] and higher instability during quiet standing with eyes closed $[12,16]$ have been reported. A reduction of the ankle strategy compensated by a greater use of hip strategy $[14,17]$ has also been described in patients with PN. More recently, Kanade et al. [13] evaluated balance in diabetic patients with PN at different stages of foot complications. Their results have shown a decrease in postural stability in 
diabetic patients with PN alone compared with patients with a partial foot amputation, based on larger COP excursion in the AP direction.

Although the conventional method is to use FPs to investigate postural control, miniature sensors such as accelerometers is becoming widely used and accepted for the evaluation of human motion in clinical settings [19]. The use of body-mounted accelerometers also allows the measurement of linear accelerations at different reference points over the body [20]. In recent years, the measurement of ML and AP trunk accelerometry data has been validated and compared with FPs [20] as well as recommended to investigate balance control (i.e. body sway) [21]. Accelerometry data could not be directly compared to COP parameters; however, they could be validated and used as an objective measure that can discriminate between different conditions challenging the balance control system [21]. Using an accelerometer fixed near the centre of mass (COM), trunk accelerometry data show good discriminative validity during standing. The root mean square (RMS) value of the accelerometric signal was used as the main parameter to discriminate young from elderly subjects during different standing conditions (i.e. quiet standing with eyes open, quiet standing with eyes closed and quiet standing on a compliant mat). Authors reported higher instability in elderly and in more perturbed conditions with larger RMS values [21]. More recently, the evaluation of body sway in participants with different athletic levels has been investigated [22] using a method similar to the one presented by Moe-Nilssen and Helbostad [21].

To the best of our knowledge, no study has yet evaluated the balance instability of diabetic patients using accelerometers [10]. In addition, no balance study has explored the combination of accelerometers fixed at lumbar and ankle levels, which could bring additional insights into distal balance instability in diabetic patients.

The aim of the present study was therefore to investigate the standing balance of type 2 diabetic patients with and without PN, using accelerometers fixed at both near the COM and at ankle levels. We also evaluated how sight affects each group during a quiet standing condition. Based on previous studies, we expected to find higher acceleration signals in diabetic patients compared with asymptomatic participants as well as higher accelerations in patients with PN compared with diabetic patients without PN. Higher values are also expected for the eyes closed condition.

\section{METHODS}

\section{Subjects}

A total of 36 participants were included in this study (12 controls and 24 diabetic type 2 patients). The diabetic patients were separated into 2 groups: diabetic patients without PN (DM; $n=12$ ) and with PN (DPN; $n=12)$. The descriptive characteristics of the participants are presented in Table 5.1. Patients were included if they were diagnosed with diabetes type 2 with a blood sugar greater than $7.0 \mathrm{mmoll}^{-1}$ in the fasting state. The presence of PN was diagnosed by a vibration perception threshold (VPT) of both big toes and medial malleoli using the Rydel-Seiffer $128-\mathrm{Hz}$ tuning fork [23]. For each specific point, the patients 
were asked to specify when they could no longer feel the vibration. The investigator rated the vibration on a 9-point grading scale (0-8). A patient was considered to have PN if the VPT was equal to, or lower than $4 / 8[23,24]$. Patients were excluded if they had foot ulcer, a non-diabetic neuropathy (i.e. due to Charcot-Marie-Tooth disease, alcohol or thyroid dysfunction) or a past history of orthopaedic, surgical or neurological conditions, which could influence the evaluation. All control participants included in the study present no past history of orthopaedic, surgical or neurological conditions. The study protocol was approved by institutional ethics committees. All participants gave their written consent to participate in this study.

\section{Instrumentation}

The Physilog ${ }^{\circledR}$ system (BioAGM, CH) was used to measure linear accelerations at trunk and ankle levels. A tri-axial accelerometer (type ADXL202, range $\pm 2 \mathrm{~g}$; Analog Devices, Norwood, USA) was taped on a sacral belt at the level of lumbar segments L5-S1. Two biaxial accelerometers (type ADXL210, range \pm 5 g; Analog Devices, Norwood, USA) were taped on the anterior face of the right and left shins just up to both malleoli and were oriented in AP and vertical (V) directions (Figure 5.1). All data were recorded simultaneously at a frequency of $200 \mathrm{~Hz}$.

Figure 5.1. Experimental setup during the quiet standing tasks, showing the position and orientation of accelerometers at lumbar and ankle levels.

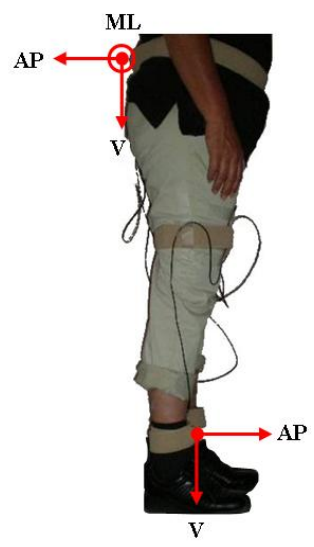

\section{Procedure}

The participant was first equipped with accelerometers. Then the Performance-Oriented Mobility Assessment scale for balance (POMA-B) [25] was performed. The POMA-B represents an evaluation of the balance skills based on 9 tasks (i.e. sitting balance, arises, attempts to arise, immediate standing balance, standing balance $1 \mathrm{~min}$ with eyes open, nudged, standing balance 1 min with eyes closed, turning 360 deg and sitting down). This test was developed and validated first to evaluate the risk of falling [26], but it is now largely used to evaluate balance disorders in the elderly [27]. The maximal score of the 
POMA-B test is 16 , which means no balance deficit, whereas the minimum score (i.e. 0 ) means a complete instability. All participants wore flat-soled shoes during testing and no restriction for feet position was imposed. The chosen position remained the same between the eyes open and eyes closed conditions.

\section{Data analysis}

Acceleration signals were analysed for the eyes open (EO) and eyes closed (EC) standing conditions obtained during the POMA-B test. From the 1 min collected data at both conditions, $30 \mathrm{~s}$ were kept for data analysis (the first and last $15 \mathrm{~s}$ were removed). All signal processing was performed using MATLAB 7.4.0 (The MathWorks: USA, Inc.). The tilt of accelerometers, considered as an undesirable source of variability, has been corrected using the method described by Moe-Nilssen and Helbostad in 2002 [21]. Then, a third-order Savitzky-Golay filter was applied to smooth the accelerometer signals [28] without affecting the signal pattern and magnitude. Linear acceleration range (i.e. maximum minus minimum) and RMS have been calculated for the AP and $M L$ components of the accelerometer fixed at the lumbar level (lumbar ${ }_{\text {acc }}$ ) and for the AP component of both accelerometers fixed at the ankle levels (ankle ${ }_{a c c}$ ). Range and RMS parameters have demonstrated good discriminative capacity in previous balance accelerometric-based studies [21, 29-31]. Since no difference has been detected between right and left ankle accelerations, parameters have been averaged for further analysis.

\section{Statistical analysis}

Statistical analysis was performed using STATISTICA 8.0 (StatSoft 8.0: USA, Inc.). Comparisons between group characteristics in terms of age, height, weight and Body Mass Index (BMI) were performed using analysis of variance (ANOVA). Comparisons between conditions (i.e. eyes open and eyes closed) for each group on accelerometric parameters were performed using paired- $t$ tests or Wilcoxon Matched Pairs test for parameters that had a non-normal distribution. Comparisons between groups on accelerometric parameters for each specific condition (i.e. eyes open or eyes closed) were then performed using ANOVA. For all accelerometric variables that had a non-normal distribution and the POMA$B$ test, a Kruskal-Wallis ANOVA was performed. For significant main effects (i.e. $p<0.05$ ), post hoc tests were performed to determine which groups were significantly different from others. The effect sizes (ES) using the partial Eta squared $\left(h_{p}{ }^{2}\right)$ were also calculated to evaluate the strength of the effect. The ES represents the proportion of the effect $\left(\mathrm{SS}_{\text {effect }}\right)+$ error variance $\left(\mathrm{SS}_{\text {error }}\right)$ that is related to the effect [32].

$\mathrm{h}_{\mathrm{p}}{ }^{2}=\mathrm{SS}_{\text {effect }} /\left(\mathrm{SS}_{\text {effect }}+\mathrm{SS}_{\text {error }}\right)$ 


\section{RESULTS}

No difference has been detected between groups in terms of age, height and weight (Table 5.1). The BMI was, however, significantly different between groups $(p=0.02)$. Coefficients of correlation between acceleration parameters and BMI were calculated to determine BMI's effect on accelerometric parameters. Results show that the BMI has no influence on any parameters with correlation coefficients ranging from 0.01 to 0.31 . In addition, since the number of male and female was not equivalent between groups, statistical analysis was performed including gender as covariate. Results show that gender has no effect on differences obtained between groups. The results presented in the next section were therefore obtained without using any covariate.

Table 5.1. Descriptive characteristics of each group presented by means and standard deviation values

\begin{tabular}{lclllll}
\hline & $\begin{array}{c}\text { Gender } \\
(\mathrm{m} / \mathrm{f})\end{array}$ & $\begin{array}{l}\text { Age (years) } \\
\text { Mean (SD) }\end{array}$ & $\begin{array}{l}\text { Height (m) } \\
\text { Mean (SD) }\end{array}$ & Mean (SD) & Mean (SD) & Mean (SD) \\
\hline Control subjects & $7 / 5$ & $55.3(7.0)$ & $1.70(0.11)$ & $78.4(15.3)$ & $26.8(3.2)$ & $14.3(1.4)$ \\
Diabetic patients without PN & $10 / 2$ & $56.1(8.3)$ & $1.71(0.11)$ & $89.4(15.6)$ & $30.4(3.8)$ & $13.5(2.0)$ \\
Diabetic patients with PN & $8 / 4$ & $60.2(5.2)$ & $1.67(0.09)$ & $86.3(9.7)$ & $30.9(4.0)^{\mathrm{a}}$ & $12.0(1.7)$ \\
\hline
\end{tabular}

${ }^{a}$ Indicates a significant difference between the control and the DPN group $(p<0.05)$.

\section{Differences between conditions}

All groups show higher AP acceleration ranges during the quiet standing task with EC compared with the EO condition (Table 5.2). The control group (CG) increased lumbar acc $_{\text {of }}$ $12.8 \%$ and ankle $e_{\text {acc }}$ of $8.1 \%$ between both conditions whereas the DM and DPN groups increased lumbar acc $_{\text {of }} 11.4 \%$ and $27.6 \%$ and increased ankle $e_{\text {acc }}$ of $36.1 \%$ and $22.6 \%$ respectively. The $\mathrm{ML}$ component of lumbar ${ }_{\text {acc }}$ remained about the same between EO and EC conditions. Excepted for the AP range of the ankle acc $_{\text {in }}$ the DM group, all increases were non-significant.

\section{Differences between groups}

Quiet standing with eyes open

Significant group effects have been detected for the AP range of the lumbar ${ }_{\text {acc }}$ and for the $A P$ range and AP RMS of the ankle acc parameters (Table 5.2). Post hoc tests revealed that AP range of the lumbar ${ }_{\text {acc }}$ were significantly higher for the DPN group than that for the CG $(p=$ 0.001 ; $E S=0.40$ ) and for the DM group $(p=0.017 ; E S=0.23$ ) (Figure 5.2a). Significant differences between control and DPN groups were also detected for AP range $(p=0.02$; ES

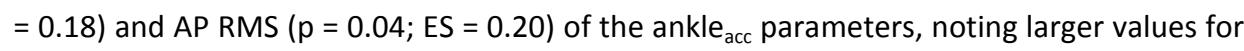
the DPN group (Figure $5.2 \mathrm{~b}$ ).

Quiet standing with eyes closed

Significant group effects have been detected in 5 parameters: AP range of the lumbar ${ }_{\mathrm{acc}} \mathrm{ML}$ range and RMS values of the lumbar ${ }_{\text {acc }}$ and AP range and RMS values of the ankle acc (Table 
5.2). Post hoc tests showed significant higher AP range of the lumbar ${ }_{\text {acc }}$ for the DPN group compared with that of the CG $(p=0.005 ; E S=0.29)$ and the DM group $(p=0.022 ; E S=0.22)$ (Figure 5.2a). For the ML range of the lumbar ${ }_{\text {acc, }}$ significant difference was noticed between DM and DPN groups ( $p=0.04$; ES = 0.26), with higher-range values for the DPN group. For the ML RMS of the lumbar ${ }_{a c c}$, significant higher value was found for the DPN group compared with that of the CG $(p=0.02 ; E S=0.24)$ and the DM group $(p=0.01 ; E S=0.27)$. As for the quiet standing with EO, significant differences between control and DPN groups were obtained for the AP range $(p=0.02 ; E S=0.23)$ and AP RMS $(p=0.01 ; E S=0.25)$ of the ankle $_{\text {acc }}$ parameters (Figure $5.2 \mathrm{~b}$ ).

Table 5.2. Results of lumar and ankle accelerations during quiet standing with eyes open and eyes closed

\begin{tabular}{|c|c|c|c|c|c|c|}
\hline & \multirow[t]{2}{*}{ Variable } & \multirow{2}{*}{$\begin{array}{c}\begin{array}{c}\text { Control } \\
\text { subjects }\end{array} \\
\text { Mean (SD) }\end{array}$} & \multirow{2}{*}{$\begin{array}{c}\begin{array}{c}\text { Diabetic } \\
\text { patients } \\
\text { without PN }\end{array} \\
\text { Mean (SD) }\end{array}$} & \multirow{2}{*}{$\begin{array}{l}\text { Diabetic } \\
\text { patients } \\
\text { with PN } \\
\text { Mean (SD) }\end{array}$} & \multicolumn{2}{|c|}{$\begin{array}{c}\text { Differences between } \\
\text { groups }\end{array}$} \\
\hline & & & & & $P$ & Effect size \\
\hline \multirow{5}{*}{ 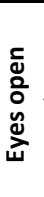 } & Lumbar acceleration $\left(\mathrm{g} \times 10^{-3}\right)$ & & & & & \\
\hline & AP RMS & $7(2)$ & $8(2)$ & $9(3)$ & 0.080 & 0.14 \\
\hline & ML RMS & $4(1)$ & $4(1)$ & $6(3)$ & 0.079 & 0.21 \\
\hline & Ankle acceleration $\left(\mathrm{g} \times 10^{-3}\right)$ & & & & & \\
\hline & AP RMS & $6(3)$ & $6(2)$ & $9(4)$ & $0.041^{a b}$ & 0.22 \\
\hline \multirow{5}{*}{ 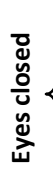 } & Lumbar acceleration $\left(\mathrm{g} \times 10^{-3}\right)$ & & & & & \\
\hline & AP RMS & $7(2)$ & $8(3)$ & $12(6)$ & 0.055 & 0.24 \\
\hline & Ankle acceleration $\left(\mathrm{g} \times 10^{-3}\right)$ & & & & & \\
\hline & ML RMS & $4(1)$ & $3(1)$ & $5(2)$ & $0.006^{a b c}$ & 0.26 \\
\hline & AP RMS & $6(3)$ & $7(2)$ & $10(4)$ & $0.015^{a b}$ & 0.22 \\
\hline
\end{tabular}

p corresponds to the between-group effect.

${ }^{a}$ Significant difference between groups with a $p$ value $<0.05$.

${ }^{\mathrm{b}}$ Significant difference between control and diabetic patients with PN with a $p<0.05$.

${ }^{\mathrm{c}}$ Significant difference between diabetic patients without and with $\mathrm{PN}$ with a $\mathrm{p}<0.05$.
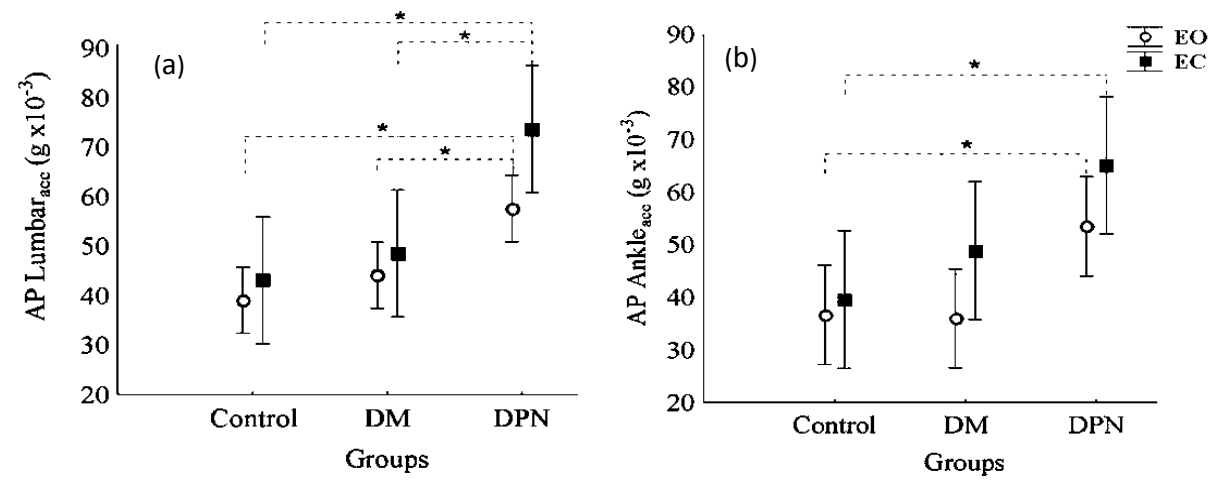

Figure 5.2. Anterior posterior (AP) acceleration range at the lumbar (a) and ankle (b) levels for the eyes open (EO) and eyes closed (EC) quiet standing conditions. Significant differences $(p<0.05)$ between control group, diabetic group without peripheral neuropathy (DM) and with peripheral neuropathy (DPN) are indicated with an asterisk $\left({ }^{*}\right)$. 


\section{POMA-B test}

A significant group effect has been found for the POMA-B test $(p=0.007)$. The CG had the higher mean score with 14.3, DM had 13.5 and DPN had the lower score with 12. Post hoc test revealed a significant difference between control and DPN group $(p=0.006 ; E S=0.39)$.

\section{DISCUSSION}

The objective of the present study was to evaluate the standing balance of diabetic patients with and without PN using accelerometers in 2 specific quiet standing conditions (i.e. EO and $\mathrm{EC}$ ). We expected diabetic patients with $\mathrm{PN}$ to have greater balance instability than control subjects and diabetic patients without PN. The results obtained in the present study confirm our hypotheses with significant higher range and RMS acceleration values in the DPN group. Lower score for the POMA-B test was also found in the DPN group, which is related to a greater instability during the standing tasks compared with that of the other groups. The larger amplitude and variability in the accelerometric signal for the DPN group could be associated with higher balance deficit [21, 29] or different postural control strategies adopted to maintain proper balance [6]. In this study, all participants chose a comfortable position to perform quiet standing test with EO. This position remained the same after removing visual inputs (i.e. quiet standing with eyes closed). Thus, the differences obtained in the accelerometric signal between both conditions could be attributed to vision deprivation. As we hypothesised, higher accelerations for each group were detected during the EC condition compared with those during that of EO. Similar results were found in another accelerometric-based study comparing healthy young and older adults [21].

No significant difference has been detected between control subjects and diabetic patients without PN. However, a trend to increase lumbar acceleration compared with CG was observed (Figure 5.2a). As described by Centomo et al. [11] a more destabilising task may have been able to detect differences between groups; however, this was beyond the scope of this article.

Several aspects are involved in postural control and thus in the capacity to maintain body equilibrium under static and dynamic conditions. It is well known that the most important aspect of balance control resides in the size and quality of base of support (i.e. feet). As reported [33] any modification in size, strength, range, pain or control of the feet will compromise balance. The onset of balance instability in diabetic patients is closely linked to the appearance of PN, which is characterised by somatosensory deficits. Complications induced by PN (i.e. decline in cutaneous sensation under feet and proprioception) will therefore lead to a reduction in the quality of information transmitted to the CNS, needed to maintain adequate balance [6]. Even though there is no important perturbation during quiet standing, the body equilibrium is still dependant of the vestibular, visual and sensory systems' integrity. As previously reported, if the integrity of one system is compromised, as it is because of the complications induced by PN, the other systems will be more solicited. In fact, interesting results were found during the quiet standing condition without visual 
inputs. The greatest difference was observed for the DM group with a significant increase of $36 \%$ for the AP range of the ankle acceleration compared with an increase of $22 \%$ and $8 \%$ for the DPN and CG, respectively. We can assume that diabetic patients with PN may have compensated their cutaneous sensory loss by increasing dependence on visual inputs [34]. We can also speculate that if diabetic patients without PN presented early signs of PN, which are not yet detectable clinically, they will use more visual inputs compared with the control subjects. Thus, when visual inputs were removed, their stability was even more compromised.

Besides the measurement of trunk accelerometry data, which has been previously recommended to evaluate body sway, this study also explored the measurement of accelerations at ankle level. Since postural control is described as a complex skill which integrates the interaction of dynamic sensorimotor processes [6], a multi-segmental approach seemed more appropriated for its investigation. For this reason, this study explored the measurement of accelerations at 2 specific levels to observe if it could bring new insights into the balance instability in diabetic patients. Our results show that control subjects as well as diabetic patients with and without PN use both ankle and lumbar sway to maintain balance. Moreover, all groups tend to increase range and RMS values at both levels during standing with EC compared with EO. However, our results clearly demonstrate higher acceleration values at both levels in the DPN group. An AP lumbar acceleration range greater than $49 \%$ and $32 \%$ in the DPN group was obtained compared with that in the control and the DM groups, respectively. An AP ankle acceleration range greater than $43 \%$ and $47 \%$ was also found in the DPN group compared with that in the control and the DM groups. It is recognised that diabetic patients with PN have distal muscle weakness, especially at ankle and knee [35]. During quiet standing, both proprioceptive dysfunctions as well as muscle weakness could have accounted for postural instability. The reduction of the muscle control next to the ankle joint could have lead to a greater solicitation of movements near the COM, increasing accelerations at both levels more than those in the other groups (i.e. control and DM). During quiet standing with EC, the DPN group had also demonstrated higher lumbar range accelerations compared with the one obtained at ankles. Further accelerometric-based balance studies are needed to evaluate the relationship of each accelerometry data level with clinical factors (e.g. muscle weakness, joint mobility) involved in PN during quiet standing and in more perturbed conditions.

Several studies have shown that diabetic patients with PN have poor stability compared with control subjects and diabetic patients without PN using COP parameters [12-14, 17, $18,36,37]$. The results found in this study support these findings. Moreover, this study confirms the potential of accelerometers to be used in the investigation of balance instability as previously reported [21, 29-31]. Furthermore, accelerometers can be fixed at different levels of the human body, adding more information on the multi-segmental nature of quiet stance.

This study had, however, some limitations that should be taken into consideration. First, neuropathy was clinically diagnosed by the VPT which could be influenced by the interrater variability as well as the experience of the investigator. In the present study, we were careful that only one trained investigator did the VPT evaluation for all patients. In addition, the VPT has also been recently recommended for routine screening of diabetic neuropathy 
[23]. Secondly, the ankle accelerations have been recorded only in the sagittal plane (i.e. AP component), since the most important movement of the ankle joint relies on the sagittal plane. However, ML ankle accelerations would have been of interest to compare their magnitudes with the one obtained at the lumbar level. Another limitation is due to the free feet position during testing. The fact that each subject chose his or her own feet position might have reduced or even eliminated differences between groups for some parameters. We can however speculate that if all subjects have selected their optimal feet position during the EO and EC balance testing (i.e. a position for optimal balance), differences between groups would have been even more important with an imposed feet placement. Further balance studies using accelerometers should also focus their analysis on more destabilising tasks, such as different perturbed standing conditions or walking on different surfaces, which have previously shown differences between diabetic patients with and without PN [38].

\section{CONCLUSIONS}

This study is the first to have investigated the balance instability of diabetic patients with and without PN using accelerometers. The simple accelerometric-based method used in this study demonstrated an interesting potential to evaluate the balance skills of diabetic patients. With the burden of cost related to diabetic disease, the development of parameters that could be used in clinics to evaluate and follow diabetic patients is essential to detect early signs of instability and thus help in therapeutic planning managements. 


\section{REFERENCES}

1. Wild S, Roglic G, Green A, Sicree R, King H: Global prevalence of diabetes: estimates for the year 2000 and projections for 2030. Diabetes Care 27:1047-1053, 2004.

2. van Schie CH: Neuropathy: mobility and quality of life. Diabetes Metab Res Rev 24 Suppl 1:45-51, 2008.

3. van Deursen RW, Simoneau GG: Foot and ankle sensory neuropathy, proprioception, and postural stability. J Orthop Sports Phys Ther 29:718-726, 1999.

4. van Deursen R: Footwear for the neuropathic patient: offloading and stability. Diabetes Metab Res Rev 24 Suppl 1:96-S100, 2008.

5. Horak F, Macpherson J: Postural orientation and equilibrium. HandBook of Physiology: Section 12, Exercise Regulation and Integration of Multiple Systems, ed. S.J. Rowell LB. 1996, New York: Oxford University Press.

6. Horak FB: Postural orientation and equilibrium: what do we need to know about neural control of balance to prevent falls? Age Ageing 35 Suppl 2:ii7-ii11, 2006.

7. Morasso PG, Schieppati M: Can muscle stiffness alone stabilize upright standing? J Neurophysiol 82:1622-1626, 1999.

8. Winter DA: Human balance and posture control during standing and walking. Gait Posture 3:193-214, 1995.

9. Hodges PW, Gurfinkel VS, Brumagne S, Smith TC, Cordo PC: Coexistence of stability and mobility in postural control: evidence from postural compensation for respiration. Exp Brain Res 144:293-302, 2002.

10. Bonnet C, Carello C, Turvey MT: Diabetes and postural stability: review and hypotheses. J Mot Behav 41:172192, 2009.

11. Centomo H, Termoz N, Savoie S, Beliveau L, Prince F: Postural control following a self-initiated reaching task in type 2 diabetic patients and age-matched controls. Gait Posture 25:509-514, 2007.

12. Corriveau H, Prince F, Hebert R, Raiche M, Tessier D, Maheux P, Ardilouze JL: Evaluation of postural stability in elderly with diabetic neuropathy. Diabetes Care 23:1187-1191, 2000.

13. Kanade RV, Van Deursen RW, Harding KG, Price PE: Investigation of standing balance in patients with diabetic neuropathy at different stages of foot complications. Clin Biomech 23:1183-1191, 2008.

14. Lafond D, Corriveau H, Prince F: Postural control mechanisms during quiet standing in patients with diabetic sensory neuropathy. Diabetes Care 27:173-178, 2004.

15. Nardone A, Grasso M, Schieppati M: Balance control in peripheral neuropathy: are patients equally unstable under static and dynamic conditions? Gait Posture 23:364-373, 2006.

16. Oppenheim U, Kohen-Raz R, Alex D, Kohen-Raz A, Azarya M: Postural characteristics of diabetic neuropathy. Diabetes Care 22:328-332, 1999.

17. Simmons RW, Richardson C, Pozos R: Postural stability of diabetic patients with and without cutaneous sensory deficit in the foot. Diabetes Res Clin Pract 36:153-160, 1997.

18. Yamamoto R, Kinoshita T, Momoki T, Arai T, Okamura A, Hirao K, Sekihara H: Postural sway and diabetic peripheral neuropathy. Diabetes Res Clin Pract 52:213-221, 2001.

19. Mathie MJ, Coster AC, Lovell NH, Celler BG: Accelerometry: providing an integrated, practical method for longterm, ambulatory monitoring of human movement. Physiol Meas 25:1-20, 2004.

20. Adlerton AK, Moritz U, Moe-Nilssen R: Forceplate and accelerometer measures for evaluating the effect of muscle fatigue on postural control during one-legged stance. Physiother Res Int 8:187-199, 2003.

21. Moe-Nilssen R, Helbostad JL: Trunk accelerometry as a measure of balance control during quiet standing. Gait Posture 16:60-68, 2002.

22. Lamoth CJ, van Lummel RC, Beek PJ: Athletic skill level is reflected in body sway: a test case for accelometry in combination with stochastic dynamics. Gait Posture 29:546-551, 2009.

23. Kastenbauer T, Sauseng S, Brath H, Abrahamian H, Irsigler K: The value of the Rydel-Seiffer tuning fork as a predictor of diabetic polyneuropathy compared with a neurothesiometer. Diabet Med 21:563-567, 2004.

24. Liniger C, Albeanu A, Bloise D, Assal JP: The tuning fork revisited. Diabet Med 7:859-864, 1990.

25. Tinetti ME: Performance-oriented assessment of mobility problems in elderly patients. J Am Geriatr Soc 34:119-126, 1986.

26. Tinetti ME, Williams TF, Mayewski R: Fall risk index for elderly patients based on number of chronic disabilities. Am J Med 80:429-434, 1986.

27. Yelnik A, Bonan I: Clinical tools for assessing balance disorders. Neurophysiol Clin 38:439-445, 2008.

28. Savitzky A, Golay MJE: Smoothing and Differenciation of Data by Simplified Least Squares Procedures. Analytical Chemistry 36:1627-1639, 1964. 
29. Kamen G, Patten C, Du CD, Sison S: An accelerometry-based system for the assessment of balance and postural sway. Gerontology 44:40-45, 1998.

30. Lamoth CJ, van Lummel RC, Beek PJ: Athletic skill level is reflected in body sway: A test case for accelometry in combination with stochastic dynamics. Gait Posture, 2009.

31. Cho CY, Kamen G: Detecting balance deficits in frequent fallers using clinical and quantitative evaluation tools. J Am Geriatr Soc 46:426-430, 1998.

32. Olejnik S, Algina J: Generalized eta and omega squared statistics: measures of effect size for some common research designs. Psychol Methods 8:434-447, 2003.

33. Tinetti ME, Speechley M, Ginter SF: Risk factors for falls among elderly persons living in the community. N Engl J Med 319:1701-1707, 1988.

34. Horak FB, Hlavacka F: Somatosensory loss increases vestibulospinal sensitivity. J Neurophysiol 86:575-585, 2001.

35. Andreassen CS, Jakobsen J, Andersen H: Muscle weakness: a progressive late complication in diabetic distal symmetric polyneuropathy. Diabetes 55:806-812, 2006.

36. Cavanagh PR, Simoneau GG, Ulbrecht JS: Ulceration, unsteadiness, and uncertainty: the biomechanical consequences of diabetes mellitus. J Biomech 26 Suppl 1:23-40, 1993.

37. Simoneau GG, Ulbrecht JS, Derr JA, Becker MB, Cavanagh PR: Postural instability in patients with diabetic sensory neuropathy. Diabetes Care 17:1411-1421, 1994.

38. Allet L, Armand S, de Bie RA, Pataky Z, Aminian K, Herrmann FR, de Bruin ED: Gait alterations of diabetic patients while walking on different surfaces. Gait Posture 29:488-493, 2009. 



\title{
Chapter 6
}

\section{Clinical factors associated with gait alterations in diabetic patients}

\author{
Allet $\mathrm{L}^{1,2}$ \\ Armand $\mathrm{S}^{3}$ \\ de Bie R.A. ${ }^{2}$ \\ Golay A. ${ }^{4}$ \\ Pataky Z. ${ }^{4}$ \\ Aminian $\mathrm{K}^{5}$ \\ de Bruin E.D. ${ }^{6}$
}

Article published in Diabet Med 26(19):1003-1009, 2009

${ }^{1}$ Department of Neuroscience, Geneva University Hospital and University of Geneva, Geneva, Switzerland.

2 Department of Epidemiology, Maastricht University and Caphri Research School, Maastricht, The Netherlands.

${ }^{3}$ Willy Taillard Laboratory of Kinesiology, Geneva University Hospital and University of Geneva, Geneva, Switzerland.

${ }^{4}$ Service of Therapeutic Education for Chronic Diseases, WHO Collaborating Centre, Geneva University Hospital and University of Geneva, Geneva, Switzerland.

${ }^{5}$ Laboratory of Movement Analysis and Measurement, EPFL, Lausanne, Switzerland.

${ }^{6}$ Institute of Human Movement Sciences and Sport, ETHZ, Zürich, Switzerland. 


\section{SUMMARY}

\section{Background}

Diabetic patients have an increased risk of injurious falls. Fifty percent of patients suffering from diabetes for more than 20 years develop peripheral neuropathy. The neuromuscular damage implied by peripheral neuropathy may result in altered lower extremity biomechanics, thereby leading to gait alterations with increased risk of falling. However, clinical factors which may be associated with these gait alterations in diabetic patients are still unclear and under debate.

\section{Aims}

To identify clinical factors associated with gait alterations in patients with type 2 diabetes.

\section{Methods}

A sample of 76 diabetic patients underwent clinical examination and an outdoor gait evaluation on tarred and cobblestone terrains. We calculated respective differences in gait speed (performance measure) and gait variability (fall risk index) on changing terrains. Associations with clinical factors were investigated using correlation coefficients and linear regression analysis.

\section{Results}

The mean walking speed on the tarred pathway was $4.52 \pm 0.6 \mathrm{kmh}^{-1}$ and $3.93 \pm 0.8 \mathrm{kmh}^{-1}$ on the cobblestone pathway $(p<0.001)$. The coefficient of variation of gait cycle time increased from $2.58 \pm 0.9 \%$ on the tarred pathway to $5.05 \pm 2.8 \%$ on the cobblestone pathway $(p<0.001)$. Regression analysis showed that $36 \%$ of the decrease in gait speed was proportionally explained by the mean of maximal isometric lower limb strength (22.2\%; $p \leq 0.01)$, fear of falls (7.4\%; $p \leq 0.01)$ and participants' perceived vibration perception threshold (6.4\%; $p \leq 0.01)$. Moreover, mean maximal isometric strength explained $11.8 \%$ ( $p \leq 0.01$ ) of the increase of the coefficient of variation of the gait cycle time when participants changed from tarred terrain to cobblestones.

\section{Discussion and conclusion}

This study indicated that both physiological (strength and proprioception), and cognitivebehavioural factors (fear of falls) should be considered when treating diabetic patients with gait alterations. Therapists should apply these findings when developing specific fall prevention and treatment programs. 


\section{INTRODUCTION}

Diabetic patients have an increased risk of injurious falls [1, 2]. Fifty percent of patients suffering from diabetes for more than 20 years develop peripheral neuropathy (PN). The neuromuscular damage implied by PN may result in altered lower extremity biomechanics [3], thereby leading to gait alterations (i.e. modified walking speed and gait pattern) with increased risk of falling. Clinical factors which may be associated with these gait alterations in diabetic patients are still unclear and under debate [4]. Allet et al. [5] showed that diabetic patients with PN present more gait alterations than patients without PN. Moreover, this same article demonstrated that gait alterations may appear well before peripheral neuropathy is detected clinically [5]. Petrofsky et al. [6] reported that patients with diabetes are at risk of falling before loss of foot sensation. Thus, clinical factors other than neuropathy [5] such as muscle strength [7], joint mobility [7], general de-conditioning or psychological traits (e.g. fear of falls) [8] may deteriorate diabetic patients' gait.

Diabetes' high incidence, related gait alterations, increased fall risk and adjunct costs [9], require the identification of factors associated with gait alterations. The World Health Organisation (WHO) recommends that diabetics have 30 min daily physical activity, 6 times a week which implies adequate gait performance and safety.

Performance can be measured by gait speed and/or walking distance. Reduced gait speed may indicate a security strategy used to avoid falls [10]. Gait safety requires among others adequate variability, stability, speed and reaction time and may be compromised by extrinsic and intrinsic factors [11]. Fall risk itself is currently assessed by variability between one gait stride to another $[12,13]$. Gait cycle time variability (cycle time, stance time, swing time and percent stance), stride length variability or step width variability are widely used parameters. Hausdorff et al. [12] showed that the coefficient of variation of the gait cycle time (CVGCT) is a sensitive measure which provides important information about patients' gait safety and fall risk.

There is evidence that irregular terrain reveals clinically relevant impairments and accentuates differences in step time variability between groups of clinical interest (older women with and without peripheral neuropathy [14] and diabetic patients versus healthy controls [5]). Diabetic patients for example were shown to reduce their walking speed and to increase their step time variability while changing from smooth to irregular terrain, which indicates patients' difficulties in adapting their gait pattern to a challenging environment [5].

As clinical factors may undermine individuals' gait performance and safety, this study aims to examine the association of clinical factors (muscle strength, joint mobility, fear of falls, perception, sensitivity, age and Body Mass Index (BMI)) with gait speed and gait variability in diabetic patients with and without neuropathy, while walking in real life conditions.

On the basis of existing knowledge [5] 2 questions were investigated: a) which clinical factors are associated with gait speed differences while changing from smooth to irregular terrain and b) which clinical factors are associated with differences in the CVGCT while changing from smooth to irregular terrain?

We hypothesised that muscle weakness, limited joint mobility, fear of falling, severity of disease (neuropathy), increased BMI and age are associated with gait alterations. Gait 
alterations will be assessed by gait speed differences (performance) and CVGCT differences (fall risk assessment) while changing from smooth to irregular terrain.

\section{METHODS}

The study was approved by the local ethics committee. All participants received written and oral information and were requested to sign an informed consent statement.

\section{Participants}

A convenience sample of 76 participants was recruited from the patients consulting the Service of Therapeutic Education for Chronic Diseases or the Service of Endocrinology at the University Hospital in Geneva. Patients were included if they were medically diagnosed with diabetes type 2 (Blood sugar $>7.0 \mathrm{mmoll}^{-1}$ in fasting state). Patients were excluded if they had concomitant foot ulcers, orthopaedic or surgical problems influencing gait parameters, a non-diabetic neuropathy (due to Charcot-Marie-Tooth disease, excessive alcohol intake or thyroid dysfunction), neurological pathology influencing gait parameters or incapacity to walk without a walking aid a minimum of $500 \mathrm{~m}$.

\section{Clinical examination}

The same experienced physiotherapist examined all participants. Participants were requested to report their fasting blood sugar level measured on the morning of the test. The physiotherapist confirmed the absence of foot ulcers. Maximum isometric strength of the hip, knee, ankle flexors and extensors was measured with a hand-held dynamometer (Microfet ${ }^{\circ}$ Hoggen health, USA) $[15,16]$. Joint mobility of the hip, knee and ankle flexion and extension were measured with a manual goniometer. Vibration perception threshold (VPT) was evaluated with a Rydel-Seiffer tuning fork [17]. Plantar foot sensitivity was tested with a 5.07 Semmes Weinstein monofilament (10 g) [18]. Participants' fear of falling was assessed with the Falls Efficacy Scale [19].

\section{Gait evaluation}

Gait analysis was performed using 4 miniature gyroscopes (ADXRS 250, Analog device) attached to both shins and thighs with Velcro straps. The gyroscopes measured the angular velocity $\left(\right.$ rads $^{-1}$ ) of each segment around the coronal axis (flexion-extension). Temporal parameters (speed, gait cycle time) were estimated from distinctive features of shin angular velocity signal recorded by Physilog (BioAGM, CH) [20]. Signals were digitised (16 bit) at a sampling rate of $200 \mathrm{~Hz}$ by a light portable data logger and stored for off-line analysis on a memory card. Equipped with the Physilog ${ }^{\circ}$, participants were asked to walk at their preferred walking speed (e.g. posting a letter). The walkway consisted of two $50 \mathrm{~m}$ tarred pathways, two 50 m grass pathways and two $20 \mathrm{~m}$ cobblestone pathways [5] in the garden of the hospital. Between each terrain the participants paused for 8 to $10 \mathrm{~s}$ to 
identify the change from one terrain to another. Three different orders were possible (beginning with tarred surface, grass or cobblestones terrain) and were randomly assigned. For this study we were only interested in the tarred and cobblestone terrains.

\section{Analysis}

\section{Definition of variables}

Mean gait speed and mean CVGCT on the tarred road and on the cobblestone terrain were calculated. Participants' difficulty in changing from the smooth tarred terrain to the more irregular cobblestone terrain was estimated by 2 dependent variables.

1. The difference in walking speed

Difference in walking speed $=$ Speed on a tarred pathway - Speed on a cobblestone pathway.

2. The difference in the CVGCT

Difference in CVGCT = CVGCT on a tarred pathway - CVGCT on a cobblestone pathway. Scatterplots and correlations between variables provided an overview of the distribution and range of measurements performed during the clinical examination. On the basis of these results as well as clinical experience, 7 independent variables were retained to be included in a linear regression model:

- Muscle strength: strength values of the different muscle groups were highly correlated and we therefore considered the mean value of all muscle groups.

- Vibration perception threshold: mean perception threshold of the medial malleoli and the big toes.

- Sensibility: the sum of all anatomical plantar foot points (toes 1, 3, 5, metatarsals 1, 3, 5 , heel, medial and lateral foot) on which a participant felt the 5.07 Semmes Weinstein monofilament (10 g) [18].

- Joint mobility: as every participant showed joint mobility values within the range necessary for normal gait except for ankle dorsiflexion, we only retained this last value.

- Fear of falls: scores between 16 (best score) and 74 (worst score) established with the fear of falls questionnaire [19].

- $\quad B M I\left(\mathrm{kgm}^{-2}\right)$ : body mass divided by the square of height.

- $\quad$ Age: patients' age in years.

\section{Statistical analysis}

All statistics were performed with SPSS (SPSS for Windows rel. 15. Chicago: SPSS Inc.). The level of significance was set for all parameters at $p \leq 0.05$. Descriptive statistics were used to evaluate participants' characteristics (Table 6.1). Statistical differences ( $p$ value) in gait speed and in CVGCT were calculated with a paired t-test. The association of each clinical parameter with each dependent gait parameter was analysed. Based on these results variables were added to a step forward regression model, respecting the importance of significance ( $p$ value) obtained with the previous independent analysis. All variables were checked for collinearity using the variance inflation factor (VIF). Three different models were analysed.

Model A (for the decrease in gait speed): mean strength, fear of falls index, VPT, plantar foot sensitivity, ankle dorsiflexion mobility, age and BMI. 
Model B1 (for the increase in CVGCT): mean strength, fear of fall index, age, ankle dorsiflexion mobility, plantar foot sensitivity, VPT and BMI.

Model B2 (for the increase in CVGCT respecting speed difference): as gait speed is a frequently discussed factor, when investigating gait variability with the CVGCT [21], the change in walking speed was added to model B1.

\section{RESULTS}

All 76 volunteers (mean age: $63 \pm 9.6$ years; BMI: $31 \pm 5.5$ ) underwent the clinical examination and gait evaluation. The mean, standard deviation and range of all clinical variables are presented in Table 6.1.

Table 6.1. Description of results obtained in the clinical examination

\begin{tabular}{|c|c|c|c|}
\hline & Mean (SD) & Minimum & Maximum \\
\hline \multicolumn{4}{|l|}{ General information } \\
\hline BMI & $31(5.5)$ & 20 & 47 \\
\hline Height $(\mathrm{cm})$ & $168(9.4)$ & 147 & 193 \\
\hline Weight (kg) & $88(15.3)$ & 54 & 138 \\
\hline Age (years) & $63(9.6)$ & 40 & 85 \\
\hline \multicolumn{4}{|l|}{ Superficial sensitivity } \\
\hline (Number of the 9 points which perceived the $10 \mathrm{~g}$ ) & $5(2.8)$ & 0 & 9 \\
\hline \multicolumn{4}{|l|}{ Vibration perception threshold } \\
\hline (Tuning fork: best score 8 , worst score 0 ) & $3.6(1.6)$ & 0 & 8 \\
\hline \multicolumn{4}{|l|}{ Fear of fall } \\
\hline (FES-I: best score 16 , worst score 64 ) & $21(5.9)$ & 16 & 46 \\
\hline \multicolumn{4}{|l|}{ Strength (N) } \\
\hline - Mean of 6 lower limb muscle groups & $199(49.3)$ & 90 & 311 \\
\hline - Hip Flexors & $243(72.5)$ & 111 & 426 \\
\hline - Hip Extensors ${ }^{a}$ & $142(63.0)$ & 30 & 322 \\
\hline - Knee Flexors & $124(39.3)$ & 50 & 235 \\
\hline - Knee extensors & $230(65.7)$ & 59 & 360 \\
\hline - Ankle Plantar Flexors & $243(56.9)$ & 96 & 356 \\
\hline - Ankle Dorsal Flexors & $211(54.6)$ & 99 & 336 \\
\hline \multicolumn{4}{|c|}{ Mobility (mean value of right and left joint expressed in deg) } \\
\hline - Hip Flexion & 104 (9) & 90 & 130 \\
\hline - Knee Flexion & $125(6)$ & 110 & 140 \\
\hline - Knee Extension & $0(1)$ & -5 & 0 \\
\hline - Ankle Plantarflexion & $43(8)$ & 20 & 60 \\
\hline - Ankle Dorsiflexion & $6(4)$ & -3 & 13 \\
\hline
\end{tabular}

${ }^{a}$ One person could not perform the hip extension in the required prone position.

The mean walking speed on the tarred pathway was $4.52 \pm 0.6 \mathrm{kmh}^{-1}$ and $3.93 \pm 0.8 \mathrm{kmh}^{-1}$ on the cobblestone pathway ( $<<0.001$ ). The CVGCT increased from $2.58 \pm 0.9 \%$ on the tarred pathway to $5.05 \pm 2.8 \%$ on the cobblestone pathway $(p<0.001)$ (Figure 6.1a and $6.1 b)$. 
As all VIF values were lower than 1.3, we assumed no collinearity of the data. Step forward analysis showed that 3 clinical factors explained $36 \%$ of the decrease in diabetic patients' gait speed when they changed from a tarred to a cobblestone terrain: mean lower limb isometric maximal strength (22.2\%), fear of falls (explains an extra $7.4 \%$ ) and VPT (explains an additional 6.4\%) (Table 6.2).

However, only mean lower limb isometric maximal strength explained the increase of CVGCT when participants changed from tarred terrain to cobblestones (11.8\%). To take into consideration the decrease in walking speed due to change of terrain we added the speed differential to the step forward model. Gait speed difference alone explained $43 \%$ of the increase of the CVGCT, whereas strength no longer explained the increase of the CVGCT. Figure 6.2 resumes the associations of clinical factors identified as predictors for gait speed reduction and increase in gait instability while changing from a smooth to a more irregular terrain.

Table 6.2. Regression model for the dependent variables: speed difference and CVGCT difference

\begin{tabular}{|c|c|c|c|c|c|c|}
\hline \multicolumn{7}{|c|}{ Model for speed difference } \\
\hline Model & $\mathrm{R}$ & $R^{2}$ & Dependent variable & Unstandardised Coefficients & $\mathrm{T}$ & $P$ \\
\hline \multirow{6}{*}{ A } & $.471(a)$ & 0.222 & Strength & $-0.07(-0.09$ to -0.04$)$ & -4.59 & $<0.001$ \\
\hline & $.544(b)$ & 0.296 & Strength & $-0.05(-0.08$ to -0.02$)$ & -3.27 & $<0.001$ \\
\hline & & & Fear of falling & 4.11 (1.15 to 7.07$)$ & 2.77 & 0.01 \\
\hline & .600 (c) & 0.360 & Strength & $-0.04(-0.07$ to -0.01$)$ & -2.54 & 0.01 \\
\hline & & & Fear of falling & 4.22 (1.38 to 7.06$)$ & 2.96 & $<0.001$ \\
\hline & & & Vibration perception threshold & $-13.52(-23.53$ to -3.51$)$ & -2.69 & 0.01 \\
\hline \multicolumn{7}{|c|}{ Model for CVGCT difference } \\
\hline Model & $\mathrm{R}$ & $R^{2}$ & Dependent variable & Unstandardised Coefficients & $\mathrm{T}$ & $P$ \\
\hline B1 & .344 (b) & 0.118 & Strength & $0.15(0.05$ to 0.24$)$ & 3.15 & $<0.001$ \\
\hline B2 & $.656(a)$ & 0.431 & Speed Difference & $-2.00(-2.53$ to -1.47$)$ & -7.48 & $<0.001$ \\
\hline
\end{tabular}

CVGCT $=$ coefficient of varation of gait cycle time.
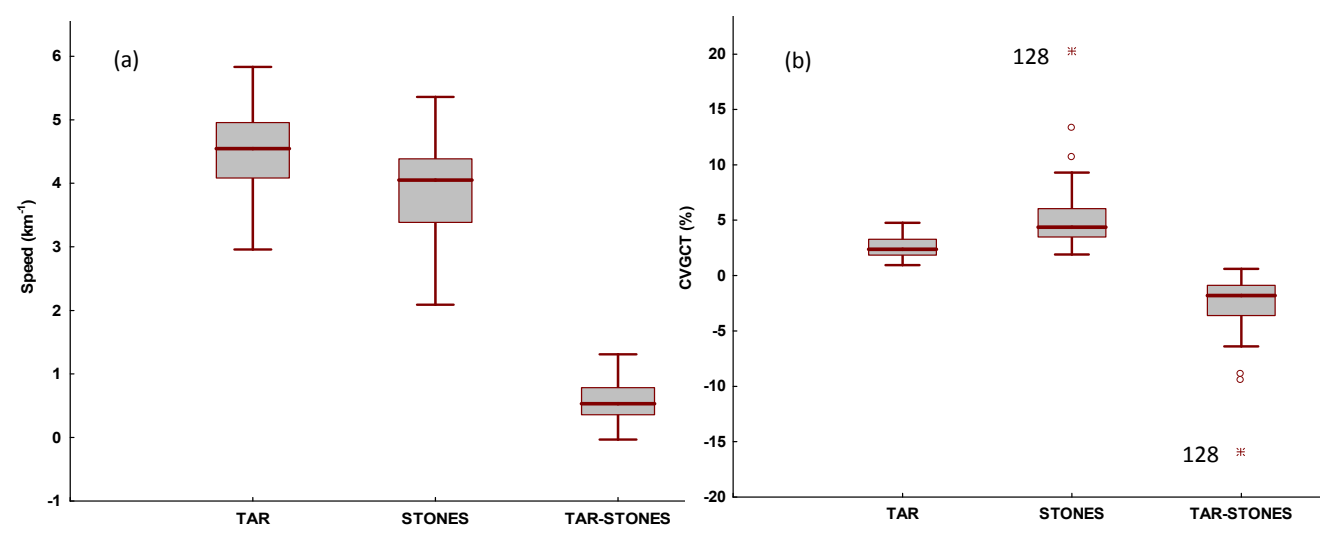

Figure 6.1a and 6.1b. Boxplot of (a) speed and (b) coefficient of variation of gait cycle time (CVGCT) recorded on a tarred surface (tar) and cobblestones (stones). The third boxplot of each figure shows the respective difference between the tarred surface and the cobblestones. 

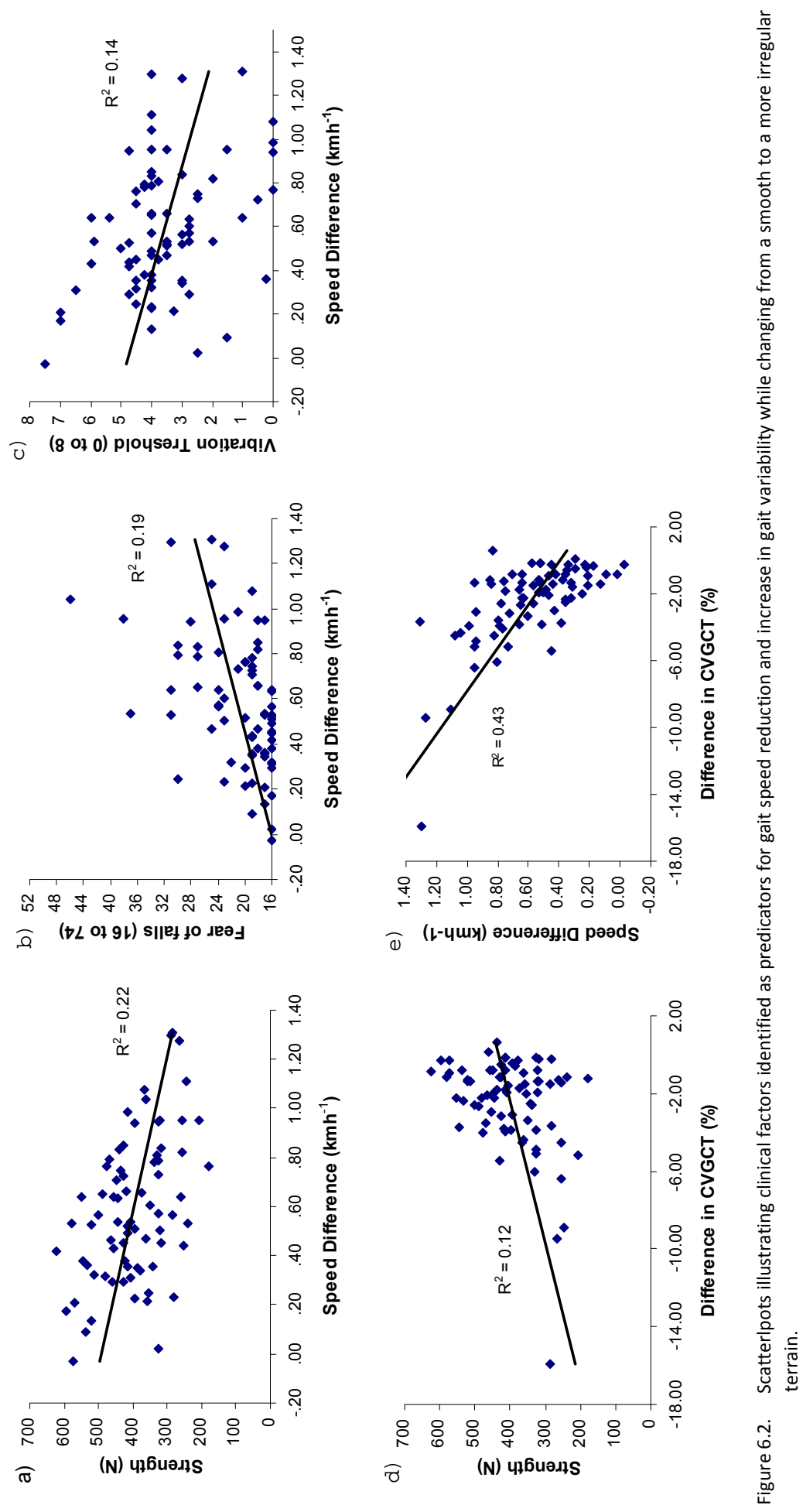


\section{DISCUSSION}

This study aimed to determine clinical factors associated with gait speed differences and/or differences in the CVGCT while changing from smooth to irregular terrain. Factors influencing diabetic individuals' gait pattern should be identified to understand the underlying mechanisms of gait alterations potentially related to a heightened fall risk. Three clinical factors explained $36 \%$ of the decrease in gait speed, namely mean lower limb isometric maximal strength, fear of falls and severity of neuropathy (vibration perception threshold). Mean lower limb isometric maximal strength alone explained $11.8 \%$ of the increase of the CVGCT when participants changed from smooth to irregular terrain. To date a majority of studies has investigated static balance, although falls mostly occur during walking [22]. Diabetic individuals' difficulties are highlighted in challenging environments [5]. Diabetic patients also use more pronounced adaptation strategies than healthy controls when changing from level to irregular terrains [5]. Thus, irregular terrains may be a useful "tool" with which to analyse individuals' gait and fall risk. Our study is one of the first to make use of this concept.

We found gait speeds that are consistent with values recorded in previous studies on comparable surfaces, where walking speeds were between $3.4 \mathrm{kmh}^{-1}$ [14] and $5.1 \mathrm{kmh}^{-1}$ [23]. The positive relationship between the decrease in gait speed and muscle strength is similar to that described, for example, by Chang et al. [24]. Perhaps lower limb weakness, especially of plantar flexors and hip extensors, influenced joint moments and muscle power, which play an important role in gait speed and balance recovery [25]. We believe that further evaluation of the latter kinematic parameters could provide extra information about the causes for gait alterations and increased fall risk.

Recent results confirm that the degree of neuropathy influences walking speed when changing terrains. Neuropathy, together with muscle weakness, could influence the neuromuscular control process. Both may affect not only joint moments and power generation but also the timing of muscle activation and thus gait performance [26]. However, reduced gait speed could also be an adaptation strategy. Perhaps diabetic patients walk slower because of altered neuromuscular control processes leading to decreased balance and stability. The association between participants' fear of falling and decreased speed could support this theory. Slowing down might be a security strategy to feel safer on irregular terrains. Nevertheless, reduced walking speed does not necessarily imply increased safety during walking according to Kang et al. [21]. Younger adults improve their dynamic stability by walking slower, whereas older adults fall yet more.

When considering gait variability in our population we found muscle strength and the CVGCT to be related. Although our study design does not allow us to draw conclusions about causal mechanisms that explain associations between strength and fall risk (CVGCT) our data was consistent with previous findings where muscle weakness and reduced reaction time were associated with increased sway and increased fall risk [27]. As diabetic neuropathy leads to feedback delays, maybe increased ankle moment latency in response to perturbations (i.e. walking over cobblestones) contributes to the postural instability observed in neuropathic individuals. Feedback delays thus probably play also a part in increased gait variability and fall risk. This hypothesis should be further investigated. 
After discussing gait speed's influence on volunteers' gait variability [28, 29], we added the variable "speed difference" to our regression model. In this model strength no longer influenced the increased CVGCT, which drew attention to the interpretation of the CVGCT. Nevertheless, our results indicated that diabetic patients' gait performance and gait variability seem to be affected by both physiological factors (neurological and muscular function) and participants' fear of falls.

The data showed 1 extreme outlier (Participant 128 on Figure 6.1). We therefore checked our dataset for inconsistencies. We did, however, not find any technical flaw to explain the outlier. The patient had worse gait than the others and was used to walking longer distances with a walking stick. His steps were discontinuous and he stopped several times on the pathway during the test session, more so on cobblestones than on a tarred terrain, which increased the CVGCT difference. Nonetheless, he fulfilled our inclusion criteria. For these reasons it was decided to maintain this participant in the regression model. The research team further debated on whether to normalise participants' lower limb strength for their body weight or height. Preliminary scatterplots showed no linear relationship between participants' weight or height and isometric strength, therefore the investigators decided to integrate participants' mean strength $(\mathrm{N})$ and their $\mathrm{BMI}\left(\mathrm{kgm}^{-2}\right)$ separately in the regression model and not to normalise participants' lower limb strength for their body weight or height.

Speed showed a high association with the CVGCT. Further work should separate the effects of walking speed, which may help to clarify the picture concerning diabetic patients who fall or are "frail" [28]. A recent publication showed that the local and orbital dynamic instability are independent of walking speed and could be other subjects for fall risk studies [29].

We measured maximal lower extremity isometric strength with a hand-held dynamometer, which provides reliable [15] and objective [30] strength measures. These measurements are more precise than with manual muscle testing although they may be limited by the investigator's ability to hold the dynamometer stationary and the fact that participants could overpower the testers. An additional point is the limited number of subjects. For power reasons we were not able to include each independent variable. Thus, the relationship between the strength of each muscle group and gait performance/stability could not be analysed. Over and above the clinical factors examined in the present study, further investigations should evaluate such specific relationships. Ideally, not only sagittal but also frontal plane muscle strength (i.e. hip adductors and abductors, which are involved in frontal plane stability during gait) should be considered. However, this was beyond the scope of this paper.

Other variables such as ankle dorsiflexion may be associated with gait variability or gait performance, although they could not be identified in this study for presumably lack of statistical power.

Correlations do not imply causality, but models examining potential contributors and how the R-square changes when potential contributors are added to the model, can help us to understand which factors determine the association between speed differences and/or CVGCT differences and how much of the association is explained. More studies are needed to verify causality between muscle strength and gait parameters in diabetic patients. 
Despite these limitations our results document new factors to be addressed when developing specific physiotherapy programs to improve diabetic patients' gait performance and safety. Programs should consider both physiological and cognitive-behavioural factors. They should include strength exercises, proprioceptive training and practice of progressively more complex activities of daily living, in order to improve the self-assurance of diabetic patients. Gait alterations are likely to influence patients' physical activity level, thus triggering a vicious circle of functional limitation. Physical activity plays a central role in the management of metabolic diseases and is part of the lifestyle recommended to avoid complications. It enables individuals to forestall medical and functional complications. For national health care systems, physical activity is a cost-effective way of improving public health across the population. Diabetic patients need adequate gait performance and sufficient safety to feel confident in different environments. A fall prevention program based on this new knowledge may provide a complementary benefit to physicians' provisions to avoid complications and help to manage fall risk [31] and thus further interdisciplinary care management.

\section{CONCLUSIONS}

This study shows an association between muscle strength, fear of falling, vibration perception threshold and gait alterations caused by surface transitions in diabetic participants. Both physiological and cognitive-behavioural factors should be considered when treating patients with gait alterations. Therapists are encouraged to develop fall prevention and/or treatment programs to improve gait performance and gait safety so that patients feel confident enough to reach the WHO's recommended level of daily activity. Further studies should investigate the efficacy of such newly developed treatment approaches. 


\section{REFERENCES}

1. Miller DK, Lui LY, Perry HM 3rd, Kaiser FE, Morley JE: Reported and measured physical functioning in older inner-city diabetic African Americans. J Gerontol A Biol Sci Med Sci 54:230-236, 1999.

2. Corsinovi L, Bo M, Ricauda Aimonino N, Marinello R, Gariglio F, Marchetto C, Gastaldi L, Fissore L, Zanocchi M, Molaschi M: Predictors of falls and hospitalization outcomes in elderly patients admitted to an acute geriatric unit. Arch Gerontol Geriatr 49:142-145, 2009.

3. Kwon OY, Minor SD, Maluf KS, Mueller MJ: Comparison of muscle activity during walking in subjects with and without diabetic neuropathy. Gait Posture 18:105-113, 2003.

4. Allet L, Armand S, Golay A, Monnin D, de Bie RA, de Bruin ED: Gait characteristics of diabetic patients: a systematic review. Diabetes Metab Res Rev 24:173-191, 2008.

5. Allet L, Armand S, de Bie RA, Pataky Z, Aminian K, Herrmann FR, de Bruin ED: Gait alterations of diabetic patients while walking on different surfaces. Gait Posture 29:488-493, 2009.

6. Petrofsky J, Lee S, Bweir S: Gait characteristics in people with type 2 diabetes mellitus. Eur J Appl Physiol 93:640-647, 2005

7. Giacomozzi C, D’Ambrogi E, Cesinaro S, Macellari V, Uccioli L: Muscle performance and ankle joint mobility in long-term patients with diabetes. BMC Musculoskelet Disord 9:99, 2008.

8. Wijlhuizen GJ, Chorus AM, Hopman-Rock M: Fragility, fear of falling, physical activity and falls among older persons: some theoretical considerations to interpret mediation. Prev Med 46:612-614, 2008.

9. Roudsari BS, Ebel BE, Corso PS, Molinari NA, Koepsell TD: The acute medical care costs of fall-related injuries among the U.S. older adults. Injury 36:1316-1322, 2005.

10. Maki BE: Gait changes in older adults: predictors of falls or indicators of fear. J Am Geriatr Soc 45:313-320, 1997.

11. Morley JE: Falls - where do we stand? Mo Med 104:63-67, 2007.

12. Hausdorff JM, Edelberg HK, Mitchell SL, Goldberger AL, Wei JY: Increased gait unsteadiness in communitydwelling elderly fallers. Arch Phys Med Rehabil 78:278-283, 1997.

13. Richardson JK, Thies S, Ashton-Miller JA: An exploration of step time variability on smooth and irregular surfaces in older persons with neuropathy. Clin Biomech 23:349-356, 2008.

14. Richardson JK, Thies SB, DeMott TK, Ashton-Miller JA: A comparison of gait characteristics between older women with and without peripheral neuropathy in standard and challenging environments. J Am Geriatr Soc 52:1532-1537, 2004.

15. Kelln BM, McKeon PO, Gontkof LM, Hertel J: Hand-held dynamometry: reliability of lower extremity muscle testing in healthy, physically active,young adults. J Sport Rehabil 17:160-170, 2008.

16. Morey JK, Joshua AC: Strength testing using hand-held dynamometry. Phys Ther Rev 10:99-112, 2005.

17. Liniger C, Albeanu A, Bloise D, Assal JP: The tuning fork revisited. Diabet Med 7:859-864, 1990.

18. Smieja M, Hunt DL, Edelman D, Etchells E, Cornuz J, Simel DL: Clinical examination for the detection of protective sensation in the feet of diabetic patients. International Cooperative Group for Clinical Examination Research. J Gen Intern Med 14:418-424, 1999.

19. Yardley L, Beyer N, Hauer K, Kempen G, Piot-Ziegler C, Todd C: Development and initial validation of the Falls Efficacy Scale-International (FES-I). Age Ageing 34:614-619, 2005.

20. Aminian K, Najafi B, Bula C, Leyvraz PF, Robert P: Spatio-temporal parameters of gait measured by an ambulatory system using miniature gyroscopes. Clin Biomech 35:689-699, 2002.

21. Kang HG, Dingwell JB: Effects of walking speed, strength and range of motion on gait stability in healthy older adults. J Biomech 41:2899-2905, 2008.

22. Tinetti ME, Speechley M, Ginter SF: Risk factors for falls among elderly persons living in the community. N Engl J Med 319:1701-1707, 1988.

23. Dingwell JB, Cavanagh PR: Increased variability of continuous overground walking in neuropathic patients is only indirectly related to sensory loss. Gait Posture 14:1-10, 2001.

24. Chang RW, Dunlop D, Gibbs J, Hughes S: The determinants of walking velocity in the elderly. An evaluation using regression trees. Arthritis Rheum 38:343-350, 1995.

25. Andrews AW, Thomas MW, Bohannon RW: Normative values for isometric muscle force measurements obtained with hand-held dynamometers. Phys Ther 76:248-259, 1996.

26. Pijnappels $\mathrm{M}$, Bobbert MF, van Dieen JH: Control of support limb muscles in recovery after tripping in young and older subjects. Exp Brain Res 160:326-333, 2005. 
27. Lord SR, Clark RD, Webster IW: Postural stability and associated physiological factors in a population of aged persons. J Gerontol 46:69-76, 1991.

28. Kang HG, Dingwell JB: Separating the effects of age and walking speed on gait variability. Gait Posture 27:572$577,2008$.

29. Dingwell JB, Kang HG, Marin LC: The effects of sensory loss and walking speed on the orbital dynamic stability of human walking. J Biomech 40:1723-1730, 2007.

30. Kolber MJ, Cleland JA: Strength testing using hand-held dynamometry. Phys Ther Rev 2005:99-112, 2005.

31. Schwartz AV, Vittinghoff E, Sellmeyer DE, Feingold KR, de Rekeneire N, Strotmeyer ES, Shorr RI, Vinik AI, Odden MC, Park SW, Faulkner KA, Harris TB: Diabetes-related complications, glycemic control, and falls in older adults. Diabetes Care 31:391-396, 2008. 



\section{Chapter 7}

\section{Diabetic patients' gait and balance can be improved with a specific training program. A randomised controlled trial}

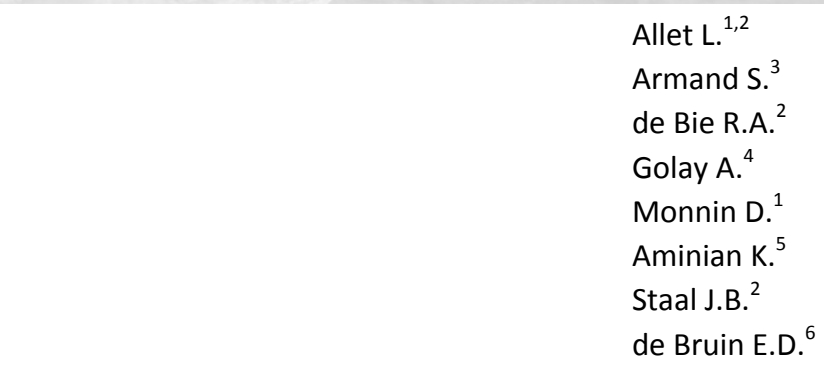

Article accepted in Diabetologia

${ }^{1}$ Department of Neurosciences, Geneva University Hospital and University of Geneva, Geneva, Switzerland.

2 Department of Epidemiology, Maastricht University and Caphri Research School, Maastricht, The Netherlands.

${ }^{3}$ Willy Taillard Laboratory of Kinesiology, Geneva University Hospital and University of Geneva, Geneva, Switzerland.

${ }^{4}$ Service of Therapeutic Education for Chronic Diseases, WHO Collaborating Centre, Geneva University Hospital and University of Geneva, Geneva, Switzerland.

${ }^{5}$ Laboratory of Movement Analysis and Measurement, EPFL, Lausanne, Switzerland

${ }^{6}$ Institute of Human Movement Sciences and Sport, ETHZ, Zürich, Switzerland. 


\section{SUMMARY}

\section{Background}

Gait characteristics and balance are altered in diabetic individuals. Little is known about possible treatment strategies.

\section{Aims}

This study aims to evaluate the effect of a specific training program on diabetic patients' gait and balance.

\section{Methods}

A randomised controlled trial $(n=71)$ with an intervention $(n=35)$ and a control group $(n=$ 36). The intervention consisted of physiotherapeutic group training including gait and balance exercises with function-orientated strengthening (twice a week over 12 weeks). Controls received no treatment. Gait, balance, fear of falls, muscle strength and joint mobility were measured at baseline, post-intervention and at 6 month follow-up.

\section{Results}

After training, the intervention group increased habitual walking speed by $0.149 \mathrm{~ms}^{-1}$ ( $\mathrm{p}<$ 0.001 ) compared to the control group. Moreover patients in the intervention group significantly improved their balance (time to walk over a beam and balance index recorded on a Biodex balance system), their performance oriented mobility (POMA), their degree of concern about falling, their hip and ankle plantar flexor strength and hip flexion mobility, compared to the control group. After 6 months, all these variables remained significant except for the Biodex sway index and the ankle plantar flexor strength.

\section{Discussion and conclusion}

Specific training can improve diabetic patients' gait speed, balance, muscle strength and joint mobility. Further studies are needed to explore these improvements' influence on the number of reported falls, patients' physical activity level and quality of life. 


\section{INTRODUCTION}

Type 2 diabetes and its common complication peripheral neuropathy (PN), affects a large population [1, 2]. PN leads to sensory and motor deficits which often result in mobilityrelated dysfunction, alterations in gait characteristics [3, 4] and balance impairments $[5,6]$. Diabetic patients with PN have lower gait velocity, decreased cadence, shorter stride length, increased stance time and higher step to step variability compared with healthy controls [3]. These gait alterations increase on irregular surfaces [3]. Moreover, these patients have less ankle moment and ankle power [7, 8], as well as a different onset and cessation time of muscle activity compared with healthy controls [7]. Patients present more co-contractions of agonist and antagonist muscles at the ankle and knee joints during stance phase. Kwon et al. [7] speculate that the co-contraction mechanism may enable these individuals to adopt a safer, more stable gait pattern to compensate for diminished sensory information. The same authors reported reduced ankle strength and mobility which they considered to be the primary factors contributing to gait alterations. Allet et al. [3] have also found lower limb strength, fear of falling and sensory problems to be related to spatiotemporal gait alterations. Additionally individuals with PN also show postural instability with a larger centre of pressure displacement [9], higher sway area [10] and greater instability [11] when standing still with eyes closed [9]. Postural instability was further found to be significantly associated with sensory neuropathy [12]. In addition to these gait and balance impairments, diabetic patients are known to suffer from increased risk of injurious falls [13]. Fall-related injuries are often assumed to trigger a vicious circle because of their potentially detrimental influence on patients' physical activity level. Public Health guidelines for diabetes management recommend that patients perform at least 30 min of physical activity a day, 6 times a week, requiring adequate gait security and balance. However, little is known about treatment strategies that could improve patients' gait and balance, thereby also reducing fall risk [4]. Although there is evidence that an exercise regimen improves clinical measures of balance in patients with PN [14], clinical trials investigating diabetic individuals' gait generally focus on increased foot pressure, another major problem in this population, related to patients' high risk of ulcers [15]. Only few studies evaluate treatments that aim to improve gait and balance and decrease fall risk [16, 17]. Petrofsky et al. [16] tested an insulin sensitiser, Rosiglitazone (RSG) which promises to reverse some of the circulatory impairments seen in diabetes, thereby improving patients' gait. These authors report encouraging results after administering RSG (decreased step width, reduction in reaction time and less acceleration at the joints). However, RSG was recently associated with an increased risk for myocardial infarction and death from cardiovascular incidents [18]. Richardson et al. [17], evaluating patients with various form of PN ( 30 of 42 with diabetic PN) found that the use of a cane, ankle orthoses or touching a wall improved step-width range, step-time variability and speed while walking under challenging conditions. To our best knowledge, only Tsang et al. [19] and Orr et al. [20] investigated the effect of a specific physical training program not only on the activity level and quality of life of diabetic patients but also on their habitual and maximal walking speed. However, both studies seem to have evaluated the same group of subjects. In their studies the effect of a "Tai Chi for Diabetes" program (twice a week for 16 weeks) on gait, balance, 
musculoskeletal and cardiovascular fitness, self-reported activity and quality of life was compared with that of sham exercises. Gait speed and balance improved, but no significant differences between groups were reported. Nevertheless, several studies [21-23] have shown positive training effects on gait speed, postural stability and mobility of elderly individuals. Additionally, a meta-analysis [24] evaluating fall prevention studies for the elderly showed a $4 \%$ decrease in the fall-rate for individuals who were in a treatment group. Since elderly people often show symptoms similar to those in diabetic patients (i.e. de-conditioning, muscle weakness, decreased joint mobility and decreased foot sensibility), we assumed that programs that have been developed for the elderly might also improve diabetic individuals' gait and balance. Thus, this study aimed to evaluate the effect of a specific training program, based on previously elaborated core components for successful fall prevention programs for the elderly [25], on the gait and balance of diabetic patients.

Gait speed and coefficient of variation of gait cycle time (CVGCT) were selected as primary outcomes because they have been shown to be related to increased risk of falls $[22,26](a$ slow gait speed and high CVGCT indicate increased fall risk). Balance control, muscle strength and joint mobility are also important fall risk factors and are salient measures that may be influenced by exercise [27]. For these reasons, they were chosen as secondary outcomes. Fear of falls is a cognitive behavioural component that was recently shown to be related to the gait velocity of diabetic patients [28]. It therefore completed our outcome list.

We hypothesised that diabetic patients participating in a training program would significantly improve their walking speed and gait variability (CVGCT). We further assumed that diabetic patients in the training program would significantly a) improve their balance, b) increase their lower limb strength (in particular hip extensors, knee extensors and ankle flexors) c) increase their ankle joint mobility and d) decrease their fear of falling.

\section{METHODS}

\section{Study design}

This randomised controlled prospective trial with 2 arms (intervention group (IG) and control group (CG)) was conducted at the University Hospital of Geneva. The study was approved by the local ethics committee and registered at Clinical Trials.gov (NCT00637546). A sample of 71 diabetic patients was recruited from the patients consulting either the Service of Therapeutic Education for Chronic Diseases or the Service of Endocrinology at the University Hospital in Geneva. Thirty-five patients were allocated to the IG and 36 to the CG. Patients were included if they were medically diagnosed with type 2 diabetes (blood sugar $>7 \mathrm{mmoll}^{-1}$ in fasting state). Only patients without medical contraindications for engaging in physical activity and with a clinically diagnosed neuropathy were enrolled. Clinically diagnosed neuropathy was evaluated by a vibration perception threshold (VPT) equal to, or lower than $4 / 8$ with a Rydel-Seiffer tuning fork ${ }^{\circ}$ [29]. Patients were requested to indicate when they could no longer feel the vibration. At this point the investigator rated the vibration on a 9-point scale ( $0=$ severe neuropathy; $8=$ no neuropathy). Patients with 
concomitant foot ulcers, orthopaedic or surgical problems affecting gait parameters, those with non-diabetic neuropathy (due to Charcot-Marie-Tooth disease and alcohol), individuals presenting a neurological pathology other than PN that could influence gait parameters, or unable to walk a minimum of $500 \mathrm{~m}$ without a walking aid, were excluded. Training programs started as soon as there were enough patients (20 to 28): in September 2007, January 2008 and April 2008. For each of these starting points a new randomisation list was electronically generated and was used by a person uninvolved in the recruitment, evaluation or treatment process. Each list ensured equal distribution over groups.

All eligible patients identified by the medical staff were asked to participate. They were informed that if willing to participate, they would be randomly assigned to an IG or CG. Patients who orally agreed to join the study were contacted by the study coordinator for an individual appointment to sign the informed consent and undergo baseline evaluation. After this initial appointment during which patients underwent a clinical examination, a gait analysis, static and dynamic balance tests and answered a fear of falls questionnaire patients were randomly allocated to either the IG or to the CG. All outcome measures were realised at baseline, after 12 weeks and after 6 months and performed by the same experienced physiotherapist.

Patients allocated to the IG received a timetable containing all planned sessions over 12 weeks. The program started within 10 working days after the examination. Patients were kept unaware of the study hypothesis. However, the nature of the study made it impossible to blind patients and therapists. After the 12 week-program patients were encouraged to continue with the learned exercises during the next 6 months. No other advice or restrictions were provided.

\section{Test description and measures}

Prior to the clinical examination the physiotherapist checked the VPT with the tuning fork [29]. Maximum isometric strength of the hip, knee, ankle flexors and extensors was then measured with a hand-held dynamometer (MicroFET ${ }^{\circledR}$, Hoggan Health Industries, Inc., USA) [30]. Joint mobility of the hip, knee and ankle flexion and extension was measured with a manual goniometer. Patients' concern about falling when performing different activities was assessed with the Falls Efficacy Scale International (FES-I) [31]. Afterwards patients underwent the following functional tests:

- Performance-Oriented Mobility Assessement (POMA) [32], which scores 17 items (9 for the evaluation of balance and 7 items for the assessement of gait).

- $\quad$ Outdoor gait assessment [33] recorded with the Physilog ${ }^{\circledR}$ (BioAGM, CH). Participants were asked to walk wearing 4 miniature gyroscopes (ADXRS 250, Analog device) attached to both shanks and thighs with Velcro straps, on a specific walkway at their preferred walking speed. The walkway consisted of two $50 \mathrm{~m}$ tarred pathways, two 50 $\mathrm{m}$ grass and two $20 \mathrm{~m}$ cobblestone pathways in the hospital's backyard. For this study only the tarred terrain was evaluated. A detailed description of this gait assessment is published elsewhere [33].

- Dynamic balance test in which participants had to walk as fast and as precisely as possible on the top of a $5 \mathrm{~m}$ beam ( $15 \mathrm{~cm}$ high and $15 \mathrm{~cm}$ wide). Time was measured 
with a stopwatch. Patients had one practice trial before the test started. If a patient had to step off the beam he could redo the test. In case that they stepped-off again patients were asked to resume the exercise where they stepped off and from there continue to finalise the test.

- $\quad$ Static balance test which evaluated the patients' postural control on a Biodex ${ }^{\circledR}$ Balance system (Biodex Medical Systems, New York, USA) [34]. The level of difficulty while standing on this platform can be manipulated by altering the resistance of the platform to deviations. The balance test is most difficult when the platform provides the least resistance to tilting and is therefore the least stable. Each subject stands barefoot on the platform and must perform 2 different tests (level $8=$ easiest level and level 6 = a more difficult level). The foot position was standardised using a pre-formed triangle (heels together and feet forming an angle of $20 \mathrm{deg}$ ). Patients were instructed to keep their hands at their sides. For safety purposes they were permitted to touch handrails, but only to re-establish balance during extreme postural deviations. Once in this position, the stability platform was unlocked to allow motion. The subjects were then instructed to find a position at which they could maintain platform stability. Each recording lasted for $60 \mathrm{~s}$ with a rest for $60 \mathrm{~s}$ between each trial. We used a single recording per test condition and only one attempt per condition to reduce fatigue [34]. All tests were realised at baseline, after the 12 weeks intervention and 6 months after the intervention. A balance index is calculated by using the time and deviation (in deg) of the platform away from a level position [35].

\section{Treatment description}

The training took place twice a week for 60 min over 12 weeks. This intensity was chosen based on previously developed successful interventions in pre-frail elderly [25, 36-38]. Each session was conducted in groups (5 to 8 participants) in order to promote long-term participation [39]. The program was directed by a physiotherapist and an assistant. Four different physiotherapists and 4 assistants were trained to direct the sessions in order to guarantee continuity. A session consisted of a warm up $(5 \mathrm{~min}$ ) followed by a circuit training (40 min) including gait and balance exercises. Each session was composed of a set of 10 tasks. Balance and walking tasks (stance on heel/toes, tandem stance, one leg stance, different kinds of walking) alternated with functional strength-endurance exercises (sit to stand, walking up and down a slope, stair climbing and mini hops). Each task was carried out twice during $1 \mathrm{~min}$ and the complexity of the task could progressively be increased (e.g. changing from stable to unstable surfaces (wobble board), increasing step height) [40]. Sessions were completed with interactive games (e.g. badminton, obstacle race in teams) to train agility (10 $\mathrm{min}$ ) and a short feedback with suggestions for individual home exercises (5 min). As currently no specific gait and balance program is offered to diabetic patients, the $C G$ received neither treatment nor specific advice. Both the IG and CG were allowed to continue their usual leisure activities. 


\section{Sample size calculation}

In prior studies the diabetic patients' gait velocity was $1.25 \pm 0.19 \mathrm{~ms}^{-1}$ compared to $1.45 \pm$ $0.14 \mathrm{~ms}^{-1}$ in a healthy CG [3]. Allowing that diabetic patients might improve their mean speed from $1.25 \mathrm{~ms}^{-1}$ to $1.35 \mathrm{~ms}^{-1}$, a total of 64 patients was needed to have an 80 percent probability that the study would detect a treatment difference at a two sided $5 \%$ significance level. We assumed a standard deviation of 0.14 of the response variable. A $10 \%$ drop out rate was hypothesised and therefore we aimed at including 71 patients in total.

\section{Data Analysis}

Statistical analyses were performed using SPSS Version 15 software package for Windows. The student t-test was used to compare baseline similarity. Each outcome was analysed by linear regression (i.e. analysis of covariance). The outcome at 12 weeks (i.e. posttreatment) and 6 months were dependent variables. The intervention allocation was considered as a dichotomous independent variable in the analysis. The baseline values of the outcome measures were incorporated in the linear regression model as covariates.

To reduce the risk of Type I error a Bonferroni corrected alpha level of $p=0.0026$ (alpha divided by number of tests per follow up) was used to determine a significant difference between groups. However, to allow identification of areas of interest for future investigations and to reduce the risk of Type II errors, the results are presented with the corrected $(p=0.0026)$ and uncorrected $(p=0.05)$ significance level.

An intention to treat analysis was performed and in case of missing values of variables, values were imputed by means of the last observation carried forward method.

\section{RESULTS}

The flow chart (Figure 7.1) provides a detailed description of drop outs and loss to followup. 130 persons were contacted; 53 refused to participate, 6 did not meet inclusion criteria. One person developed a depression and 2 were concomitantly diagnosed with cancer and thus cancelled their participation. Finally, 71 patients with diabetes type 2 were randomly assigned, 36 to the CG and 35 to the IG. Five participants of the CG and 7 of the IG were lost to follow- up. Two patients developed pain in their Achilles tendon obliging us to slow down the progression for "toe walking" and "one leg stance" exercises. Exercise adherence ranged from 11 to 24 treatments with a median of 21 . Groups were similar at baseline. Descriptive statistics show patients' characteristics (Table 7.1) and illustrate the improvement of the IG in all variables post-intervention (PI) (Table 7.2; Figure 7.2). 


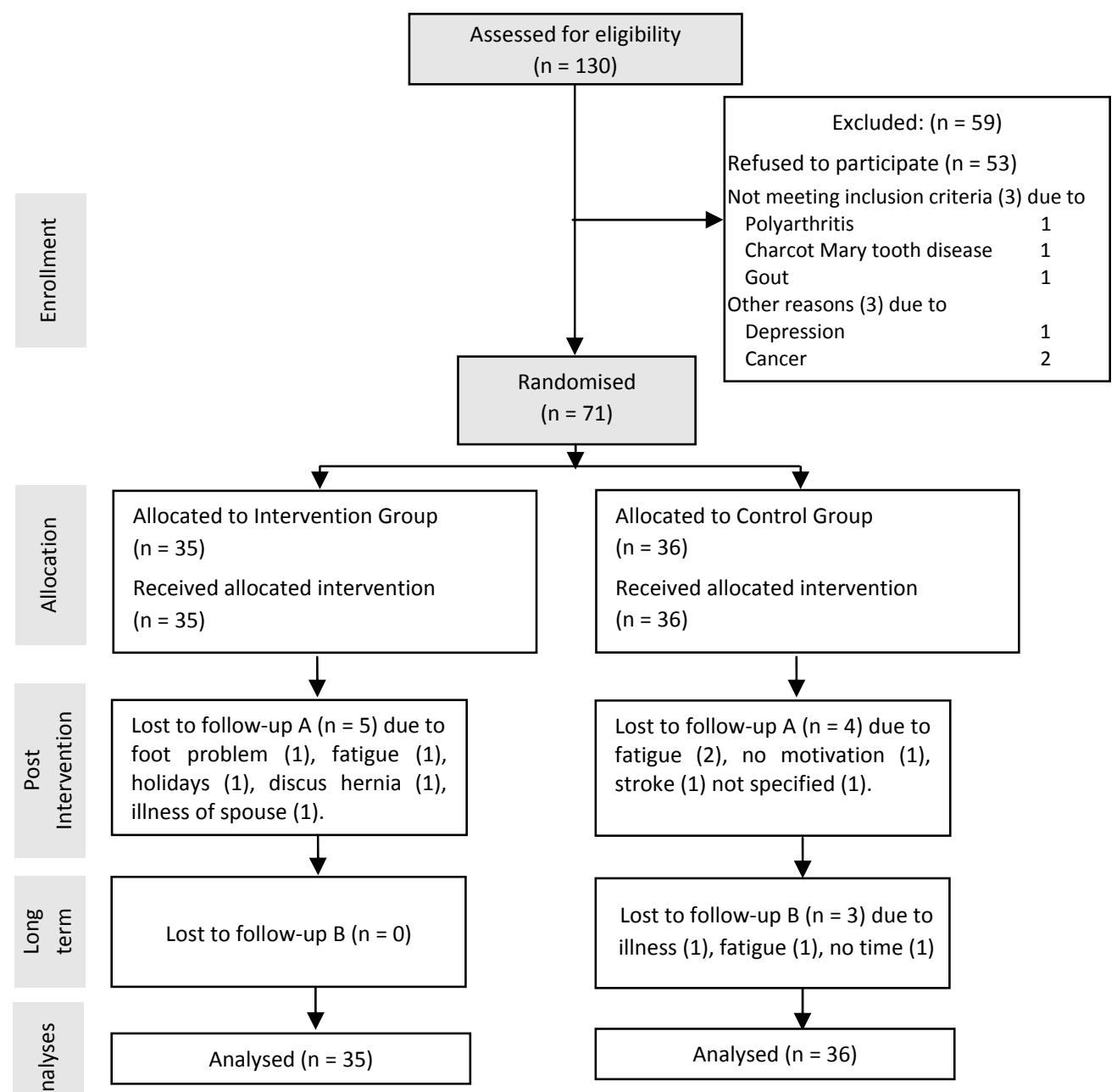

Figure 7.1. Flow chart with detailed description of recruitment, number of drop outs and reasons for abandon. The flow chart is based on the CONSORT statement recommendations [41].

IG participants partially lost their treatment benefit in the 6 month follow-up but their performance remained superior to that at baseline. CG patients' parameters all progressively deteriorated compared to their baseline performance (Table 7.2).

After intervention the IG increased their habitual walking speed by $0.149 \mathrm{~ms}^{-1}\left(0.54 \mathrm{kmh}^{-1}\right.$; $\mathrm{p}<0.001)$ compared to the CG. In addition, a majority of secondary outcome variables showed significant between-group differences (at the Bonferroni corrected significance level of $p<0.0026$ ) in favour of the IG: the dynamic balance test (time to walk over a beam), the POMA test (total score and sub-scores), the Biodex sway index recorded on the level 6, the FES-I score, the hip and ankle plantar flexor strength and the hip flexions mobility. After 6 months, all these variables remained significant $(p<0.0026)$ except for the Biodex sway index $(p=0.005)$ and the ankle plantar flexor strength $(p=0.217)$ (Table 7.2). 
Table 7.1. Description of patients' baseline characteristics

\begin{tabular}{lcc}
\hline Baseline evaluation & Intervention group & Control group \\
& Mean(SD) & Mean (SD) \\
\hline Age (years) & $63(7.99)$ & $64(8.89)$ \\
BMI (kgm ${ }^{-2}$ ) & $30.46(6.03)$ & $31.46(5.25)$ \\
Number of falls in 12 months $^{*}$ & $0.71(1.07)$ & $0.45(0.89)$ \\
Test with Tuning fork (score between 0 and 8) & $3.23(1.26)$ & $3.32(1.32)$ \\
Height (cm) & $166.14(8.5)$ & $168.56(8.64)$ \\
Weight (kg) & $83.62(16.56)$ & $89.17(12.33)$ \\
\hline
\end{tabular}

The table shows the mean and standard deviation of evaluated patients' characteristics per group.

*A fall was defined as an unexpected event in which the participant comes to rest on the ground, floor or a lower level.

(a)

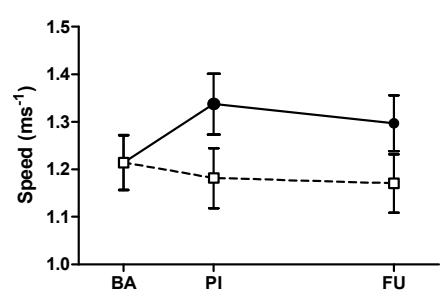

(c)

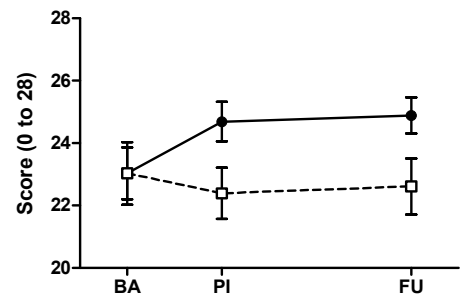

(e)

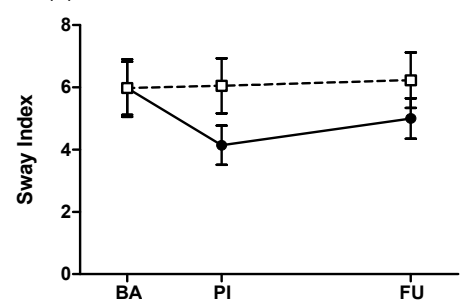

(b)

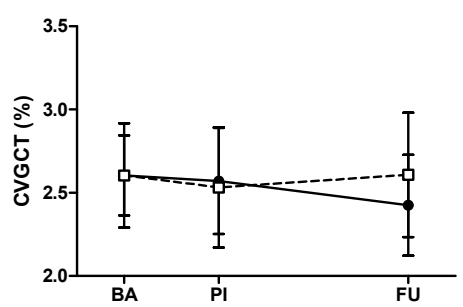

(d)

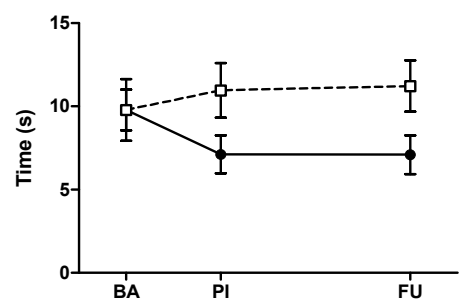

(f)

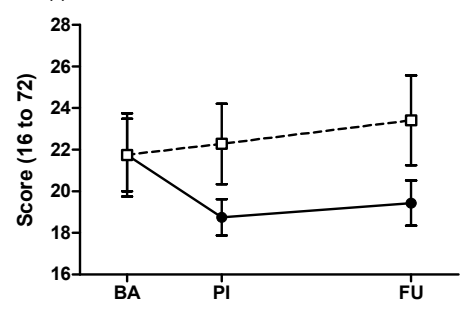

Figure 7.2. Plots illustrating the baseline difference adjusted mean and the $95 \% \mathrm{Cl}$ of (a) gait speed, (b) CVGCT, (c) POMA score, (d) time to walk over a beam, (e) Biodex Sway Index (Level 6), (f) fear of falls for each group at baseline, after the intervention and at the 6 month follow-up. White squares and dotted line indicate the control group (CG), black circles and the continuous line represent the intervention group (IG). 


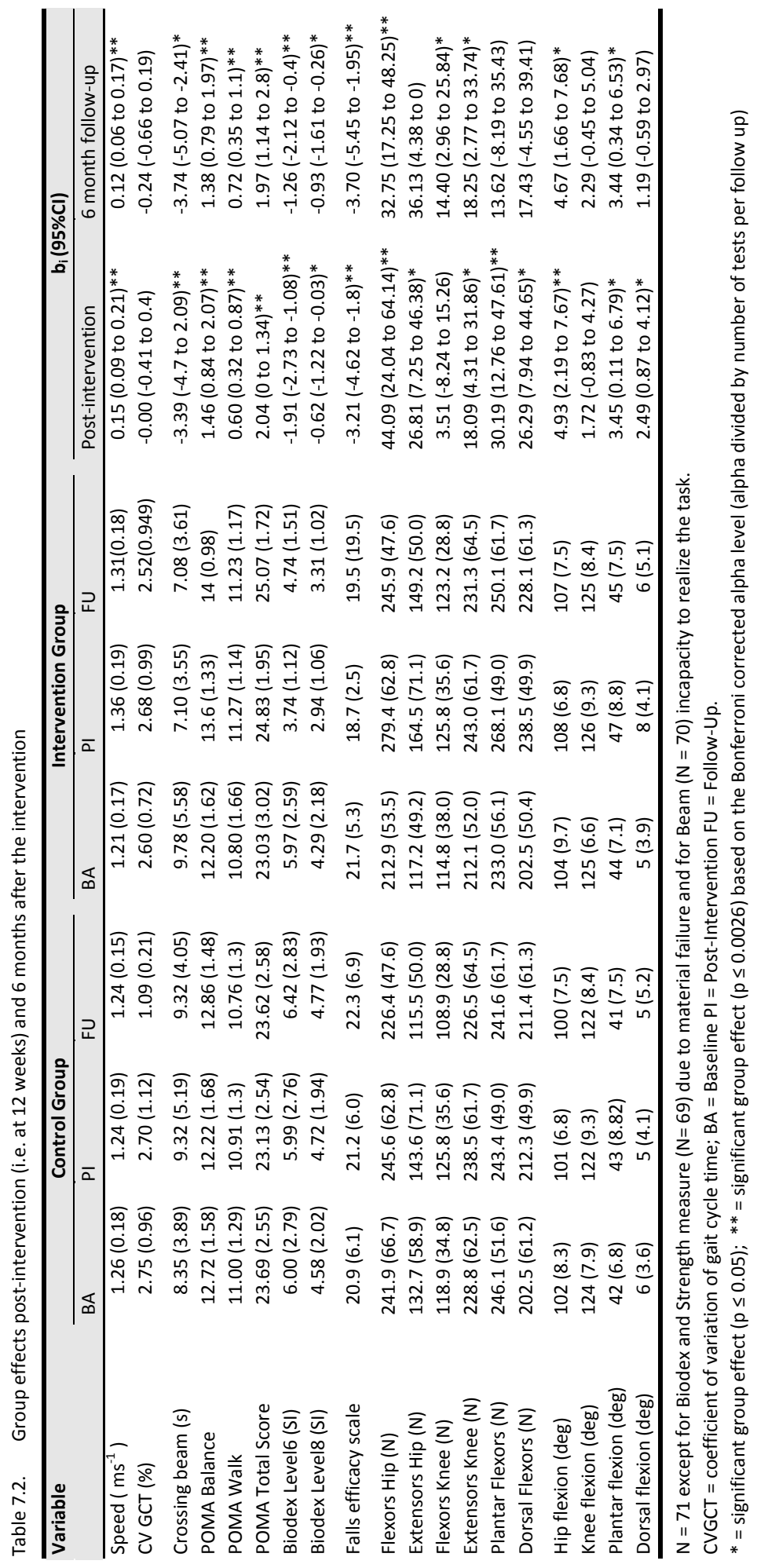




\section{DISCUSSION}

This study aimed to evaluate the effect of a training program, based on core components for successful fall prevention in the elderly [25], on diabetic patients' gait and balance. Our study results confirm that diabetic patients' gait and balance can be concurrently improved by a targeted intervention. Patients in the IG increased gait velocity, balance, muscle strength and joint mobility and decreased their fear of falling. However, post-intervention evaluation showed no difference between groups for the CVGCT (Table 7.2). Possibly the tarred surface was not challenging enough to fully reveal diabetic patients' gait problems. The CVGCT was relatively low at baseline $(2.75 \%$ for CG and $2.6 \%$ for IG) and did consequently not improve (decrease) after treatment, probably due to a floor effect. Step time variability on smooth and irregular surfaces was recently shown to be most strongly associated with reduction in step length on the irregular surface as compared to the smooth surface [42]. Richardson et al. [42] showed that the greater the decrease in step length on the irregular surface, the greater the step time variability on both surfaces and the greater the increase in step time variability on the irregular surface. Thus, it may be that an analysis on a more challenging surface, e.g. cobblestone pathway, which was beyond this paper's aim, would have revealed differences between groups. However, IG patients' amount of improvement in gait velocity $\left(0.54 \mathrm{kmh}^{-1}\right.$ or $\left.11.6 \%\right)$ and dynamic balance - walking over a beam (3.39 s or $34 \%$ ) - are not only significant but also clinically relevant. A decrease in gait speed of $0.1 \mathrm{~ms}^{-1}$ in the elderly has been associated with a $10 \%$ decrease in the ability to perform daily living activities [43]. Balance tests underscored patients' progress. At baseline our population scored 23 to 24 points out of 28 possible on the POMA. These values were just within the critical range (19 to 24 points) that implies a moderate risk for falling [44]. IG patients passed this moderate risk for falling cut-off point after the training. In addition, their change of 2.0 points signifies a real improvement considering that effects greater than 0.8 (with a group size of $n=30$ ), reputedly represent a significant improvement unrelated to chance fluctuations [44]. The more difficult Biodex balance test (level 6) also highlighted patients' progress in postural control. The sway index' decrease of 1.9 at level 6 represents a 31\% progress. All gait and balance parameters (excepting the Biodex balance test) remained significant at 6 month follow-up although some treatment benefit was lost. Increased hip and ankle strength as well as ankle mobility may explain the progress in gait velocity and static and dynamic balance, although that the improvement of ankle dorsal flexor strength and of ankle dorsiflexion mobility just failed to be significant at the Bonferroni corrected significance level. These 2 values further decreased at 6 month which may explain the gait and balance measures' regression. Knee flexion mobility showed normal baseline values, thereby explaining the absence of improvement after training. We decided not to calculate the post-treatment group effect on knee and hip extension mobility as none of the patients had a flexor contracture. Regarding the FES-I, patients showed a relatively small level of concern about falling. Perhaps this result reflects our study population's relatively good gait function and functional capacity. Apparently, the degree of severity of participants' diabetes was moderate, with on average only minimal neuropathy. This may have been influenced by the applied inclusion and exclusion criteria and must be considered for clinical decision making. 
It may be hypothesised that patients with more severe diabetic PN or with worse functional capacity would benefit less from training, due to the fact that, from a functional point of view, the detrimental effects of the disease are impossible to reverse or compensate. However, the reverse may be considered. Patients that suffer from more severe PN may benefit even more from a structured exercise regimen, as their condition gives more scope for improvement. If balance and gait changes noticed in diabetic patients are probably primarily due to neuropathy, there are other potential contributors [5]. The fact that a recent article showed that gait impairments may be observed in diabetic patients without clinically detectable neuropathy [3], raises the question whether it could be worthwhile testing a similar program, only more intensive, on diabetic patients without neuropathy in order to prevent further gait and balance impairments.

All exercises were taught by qualified physiotherapists and were function-orientated. To boost patients' motivation and enable them to interact with other patients the program was carried out in small groups (5 to 8 patients) at the hospital's gymnasium. For further discussion of the results, the effect of our primary outcome was compared with the results of a meta-analysis evaluating the effect of exercise on gait speed in the elderly [22]. This meta-analysis reported a success rate of $57 \%$ for exercise training on habitual gait speed. The overall gait speed change was $0.01 \mathrm{~ms}^{-1}$ compared to our $0.15 \mathrm{~ms}^{-1}$. However, the range of velocity change was large $\left(-0.2 \mathrm{~ms}^{-1}\right.$ to $\left.0.34 \mathrm{~ms}^{-1}\right)$ which could be due to the various studies included, evaluating populations with diverse comorbidities under varied conditions (e.g. $6 \mathrm{~m}$ distance compared to a 6 min walk). We further compared the baseline CVGCT with values reported for elderly patients. The values of our population (CG 2.6\%; IG 2.75\%) are between those reported for elderly non-fallers (2.1\%; mean age of 76 years) and those for elderly fallers (3.8\%; mean age of 82) [45], which was somewhat better than expected. However, this may be explained by the fact that our population was about 15 years younger than the participants in Hausdorff's trial [45].

Despite the beneficial effect of our program on gait speed and balance, its influence on diabetic patients' fall frequency still needs to be properly assessed. Although the CVGCT did not improve, our results provide encouraging data that justify further studies with larger sample sizes focusing on fall frequency itself, physical activity level and quality of life.

Our baseline evaluation contains no information about patients' cardiac status, severity of retinopathy, visual acuity, disease duration, orthostatic hypotension, medications or other possible factors related to gait and balance impairments and to treatment responsiveness. Nevertheless, we assume that randomisation balanced these potential confounders between groups.

The fact that the CG was given no attention at all may have represented a confounder for this study's results. The degree to which participants' improvement depends on personal attention from the therapists, versus the effect of the actual exercise regimen, needs to be considered. However, the positive result on all different measured outcomes clearly points to a beneficial effect due to therapeutic exercise.

Muscle strength was measured with a hand-held dynamometer, which gives a more precise measurement than manual muscle testing. However, the reliability and accuracy of the measurement may be limited by the investigator's ability to hold the dynamometer stationary and by the fact that participants could overpower the testers. We tried to 
minimize this problem by ensuring that the same person always carried out the tests. Nevertheless, the relatively low ratio between the ankle plantar flexor and the ankle dorsal flexor strength may indicate an underestimation of plantar flexor strength. Further investigations should address this limitation. In addition, not only sagittal but also frontal plane muscle strength (i.e. hip abductors and adductors), which is involved in frontal plane stability during gait, should be evaluated.

Although our study showed positive results we would like to caution clinicians about adverse events. Two patients developed pain in their Achilles tendon obliging us to slow down the progression for "toe walking" and "one leg stance" exercises. More moderate progression and a longer warm up could possibly avoid such incidents.

To our best knowledge this is one of the first randomised controlled trials which describe an effective physiotherapy training program to improve concurrently diabetic patients' balance and gait in "challenging" environments. Future studies should examine the effect of exercise regimens on patient groups differentiated by neuropathy status (patients without PN, with mild or with severe $\mathrm{PN}$, identified by a more complex instrument for $\mathrm{PN}^{\prime}$ screening). In addition, outcomes such as patients' functional capacity, the number of falls itself or patients' physical activity level should be considered in order to draw final conclusions about exercise efficacy among patients with diabetes, thereby facilitating medical decision making. To appraise advantages, difficulties and feasibility of "treatment" and/or "prevention" of gait and balance problems and their related fall risk in diabetic patients may be another interesting issue for further quantitative and qualitative studies.

\section{CONCLUSION}

A specific gait and balance training program based on a circuit approach and including gait and balance exercises combined with function-orientated strengthening, can improve gait speed and balance, and increase muscle strength and joint mobility of diabetic patients with a VPT equal to, or lower than 4/8. Further studies with a larger sample size are needed to explore the influence of these improvements on the number of reported falls, patients' physical activity level and quality of life.

\section{ADDITIONAL UNPUBLISHED DATA OF THE RANDOMISED CONTROLLED TRIAL}

In the recently submitted paper describing our randomised controlled trial we chose to present the results for only 2 gait parameters (gait speed and CVGCT measured on a tarred surface), together with the results concerning balance, strength, mobility and fear of falls. The aim was to make the paper of immediate relevance and interest to the clinician. However, several other gait parameters were explored during the study and these findings will also be submitted for publication. For the sake of completeness we summarise below the results of these other evaluated gait parameters. 
Table 7.3 illustrates the gait characteristics of the included patients before and after treatment and at the 6 month follow-up. The IG showed improvement in all variables at post-intervention. IG participants partially lost their treatment benefits during follow-up, but their levels remained superior to that at baseline. All parameters in the CG progressively deteriorated. Table 7.4 provides the corresponding test statistics. After intervention a significant between group difference $(p \leq 0.05)$ was found for all measured variables except for the coefficient of variation of gait cycle time (CVGCT) ( $p=0.99$ for the tarred surface and 0.16 for cobblestones). These differences remained significant at 6 month follow-up (Table7.4).

Table 7.3. Gait characteristics at baseline, post-intervention and after 6 month follow-up

\begin{tabular}{|c|c|c|c|c|c|c|}
\hline \multirow[t]{2}{*}{ Variable } & \multicolumn{2}{|c|}{$\begin{array}{c}\text { Baseline } \\
\text { Mean (SD) }\end{array}$} & \multicolumn{2}{|c|}{$\begin{array}{l}\text { Post-intervention } \\
\text { Mean (SD) }\end{array}$} & \multicolumn{2}{|c|}{$\begin{array}{l}\text { After } 6 \text { months } \\
\text { Mean (SD) }\end{array}$} \\
\hline & $\begin{array}{l}\text { Intervention } \\
\text { Group }\end{array}$ & $\begin{array}{l}\text { Control } \\
\text { Group }\end{array}$ & $\begin{array}{l}\text { Intervention } \\
\text { Group }\end{array}$ & $\begin{array}{l}\text { Control } \\
\text { Group }\end{array}$ & $\begin{array}{l}\text { Intervention } \\
\text { Group }\end{array}$ & $\begin{array}{l}\text { Control } \\
\text { Group }\end{array}$ \\
\hline Speed T $\left(\mathrm{ms}^{-1}\right)$ & $1.22(0.17)$ & $1.26(0.18)$ & $1.36(0.19)$ & $1.24(0.19)$ & $1.31(0.18)$ & $1.24(0.15)$ \\
\hline Speed S $\left(\mathrm{m}^{-1}\right)$ & $1.05(0.21)$ & $1.10(0.21)$ & $1.22(0.23)$ & $1.08(0.21)$ & $1.19(0.23)$ & $1.09(0.21)$ \\
\hline Cad T (stridemin $\left.{ }^{-1}\right)$ & $55.03(5.41)$ & $56.34(5.27)$ & $60.31(6.24)$ & $55.57(4.74)$ & $58.55(5.11)$ & $56.10(4.37)$ \\
\hline Cad S (stridemin ${ }^{-1}$ ) & $50.92(5.8)$ & $52.59(5.78)$ & $56.82(6.75)$ & $51.79(5.52)$ & $55.80(5.68)$ & $52.57(5.45)$ \\
\hline GCT T (\%) & $1.10(0.12)$ & $1.08(0.1)$ & $1.01(0.11)$ & $1.09(0.1)$ & $1.03(0.1)$ & $1.08(0.08)$ \\
\hline GCT S (\%) & $1.20(0.15)$ & $1.16(0.14)$ & $1.07(0.14)$ & $1.18(0.15)$ & $1.09(0.12)$ & $1.16(0.13)$ \\
\hline CVGCT T (\%) & $2.60(0.73)$ & $2.75(0.96)$ & $2.69(0.99)$ & $2.70(1.12)$ & $2.52(0.95)$ & $2.72(0.88)$ \\
\hline CVGCT S (\%) & $4.93(2.61)$ & $5.11(2.27)$ & 4.29 (1.97) & $5.12(2.23)$ & $4.69(2.32)$ & $5.12(2.82)$ \\
\hline Stride $T(m)$ & $1.32(0.13)$ & $1.35(0.15)$ & $1.35(0.14)$ & $1.33(0.17)$ & $1.34(0.14)$ & $1.33(0.16)$ \\
\hline Stride $S(m)$ & $1.24(0.17)$ & $1.25(0.17)$ & $1.29(0.15)$ & $1.24(0.19)$ & $1.27(0.17)$ & $1.24(0.2)$ \\
\hline Stance T (\%) & 60.67 (1.87) & 60.35 (1.78) & $59.69(2.47)$ & 60.55 (1.96) & $60.14(2.28)$ & $60.49(2.03)$ \\
\hline Stance S (\%) & $61.38(2.65)$ & $60.68(1.97)$ & 59.89 (2.39) & $60.91(2.27)$ & $60.36(2.52)$ & $60.69(2.07)$ \\
\hline
\end{tabular}

$\mathrm{CV}=$ coefficient of variation; $\mathrm{GCT}=$ gait cycle time; $\mathrm{Cad}=$ cadence; $\mathrm{T}=$ tarred surface and $\mathrm{S}=$ cobblestones.

Table 7.4. Effect of the treatment exercises on all gait parameters

\begin{tabular}{|c|c|c|c|c|}
\hline \multirow[t]{2}{*}{ Variable } & \multicolumn{2}{|l|}{ Post-intervention } & \multicolumn{2}{|c|}{6 months follow-up } \\
\hline & $\mathrm{b}_{\mathrm{i}}(95 \% \mathrm{Cl})$ & $P$ & bi $(95 \% \mathrm{Cl})$ & $p$ \\
\hline Speed T $\left(\mathrm{ms}^{-1}\right)$ & 0.149 (0.090 to 0.207$)$ & $<0.001$ & 0.117 (0.063 to 0.172$)$ & $<0.001$ \\
\hline Speed S $\left(\mathrm{ms}^{-1}\right)$ & 0.169 (0.111 to 0.226$)$ & $<0.001$ & $0.144(0.081$ to 0.206$)$ & $<0.001$ \\
\hline Cad T (stridemin ${ }^{-1}$ ) & 5.050 (3.663 to 6.437$)$ & $<0.001$ & 3.207 (1.953 to 4.461$)$ & $<0.001$ \\
\hline Cad T (stridemin ${ }^{-1}$ ) & $5.629(4.145$ to 7.114$)$ & $<0.001$ & 4.367 (2.829 to 5.906$)$ & $<0.001$ \\
\hline GCT T (\%) & $-0.089(-0.114$ to -0.065$)$ & $<0.001$ & $-0.059(-0.084$ to -0.035$)$ & $<0.001$ \\
\hline GCT S (\%) & $-0.119(-0.151$ to -0.086$)$ & $<0.001$ & $-0.099(-0.137$ to -0.062$)$ & $<0.001$ \\
\hline CVGCT T (\%) & $-0.003(-0.406$ to 0.400$)$ & 0.989 & $-0.235(-0.659$ to 0.188$)$ & 0.272 \\
\hline CVGCT S (\%) & $-0.533(-1.291$ to 0.224$)$ & 0.164 & $-0.198(-0.906$ to 0.510$)$ & 0.579 \\
\hline Stride $\mathrm{T}(\mathrm{m})$ & $0.043(0.002$ to 0.084$)$ & 0.039 & 0.0510 .011 to 0.091 ) & 0.012 \\
\hline Stride S (m) & 0.060 (0.016 to 0.106$)$ & 0.009 & $0.062(0.014$ to 0.110$)$ & 0.012 \\
\hline Stance T (\%) & $-1.033(-1.561$ to -0.506$)$ & $<0.001$ & $-0.533(-1.105$ to 0.040$)$ & 0.068 \\
\hline Stance S (\%) & $-1.473(-2.027$ to -0.919$)$ & $<0.001$ & $-0.957(-1.570$ to -0.344$)$ & 0.003 \\
\hline
\end{tabular}




\section{REFERENCES}

1. Dyck PJ, Kratz KM, Karnes JL, Litchy WJ, Klein R, Pach JM, Wilson DM, O'Brien PC, Melton L, Service FJ: The prevalence by staged severity of various types of diabetic neuropathy, retinopathy, and nephropathy in a population-based cohort: the Rochester Diabetic Neuropathy Study. Neurology 43:817-824, 1993.

2. Ziegler D, Gries FA, Spuler M, Lessmann F: The epidemiology of diabetic neuropathy. Diabetic Cardiovascular Autonomic Neuropathy Multicenter Study Group. J Diabetes Complications 6:49-57, 1992.

3. Allet L, Armand S, de Bie RA, Pataky Z, Aminian K, Herrmann FR, de Bruin ED: Gait alterations of diabetic patients while walking on different surfaces. Gait Posture 29:488-493, 2009.

4. Allet L, Armand S, Golay A, Monnin D, de Bie R, de Bruin ED: Gait characteristics of diabetic patients: a systematic review. Diabetes Metab Res Rev 24:173-191, 2008.

5. Goldberg A, Russell JW, Alexander NB: Standing balance and trunk position sense in impaired glucose tolerance (IGT)-related peripheral neuropathy. J Neurol Sci 270:165-171, 2008.

6. Bonnet C, Carello C, Turvey MT: Diabetes and postural stability: review and hypotheses. J Mot Behav 41:172190, 2009.

7. Kwon OY, Minor SD, Maluf KS, Mueller MJ: Comparison of muscle activity during walking in subjects with and without diabetic neuropathy. Gait Posture 18:105-113, 2003.

8. Mueller MJ, Minor SD, Sahrmann SA, Schaaf JA, Strube MJ: Differences in the gait characteristics of patients with diabetes and peripheral neuropathy compared with age-matched controls. Phys Ther 74:299-308, 1994.

9. Lafond D, Corriveau H, Prince F: Postural control mechanisms during quiet standing in patients with diabetic sensory neuropathy. Diabetes Care 27:173-178, 2004

10. Nardone A, Grasso M, Schieppati M: Balance control in peripheral neuropathy: are patients equally unstable under static and dynamic conditions? Gait Posture 23:364-373, 2006.

11. Turcot K, Allet L, Golay A, Hoffmeyer P, Armand S: Investigation of Standing Balance in Diabetic Patients with and without peripheral neuropathy using accelerometers. Clin Biomech 24:716-21, 2009.

12. Simoneau GG, Ulbrecht JS, Derr JA, Becker MB, Cavanagh PR: Postural instability in patients with diabetic sensory neuropathy. Diabetes Care 17:1411-1421, 1994.

13. Maurer MS, Burcham J, Cheng $\mathrm{H}$ : Diabetes mellitus is associated with an increased risk of falls in elderly residents of a long-term care facility. J Gerontol A Biol Sci Med Sci 60:1157-1162, 2005.

14. Richardson JK, Sandman D, Vela S: A focused exercise regimen improves clinical measures of balance in patients with peripheral neuropathy. Arch Phys Med Rehabil 82:205-209, 2001.

15. Pataky Z, Vischer U: Diabetic foot disease in the elderly. Diabetes Metab 33 Suppl 1:56-65, 2007.

16. Petrofsky J, Lee S, Cuneo ML: Gait characteristics in patients with type 2 diabetes; improvement after administration of rosiglitazone. Med Sci Monit 11:43-51, 2005.

17. Richardson JK, Thies SB, DeMott TK, Ashton-Miller JA: Interventions improve gait regularity in patients with peripheral neuropathy while walking on an irregular surface under low light. J Am Geriatr Soc 52:510-515, 2004.

18. Nissen SE, Wolski K: Effect of rosiglitazone on the risk of myocardial infarction and death from cardiovascular causes. N Engl J Med 356:2457-2471, 2007.

19. Tsang T, Orr R, Lam P, Comino EJ, Singh MF: Health benefits of Tai Chi for older patients with type 2 diabetes: the "Move It For Diabetes study"--a randomized controlled trial. Clin Interv Aging 2:429-439, 2007.

20. Orr R, Tsang T, Lam P, Comino E, Singh MF: Mobility impairment in type 2 diabetes: association with muscle power and effect of Tai Chi intervention. Diabetes Care 29:2120-2122, 2006.

21. Steadman J, Donaldson N, Kalra L: A randomized controlled trial of an enhanced balance training program to improve mobility and reduce falls in elderly patients. J Am Geriatr Soc 51:847-852, 2003.

22. Lopopolo RB, Greco M, Sullivan D, Craik RL, Mangione KK: Effect of therapeutic exercise on gait speed in community-dwelling elderly people: a meta-analysis. Phys Ther 86:520-540, 2006.

23. de Bruin ED, Murer K: Effect of additional functional exercises on balance in elderly people. Clin Rehabil 21:112121, 2007

24. Hill-Westmoreland EE, Soeken K, Spellbring AM: A meta-analysis of fall prevention programs for the elderly: how effective are they? Nurs Res 51:1-8, 2002.

25. Gillespie LD, Gillespie WJ, Robertson MC, Lamb SE, Cumming RG, Rowe BH: Interventions for preventing falls in elderly people. Cochrane Database Syst Rev:CD000340, 2003.

26. Hausdorff JM, Rios DA, Edelberg HK: Gait variability and fall risk in community-living older adults: a 1-year prospective study. Arch Phys Med Rehabil 82:1050-1056, 2001. 
27. Barnett A, Smith B, Lord SR, Williams M, Baumand A: Community-based group exercise improves balance and reduces falls in at-risk older people: a randomised controlled trial. Age ageing 32:407-414, 2003.

28. Allet L, Armand S, deBie R, Golay A, Pataky Z, Aminian K, deBruin E: Clinical factors associated with gait alterations in diabetic patients. Diabet Med 26:1003-1009, 2009.

29. Kastenbauer T, Sauseng S, Brath H, Abrahamian H, Irsigler K: The value of the Rydel-Seiffer tuning fork as a predictor of diabetic polyneuropathy compared with a neurothesiometer. Diabet Med 21:563-567, 2004.

30. Morey JK, Joshua AC: Strength testing using hand-held dynamometry. Physical Therapy Reviews:99-112, 2005.

31. Yardley L, Beyer N, Hauer K, Kempen G, Piot-Ziegler C, Todd C: Development and initial validation of the Falls Efficacy Scale-International (FES-I). Age ageing 34:614-619, 2005.

32. Tinetti ME: Performance-oriented assessment of mobility problems in elderly patients. J Am Geriatr Soc 34:119-126, 1986.

33. Allet L, Armand S, de Bie R, Golay A, Monnin D, Aminian K, de Bruin ED: Reliability of diabetic patients' gait parameters in a challenging environment. Gait Posture 28:680-686, 2008.

34. Arnold BL, Schmitz RJ: Examination of Balance Measures Produced by the Biodex Stability System. J Athl Train 33:323-327, 1998.

35. Swanik CB, Lephart SM, Rubash HE: Proprioception, kinesthesia, and balance after total knee arthroplasty with cruciate-retaining and posterior stabilized prostheses. J Bone Joint Surg Am 86:328-334, 2004.

36. Barrett CJ, Smerdely P: A comparison of community-based resistance exercise and flexibility exercise for seniors. Aust J Physiother 48:215-219, 2002.

37. Faber MJ, Bosscher RJ, Chin APMJ, van Wieringen PC: Effects of exercise programs on falls and mobility in frail and pre-frail older adults: A multicenter randomized controlled trial. Arch Phys Med Rehabil 87:885-896, 2006.

38. Rubenstein LZ, Josephson KR, Trueblood PR, Loy S, Harker JO, Pietruszka FM, Robbins AS: Effects of a group exercise program on strength, mobility, and falls among fall-prone elderly men. J Gerontol A Biol Sci Med Sci 55:317-321, 2000.

39. Estabrooks PA: Sustaining exercise participation through group cohesion. Exerc Sport Sci Rev 28:63-67, 2000.

40. Robertson MC, Campbell AJ, Gardner MM, Devlin N: Preventing injuries in older people by preventing falls: a meta-analysis of individual-level data. J Am Geriatr Soc 50:905-911, 2002.

41. Boutron I, Moher D, Altman DG, Schulz KF, Ravaud P: Extending the CONSORT statement to randomized trials of nonpharmacologic treatment: explanation and elaboration. Ann Intern Med 148:295-309, 2008.

42. Richardson JK, Thies S, Ashton-Miller JA: An exploration of step time variability on smooth and irregular surfaces in older persons with neuropathy. Clin Biomech 23:349-356, 2008.

43. Judge JO, Schechtman K, Cress E: The relationship between physical performance measures and independence in instrumental activities of daily living. The FICSIT Group. Frailty and Injury: Cooperative Studies of Intervention Trials. J Am Geriatr Soc 44:1332-1341, 1996.

44. Faber MJ, Bosscher RJ, van Wieringen PC: Clinimetric properties of the performance-oriented mobility assessment. Phys Ther 86:944-954, 2006.

45. Hausdorff JM, Edelberg HK, Mitchell SL, Goldberger AL, Wei JY: Increased gait unsteadiness in communitydwelling elderly fallers. Arch Phys Med Rehabil 78:278-283, 1997. 
Chapter 8

General discussion 
The goal of primary public health care is to increase individuals' number of years of good health and to maintain their independence and quality of life for as long as possible [1]. Diabetes and diabetes-related complications may endanger mobility, physical performance and health [2-4]. Gait performance and gait safety are vital for ensuring mobility and independence [5-8]. Moreover, they are essential for carrying out the amount of daily physical activity recommended for preventing diabetes-related complications. Physical exercise in itself is one of the most important intervention strategies to improve physical performance. Exercise has also been shown to minimise or eliminate various fall risk factors such as impaired balance or gait, muscle weakness and limited range of motion [9-13]. Our studies focusing on gait characteristics in diabetic patients were performed with reference to known risk factors. The following chapter provides an overview and a discussion about our main findings and their limitations, as well as implications for practice and for future research.

\section{MAIN FINDINGS AND DISCUSSION}

\section{Systematic Review}

In order to acquire an overview of gait characteristics in patients with type 2 diabetes, we first performed a systematic review of the literature (Chapter 2) [14]. Our review showed that authors investigating gait in a diabetic population are either interested in parameters associated with fall risk (gait speed, step length or step time variability) or with ulcers (pressure). The impact of abnormal gait parameters on falls in diabetic patients has been demonstrated and researchers agree that diabetic patients walk slower and with greater step variability. Nevertheless, results varied across different studies and questions remained about the main causes, especially about factors related to gait abnormalities. Although we know that most falls occur in a complex environment [15], only 2 authors [16, 17] measured gait parameters in a challenging situation (a poorly lit walkway or with partially yielding, irregular surface). Moreover, only few interventions that aim to improve gait parameters were tested (auditory feedback, different shoes or soles, medication) [16, 18-22].

Despite the known gait difficulties of diabetic patients and in spite of the recognition of the significance of gait safety and performance on an individual's fall risk and independence, authors generally do not address these specific parameters in randomised controlled trials. To date, randomised controlled trials evaluating the effect of physical interventions or rehabilitation programs in diabetic patients focus on individuals' mobility [23], musculoskeletal and cardiovascular fitness [23-25], patients' physical activity level [23, 26, 27], insulin resistance [24, 28] or quality of life [24]. Gait parameters seem to be overlooked.

These findings prompted us to investigate gait characteristics in patients with type 2 diabetes in greater detail and to assess the potential beneficial effects of a specific training program on spatiotemporal gait parameters, balance and clinical related factors. So far, no randomised controlled trial, other than the one that we conducted, has investigated the 
effect of a specific physiotherapeutic training program on fall risk related gait parameters of diabetic patients since the aforementioned systematic review [14] was written.

\section{Assessments}

The prerequisite for an objective assessment of diabetic patients' gait parameters in an outdoor setting was to have an appropriate, valid and reliable measurement instrument. In Chapter 3 the precision of an ambulatory gait measurement system (Physilog ; BioAGM, $\mathrm{CH}$ ) with which to assess diabetic patients' gait while walking on a tarred surface, grass and on cobblestones was investigated [29]. The Physilog ${ }^{\circ}$ was shown to be a useful, reliable instrument for ambulatory gait assessment in a challenging environment for diabetic patients.

\section{Gait characteristics of diabetic patients while walking under real life conditions}

Based on the results of our systematic review, we were interested to know if gait parameters deteriorate proportionally to the severity of diabetes. We also wondered whether a more complex surface could reveal gait difficulties of patients better. We therefore conducted a study to evaluate the gait of 3 patient groups (healthy controls versus diabetic patients without peripheral neuropathy (PN), versus diabetic patients with PN) while participants walked on a tarred surface, grass and on cobblestones (Chapter 4) [30]. Results showed that gait parameters differ between healthy controls and diabetic patients with PN (for all measured parameters: speed, cadence, stance, double support, stride length, gait cycle time, knee range, thigh range, shin range and coefficient of variation of stride length and gait cycle time). We further demonstrated a difference between healthy controls and diabetic patients without PN for gait speed, cadence and gait cycle time. The gait parameters in diabetic patients with PN tend to be more altered than gait parameters in patients without PN. However, no significant difference was detected between patients with and without PN. These results indicate that gait parameters are already altered before PN is clinically detectable, a statement which is in line with the study results of Petrofsky et al. [31]. These authors investigated gait in a group of subjects with no impairment in feeling and no discernable loss of muscle strength. Slower reaction time and greater motor error at the joints (acceleration) were observed. The authors explained these findings by somatic motor and vestibular damage associated with diabetes. The mechanism of damage to the vestibular, somatic and autonomous nervous systems has been linked to compromised microcirculation associated with poor glycaemic control in type 2 diabetes. The vestibular apparatus in the inner ear and nerve synapses are richly vascularised: the diminished supply of oxygen and nutrients consecutive to microvascular lesions may be therefore expected to decrease autonomic and somatic reflexes [31, 32]. Petrofsky et al. [31] concluded that whatever the mechanism of endothelial cell damage in the peripheral circulation, there is indication of gait impairment independent of muscle strength and sensory loss in the foot. They further suggested that while part of the abruptness in gait could be linked to vestibular losses, another explanation might be the slowing of nerve conduction itself in the somatic nervous system, including the cerebellum 
or motor cortex. A recent report [33] describes slowing of conduction in the peripheral nervous system (dorsal sural nerve) in diabetic patients (children with type 1 diabetes) before noticeable sensory and motor loss becomes apparent. A sluggish conduction would slow reflexes and motor control schemes and cause errors in movement, represented by increases in the acceleration at the joints during gait and an increased risk of falling. The overview of these findings confirmed the importance of further investigations regarding the factors associated with gait alterations in patients with diabetes.

In addition to the observation of gait parameters in healthy controls and diabetic patients with and without PN, we were interested in the walking strategy of diabetic patients when they have to change from a regular to an irregular surface. Diabetic patients with and without PN adjust their walking technique to the varying of surfaces by using identical strategies. These strategies were similar to those used by healthy controls. To change from a level (tarred) to an irregular surface (cobblestones), patients with diabetes and controls decreased their gait speed by reducing their cadence and increasing their gait cycle time. They also shortened their stride length and increased their stride to stride variability. Nevertheless, the highest surface effect was found in patients with diabetic PN followed by patients without PN and lastly healthy controls. These observations illustrate how patients act in response to challenging environments, even if these conditions only approximate real life. Real life conditions require an unsupervised assessment in the patient's usual environment. To adequately evaluate the influence of varying surfaces on these patients' gait, one needs to know which gait strategy to associate with which surface and thus a supervised and standardised acquisition of data is necessary. Furthermore, real life conditions should incorporate a combination of stair climbing, walking up and down a slope, crossing a street and other multiple-task situations for which the measurement system used has yet to be validated.

\section{Standing balance in diabetic patients with and without neuropathy}

In the presence of diabetic PN, both plantar cutaneous and proprioceptive sensations are compromised, thus resulting in postural instability and increased risk of falling [34]. Falling is a complex phenomenon and poor balance is one of the major risk factors for falls among the elderly. We therefore also investigated standing balance with eyes open and eyes closed using accelerometers and the Performance-Oriented Mobility Assessment scale for balance (POMA-B) [35] in diabetic patients with and without PN (Chapter 5). Results confirmed that diabetic patients with $\mathrm{PN}$ have higher postural instability with higher acceleration values than those of the control group and diabetic patients without PN. Furthermore, postural instability increased with eyes closed. The greatest difference between eyes open and eyes closed was found in diabetic patients with PN.

Taking into account our previous findings, we can conclude that gait and balance impairments seem to increase with the presence of neuropathy (screened by vibration perception threshold (VPT)). However, in the study which compared gait parameters of healthy controls with patients with and without PN (Chapter 4), significant gait alterations were already observable in patients without PN. With regard to balance, balance impairments tended to progressively increase from healthy controls to diabetic patients 
without PN and patients with PN. However, the only significant difference was that observed between healthy controls and patients with PN. Nevertheless, these balance impairments seem likely to contribute to the gait alterations of diabetic patients.

Structures, such as muscles, the vestibular system, or receptors involved in the perception of the position of a body-part (proprioception) affect both gait and balance. Consequently, the results of this study provided relevant and useful information for the development of a specific treatment approach.

\section{Clinical factors associated with gait difficulties of patients with type $\mathbf{2}$ diabetes}

In Chapter 6, clinical factors associated with gait difficulties of patients with type 2 diabetes are identified. It was decided to focus on 2 clinically relevant and commonly used fall related gait parameters, gait speed and the coefficient of variation of the gait cycle time (CVGCT). Regression analysis showed that the reduction of gait speed observed on cobblestones, compared with a tarred terrain, was partially associated with the mean of maximal isometric lower limb strength, fear of falls and participants' perceived vibration threshold. Mean maximal isometric strength was associated with an increased CVGCT in the same conditions. Since gait speed was shown to influence volunteers' gait variability [36] we also added the variable "speed difference" as an independent variable to our regression model. However, in this model, strength was no longer considered as a factor influencing the CVGCT. Therefore it may have been interesting to adjust for speed. However, as gait speed itself was one of the variables of interest, these adjustments could not be carried out.

This study documents relevant factors to be addressed when developing specific physiotherapy programs to improve diabetic patients' gait performance and safety. It was concluded that treatment programs for diabetic patients should consider both physiological (strength and proprioception) and cognitive-behavioural factors (fear of falls). They should include progressively more complex strength exercises, proprioceptive training and daily life activities in order to improve diabetic patients' self-assurance.

While the fact that patients with diabetic PN exhibit gait instability may appear trivial to the treating clinician, our results show the importance of considering the increased fall risk in a wider context. This result is in line with our previous findings (Chapter 4), where it was found that gait parameters are already altered before $\mathrm{PN}$ is clinically detectable and therefore factors, other than sensory loss, should be considered.

When these results are compared to other studies some interesting points emerge. The association between fear of falls and gait speed difference, for example, is similar to the results of Chamberlin et al. [37] who found that fearful walkers demonstrated a slower walking speed, shorter stride length and longer double support time than walkers not identified as fearful. However, regarding cognitive-behavioural factors, we only investigated fear of falling. It may have been interesting to consider other factors such as patients' motivation or awareness of the disease.

Regarding the context of sensory loss and gait alterations, several studies deserve to be mentioned. Deshpande et al. [38] evaluated the association of vibrotactile and monofilament sensitivity with self-selected usual gait speed and gait speed over a 
challenging narrow (20 cm wide) course in an elderly population. Both vibrotactile and monofilament sensitivity were significantly worse in elderly people who demonstrated reduced gait speed. However, after having adjusted for covariates (knee extensor torque, standing balance, visual acuity and contrast sensitivity, knee pain, depressive symptoms, high fasting glucose levels and peripheral arterial disease), vibrotactile, but not monofilament sensitivity, was independently associated with self-selected normal gait speed. Deshpande et al. [38] further stated that neither sensory function was associated with narrow-base gait speed, which was not studied in our population (see Chapter 6).

Another study published in 2009 by Wrobel et al. [39] investigated, similarly to our study, clinical factors associated with a conservative gait pattern in older male veterans with diabetes. Conservative gait pattern was defined using visual gait analysis as failure to demonstrate a heel-to-toe gait during the propulsive phase. As could be expected, patients with a conservative gait pattern had a lower walking speed and decreased stride length compared to normal gait. In multivariate analysis, walking speed, age, ankle dorsiflexion and the presence of a forefoot weight-bearing callus were retained in the final model and explained $36 \%$ of the variance. The authors underscored the fact that with the inclusion of ankle dorsiflexion in the multivariate model, monofilament insensitivity was no longer an independent predictor for a conservative gait pattern. Walking speed, advanced age, limited ankle dorsiflexion and forefoot weight-bearing callus therefore characterise conservative gait better than clinical measures of neuropathy. In spite of their similarities, however, a one-to-one comparison between our findings and the findings of Wrobel et al. [39] cannot be performed, since we used gait speed as the dependent variable, whereas Wrobel et al. [39] used gait speed as an independent variable for explaining the conservative gait pattern. Nonetheless, these authors' results are of interest, because monofilament insensitivity did not explain the patients' conservative gait pattern.

Similar to the results of Deshpande et al. [38] and Wrobel et al. [39], monofilament sensitivity was also not associated with diabetic patients' gait alterations (reduced speed or increased CVGCT) in our study (Chapter 6). However, the gait speed reduction in our study was associated with the individuals' perceived vibration threshold, which is another commonly used clinical diagnostic test for PN [40].

The test with monofilaments detects deteriorating sensory perception and absence of protective sensation [41]. It is thus a clinical tool for the detection of diabetic peripheral sensory neuropathy. The tuning fork is another commonly used screening tool for peripheral nerve dysfunction and symptomatic neuropathy [40]. It was shown to reliably detect peripheral neuropathy in comparison with the neurothesiometer [40]. More indepth investigations examining the association and interaction between gait parameters, monofilament insensitivity and abnormal perception of vibration are necessary and may reveal interesting findings for a better understanding of diabetic patients gait alterations. Although both methods mentioned above (monofilament and VPT) are commonly used clinical tools for evaluating diabetic PN, neither of them represents the gold standard tool for evaluating peripheral neuropathies. The diagnostic gold standard for PN is thought to be invasive electroneuromyography (ENMG), a test which may be complemented by nerve and muscle imaging [42]. Consequently the results of our study and those of Deshpande et al. [38] and Wrobel et al. [39] should be interpreted with care and it seems premature to 
draw any final conclusions about the degree of neuropathy itself on diabetic patients' gait alterations.

We further wondered why Wrobel et al. [39] found an association between ankle dorsiflexion mobility and conservative gait when ankle dorsiflexion was not retained in our final model. One explanation could be that variables such as strength, VPT and fear of falling were not considered in their study [39].

Regarding the positive relationship between the decrease in gait speed and muscle strength in our study, similar results were previously described, for example, by Chang et al. [43]. They noted that quadriceps strength and hip flexion strength are associated with walking speed in an elderly population. Manor et al. [44], who investigated functional gait characteristics among individuals with and without PN, demonstrated that the PN group presented reduced functional gait, indicated by decreased "6 min walking distance" and increased "timed up and go time". The PN group further presented a greater area of the centre of pressure trajectory during quiet standing and a higher standard deviation of the mean gait cycle time during treadmill walking. No group differences were observed in the knee extensor peak torque or local instability during treadmill walking (rate of kinematic divergence caused by small-scale perturbations). Interestingly, in control subjects leg strength and gait kinematics, but not standing balance, correlated significantly with functional gait, whereas in the PN group, neither measures of leg strength nor locomotor kinematics were significantly correlated with functional gait. Instead, only standing balance was associated with shorter "6 min walking distance" and longer "timed up and go time". The authors of this study concluded that leg strength is an important factor for functional gait, providing that standing balance is adequate. Good standing balance seems thus to be a pre-requisite to functional gait in the PN group, contrary to individuals without PN. For this reason authors of this study recommend to tailor functional gait-related rehabilitation programs specifically for PN patients. In our study a relationship between strength and gait of diabetic patients was identified. However, we have not evaluated the associated factors separately for patients with or without PN. In addition it should be noted that in the study of Manor et al. [44] leg strength refers to the knee extensor peak torque, whereas in our study leg strength refers to the mean of the isometric hip, knee and ankle strength. Another difference is the environment of the gait evaluation. We focused on gait parameters evaluated outdoors, instead of on tests conducted under artificial and indoor conditions.

In our study, because of the rather small sample size, no association between individual muscle groups and dependent variables "walking speed difference" or the "stride to stride variability difference" could be evaluated. Perhaps lower limb weakness, especially of plantar flexors and hip extensors, influenced joint moments and muscle power, which play also an important role in gait speed and balance recovery. We believe that further evaluation of three-dimensional kinematics, kinetics and muscle activity parameters could provide extra information about the causes for gait alterations and increased fall risk. Neuropathy, together with muscle weakness, could influence the neuromuscular control process. Both may affect not only joint moments and power generation but also the timing of muscle activation and thus gait performance [45]. Muscle weakness and reduced reaction time were previously associated with increased sway and increased fall risk [46]. 
As diabetic PN leads to feedback delays, perhaps increased ankle moment latency in response to perturbations (i.e. walking over cobblestones) causes patients with PN to be unstable, which results in a slow gait and an increased gait variability. However, again no definitive conclusion may be drawn. Reduced gait speed could also be a simple adaptation strategy as discussed earlier with reference to Chamberlin et al. [37]. Perhaps diabetic patients walk slower because of the altered neuromuscular control processes leading to decreased balance and consequently fear of falling. The association between participants' fear of falling and decreased speed could support this theory. Slowing down might be a security strategy to feel safer on irregular terrains.

\section{Efficiency of a physiotherapeutic approach to improve diabetic patients gait and gait- related clinical factors}

The main part of this thesis consists of the development of a physiotherapeutic approach to improve diabetic patients' gait and gait-related clinical factors. The effectiveness of this treatment had then to be assessed (Chapter 7). The intervention investigated was performed twice a week for 12 weeks. Patients in the intervention group significantly improved their gait speed, their balance (time to walk over a beam and balance index recorded on a Biodex balance system), their performance oriented mobility (POMA), their degree of concern about falling, their hip and ankle plantar flexor strength and their hip flexion mobility, compared to the control group. The positive effect mostly remained significant at 6 month follow-up although some treatment benefits were lost. This indicates the need for a periodically renewed participation in such a program. It can be concluded that the specific training program, which was based on a circuit approach including gait and balance exercises combined with function-oriented strengthening, improved diabetic patients' gait speed and balance and increased muscle strength and joint mobility. The improvements in gait speed and balance were also shown to be clinically relevant.

In order to understand the absence of improvement of the CVGCT, we compared the baseline values of the CVGCT of our study population with values reported for elderly patients. The values of our population (control group 2.6; intervention group 2.75) are between those reported for elderly non-fallers (2.1; mean age of 76) and those for elderly fallers (3.8; mean age of 82) [47], which was somewhat better than expected. This may be explained by the fact that our population was about 15 years younger than participants in Hausdorff et al.'s trial [47]. Thus, maybe the relatively low (good) CVGCT of our population at baseline explained the lack of improvement. For this reason, we expected the treatment effect to be greater on the CVGCT measured on the more challenging cobblestone surface. This however, was shown not to be the case (see additional data chapter 7). Another possible explanation is that the intervention period of 12 weeks was not long enough to produce a significant improvement in the CVGCT. In addition, as gait parameters of diabetic patients were shown to decline with the severity of disease, maintaining a baseline value could be considered a positive result.

Concerning the Falls Efficacy Scale we were surprised at patients' relatively small level of concern about falling. Given the results of the previous study [48], which showed an association between the decrease in gait speed and fear of falls, we expected our patients 
to be more afraid of falling. The clinical importance of this issue warrants further discussion and evaluation. Future qualitative studies may also usefully investigate this topic. Furthermore, other cognitive-behavioural factors, such as motivation, awareness of difficulties, general beliefs and self-efficacy should be taken into account. Finally, it must be specified that our results are applicable to patients with a VPT equal to, or lower than $4 / 8$. A training program such as ours may not have any significantly beneficial impact on patients with more severe diabetic PN, due to the extent and potentially irreversible character of the physiological damages in these patients. Conversely, more severe PN may offer greater scope for improvement with carefully tailored rehabilitation. A further study is needed to clarify these hypotheses.

\section{LIMITATIONS: \\ METHODOLOGICAL AND INTERVENTION RELATED CONSIDERATIONS}

\section{Group attribution}

Diabetic patients with PN or patients without PN were divided in groups based on a clinical test. This test measures the VPT with a $128 \mathrm{~Hz}$ Rydel-Seiffer tuning fork at the big toe and medial malleolus of both feet. The vibration is evaluated on a 9-point scale (0-8) and the patient is considered to have PN if the VPT is equal to, or lower than 4/8. Although this tool is recommended as a screening test for diabetic PN [40], it cannot precisely evaluate the degree of severity of peripheral neuropathy. To do so, more complex methods like ENG or ENMG $[42,49]$ are needed. For this reason, in the study identifying factors associated with gait abnormalities, we could only conclude that PN was associated with gait abnormalities, without making any distinction between the degrees of severity of neuropathy.

\section{Surface effect}

A recent study [50] showed that individuals probably choose a higher gait speed strategy over long walking distances $(20 \mathrm{~m})$ than on short walking distances $(10 \mathrm{~m})$. To evaluate the effect of 3 surfaces, gait parameters on a tarred pathway, grass and cobblestones were compared. The walking distances for all surfaces were equal to, or greater than $20 \mathrm{~m}$. However, the walking distance on cobblestones was only $20 \mathrm{~m}$ while the distance on the tarred surface and grass was $50 \mathrm{~m}$. Najafi et al. [50] brought 2 potential biases to our attention in the interpretation of the results concerning the influence of surfaces on gait parameters. Firstly, we did not evaluate fatigue during the $50 \mathrm{~m}$ walk on the tarred surface or grass. Secondly, regarding the change from slow to fast when comparing a short $(10 \mathrm{~m})$ to a long $(20 \mathrm{~m})$ distance in the study of Najafi [50], we cannot exclude that the change from a long distance $(20 \mathrm{~m})$ to an even longer distance (50 meter) would provoke another speed switch. However, only the comparisons between the different surfaces may have been potentially biased by this distance change during testing. As the protocol is the same for all the subjects, the differences between groups (healthy versus patients with PN versus 
patients without PN) and the comparisons between pre- and post-treatment could not have been affected. Further research is required to investigate the trigger distances when the walking strategy switches from slow to fast.

\section{Standing balance}

The article evaluating standing balance [51] confirms the instability of diabetic patients with PN and highlights the tendency that balance instability increases with the severity of disease. Patients had a self-selected preferred standing position during the testing because of the fact that the recording of the accelerations on trunk and shin were simultaneously done with the POMA-B test. The POMA-B test normally requires free foot position for the "eyes open" test, whereas feet are kept as close together as possible for the "eyes closed" position. The fact that each subject chose their own foot position might have reduced or even eliminated differences between groups with regards to the acceleration values. Thus, it is likely that the differences between groups would have been even more important had foot placement been imposed.

In our study, in order to compare the condition "eyes open" with "eyes closed", patients maintained the same chosen foot position during the whole POMA-B test, which may have influenced the test results. For this reason a slight overestimation of the POMA-B score can also not be excluded. However, as it was the same for every group, this methodological weakness will probably not have influenced the between-group difference as regards the POMA-B.

\section{Selected dependent variables in the study: clinical factors associated with gait alterations in diabetic patients}

Our study evaluating factors associated with gait alterations was not exhaustive. Firstly, only global muscle strength was added to the model because our sample size did not allow us to consider separate muscle groups. Occasionally patients had some difficulty recruiting muscles selectively or to understand the isometric leg strength tests, which may have negatively influenced their real performance. Secondly, variables other than the mainly physical ones, such as mental status, duration of disease or medication, may also be associated with gait difficulties although they were not evaluated here.

\section{Randomised controlled trial and subjects}

The intervention study included only patients with a VPT equal to, or lower than $4 / 8$. Consequently, the positive results of our intervention study cannot be generalised to all diabetic patients. In addition patients' responsiveness was an issue, in particular that of patients with more severe diabetes. The patients who took part in our project were basically willing to perform physical exercises. Thus, the final study population is probably not representative of the most severely affected diabetic patients, who also present the worst gait alterations. This observation was confirmed by the relatively high VPT score (mean $=3.3$ ) and the limited mean number of falls per person during the last 12 months $(<$ 
1). In addition, at baseline the outcome parameters were generally rather higher than expected. This fact influences the external validity and must thus be considered for clinical decision making and when comparing our results with those of other studies. Future studies should include patients with and without PN. In order to have enough participants with severe diabetic PN, multicentre studies might be helpful.

\section{Randomised controlled trial and blinding}

The study's quality would improve considerably with a double blinded study design. This is, however, one of the most problematical points for all non-drug clinical trials. Patients know if they receive a treatment or not and which kind of treatment protocol they have joined. Furthermore, the investigator (L.A.) was not blinded as she also had to conduct the physiotherapy program.

\section{Randomised controlled trial and main outcome}

A major challenge is to determine the best outcome measure to use. In this intervention study we focused on gait speed and CVGCT. These are 2 clinically relevant gait parameters which are also currently used as fall risk predictors. In our intervention study all gait parameters were measured outdoors on predefined walking distances. With this method we expected to assess subjects' gait during daily life more adequately. Measuring gait outdoors also enabled us to evaluate several gait cycles over a long distance. This strategy was approved by the results of a recent study [50] where test-retest reliability for long walking distances was consistently better than for short walking distances. However, the same authors observed that test-retest reliability for gait variability was poor, irrespective of walking distance or instrument. When we studied the reliability of the Physilog, we only assessed the "direct" outcomes and not the calculated stride to stride variability (SD/mean $\times 100$ ). With respect to this recent result of Najafi et al. [50] and in view of the known speed dependence of the CVGCT [36], the value of the measured stride to stride variability as an independent fall risk predictor should be re-discussed. In addition, the CVGCT of our population was rather low. Thus, another question to be addressed is whether the CVGCT threshold previously elaborated in the elderly [52] can be applied to diabetic patients.

Our data was recorded on challenging surfaces and therefore reflects real life conditions better than studies conducted in a gait laboratory. Nevertheless, such conditions remain an approximation to real life situations. The walkway had to be standardised in order to fulfil the methodological criteria for a research proposal.

This intervention study was important to establish whether gait in diabetes patients could be improved with a specific training program. Gait parameters and clinical variables such as strength are of great clinical relevance. However, these outcomes are only considered as a proxy to fall events. We cannot make any conclusions about falls themselves at this point in time. The Prevention of Falls Network Europe (ProFaNE) [53], a collaborative project to reduce the burden of fall injuries in older people, clearly recommends focusing on falls as a primary outcome in trials that intend to reduce falls in older persons. Further studies with a 
larger sample size and longer follow-up are therefore needed to focus on diabetic patients' falls as a primary outcome.

\section{Randomised controlled trial and compliance}

The subjects in this randomised controlled trial are volunteers who agreed to participate and who signed the informed consent. It would therefore be reasonable to believe that they were motivated to perform the exercises. Nevertheless, some individuals needed to be re-motivated regularly by the physiotherapists. Considering this, it would have been interesting to evaluate patients' compliance with the individual tailored advice for home exercise - an issue that was omitted in the elaboration of this study protocol. Patient motivation seems to be a serious challenge. A more qualitative study aiming to evaluate experience, beliefs, motivation and attitudes of patients concerning this specific program may be helpful in order to achieve and optimise compliance, adherence and selfmanagement. In a similar vein, it would also be interesting to evaluate the effect of patients' education about their condition on their compliance with the treatment program.

\section{Randomised controlled trial and adverse events}

Two patients developed pain in their Achilles tendon obliging us to slow down the progression for "toe walking" and "one leg stance" exercises. More moderate progression and a longer warm up could probably avoid such incidents.

\section{IMPLICATION FOR PRACTICE}

Although further research is needed to provide a stronger evidence base for the clinical usefulness of our treatment approach, our initial results show that patients with type 2 diabetes may benefit from a specific gait and balance training program. A major challenge, however, is managing patients' compliance. Diabetic patients are known to show only moderate motivation as well as poor compliance concerning the completion of treatments. A recent study [54] showed that $71.9 \%$ of patients with type 2 diabetes were not achieving the recommended physical activity levels. Physiotherapists in our study constantly encouraged and motivated the participants. We think that this therapeutic attitude, together with a "group effect", helped to ensure that patients took part in a maximum number of training sessions. Social interaction and enjoyment may promote long-term participation [55]. For this reason, we believe that this particular population needs supervised training. Training improved gait parameters, balance, strength and joint mobility. Moreover, patients were sure to perform their recommended physical activity twice a week. However, as it was shown that the training effect decreased after 6 months, it is recommended that diabetic patients should take part twice a year in such a specific training program. Unfortunately, no such training program is currently offered at the University Hospital of Geneva. It is now important not only to publish this data, but also to consider how to integrate these findings into everyday clinical practice. 
Collaboration between hospitals, patient organisations and other interested parties may facilitate and enhance the organisation of specific training programs. Thus, first contacts with the Diabetes Association in Geneva have been established and collaboration strategies between the University Hospital of Geneva and the Diabetes Association have been discussed. It was agreed that each party, with its specific competencies, could usefully contribute to the project. The hospital is responsible for providing well trained therapists, guaranteeing the quality of treatment and allocating an adequate infrastructure. The associations would be in charge of propagating the program (e.g. placing leaflets at patients' disposal via general practitioners), emphasising its importance and performing all administrative tasks (e.g. registration, physiotherapists' remuneration, patient information etc.) An initial program should start in September 2009. At the same time, this newly developed program could offer further research possibilities such as the evaluation of participants' beliefs and experience, which could be the basis for recommendations on the behavioural-cognitive aspects to be considered in a training program for type 2 diabetes subjects. An overview of behaviours influencing treatment adherence, the type of patients which participate in such training programs and information about the potential reasons why others refuse to join in could be used by health care professionals and managers for future organisation, to improve patients' motivation and treatment adherence.

\section{DIRECTIONS FOR FUTURE RESEARCH}

Ideas for future research, with 2 main directions, have emerged from this work on diabetic patients gait alterations: understanding gait alterations and evaluating the effect of the physiotherapy program.

\section{Understanding gait alterations}

Gait as a screening tool in neuropathy

It would be interesting to examine, by using ENMG and muscle imaging, the relationship between the severity of neuropathy and gait characteristics and that between the severity of neuropathy and balance. Gait alterations or balance impairments could signal the early onset of neuropathy, undetected by the more commonly used clinical tests. If so, gait analysis and balance assessments could become useful screening tools and thus improve clinical decision making.

\section{Evaluating gait characteristics under self-selected speed and imposed speed}

To compare diabetic patients' gait characteristics under both conditions (e.g. self-selected speed and imposed speed) may enhance the understanding of the different speed dependent gait parameters.

Post-perturbation feedback loop delay as cause of gait and balance alteration

Understanding of the mechanisms underlying diabetic individuals' gait and balance alterations could be further enhanced by studying the relationship between specific muscle groups and gait. Similarly, post-perturbation step characteristics (e.g. post-perturbation 
step width) and post-perturbation feedback loop delay (FLD - e.g. ankle inversion moment latency and inversion force latency) may be of mechanistic but also of clinical interest: a research team at the University of Michigan (USA) has recently started investigating such post-perturbation stimuli characteristics.

\section{Effect of the physiotherapy program}

Impact of the treatment program on falls themselves

A major concern is to evaluate the impact of this program on fall risk itself [53]. In view of this objective, a study with a larger sample size and a longer follow-up is needed. The same study could further assess the impact of the program on patients' physical activity level and their quality of daily life. These subsequent intervention studies should evaluate patients with and without PN. Our intervention study only included patients with a VPT equal to, or lower than 4/8. A subgroup analysis for different degrees of diabetes severity may help to identify the target population for such training programs. For example, individuals with diabetes, but without clinically detectable neuropathy, may also benefit from such a program, since we showed that these subjects have impaired gait as well. In our trial, the content of the physiotherapeutic treatment was chosen with reference to successful training programs for the elderly. Gait and balance training for diabetic patients may, however, benefit from other approaches such as the providing of assistive technologies, practicing walking in different environments alone, or a simple muscle strengthening program. More research is needed to explore these issues.

Impact of this program on compliance and patient satisfaction

Rehabilitation requires individuals' adherence and compliance, which is why the evaluation of objective functional components should be complemented with the assessment of the beliefs and perceptions of the participants. Similarly, a measure of the effect of patient education programs on compliance with treatment interventions could also serve to confirm or to question programs' value in disease management.

Cost-effectiveness of this program

Lastly, an evaluation of the consequences of falls in diabetic patients and their related costs, as well as an assessment of the benefit and costs of the treatment could provide further information about the utility of such intervention programs.

\section{PERSONAL OPINION AND CONCLUSIONS}

Diabetes is an international problem and a growing public health burden across the world. The increasing prevalence of diabetes will inevitably result in a greater number of patients presenting complications (micro-and macrovascular disease, retinopathy, nephropathy and neuropathy). Thus, the International Diabetes Federation has suggested using a multidisciplinary care team with specific diabetes expertise maintained by continuing professional education [56]. My experience is that physiotherapists, at least in Switzerland, are poorly integrated in the management of diabetes. Although there is ample evidence 
about gait difficulties and increased risk of falling in diabetic patients, health care professionals are often oblivious to the problem. Falls are mostly associated with the elderly and concern about diabetic individuals' gait problems is limited to fear of high foot pressures and ulcers. In contrast, this thesis shows that it is important not to limit fall risk assessment and fall prevention to the aged, and to consider gait parameters as much as pressure values when assessing the gait of diabetic patients. I am convinced that physiotherapy can significantly contribute to an interdisciplinary diabetes care management approach. The role of the physiotherapist should not be limited to conducting physical activity programs. Physiotherapists should perform standardised clinical testing combined with gait and/or balance assessments, thereby contributing useful information for best practice.

This thesis provides promising results. Several fall risk related parameters have been improved by a specific treatment program. However, additional intervention studies are needed before any recommendations as to best clinical practice can be provided. Attracting clinicians' attention and stimulating their awareness of the problem is now a major challenge so as to avoid a gap between research and practice. To maximise patient motivation, programs should be adapted to individuals' needs and abilities. The focus of intervention programs should not be limited to short-term benefits. Patients' enjoyment, sense of satisfaction and the programs' functional relevance may be keys for long-term success. 


\section{REFERENCES}

1. Wallace SP: The public health perspective on aging. Generations 29:5-10, 2005.

2. Bruce DG, Casey GP, Grange V, Clarnette RC, Almeida OP, Foster JK, Ives FJ, Davis TM: Cognitive impairment, physical disability and depressive symptoms in older diabetic patients: the Fremantle Cognition in Diabetes Study. Diabetes Res Clin Pract 61:59-67, 2003.

3. Bruce DG, Davis WA, Davis TM: Longitudinal predictors of reduced mobility and physical disability in patients with type 2 diabetes: the Fremantle Diabetes Study. Diabetes Care 28:2441-2447, 2005.

4. Gregg EW, Beckles GL, Williamson DF, Leveille SG, Langlois JA, Engelgau MM, Narayan KM: Diabetes and physical disability among older U.S. adults. Diabetes Care 23:1272-1277, 2000.

5. Guralnik JM, Ferrucci L, Pieper CF, Leveille SG, Markides KS, Ostir GV, Studenski S, Berkman LF, Wallace RB: Lower extremity function and subsequent disability: consistency across studies, predictive models, and value of gait speed alone compared with the short physical performance battery. J Gerontol A Biol Sci Med Sci 55:221231, 2000.

6. Herman T, Giladi N, Gruendlinger L, Hausdorff JM: Six weeks of intensive treadmill training improves gait and quality of life in patients with Parkinson's disease: a pilot study. Arch Phys Med Rehabil 88:1154-1158, 2007.

7. Montero-Odasso M, Schapira M, Soriano ER, Varela M, Kaplan R, Camera LA, Mayorga LM: Gait velocity as a single predictor of adverse events in healthy seniors aged 75 years and older. J Gerontol A Biol Sci Med Sci 60:1304-1309, 2005.

8. Sliwinski M, Sisto S: Gait, quality of life, and their association following total hip arthroplasty. J Geriatr Phys Ther 29:10-17, 2006.

9. Paterson $\mathrm{DH}$, Jones $\mathrm{GR}$, Rice $\mathrm{CL}$ : Ageing and physical activity: evidence to develop exercise recommendations for older adults. Can J Public Health 98 Suppl 2:69-108, 2007.

10. Frank JS, Patla AE: Balance and mobility challenges in older adults: implications for preserving community mobility. Am J Prev Med 25:157-163, 2003.

11. Macaluso A, De Vito G: Muscle strength, power and adaptations to resistance training in older people. Eur J Appl Physiol 91:450-472, 2004.

12. Rosendahl E, Gustafson Y, Nordin E, Lundin-Olsson L, Nyberg L: A randomized controlled trial of fall prevention by a high-intensity functional exercise program for older people living in residential care facilities. Aging Clin Exp Res. 20:67-75, 2008.

13. Latham NK, Bennett DA, Stretton CM, Anderson CS: Systematic review of progressive resistance strength training in older adults. J Gerontol A Biol Sci Med Sci 59:48-61, 2004.

14. Allet L, Armand S, Golay A, Monnin D, de Bie RA, de Bruin ED: Gait characteristics of diabetic patients: a systematic review. Diabetes Metab Res Rev 24:173-191, 2008.

15. Freiberger E, Menz HB: [Characteristics of falls in physically active community-dwelling older people: findings from the "Standfest im Alter" study] in German. Z Gerontol Geriatr 39:261-267, 2006.

16. Menz HB, Lord SR, St George R, Fitzpatrick RC: Walking stability and sensorimotor function in older people with diabetic peripheral neuropathy. Arch Phys Med Rehabil 85:245-252, 2004.

17. Richardson JK, Thies SB, DeMott TK, Ashton-Miller JA: Gait analysis in a challenging environment differentiates between fallers and nonfallers among older patients with peripheral neuropathy. Arch Phys Med Rehabil 86:1539-1544, 2005.

18. Hsi WL, Chai HM, Lai JS: Evaluation of rocker sole by pressure-time curves in insensate forefoot during gait. Am J Phys Med Rehabil 83:500-506, 2004.

19. Perry JE, Ulbrecht JS, Derr JA, Cavanagh PR: The use of running shoes to reduce plantar pressures in patients who have diabetes. J Bone Joint Surg Am 77:1819-1828, 1995.

20. Petrofsky J, Lee S, Cuneo ML: Gait characteristics in patients with type 2 diabetes; improvement after administration of rosiglitazone. Med Sci Monit 11:43-51, 2005.

21. Richardson JK, Thies SB, DeMott TK, Ashton-Miller JA: Interventions improve gait regularity in patients with peripheral neuropathy while walking on an irregular surface under low light. J Am Geriatr Soc 52:510-515, 2004.

22. Walker SC, Helm PA, Lavery LA: Gait pattern alteration by functional sensory substitution in healthy subjects and in diabetic subjects with peripheral neuropathy. Arch Phys Med Rehabil 78:853-856, 1997.

23. Tsang T, Orr R, Lam P, Comino EJ, Singh MF: Health benefits of Tai Chi for older patients with type 2 diabetes: the "Move It For Diabetes study"--a randomised controlled trial. Clin Interv Aging 2:429-439, 2007. 
24. Vadstrup ES, Frolich A, Perrild H, Borg E, Roder M: Lifestyle intervention for type 2 diabetes patients - trial protocol of The Copenhagen Type 2 Diabetes Rehabilitation Project. BMC Public Health 9:166, 2009.

25. Lam P, Dennis SM, Diamond TH, Zwar N: Improving glycaemic and BP control in type 2 diabetes. The effectiveness of tai chi. Aust Fam Physician 37:884-887, 2008.

26. Bjorgaas MR, Vik JT, Stolen T, Lydersen S, Grill V: Regular use of pedometer does not enhance beneficial outcomes in a physical activity intervention study in type 2 diabetes mellitus. Metabolism 57:605-611, 2008.

27. Allen NA, Fain JA, Braun B, Chipkin SR: Continuous glucose monitoring counseling improves physical activity behaviors of individuals with type 2 diabetes: A randomized clinical trial. Diabetes Res Clin Pract 80:371-379, 2008.

28. Tsang T, Orr R, Lam P, Comino E, Singh MF: Effects of Tai Chi on glucose homeostasis and insulin sensitivity in older adults with type 2 diabetes: a randomised double-blind sham-exercise-controlled trial. Age Ageing 37:6471, 2008.

29. Allet L, Armand S, de Bie RA, Golay A, Monnin D, Aminian K, de Bruin ED: Reliability of diabetic patients' gait parameters in a challenging environment. Gait Posture 28:680-686, 2008.

30. Allet L, Armand S, de Bie RA, Pataky Z, Aminian K, Herrmann FR, de Bruin ED: Gait alterations of diabetic patients while walking on different surfaces. Gait Posture 29:488-493, 2009.

31. Petrofsky J, Lee S, Bweir S: Gait characteristics in people with type 2 diabetes mellitus. Eur J Appl Physiol 93:640-647, 2005.

32. Stansberry KB, Hill MA, Shapiro SA, McNitt PM, Bhatt BA, Vinik Al: Impairment of peripheral blood flow responses in diabetes resembles an enhanced aging effect. Diabetes Care 20:1711-1716, 1997.

33. Turgut N, Karasalihoglu S, Kucukugurluoglu Y, Balci K, Ekuklu G, Tutunculer F: Clinical utility of dorsal sural nerve conduction studies in healthy and diabetic children. Clin Neurophysiol 115:1452-1456, 2004.

34. van Deursen RW, Simoneau GG: Foot and ankle sensory neuropathy, proprioception, and postural stability. J Orthop Sports Phys Ther 29:718-726, 1999.

35. Tinetti ME: Performance-oriented assessment of mobility problems in elderly patients. J Am Geriatr Soc 34:119-126, 1986.

36. Jordan K, Newell KM: The structure of variability in human walking and running is speed-dependent. Exerc Sport Sci Rev 36:200-204, 2008.

37. Chamberlin ME, Fulwider BD, Sanders SL, Medeiros JM: Does fear of falling influence spatial and temporal gait parameters in elderly persons beyond changes associated with normal aging? J Gerontol A Biol Sci Med Sci 60:1163-1167, 2005.

38. Deshpande N, Ferrucci L, Metter J, Faulkner KA, Strotmeyer E, Satterfield S, Schwartz A, Simonsick E: Association of lower limb cutaneous sensitivity with gait speed in the elderly: the health $A B C$ study. Am J Phys Med Rehabil 87:921-928, 2008.

39. Wrobel JS, Crews RT, Connolly JE: Clinical factors associated with a conservative gait pattern in older male veterans with diabetes. J Foot Ankle Res 2:11, 2009.

40. Kastenbauer T, Sauseng S, Brath H, Abrahamian H, Irsigler K: The value of the Rydel-Seiffer tuning fork as a predictor of diabetic polyneuropathy compared with a neurothesiometer. Diabet Med 21:563-567, 2004.

41. Thomson MP, Potter J, Finch PM, Paisey RB: Threshold for detection of diabetic peripheral sensory neuropathy using a range of research grade monofilaments in persons with Type 2 diabetes mellitus. J Foot Ankle Res 1:9, 2008.

42. Deroide N, Bousson V, Levy BI, Laredo JD, Kubis N: [Nerve and muscle imaging in peripheral neuropathy associated to electroneuromyography: The ideal couple?] in French. Rev Med Interne, 2009.

43. Chang RW, Dunlop D, Gibbs J, Hughes S: The determinants of walking velocity in the elderly. An evaluation using regression trees. Arthritis Rheum 38:343-350, 1995.

44. Manor B, Li L: Characteristics of functional gait among people with and without peripheral neuropathy. Gait Posture 30:253-256, 2009.

45. Pijnappels $\mathrm{M}$, Bobbert MF, van Dieen $\mathrm{JH}$ : Control of support limb muscles in recovery after tripping in young and older subjects. Exp Brain Res 160:326-333, 2005.

46. Kang HG, Dingwell JB: Effects of walking speed, strength and range of motion on gait stability in healthy older adults. J Biomech 41:2899-2905, 2008.

47. Hausdorff JM, Edelberg HK, Mitchell SL, Goldberger AL, Wei JY: Increased gait unsteadiness in communitydwelling elderly fallers. Arch Phys Med Rehabil 78:278-283, 1997.

48. Allet L, Armand S, de Bie RA, Golay A, Pataky Z, Aminian K, de Bruin ED: Clinical factors associated with gait alterations in diabetic patients. Diabet Med 26:1003-1009, 2009. 
49. Sendur OF, Turan Y, Bal S, Gurgan A: Toxic neuropathy due to N-hexane: report of three cases. Inhal Toxicol 21:210-214, 2009.

50. Najafi B, Helbostad JL, Moe-Nilssen R, Zijlstra W, Aminian K: Does walking strategy in older people change as a function of walking distance? Gait Posture 29:261-266, 2009.

51. Turcot K, Allet L, Golay A, Hoffmeyer P, Armand S: Investigation of Standing Balance in Diabetic Patients with and without Peripheral Neuropathy using Accelerometers. Clin Biomech 24:716-21, 2009.

52. Kressig RW, Herrmann FR, Grandjean R, Michel JP, Beauchet O: Gait variability while dual-tasking: fall predictor in older inpatients? Aging Clin Exp Res 20:123-130, 2008.

53. Lamb SE, Jorstad-Stein EC, Hauer K, Becker C: Development of a common outcome data set for fall injury prevention trials: the Prevention of Falls Network Europe consensus. J Am Geriatr Soc 53:1618-1622, 2005.

54. Plotnikoff RC, Taylor LM, Wilson PM, Courneya KS, Sigal RJ, Birkett N, Raine K, Svenson LW: Factors associated with physical activity in Canadian adults with diabetes. Med Sci Sports Exerc 38:1526-1534, 2006.

55. Estabrooks PA: Sustaining exercise participation through group cohesion. Exerc Sport Sci Rev 28:63-67, 2000.

56. IDF Clinical Guidelines Task Force and International Diabetes Federation in Brussels, Belgium: Global guideline for type 2 diabetes: recommendations for standard, comprehensive, and minimal care. Diabet Med 23:579$593,2006$. 
Summary in English, Dutch and French 


\section{ENGLISH SUMMARY}

The World Health Organisation has described type 2 diabetes as an international epidemic. Recent estimates indicated 171 million people in the world with diabetes in the year 2000 . The number is projected to increase to 366 million by the year 2030 . Approximately $58 \%$ of patients with type 2 diabetes have one or more complications from the disease resulting in an increased demand for medical services. The most symptomatic complication of this disease is peripheral neuropathy which affects nerve function from the periphery to more proximal regions. Approximately $50 \%$ of patients who have diabetes for more than 20 years develop peripheral neuropathy. Two main care paradigms are suggested for diabetic patients. The first paradigm is lifestyle management (including behavioural advice on diet and physical activity) and the second is medication (oral hypoglycaemics and insulin) proposed when lifestyle changes fail to be effective. In order to avoid the complications of diabetes, patients are recommended to be physically active for at least 30 minutes a day, 6 days a week. However, as diabetes is associated with an increased risk of injurious falls, this advice leads to a dilemma: how can individuals with an increased risk of falling carry out regular physical activity? Patients with inadequate gait stability, who experience a fall related injury, may not be able to meet these recommendations and may fall into a vicious circle of reduced physical activity levels leading to an increased risk of diabetic complications and decreased musculoskeletal function.

Thus, the overall aim of this project was to develop and test the efficacy of a physiotherapeutic approach seeking to improve diabetic patients' gait, balance and related clinical factors. To achieve this aim, several steps were necessary and each of these steps is described in separate chapters of this thesis.

The project started with a systematic literature review about gait characteristics of diabetic patients (Chapter 2: Gait characteristics of diabetic patients: a systematic review). The systematic review showed that the quality of existing articles investigating gait characteristics in diabetic patients is moderate to high. Results varied over different studies and questions remained about the main causes for impaired gait in diabetic patients, especially about factors related to observed gait abnormalities. Although we know that most falls occur in a complex environment, gait parameters were only rarely studied in a challenging situation (a poorly lit walkway or with a partially yielding, irregular surface). In addition, only few interventions that aim to improve gait parameters were tested (auditory feedback, different shoes or soles, medication). These findings confirmed the necessity of investigating gait characteristics in diabetic patients outdoors under real life conditions. In view of this objective an ambulatory gait measurement system was needed, for which reliability under the different measurement conditions had first to be tested (Chapter 3: Reliability of diabetic patients' gait parameters in a challenging environment). Bland and Altman plots provided with a qualitative estimate of our measurement instrument's (Physilog ) precision. Overall it showed similar results for the 3 tested surfaces (tarred surface, grass and cobblestones). The mean differences of each variable measured on 2 different days were small and all mean difference values were well distributed around zero. These results were confirmed by the high reliability (Intraclass correlation coefficient values $>0.8$ ) for all evaluated parameters (except for knee range, for which we only achieved fair 
reliability). Based on these good inter-visit reliability measurements, together with the small measurement errors obtained and values of minimal detectable change, we decided to use the Physilog for our investigations. This instrument was shown to be a useful, reliable instrument for ambulatory gait assessment in a challenging environment for diabetic patients. Following this reliability study, the gait characteristics of diabetic patients, with and without peripheral neuropathy, were evaluated outdoors on the 3 different surfaces aiming to acquire a more in-depth insight into diabetic patients' gait. (Chapter 4: Gait alterations of diabetic patients while walking on different surfaces). It was shown that gait parameters differ between healthy controls and diabetic patients with peripheral neuropathy (for all measured parameters: speed, cadence, stance, double support, stride length and gait cycle time, knee range, thigh range, shin range and coefficient of variation of stride length and gait cycle time). In addition, a difference between healthy controls and diabetic patients without peripheral neuropathy could be identified for gait speed, cadence and gait cycle time. The gait parameters in diabetic patients with peripheral neuropathy tend to be more altered than gait parameters in patients without peripheral neuropathy. However, no significant difference was detected between patients with and without peripheral neuropathy. Another interesting element in this study was the walking strategy of diabetic patients when they changed from a regular to an irregular surface. Diabetic patients with and without peripheral neuropathy, adjusted their walking technique to the varying surfaces using identical strategies. These strategies were similar to those used by healthy controls. To change from a level (tarred) to irregular surface (cobblestones) patients with diabetes and controls decreased their gait speed by reducing their cadence and increasing their gait cycle time. They also shortened their stride length and increased their stride to stride variability. Nevertheless, the highest surface effect was found in diabetic patients with peripheral neuropathy followed by patients without peripheral neuropathy and then healthy controls.

Given that falling is a complex phenomenon and that poor balance is one of the major risk factors for falls, the balance performance of diabetic patients with and without peripheral neuropathy was compared to a healthy control group (Chapter 5: Investigation of standing balance in diabetic patients with and without peripheral neuropathy using accelerometers). Quiet standing balance (eyes open, eyes closed) was investigated using an accelerometer-based method. Accelerations were measured at lumbar and ankle levels using 3 accelerometers. Results demonstrated that diabetic patients with peripheral neuropathy have higher postural instability with higher acceleration values than those of the control group and of the diabetic patients without peripheral neuropathy. Furthermore, postural instability increased with eyes closed and the most important difference between eyes open and eyes closed was found in diabetic patients with peripheral neuropathy. Before developing the specific treatment approach, another scientific work which identified clinical parameters associated with gait abnormalities of patients with type 2 diabetes was conducted (Chapter 6: Clinical factors associated with gait alterations in diabetic patients). A sample of 76 diabetic patients underwent clinical examination and an outdoor gait evaluation on tarred and cobblestone terrains. Differential in gait speed (performance measure) and in gait variability (coefficient of variation of the gait cycle time as a fall risk index) on different terrains were respectively calculated. Differentials' associations with 
clinical factors were investigated using correlation coefficients and linear regression analysis. This study reveals that a decrease in gait speed is partially associated with the mean of maximal isometric lower limb strength, fear of falls and participants' perceived vibration threshold. Moreover, mean maximal isometric strength is associated with an increased coefficient of variation of the gait cycle time. These results indicate that both physiological (strength and proprioception) and cognitive-behavioural factors (fear of falls) are associated with diabetic patients' gait difficulties and should therefore be considered when treating diabetic patients with gait alterations. Treatment programs should include progressively more complex strength exercises, proprioceptive training and activities of daily life to improve diabetic patients' self-assurance. Based on these aforementioned investigations a physiotherapeutic approach was developed and tested by means of a randomised controlled trial (Chapter 7: Diabetic patients' gait and balance can be improved with a specific training program. A randomised controlled trial). Seventy-one patients were randomly assigned to either an intervention $(n=35)$ or a control group $(n=$ 36). The intervention consisted of group training, which was performed twice a week for 12 weeks. A session consisted of a warm up followed by circuit training with gait and balance exercises (i.e. stance on heel/ toes, tandem stance, one leg stance, walking). These exercises alternated with functional strength exercises (i.e. sit to stand, walking up and down a slope, steps, jumps) expected to make patients more confident with daily activities. The complexity of the task could progressively be increased. Sessions were completed with interactive games and a short feedback with suggestions for individual home exercises. The training was shown to have a positive effect on diabetic patients' gait speed, balance, muscle strength and joint mobility. After the 12 week program patients were encouraged to continue performing the exercises learned for the following 6 months. No other advice or restrictions were provided. Participants partially lost their treatment benefit during the 6 months of follow-up but their performance level remained superior to baseline.

Despite several limitations, discussed in detail in Chapter 8 (Chapter 8: General Discussion), this study provides promising results for improving gait and balance in patients with type 2 diabetes. However, further intervention studies are needed before any recommendations can be provided to serve as best practice examples. Other approaches such as providing assistive technologies, practicing walking alone in different environments, or a simple muscle strengthening program, may also be effective for improving diabetic patients' gait and balance. In addition, a more qualitative study aiming to evaluate experience, selfefficacy, motivations and attitudes of patients concerning this specific program may be helpful in order to achieve and optimise compliance, adherence and self-management.

Attracting clinicians' attention and stimulating their awareness of diabetic patients' gait problems and related fall risk represents a major challenge for the future. Only by bridging the gap between researchers and clinicians can this objective be achieved. 


\section{NEDERLANDSE SAMENVATTING}

De Wereldgezondheidsorganisatie omschrijft diabetes mellitus type 2 als een internationale epidemie. Het aantal patiënten met diabetes werd in 2000 op 171 miljoen geschat en zal in 2030366 miljoen bedragen. Ongeveer 58\% van de patiënten met diabetes mellitus type 2 zal één of meerdere complicaties van de ziekte ontwikkelen, waardoor zij meer behoefte aan medische zorg hebben. De meest voorkomende complicatie is perifere neuropathie. Ongeveer $50 \%$ van de patiënten die langer dan 20 jaar diabetes hebben, ontwikkelen perifere neuropathie. De behandeling van diabetes kent twee benaderingswijzen. De eerste benadering is gericht op leefstijl (waaronder adviezen gericht op gezonde voeding en beweging). De tweede benadering bestaat uit een medicamenteus beleid (orale bloedglucoseverlagende middelen en insuline) dat onder andere toegepast wordt wanneer leefstijlveranderingen onvoldoende effect hebben. Om complicaties van diabetes te voorkomen wordt patiënten geadviseerd 6 dagen per week minstens 30 minuten per dag te bewegen. Diabetes verhoogt echter de kans op vallen met letsel tot gevolg, en het bewegingsadvies leidt dus tot het volgende dilemma: hoe kunnen mensen met een verhoogd valrisico toch in voldoende mate veilig bewegen? Patiënten met onvoldoende stabiliteit gedurende het lopen, die traumatisch letsel na een val ervaren, kunnen de bewegingsadviezen mogelijk niet opvolgen, wat kan leiden tot een vicieuze cirkel, waarin verminderde beweging zorgt voor een verhoogde kans op diabetescomplicaties met weer een verminderde functie van het bewegingsapparaat tot gevolg.

Het doel van deze studie was het ontwikkelen en testen van een fysiotherapeutische benadering om het looppatroon, de balans en daaraan gerelateerde klinische factoren van patiënten met diabetes te verbeteren. Om dit te bereiken waren verschillende onderzoeksen ontwikkelingsstappen noodzakelijk, en elke stap wordt in een ander hoofdstuk van dit proefschrift beschreven.

Het onderzoeksproject startte met een systematisch literatuuronderzoek over de gang en gangkenmerken (looppatronen) van patiënten met diabetes (Hoofdstuk 2: "Gait characteristics of diabetic patients: a systematic review"). Het literatuuronderzoek laat zien dat de methodologische kwaliteit van de bestaande artikelen over karakteristieken van het looppatroon bij patiënten met diabetes gemiddeld tot hoog is. De resultaten van de verschillende studies zijn divers, en er blijven vragen bestaan over de oorzaak van een afwijkend looppatroon bij patiënten met diabetes, met name over factoren betreffende waargenomen afwijkingen in de gang (waargenomen gangafwijkingen). Hoewel we weten dat vallen meestal plaatsvindt in een complexe omgeving, zijn looppatronen maar zelden onderzocht in een uitdagende omgeving (bijv. een voetpad met slechte verlichting of een onregelmatig oppervlak). Daarnaast zijn slechts enkele interventies onderzocht die als doel hadden looppatronen te verbeteren (bijv. auditieve feedback, andere schoenen of inlegzolen, medicatie). Deze beperkingen bevestigen de noodzaak van een onderzoek naar looppatronen bij patiënten met diabetes buitenshuis onder real life omstandigheden. Om dit te bereiken was er een mobiel ganganalyse systeem nodig, waarbij eerst de betrouwbaarheid onder verschillende omstandigheden getest moest worden (Hoofdstuk 3: 
“Reliability of diabetic patients' gait parameters in a challenging environment"). Bland en Altman plots gaven een kwalitatieve schatting van de precisie van ons meetinstrument (Physilog). Over het algemeen werden vergelijkbare resultaten voor de drie bestudeerde ondergronden (asfalt, gras en keien) gevonden. Het gemiddelde verschil tussen de gemeten variabelen op twee verschillende dagen was klein, en alle gemiddelde verschilwaarden lagen rond de nul. Deze resultaten werden bevestigd door de hoge betrouwbaarheid (ICC waarden $>0.8$ ) van alle onderzochte parameters (met uitzondering van de bewegingsomvang van de knie waarvoor we alleen een redelijke betrouwbaarheid konden bereiken). Gebaseerd op deze goede test-hertest betrouwbaarheidsmetingen, kleine meetfouten en waarden van kleinst waarneembare verandering besloten wij de Physilog voor onze studie te gebruiken. De Physilog bleek een bruikbaar en betrouwbaar instrument te zijn voor de mobiele ganganalyse in een uitdagende omgeving voor patiënten met diabetes. Na deze studie naar de betrouwbaarheid werden de gangkenmerken van patiënten met diabetes, met en zonder neuropathie onderzocht, buitenshuis en op de drie verschillende ondergronden met als doel meer inzicht te krijgen in het looppatroon van patiënten met diabetes (Hoofdstuk 4: "Gait alterations of diabetic patients while walking on different surfaces"). Looppatronen tussen gezonde controlepersonen en patiënten met diabetes met perifere neuropathie verschilden (voor alle onderzochte parameters: snelheid, cadans, standfase, 'double support', paslengte en pastijd, bewegingsomvang van de knie, heup en enkel en de variatiecoëfficiënt van paslengte en tijd). Daarnaast was er een verschil tussen gezonde controlepersonen en patiënten met diabetes zonder perifere neuropathie zichtbaar, met name voor loopsnelheid, cadans en duur van de loopcyclus. De looppatronen bij diabetespatiënten met perifere neuropathie leken meer afwijkend te zijn dan looppatronen bij patiënten zonder perifere neuropathie. Er was echter geen significant verschil meetbaar tussen patiënten met en zonder perifere neuropathie. Daarnaast waren wij geïnteresseerd in de loopstrategie van patiënten met diabetes wanneer zij moesten veranderen van een regelmatige naar een onregelmatige ondergrond. Hierbij pasten zowel diabetespatiënten met als zonder perifere neuropathie hun looptechniek op vergelijkbare wijze aan. Deze methoden waren vergelijkbaar met die van gezonde controlepersonen. Om van een gladde (geasfalteerd) naar een onregelmatige ondergrond (keien) te gaan verminderden zowel patiënten met diabetes als controlepersonen hun loopsnelheid door hun stapfrequentie te reduceren en hun pasduur te vergroten. Daarnaast verkortten zij ook hun paslengte en verhoogden zij de variatie in pasduur. Desondanks werd het grootste oppervlakte-effect gevonden bij diabetespatiënten met perifere neuropathie, gevolgd door patiënten zonder perifere neuropathie en gezonde controlepersonen.

Bewust van het feit dat vallen een complex fenomeen is en dat een slechte balans één van de grootste risicofactoren is voor vallen, werd de balans van patiënten met en zonder perifere neuropathie vergeleken met een gezonde controlegroep (Hoofdstuk 5: "Investigation of standing balance in diabetic patients with and without peripheral neuropathy using accelerometers"). Balans in rust (ogen open, ogen gesloten) werd onderzocht met een op een accelerometer gebaseerde methode. Bewegingen werden lumbaal en ter hoogte van de enkel gemeten met drie bewegingsmeters. Ons onderzoek laat zien dat patiënten met diabetes en perifere neuropathie een grotere houdingsinstabiliteit met meer bewegingsuitslag hebben dan de gezonde controlegroep of 
patiënten met diabetes zonder perifere neuropathie. Daarnaast werd de houdingsinstabiliteit groter bij gesloten ogen. Het grootste verschil tussen de condities gesloten en open ogen werd gevonden bij diabetespatiënten met perifere neuropathie. Voordat wij een specifieke therapeutische benadering ontwikkelden, verrichtten wij eerst een ander onderzoek naar klinische parameters die geassocieerd zijn met afwijkingen in het looppatroon bij patiënten met type 2 diabetes (Hoofdstuk 6: "Clinical factors associated with gait alterations in diabetic patients"). Een steekproef van 76 patiënten met diabetes onderging een klinisch onderzoek waarin het looppatroon buitenshuis op een geasfalteerde oppervlakte en op keien werd geëvalueerd. Respectievelijke verschillen in loopsnelheid (mate van prestatie) en loopcyclus variatie (variatiecoëfficiënt van de loopcyclus duur als indicatie van het valrisico) op verschillende ondergronden werden berekend. Associaties met klinische factoren werden onderzocht met behulp van correlatiecoëfficiënten en lineaire regressieanalyse. Deze studie laat zien dat een vermindering van de loopsnelheid gedeeltelijk geassocieerd is met de gemiddelde maximale isometrische beenkracht, angst om te vallen en mate van neuropathie. Bovendien is de maximale isometrische kracht geassocieerd met een toegenomen variatie coëfficiënt van de loopcyclus. Deze resultaten laten zien dat zowel fysiologische (kracht en proprioceptie) als cognitieve gedragsfactoren (angst om te vallen) geassocieerd zijn met moeilijkheden die patiënten met diabetes ondervinden gedurende het lopen. Het verdient dus aanbeveling hiermee rekening te houden in de behandeling van patiënten met diabetes en afwijkingen in het looppatroon. Behandelprogramma's moeten gericht zijn op progressief in moeilijkheidsgraad toenemende krachtoefeningen, proprioceptieve training en dagelijkse activiteiten om de zelfverzekerdheid van patiënten met diabetes te vergroten. Een fysiotherapeutische benadering gericht op deze adviezen werd ontwikkeld en onderzocht in een randomised controlled trial (Hoofdstuk 7: “Diabetic patients' gait and balance can be improved with a specific training program. A randomised controlled trial"). Eenenzeventig patiënten werden gerandomiseerd toegewezen aan een interventie $(n=35)$ of een controlegroep $(n=$ 36). De interventie bestond uit groepstraining, tweemaal per week gedurende 12 weken. Elke training bestond uit een warming-up gevolgd door een circuittraining met daarin loopen balansoefeningen (hielen- en tenenstand, tweebenen stand, stand op één been, lopen). Deze loop- en balansoefeningen werden afgewisseld met functionele krachtoefeningen (van zit tot stand, een helling op en neer lopen, traptreden, sprongen), die naast opbouw van kracht, patiënten meer vertrouwd moeten maken met dagelijkse activiteiten. De complexiteit van de taken werd progressief verhoogd. De training werd afgesloten met interactieve spelletjes en met een korte feedback en suggesties voor individuele oefeningen thuis. De training had een positief effect op de loopsnelheid, balans, spierkracht en gewrichtsmobiliteit van patiënten. $\mathrm{Na}$ het 12 weken durende programma werden patiënten aangemoedigd thuis door te gaan met de aangeleerde oefeningen gedurende een half jaar. De deelnemers ontvingen verder geen advies en er werden hen geen beperkingen opgelegd. Het voordeel van de behandeling was na 6 maanden follow-up gedeeltelijk verdwenen, maar de prestaties bleven beter dan bij aanvang van de studie.

Ondanks verschillende beperkingen, welke meer gedetailleerd worden besproken in het laatste hoofdstuk (Hoofdstuk 8: "General discussion"), geeft deze studie hoopvolle resultaten voor de verbetering van de gang en de balans bij patiënten met diabetes type 2 . 
Er is echter meer onderzoek nodig voordat er aanbevelingen kunnen worden gedaan over de beste behandelmethode. Andere benaderingen zoals het gebruik van een hulpmiddel, training in het lopen in verschillende (en uitdagende) omgevingen of een krachttrainingsprogramma kunnen ook effectief zijn in het verbeteren van looppatroon en balans bij patiënten met diabetes. Daarnaast kan een meer kwalitatieve studie, gericht op het evalueren van ervaringen, zelfredzaamheid, motivatie en attitude van patiënten nuttig zijn om een optimale compliance, adhesie and zelfmanagement te bereiken.

Het onder de aandacht brengen van de bevindingen uit dit proefschrift, met name de diabetes gerelateerde loop- en valproblematiek, bij clinici vormt nog een uitdaging voor de toekomst. 


\section{RESUME EN FRANÇAIS}

L'Organisation Mondiale de la Santé considère le diabète de type 2 comme une épidémie internationale. En 2000, 171 millions d'individus souffraient de diabète dans le monde. Une estimation prévoit que ce nombre devrait atteindre 360 millions en 2030. Environ 58\% des patients diabétiques présentent une ou plusieurs complications liées à leur maladie, ce qui engendre une augmentation de la demande de soins médicaux. La complication la plus fréquente est la neuropathie périphérique qui affecte les fonctions neurales et se développe des régions périphériques vers les régions plus proximales. Près de $50 \%$ des patients souffrant depuis plus de 20 ans d'un diabète présentent une neuropathie périphérique.

Deux axes principaux de traitement sont proposés aux patients diabétiques. Le premier est basé sur I'hygiène de vie: conseils diététiques et recommandations concernant l'activité physique. Le deuxième, utilisé lorsque le premier s'avère insuffisant ou inefficace, fait appel aux médicaments (insuline et antidiabétiques oraux).

Pour éviter les complications liées au diabète, une activité physique de 30 minutes par jour, 6 jours par semaine est conseillée. Comme il est connu que les patients diabétiques sont sujets à un risque de chute important ces recommandations créent un dilemme. Des personnes qui présentent un risque de chute élevé, des déséquilibres à la marche ou qui ont subi un traumatisme suite à une chute peuvent-elles suivre ces recommandations et réaliser une activité physique régulière? Si elles ne le font pas, elles vont entrer dans un cercle vicieux où la réduction de l'activité physique augmente le risque de complications diabétiques qui, à leur tour, limiteront le fonctionnement musculo-squelettique.

L'objectif de ce projet était de développer et de tester l'efficacité d'une approche physiothérapeutique visant à améliorer la marche des patients diabétiques, leur équilibration et certains les facteurs cliniques liés à ces fonctions. Cette démarche nécessitait plusieurs étapes; chacune d'entre elles est décrite dans les chapitres de cette thèse.

La première étape a consisté en une revue systématique de la littérature au sujet des caractéristiques de la marche des patients diabétiques (Chapitre 2: "Gait characteristics of diabetic patients: a systematic review"). Cette revue systématique a montré que la qualité des études existantes sur la marche des patients diabétiques est de modérée à très bonne. Les résultats obtenus étaient variables. Cependant, les questions concernant les principales causes et particulièrement les différents facteurs cliniques en lien avec des altérations de la marche des patients diabétiques restent actuellement sans réponse. Par ailleurs, bien que la plupart des chutes se produisent dans un environnent complexe, les paramètres de la marche ont rarement été évalués dans des situations réelles (à l'extérieur, passage peu éclairé, surface irrégulière). De plus, peu d'études ont investigué l'effet d'interventions visant à améliorer la qualité de la marche (feedback auditif, différentes chaussures ou semelles, médicaments). En conclusion, les résultats de cette revue montrent qu'il est nécessaire d'étudier les caractéristiques de la marche des patients diabétiques dans des conditions proches d'un environnement réel. Pour réaliser de telles études, il fallait 
disposer d'un système de mesure dont la précision serait préalablement testée dans les différentes conditions concernées. (Chapitre 3: “Reliability of diabetic patients' gait parameters in a challenging environment"). Les profils de Bland et Altman nous ont fourni une image qualitative de la précision de notre instrument de mesure. Globalement, les résultats sont similaires pour les trois surfaces sur lesquelles des tests ont été effectués: goudron, gazon et pierres. La différence moyenne au sein de chaque variable mesurée sur 2 jours différents était faible et toutes les différences étaient distribuées autour de zéro. Ces résultats ont été confirmés par une bonne fiabilité (valeurs ICC $>0.8$ ) pour tous les paramètres testés (excepté la mesure de la mobilité du genou qui n'a montré qu'une fiabilité moyenne). Au vu de cette bonne fiabilité inter-séance et des valeurs de changement minimal détectable ainsi que des faibles erreurs de mesures constatées, nous avons décidé d'utiliser le système Physilog pour effectuer nos recherches. Ce système de mesure s'est relevé être un instrument utile, précis et fiable pour évaluer la marche des patients diabétiques à l'extérieur, sur les différents terrains testés. Après avoir mené cette étude de reproductibilité, nous avons testé la marche des patients diabétiques, avec et sans neuropathie périphérique, à l'extérieur, sur ces 3 surfaces différentes (goudron, gazon et pierres) afin de mieux comprendre la marche de ces patients. (Chapitre 4: "Gait alterations of diabetic patients while walking on different surfaces"). Cette étude a montré que les paramètres de marche diffèrent entre les sujets sains et les patients atteints de neuropathie périphérique pour toutes les variables mesurées: vitesse de marche, cadence, durée de la phase d'appui et de l'appui bipodal, longueur et durée du cycle, mobilité du genou, de la hanche et de la cheville, coefficient de variation de la longueur et de la durée du cycle. De plus, une différence a été mesurée entre les sujets sains et les patients diabétiques sans neuropathie périphérique pour la vitesse de marche, la cadence et la durée du cycle de marche. Les paramètres de marche semblaient être plus altérés chez les patients atteints de neuropathie périphérique que chez les patients sans neuropathie périphérique. Néanmoins, aucune différence significative n'a été détectée entre les patients diabétiques atteints ou non de neuropathie périphérique. Cette étude s'intéressait également à la stratégie de marche utilisée par les patients diabétiques lorsqu'ils devaient passer d'une surface régulière à une surface irrégulière. Les patients diabétiques, avec ou sans neuropathie périphérique, adaptaient leur façon de marcher aux différentes surfaces en utilisant des stratégies identiques. Ces stratégies étaient semblables à celles utilisées par le groupe contrôle des sujets sains. En passant d'un terrain plat (goudron) à un terrain irrégulier (pierres), les patients diabétiques et les sujets contrôles ont diminué leur vitesse de marche en réduisant la cadence et en augmentant la durée du cycle. Ils ont diminué la longueur de leur pas et ont augmenté la variabilité entre les pas. L'effet le plus important dû au type de surface de marche a néanmoins été constaté chez les patients diabétiques atteints de neuropathie périphérique, suivi par les patients sans neuropathie périphérique et les sujets sains.

Sachant que les chutes sont un phénomène complexe et que les lacunes de l'équilibration constituent un des risques majeurs de chute, nous avons comparé l'équilibre des patients diabétiques atteints ou non de neuropathie périphérique, avec un groupe contrôle. (Chaptitre 5: "Investigation of standing balance in diabetic patients with and without peripheral neuropathy using accelerometers"). L'équilibre debout (yeux ouverts et fermés) 
a été analysé avec des accéléromètres. Les accélérations ont été mesurées au niveau lombaire et au niveau des chevilles en utilisant des accéléromètres. Les résultats ont montré que les patients diabétiques atteints de neuropathie périphérique présentaient une plus grande instabilité avec des accélérations plus élevées que les sujets sains et que les patients diabétiques sans neuropathie périphérique. L'instabilité posturale augmentait avec les yeux fermés. Les patients diabétiques atteints de neuropathie périphérique présentaient aussi une différence plus importante entre les tests "yeux ouverts» et "yeux fermés». Avant de développer un traitement spécifique, il était nécessaire de mener une autre étude pour identifier les paramètres cliniques associés aux altérations de la marche des patients diabétiques. (Chapitre 6: "Clinical factors associated with gait alterations in diabetic patients"). Soixante-seize patients diabétiques ont été testés. Un examen clinique précédait l'évaluation de la marche qui a été réalisée sur une surface goudronnée et sur une surface pierreuse. Les différences respectives de vitesse de marche (performance de la marche) et de variabilité des pas (coefficient de variabilité de la durée du cycle - qui constitue un index de risque de chute) ont été calculées en comparant la marche entre ces deux surfaces (goudron versus pierre). Les associations entre cette différence et les facteurs cliniques ont été analysées au moyen de coefficients de corrélation et d'une régression linéaire. L'étude a montré que la diminution de la vitesse de marche liée au changement de terrain était partiellement associée à la force isométrique maximale moyenne des membres inférieurs, à la peur de tomber et à la capacité de perception des vibrations (neuropathie périphérique). La force isométrique maximale moyenne des membres inférieurs était également associée au coefficient de variabilité de la durée du cycle. Ces résultats montrent que les facteurs physiologiques (force et proprioception) et cognitivo-comportementaux (peur de tomber) sont associés aux problèmes de marche des patients diabétiques et devraient donc être pris en considération dans les traitements proposés à ces patients. Les programmes d'entraînement devraient inclure des exercices de force d'intensité progressive, un entraînement de la proprioception et des activités quotidiennes dans le but d'améliorer la confiance des patients. Considérant les résultats mentionnés ci-dessus, un programme d'exercices de physiothérapie a été développé et testé au moyen d'une étude randomisée contrôlée (Chapitre 7: “Diabetic patients' gait and balance can be improved with a specific training program. A randomised controlled trial"). Un échantillon de 71 patients a été attribué de façon aléatoire à un groupe de traitement $(n=35)$ ou de contrôle $(n=36)$. L'intervention était réalisée en groupe, 2 fois par semaine, pendant 12 semaines. La séance était composée d'un échauffement, suivi d'un entraînement comportant des exercices d'équilibration (talons et pointes des pieds, en fente avant ou sur une jambe) ainsi que différentes formes de marche. Ces exercices alternaient avec des exercices fonctionnels de renforcement (se lever, s'asseoir, monter, descendre une pente ou des escaliers, sauter) qui, en plus du renforcement, visaient à rendre les patients plus confiants face aux activités de la vie quotidienne. Les exercices devenaient progressivement plus complexes. Les séances se terminaient par des jeux interactifs, un feedback et des recommandations d'exercices à effectuer à domicile. L'entraînement a montré un effet positif sur la vitesse de marche, l'équilibre, la force musculaire et la mobilité articulaire des patients diabétiques. Après un programme de 12 semaines, les patients étaient encouragés à poursuivre au cours des 6 mois à venir les 
exercices appris pendant les séances. Ils ne recevaient ni autres conseils, ni autres restrictions. Le suivi à 6 mois a montré que les participants ont partiellement perdu l'effet de l'entraînement, mais leur niveau de performance est resté supérieur à celui qu'ils avaient avant l'entraînement.

Malgré plusieurs limites discutées dans le dernier chapitre (Chapitre 8: "General Discussion"), cette étude fournit des résultats prometteurs pour l'amélioration des problèmes de marche et d'équilibration des patients diabétiques de type 2. Cependant, d'autres études sont nécessaires avant de pouvoir énoncer des recommandations définitives pour la pratique. D'autres approches, telles que l'aménagement de l'environnement, l'utilisation d'aides techniques, l'entraînement à la marche dans des environnements variés ou un programme de renforcement musculaire séparé de toute autre intervention pourraient également être en mesure d'améliorer la marche et l'équilibration des patients diabétiques. D'autre part, une approche plus qualitative qui évaluerait l'expérience, l'autonomie, les motivations personnelles ainsi que les attitudes des patients envers ce programme pourrait les aider à optimiser leur participation et leur auto-gestion.

Un des défis futurs consistera à attirer l'attention des cliniciens sur les problèmes de marche ainsi que sur les risques de chute que rencontrent les patients diabétiques afin de combler le fossé existant entre la recherche et la clinique. 


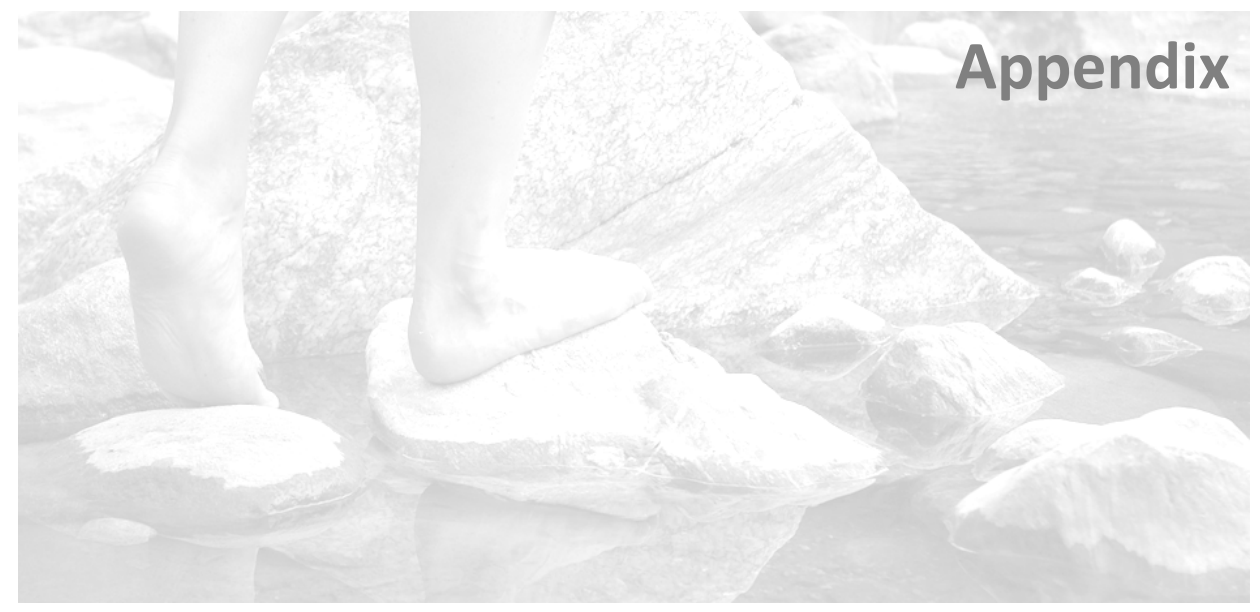




\section{GAIT CYCLE}

With reference to Perry [1] 8 phases can be distinguished within one gait cycle: initial contact, loading response, mid-stance, terminal stance, pre-swing, initial swing, mid-swing and terminal swing (Figure $\mathrm{A} I$ and $\mathrm{A} I \mathrm{I}$ ).

\section{Definition of gait phases}

1. Initial contact: this phase comprises the moment when the foot just touches the floor. Its primary concern is the way the foot strikes the floor.

2. Loading response: this is the initial double stance period. The phase begins with the initial floor contact and continues until the other foot is lifted. The goal is the acceptance of body weight in a manner that ensures limb stability and still permits progression.

3. Mid-stance: this is the first half of the single limb support interval. It begins as the other foot is lifted and continues until body weight is aligned over the forefoot. The advancement of the body and limb over a stationary foot is the functional objective of this gait phase.

4. Terminal stance: this phase completes the single limb support. It begins with heel rise and continues until the other foot strikes the ground. Here, the forward fall to generate a propulsive force is the primary objective.

5. Pre-swing: this final phase of stance is the second double stance interval in the gait cycle. It begins with initial contact of the opposite limb and ends with ipsilateral toeoff. Preparation of the limb for swing is the purpose of the actions that occur during the pre-swing phase.

6. Initial swing: this phase begins with lift of the foot from the ground and ends when the swinging foot is opposite the stance limb. Limb advancement and preparation for stance are the objectives of this phase.

7. Mid-swing: this phase begins when the swinging limb is opposite the stance limb. The phase ends when the swinging limb is forward and the tibia vertical.

8. Terminal swing: this phase begins with a vertical tibia and ends when the foot strikes the floor. Advancement is terminated and the limb is prepared for stance. 


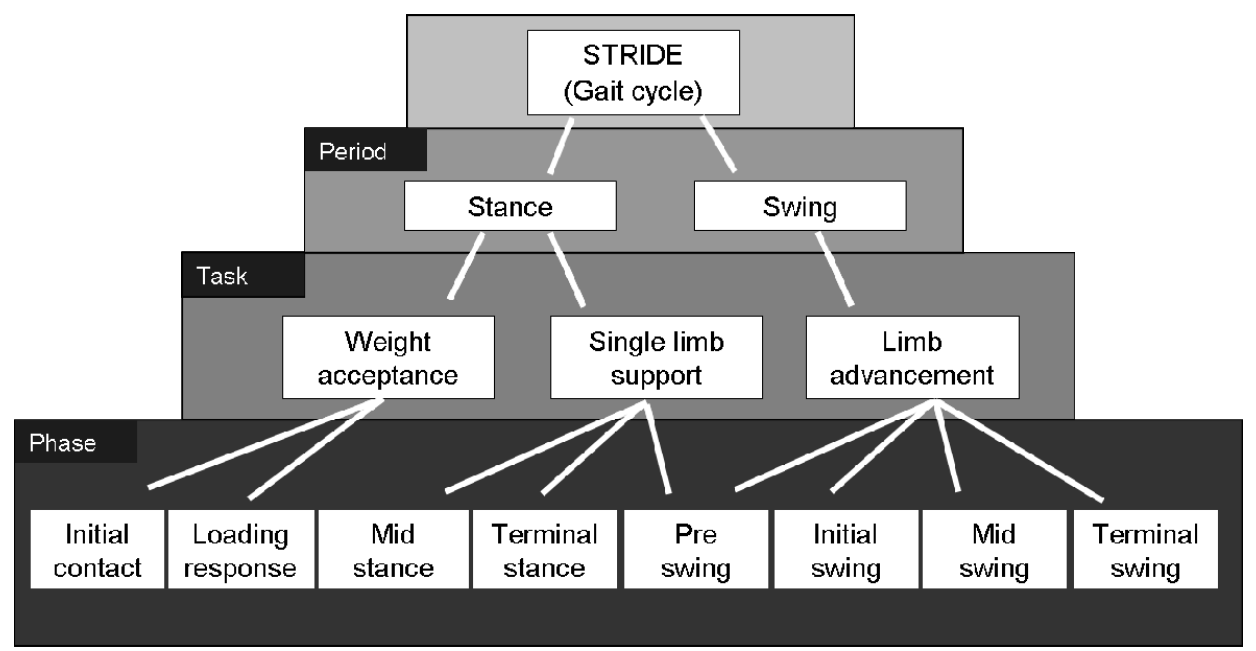

Figure A I.1. Divisions of the gait cycles defined by Perry [1].

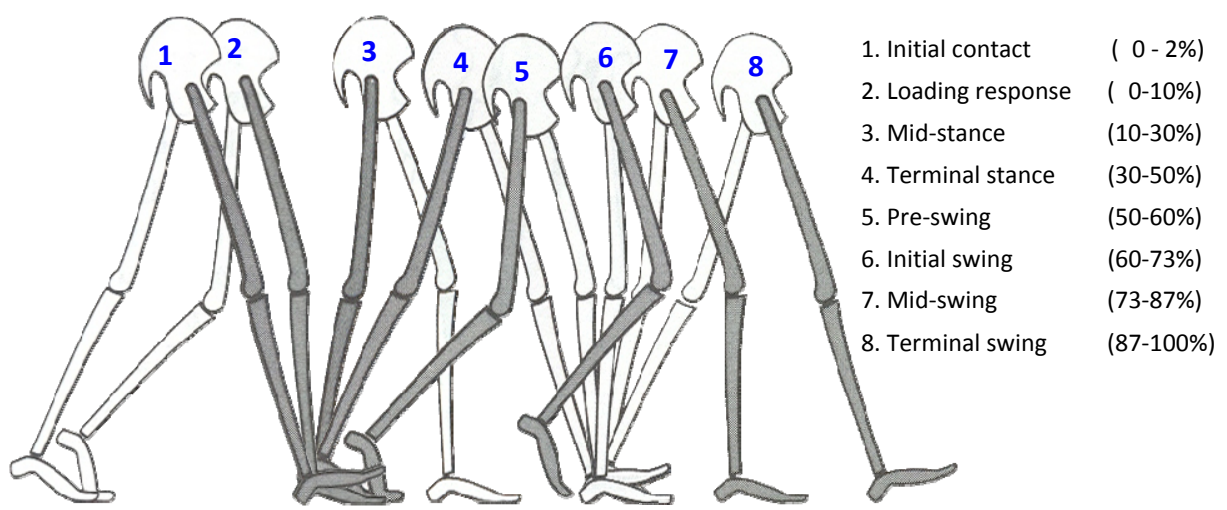

Figure A I.2. Representations of a gait cycle (stride) following Perry [1]. 


\section{DEFINITION OF SPATIOTEMPORAL GAIT PARAMETERS}

1. Gait speed or velocity (metre per second): gait speed or velocity is the distance travelled per unit time. The units for speed are metres per second $\left(\mathrm{ms}^{-1}\right)$.

2. Cadence (steps per minute): cadence defines the rhythm of the gait. It is the number of steps per minute (stepsmin ${ }^{-1}$ ).

3. Stride length or gait cycle length (metres): stride length is defined as the distance from initial contact of one foot to the following initial contact of the same foot. This term may also be referred to as gait cycle length.

4. Step length (metre): the step length is the distance from initial contact of one foot to the following initial contact of the opposite foot (Figure A III).

5. Stance Phase (percentage of gait cycle): the stance time is the period of time when the foot is in contact with the ground. The stance phase represents about $60 \%$ of the gait cycle.

6. Swing Phase (percentage of gait cycle): this is the period of time when the foot is not in contact with the ground. The swing phase represents about $40 \%$ of the gait cycle.

7. Double Support Phase (percentage of gait cycle): the double support time is the period of time when both feet are in contact with the ground. This occurs twice in the gait cycle, at the beginning and at the end of the stance phase. This term is also referred to as left and right double limb stance. The double support time represents $20 \%$ of the gait cycle $(2 \times 10 \%)$.

8. Single Support Phase (percentage of gait cycle): the single support time is the period of time when only one foot is in contact with the ground. The single support time represents $40 \%$ of the gait cycle. 


\section{Additional important definition}

Coefficient of variation (percentage): the coefficient of variation (CV) expresses the gait (stride to stride) variability. It is calculated as: standard deviation/mean $\times 100$. Several studies showed associations between increased gait variability and the fall risk [2-4].

\section{THE AMBULATORY GAIT MEASUREMENT SYSTEM}

The Physilog (BioAGM, CH) [5] is an ambulatory acquisition system with 16 channels. All data are stored on a multimedia memory card. This system records analog signals of 5 sensors which are placed on both shins, both thighs and on the trunk (Figure A IV).

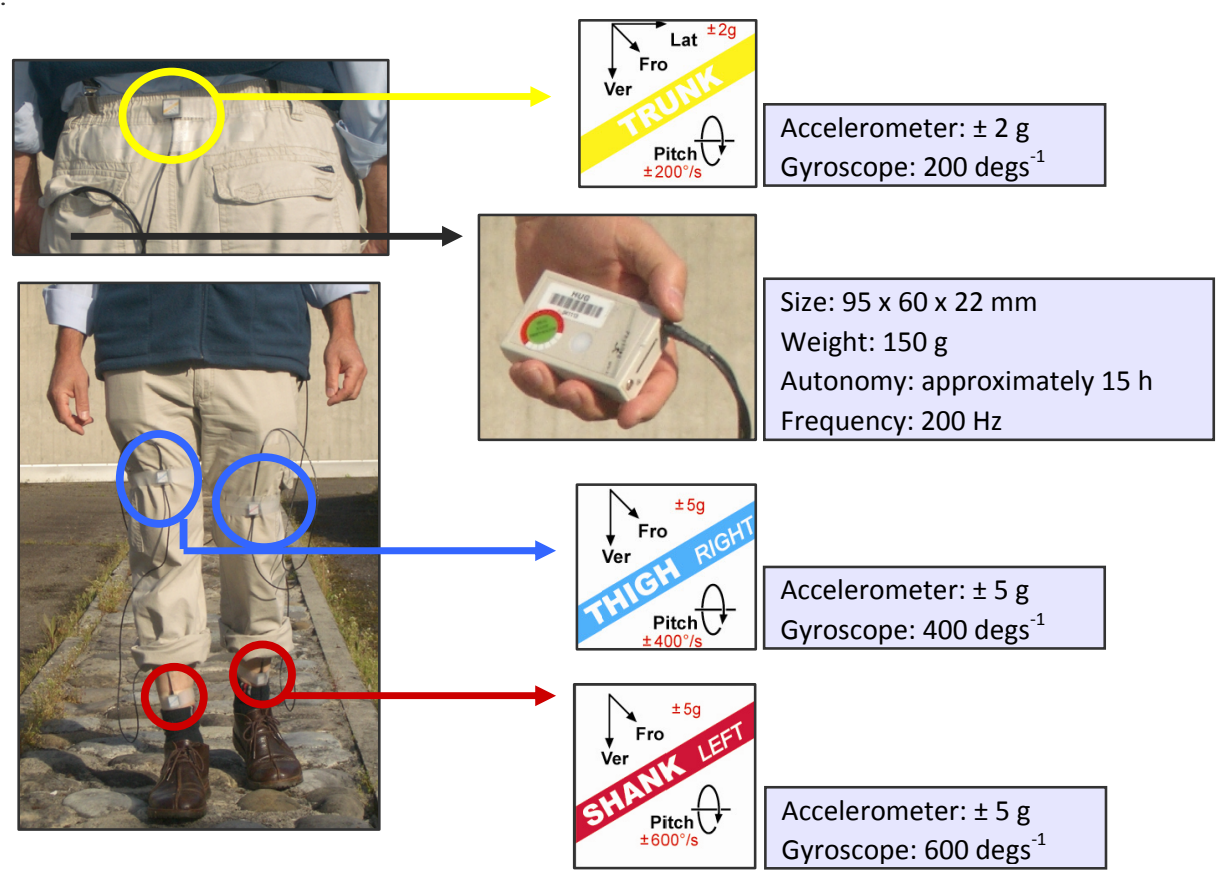

Figure A III. Presentation of the main material used in this project.

The sensor on the trunk contains tri-axial accelerometers (type ADXL202, range $\pm 2 \mathrm{~g}$; Analog Devices, 162 Norwood, USA) and a gyroscope (type ADXRS150, sensitivity \pm 200 $\operatorname{degs}^{-1}$; Analog Devices, 162 Norwood, USA). Each sensor on the limbs contains bi-axial accelerometers (type ADXL210, range $\pm 5 \mathrm{~g}$; Analog Devices, Norwood, USA) and a gyroscope (type ADXRS150, sensitivity \pm 500 degs $^{-1}$ for thighs and 400 for shins; Analog Devices, 162 Norwood, USA).

For the interpretation of gait, only the gyroscopes of the lower limbs are used. Each gyroscope measures the velocity of the angular rotation per segment around the coronal 
axis (flexion-extension). Signals are digitised (16 bit) at a sampling rate of $200 \mathrm{~Hz}$ and stored for off-line analysis on a memory card.

In order to compute the temporal parameters such as the duration of swing, single and double stances during a gait cycle, it is necessary and sufficient to determine for each leg the precise moments of heel strike (when the foot first touches the floor) and toe-off (when it takes off) during that cycle. These events have distinctive signal features of shin angular velocity appearing as rather sharp negative peaks involving some medium and relative high frequencies [5] (see Chapter 3 Figure 3.3).

For spatial parameters estimation, a double segment gait model involving both shins and thighs was used. In this model, the swing phase is considered as a double pendulum model, while the stance phase is considered as an inverse double pendulum model.

\section{Environment of gait analysis}

The environment used for gait analysis in this project was a walking course outside in the backyard of the University hospital offering 3 possibilities for combining the sequence of surfaces. Between each change of surface, patients had to wait for 8-10 s. This time was necessary to allow the identification of each surface change on the raw data. The two first and last cycles were not considered in the analysis to avoid acceleration and deceleration.

First combination: $\quad 50 \mathrm{~m}$ tarred pathway - $50 \mathrm{~m}$ grass - $50 \mathrm{~m}$ tarred pathway - go up $20 \mathrm{~m}$ slope at $10 \%$ - go down $20 \mathrm{~m}$ slope at $10 \%-50 \mathrm{~m}$ grass - $20 \mathrm{~m}$ cobblestones - go up and down 6 steps - 20 m cobblestones - go up and down 6 steps.

Second combination: $50 \mathrm{~m}$ grass - $50 \mathrm{~m}$ tarred pathway - $50 \mathrm{~m}$ grass - go up $20 \mathrm{~m}$ slope at $10 \%$ - go down $20 \mathrm{~m}$ slope at $10 \%$ - $50 \mathrm{~m}$ tarred pathway - $20 \mathrm{~m}$ cobblestones - go up and down 6 steps - 20 m cobblestones - go up and down 6 steps.

Third combination: $20 \mathrm{~m}$ cobblestones - go up and down 6 steps - $20 \mathrm{~m}$ cobblestones go up and down 6 steps - $50 \mathrm{~m}$ tarred pathway -- $50 \mathrm{~m}$ grass $-50 \mathrm{~m}$ tarred pathway - go up $20 \mathrm{~m}$ slope at $10 \%$ - go down $20 \mathrm{~m}$ slope at $10 \%-50 \mathrm{~m}$ grass. 


\section{TREATMENT}

A session consisted of a warm up ( $5 \mathrm{~min}$ ) followed by a circuit training ( $40 \mathrm{~min}$ ) including gait and balance exercises. The circuit training was composed of a set 10 tasks. Static and dynamic balance tasks were alternated with functional strength exercises. Each task was carried out twice during $1 \mathrm{~min}$ and the complexity of the task could progressively be increased. Each session was completed with interactive games $(10 \mathrm{~min})$ and a short feedback with suggestions for individual home exercises $(5 \mathrm{~min})$. The circuit training consisted of 10 circuit stations: 5 static or dynamic posts (depending on the balance capacity of each patient) linked with 5 functional posts. Patients worked alternatively for 1 min on a static/dynamic station and then $1 \mathrm{~min}$ on a linked functional station. Patients should repeat each combined station twice before starting a new post.

One of the main circuit stations of each session was the Biodex stability system or the wobble board (Figure A V). Each patient received specific training for 8 min (equivalent of one combined post ( 4 times $2 \mathrm{~min})$ ). One patient worked on the Biodex system with a visual feedback and the other on the wobble board. In the next treatment session they exchanged the therapeutic instrument. The Biodex differs from a static force platform. Any movement of the body's centre of gravity away from a perfectly balanced position (directly over the central portion of the base of support) results in the creation of a force moment that must be counteracted by an appropriate muscle activation pattern and generation of sufficient muscular torque to prevent the support surface from tilting. The level of difficulty while standing on the platform can be manipulated by altering the resistance of the platform to deviations [6, 7].

The level of difficulty of the training was progressively increased: with hands $\rightarrow$ without hands $\rightarrow$ bipodal $\rightarrow$ tandem stance $\rightarrow$ unipodal (and by decreasing the platform stability on the Biodex system).

These postural exercises improve individual's ability to perceive and to align gravitational and ground reaction forces through enhanced kinaesthetic awareness and rapid activation of the appropriate muscle recruitment patterns. The level of difficulty was progressively increased. 


\section{STATIC EXERCISES}

\section{Circuit I: Balance exercises}

Rubbing firmly one's legs and ankles with the hands or with different materials.

Circuit II: Unipodal (for all variations: 3 series of $10 \mathrm{~s}$ for both legs)

Standing on one leg with support.

Standing on one leg without support.

Standing without support and holding a ball, cup or tray.

Circuit III: Heel stands and walks

Standing on heels with support.

Standing on heels without support.

Standing on heels and holding a ball, cup or tray.

Circuit IV: Toe stands and walks

Standing on toes with support.

Standing on toes without support.

Standing on toes without support and holding a ball, cup or tray.

Circuit V: Standing on an unstable surface

\section{DYNAMIC EXERCISES}

\section{Circuit I: Unipodal (30 s for both legs)}

Standing without support while swinging the no supporting leg forward and backward or while playing with a ball.

Circuit II: Heel stands and walk

Walking along a straight line on heels with support.

Walking along a straight line on heels without support.

Walking along a straight line holding a tray.

Circuit III: Toe stands and walk

Walking along a straight line on toes with support.

Walking along a straight line on toes without support.

Walking along a straight line holding a tray.

Circuit IV: Stepping

Stepping up and down a step $(15-20 \mathrm{~cm})$, with support (30 s steps up with both legs as the leading leg).

Stepping onto the step with the leading leg, tipping with the non-leading leg on the step and stepping off the step, without placing the non-leading leg onto the step, without support (30 s steps up with the leading leg and $30 \mathrm{~s}$ with the non-leading leg).

Stepping over the step, without support (30 s steps up with both legs).

Step over step, while holding a cup or tray.

Circuit V: Standing on an unstable surface 
FUNCTIONAL EXERCISES

\section{Circuit l: Sit to stand}

Seat height adjusted to the knee position.

With the use of arms.

Without the use of arms for push-off and with seat height adjusted (knee flexed < 90deg).

Without the use of arms for push-off and with seat height adjusted (knee flexed 90deg).

Without the use of arms for push-off and with seat height adjusted (knee flexed > 90deg).

Stand up from the floor, with and without support of a chair and in different ways.

Circuit II: Walking along a straight line forward, backward and sideways

Walking without support.

Stepping over sticks (height, $3 \mathrm{~cm}$ ) that are lined up over a distance of $8 \mathrm{~m}$ with a variable inter-stick distance that can be covered in one step without support.

Walking while carrying a cup filled with water.

Walking while carrying a tray so the feet cannot be seen.

Circuit III: Steps (up, down)

Circuit IV: Slope

Circuit V: Jump (up and down on different surfaces)

Circuit VI: Running

Figure A IV.

(a) Biodex balance ${ }^{\circledR}$ system

(b) wobble board.

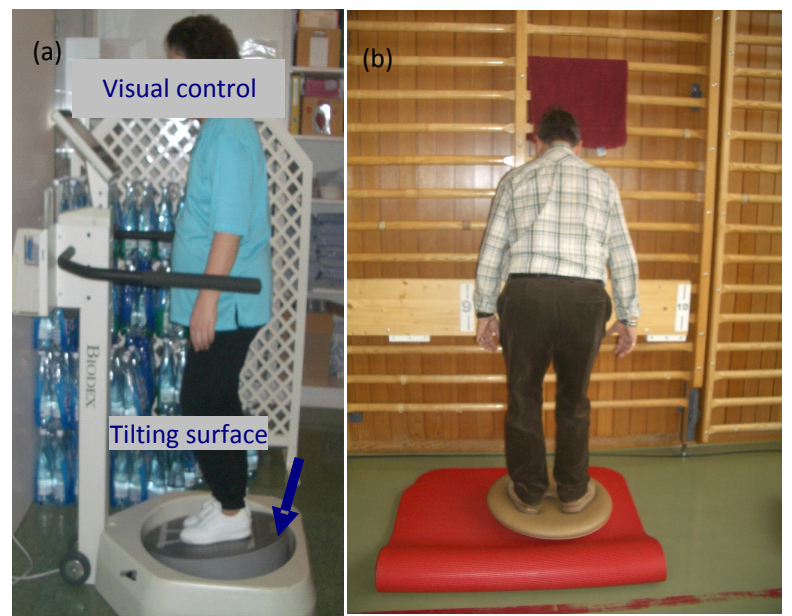




\section{REFERENCES}

1. Perry J. (1992): Gait Analysis: Normal and Pathological Function. Thorofare (NJ): Slack; p. 1-19.

2. Hausdorff JM, Edelberg HK, Cudkowicz ME, Singh MA, Wei JY: The relationship between gait changes and falls. J Am Geriatr Soc 45:1406, 1997.

3. Hausdorff JM, Edelberg HK, Mitchell SL, Goldberger AL, Wei JY: Increased gait unsteadiness in communitydwelling elderly fallers. Arch Phys Med Rehabil 78:278-283, 1997.

4. Maki BE: Gait changes in older adults: predictors of falls or indicators of fear. J Am Geriatr Soc 45:313-320, 1997.

5. Aminian K, Najafi B, Bula C, Leyvraz PF, Robert P: Spatio-temporal parameters of gait measured by an ambulatory system using miniature gyroscopes. J Biomech 35:689-699, 2002.

6. Arnold BL, Schmitz RJ: Examination of Balance Measures Produced by the Biodex Stability System. J Athl Train 33:323-327, 1998.

7. Mizuta $\mathrm{H}$, Shiraishi M, Kubota K, Kai K, Takagi K: A stabilometric technique for evaluation of functional instability in anterior cruciate ligament-deficient knee. Sport Med 2:235-239, 1992. 


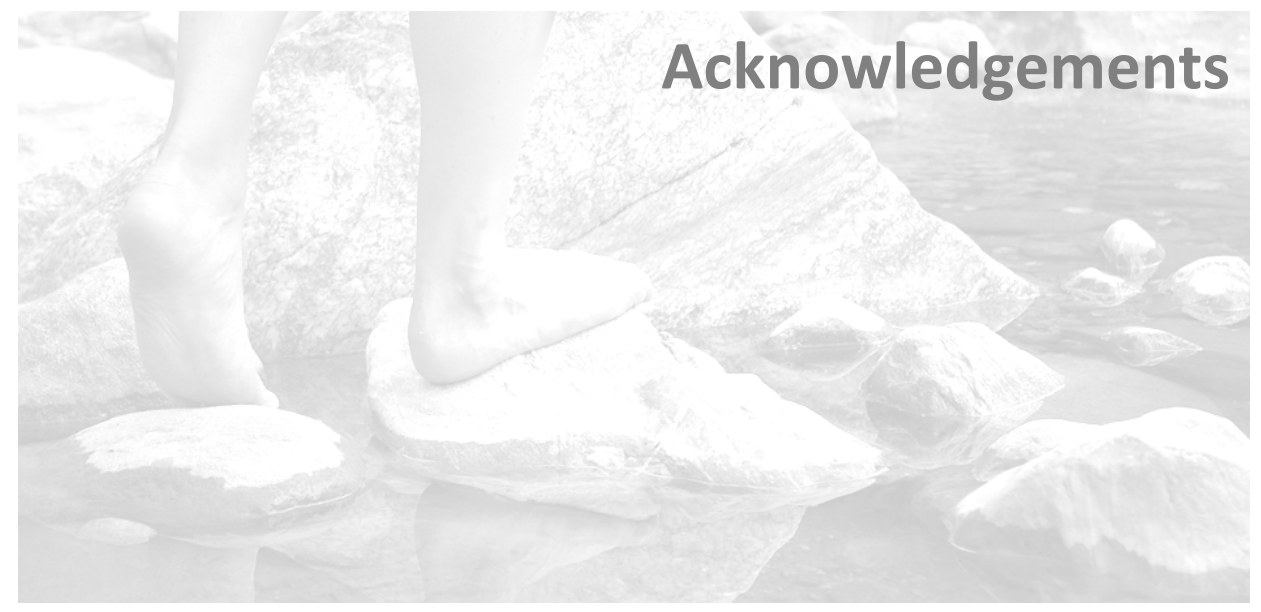


This PhD thesis would have been impossible without the help of many people.

First of all I would like to thank my promoter, Prof. dr. Rob A. de Bie who guided me through the writing of my publications and the editing of this thesis. Rob, thank you for your constructive and motivating feedback. I also would like to thank you for giving me the opportunity to spend such an instructive time at the Department of Epidemiology, School for Public Health and Primary Care (CAPHRI) at Maastricht University. Your professionalism combined with your humanity made conducting this project a pleasure.

I want to thank my co-promoters in Switzerland, Dr. Eling D. de Bruin and Dr. Stéphane Armand, who strongly supported and encouraged me during the past 3 years. The discussions, encouragements and critiques made by you both were crucial to the progress of this work. Eling, special thanks for your exchange of ideas while I was browsing to find my PhD topic and for your role as coordinator between the University of Maastricht, the Ecole Polytechnique Fédérale de Lausanne and the University Hospital of Geneva. Without this networking I would have encountered much greater difficulties in the realisation of this project. Stéphane, I learnt a lot from you and laughing with you made work much more fun. During our fruitful and intensive collaboration you provided constant motivation and support, which was most important to me. Your precision, technical knowledge and large experience in gait analysis improved this project considerably. I had a great time in your gait laboratory and I hope we will continue to work together after my thesis.

Before conducting this study I had to learn a lot about the disease of "diabetes". Prof. dr. Alain Golay, I gained great experience while working in your department, carrying out physical activity with diabetic patients and collaborating with the nursing staff specialised in patient education. You introduced me to this interesting chronic disease, helped me to acquire new contacts, corrected my articles and motivated me during the whole project. Thank you very much.

An essential part of this study was the recruitment of diabetic patients. Many people were involved in this and I would like to thank in particular Dr. Vincent Barthassat, Dr. Zoltan Pataky and Dr. Sébastien Thalmann. Zoltan, thank you also for having participated in the data interpretation and the writing of 2 articles.

Dominique Monnin, thank you for giving me the opportunity of doing research while I was still a student and for encouraging me, together with Eling, to do a PhD. All the administrative details you arranged for me made my time as a PhD student easier. Your clinical knowledge and your management experience greatly contributed to the success of this project.

An essential part of this study was the collaboration with the Laboratory of Movement Analysis and Measurement of the Ecole Polytechnique Fédérale de Lausanne. Prof. dr. Kamiar Aminian, thank you very much for the technical support that you and your research team (in particular Benoît Le Callennec and Pascal Morel) provided me with 
for my data processing. I am also grateful for the time you invested in reviewing my papers and presentations.

Thanks also to Dr. François Herrmann and Dr. Thomas Pernegger for their statistical advice during this project.

I want to express thanks to Sylvie Tupin for all the work you did for this project; calling, planning, mailing many people. Thank you very much for the very good job you have done.

I want to thank my "English girls" Pascale Sclison and Laura Murphy. You corrected the English in all my articles and in my thesis. You're wonderful.

To my other proof readers, Verena Bensaddik, Sandra Leal, Elisabeth Bürge and Stéphane Armand who re-read and cross-checked the final manuscript for misplaced commas, missing letters or other typographical errors, a heartfelt thank you.

Special thanks to Marlieke Notenboom and Audrey Merry who translated my summary in Dutch.

The Swiss Association for Physiotherapists (physioswiss) sponsored the Physilog ${ }^{\circledR}$ which was an indispensable piece of equipment for this project. I am grateful for this funding.

I also would like to thank Prof. dr. Pierre Hoffmeyer, who provided the funding necessary to start this project. Prof. dr. Hoffmeyer, thank you very much, not only for your financial support but also for the infrastructure that you made available to me and for advancing my professional career.

The Swiss National Foundation offered me a fellowship for prospective researchers which gave me the possibility to stay at the CAPHRI Research Institution here in Maastricht, where I finalised my project and where I wrote my thesis. I would like to thank this funding organisation for their support. It is a wondeful opportunity for a PhD student to go abroad, collaborate with other research teams and expand their horizons.

Thanks also to the Dutch Diabetes Research Foundation (Diabetes Fonds), the Clinical Services Directorate and the Service of Therapeutic Education for Chronic Diseases of the University Hospitals of Geneva for their financial contribution towards printing costs.

Dr. Katia Turcot, you arrived at the Willy Taillard Laboratory of Kinesiology at the University Hospital in Geneva in 2008. Your new insight helped to better explore our study findings. I also appreciate your creativity and design skills for giving the last touch to presentations. I'm happy that you will continue working on some of these data and hope that we can continue collaborating.

We spend at least one third of our life at work. Friendly and competent colleagues are therefore essential to our happiness. I have enjoyed working at the University Hospital in Geneva and would like to thank Emmanuel Guyen and his team as well as all my colleagues who supported me during this project. I would in particular like to thank Pernelle Fritschy, Sandra Leal and Jean-Luc Ziltener with whom I was able to exchange 
ideas during running sessions; Olivier Rime for his cheerful and motivational attitude; Verena Bensaddik and Irmgard Feldmann for their encouraging discussions and the colleagues with whom I regularly played beach volleyball.

I am also very grateful for the lovely and interesting time I had with my new colleagues and other PhD students at Maastricht University in the Department of Epidemiology. I would also like to thank Prof. dr. Hans Savelberg, who integrated me in his research team. The collaboration with you and your colleagues of the institute of Human Movement Sciences enriched my stay in the Netherlands.

I would also like to thank the members of the reading committee of my PhD thesis and the corona for their time and interest in my work: Prof. dr. C.P. van Schayck, Prof. dr. M.H. Prins, Prof. dr. H.H.C.M. Savelberg, Prof. dr. G.H.I.M. Walenkamp and Prof. dr. M.W.G. Nijhuis - Van der Sanden.

A special thank to my "Paranimfen" Laura Steinbusch and Axel de Preux.

To all the participants in my study, whose interest stimulated them to become involved in an unknown area of research; many thanks for having such an open mind.

Last but not least, I would very much like to thank my family and my partner. Sonja and Josef, you are wonderful parents. What I have achieved in my life so far would hardly have been possible without your unlimited support. Kathleen, your encouragement and emotional support in bad and good times was invaluable; you're a wonderful sister. Axel, I spent seven months abroad, abandoning you in Switzerland. We had very few days together, but each of them was beautiful and gave me new energy to successfully complete my thesis. I may not often have stated this explicitly, but your positive attitude, your laugh and your support mean everything to me.

Maastricht, $10^{\text {th }}$ of October 2009

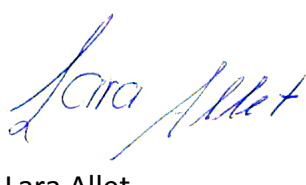

Lara Allet

PS: So many people have been involved in this PhD project; I may have forgotten to acknowledge somebody here, in which case I am very sorry. If it's you, please put your name down here.

I would also like to thank: 


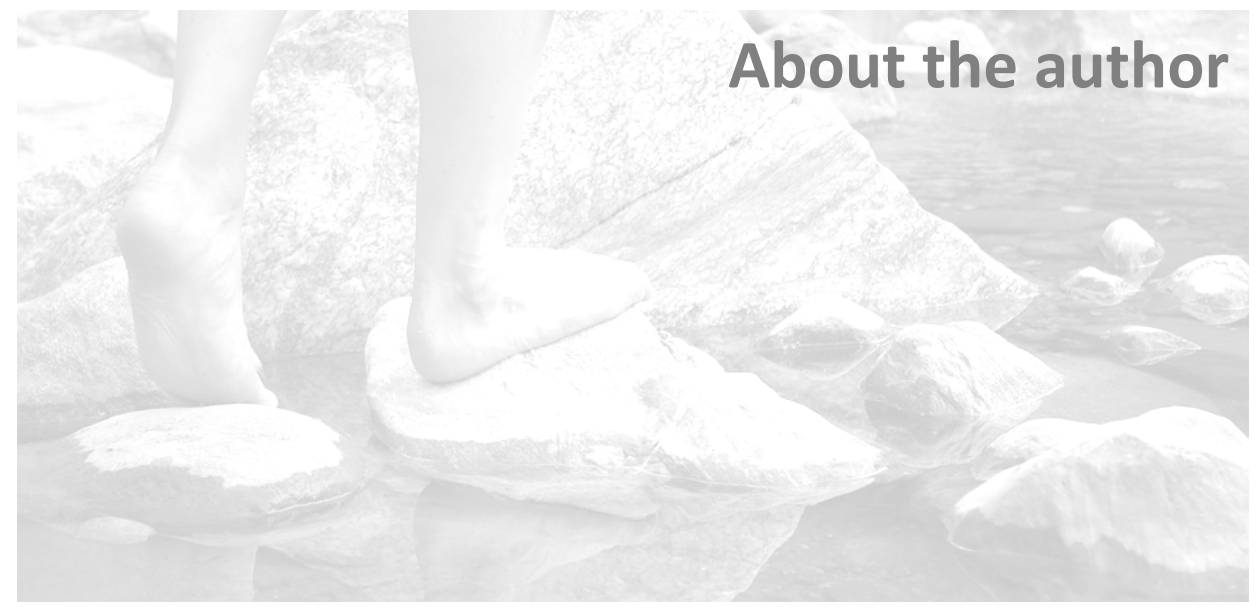




\section{CURRICULUM VITAE}

Lara Allet was born in Leukerbad, Switzerland, on the 22nd of February 1977. She attended Spiritus Sanctus College in Brig where she obtained her senior high school diploma (Matura Typ B). She then returned to Leukerbad to study Physiotherapy at the School of Physiotherapy where she received her diploma in $2002^{1}$. She worked as a physiotherapist at the University Hospital of Geneva from 2002 to 2005, gaining experience in the fields of Neurology, Musculoskeletal Rehabilitation, Internal Medicine and Sports Medicine. During this time she undertook many continuing education courses, gaining a Certificate of Advanced Studies in Manual Therapy, a Certificate of basic Bobath Rehabilitation and a Certificate in Proprioceptive Neuromuscular Facilitation (IPNF 2).

Being particularly attracted by the analytical aspects of Physiotherapy and having a great interest in evidence based practice, Ms. Allet continued her training. In 2006 she was awarded a Masters degree in Physiotherapy Science from the University of Maastricht ${ }^{2}$. The subject of her Masters thesis was the application of the International Classification of Functioning, Disability and Health into clinical practice. For this work she received an award for the best poster presentation at the conference of the Swiss Society of Rheumatology in Geneva $^{3}$. During her time as a master's student she became increasingly interested in human movement analysis with a particular focus on gait abnormalities and fall risk. As a result, she started to collaborate closely with the Willy Taillard Laboratory of Kinesiology of the University Hospital of Geneva. Fascinated by the scientific world, Ms. Allet felt she needed to deepen her scientific skills and knowledge of human movement analysis. In 2006 she had the opportunity to work as a junior researcher at the University Hospital of Geneva and registered as a PhD student at the department of Epidemiology, Faculty of Health Sciences and Medicine at Maastricht University. Her primary research project was to design and conduct a randomised controlled trial evaluating the efficacy of a physiotherapy treatment on the gait and balance of diabetic patients. The project was presented for the first time in 2007 at the conference organised by GAMEA (Groupe d'Analyse du Mouvement chez l'Enfant et l'Adulte: Tribune des jeunes chercheurs), a movement analysis research group, where she received the award for the best presentation ${ }^{4}$.

The PhD project of Ms. Allet required specific material with which to measure gait characteristics outdoors, for which she received financial support from the Swiss Physiotherapy association. In addition, a grant from the Swiss National Foundation (Fellowships for prospective researchers) enabled her to move to Maastricht to complete her PhD at the Department of Epidemiology of the Faculty of Health Sciences and Medicine at the Maastricht University. Ms. Allet's stay provided her with the opportunity to gain

${ }^{1}$ Bachelor of Science in Physiotherapy from the University of Applied Sciences (HES-SO).

${ }^{2}$ A collaborative program between the University Hospital of Zürich (Switzerland) and the University of Maastricht (The Netherlands).

${ }^{3}$ ICF- Une partition pour les physiothérapeutes; un outil pratique et adapté.

${ }^{4}$ La marche chez les patients atteints d'un diabète type 2. 
international experience, enlarge her knowledge in the field of Health Sciences and take part in specific modules from the Health Science Research Masters programme.

Concurrently to her PhD programme, Ms. Allet studied Academic Didactics at the University of Fribourg where she was awarded her diploma in 2008.

\section{LIST OF PUBLICATIONS}

\section{SCIENTIFIC PAPERS (PEER-REVIEW)}

Allet L, Armand S, de Bie RA, Golay A, Monnin D, Aminian K, Staal JB, de Bruin ED: Diabetic patients' gait and balance can be improved. A randomised controlled trial. Accepted in Diabetologia in October 2009.

Pataky Z, De León DR, Allet L, Golay A, Assal JP, Hauert CA: Biofeedback for foot off-loading in diabetic patients with peripheral neuropathy. Accepted in Diabet Med in September 2009.

Allet L, Armand S, de Bie RA, Pataky Z, Golay A, Aminian K, de Bruin ED: Clinical factors related to gait alterations in diabetic patients. Diabet Med 2009; 26(10):1003-1009.

Turcot K, Allet L, Golay A, Hoffmeyer P, Armand S: Investigation of Standing Balance in Diabetic Patients with and without Peripheral Neuropathy using Accelerometers. Clin Biomech 2009; 24(9):716-21.

Allet L, Leemann B, Guyen E, Murphy L, Monnin D, Herrmann F, Schnider A: Effect of different walking aids on walking capacity of patients with poststroke hemiparesis. Arch Phys Med Rehabil 2009; 90(8):1408-13.

Allet L, Armand S, de Bie RA, Pataky Z, Herrmann F, Aminian K, de Bruin ED: Gait alterations of diabetic patients while walking on different surfaces. Gait Posture 2009; 29(3):488493.

Allet L: La CIF: Un enjeu pour la physiothérapie et l'enseignement. Kinésiether Rev 2009; 9(85-86):37-39

Allet L, Armand S, de Bie RA, Golay A, Monnin D, Aminian K, de Bruin ED: Reliability of diabetic patients' gait parameters in a challenging environment. Gait Posture 2008; 28(4):680-686.

Allet L, Bürge E, Monnin D: ICF - Clinical relevance for physiotherapy? A critical review. Adv Physiother 2008; 10(3):127-137(11).

Allet L, Armand S, Golay A, Monnin D, de Bie RA, de Bruin ED: Gait characteristics of diabetic patients: a systematic review. Diabetes Metab Res Rev 2008; 24(3):173-91. 
Bürge E, Cieza A, Allet L, Finger ME, Stucki G, Huber EO: Intervention categories for physiotherapists treating patients with internal medicine conditions on the basis of the International Classification of Functioning, Disability and Health. Int J Rehabil Res 2008; 31(1):43-50.

Allet L, Cieza A, Bürge E, Finger M, Monnin D, Roth J, Huber EO: Les catégories d'interventions CIF s'appliquant à la physiothérapie des affections muscolusquelettiques. Kinesither Rev 2008; 8(73):19-28.

Bürge E, Cieza A, Allet L, Finger M, Gerold S, Karcher Faval C, Gérin B, Huber EO: Les catégories d'interventions CIF s'appliquant à la physiothérapie des affections des systèmes et organes internes. Kinesither Rev 2008; 8(73):40-49.

Finger M, Cieza A, Allet L, Bürge E, Baumann Y, Albert S, Stucki G, Huber EO: Les catégories d'interventions CIF s'appliquant à la physiothérapie des affections neurologiques. Kinesither Rev 2008; 8(73):29-39.

Allet L, Cieza A, Bürge E, Finger M, Stucki G, Affolter J, Tal-akabi A, Huber EO: ICF Interventionskategorien für Physiotherapie bei muskuloskelettalen Gesundheitsstörungen. Physioscience 2007; 3:54-62.

Bürge E, Cieza A, Allet L, Finger M, Stucki G, Kramer E, Wiggers-Müller B, Huber EO: ICF Interventionskategorien für Physiotherapie bei internistischen Gesundheitsstörungen. Physioscience 2007; 3:72-79.

Finger ME, Cieza A, Allet L, Bürge E, Baumann Y, Albert S, Stucki G, Huber EO: ICF Interventionskategorien für Physiotherapie bei neurologischen Gesundheitsstörungen. Physioscience 2007; 3:63-71.

Allet L, Cieza A, Bürge E, Finger M, Stucki G, Huber EO: Intervention categories for physiotherapists treating patients with musculoskeletal conditions on the basis of the International Classification of Functioning, Disability and Health. Int J Rehabil Res 2007; 30(4):273-80.

\section{Other scientific papers}

Allet L, Burge E, Monnin D: ICF - Vorteile und Grenzen im Alltag eines Physiotherapeuten. Physiopraxis $2008 ;$ 5:26-29.

Ziltener J-L, Allet L, Monnin D: Le Stretching, un mythe . . . et des constats. Journal de traumatologie du sport 2005; 22:112-115. 